Higor Amario de Souza

\title{
Depuração de programas baseada em cobertura de integração
}

São Paulo

Dezembro / 2012 

Higor Amario de Souza

\section{Depuração de programas baseada em cobertura de integração}

Dissertação apresentada ao Programa de Pós-graduação em Sistemas de Informação da Escola de Artes, Ciências e Humanidades da Universidade de São Paulo como requisito parcial para obtenção do título de Mestre em Ciências.

Orientador: Prof. Dr. Marcos Lordello Chaim

Versão corrigida contendo as alterações e correções sugeridas pela banca examinadora. A versão original encontra-se na Biblioteca da Escola de Artes, Ciências e Humanidades da Universidade de São Paulo.

São Paulo

Dezembro / 2012 
Autorizo a reprodução e divulgação total ou parcial deste trabalho, por qualquer meio convencional ou eletrônico, para fins de estudo e pesquisa, desde que citada à fonte.

\section{CATALOGAÇÃO-NA-PUBLICAÇÃO \\ Biblioteca}

Escola de Artes, Ciências e Humanidades da Universidade de São Paulo

Souza, Higor Amario de

Depuração de programas baseada em cobertura de integração /

Higor Amario de Souza ; orientador Marcos Lordello Chaim. - São

Paulo, 2012.

172 p. : il.

Dissertação (Mestrado em Ciências) - Programa de Pós-Graduação em Sistemas de Informação, Escola de Artes, Ciências e

Humanidades da Universidade de São Paulo, em 2012.

Versão corrigida.

1. Teste e avaliação de software. 2. Verificação e validação de software. 3. Análise de erros. 4. Especificação de sistemas e programas. 5. Geração de código. I. Chaim, Marcos Lordello, orient. II. Título.

CDD 22.ed. - 005.14 
Dissertação sob o título "Depuração de programas baseada em cobertura de integração", defendida por Higor Amario de Souza e aprovada em 20 de dezembro de 2012, em São Paulo, Estado de São Paulo, pela banca examinadora constituída pelos doutores:

Prof. Dr. Marcos Lordello Chaim Orientador

Prof. Dr. Marcio Eduardo Delamaro

Universidade de São Paulo

Prof. Dr. Auri Marcelo Rizzo Vincenzi

Universidade Federal de Goiás 



\section{Agradecimentos}

Agradeço à Rose e ao Gustavo por todo amor, carinho e compreensão. Vocês são a minha vida!

Aos meus pais, Regina e Osvaldo, pelo amor, carinho e por me ensinarem a ser gente. Obrigado por tudo que sempre fizeram por mim.

Ao meu irmão Raphael, pela amizade e apoio.

Ao Seu Takao e à Dona Deiko, por todo carinho e apoio, vocês são como pais para mim.

Ao meu orientador Prof. Dr. Marcos Lordello Chaim, pela excelente orientação, ensinamentos, amizade e exemplo de conduta. Muito obrigado por tudo.

A todos meus amigos do PPgSI, do SAEG e do LApIS: Ana Cláudia, Cláudio, Danilo, Éric, Felipe, Fernando, Jadson, Jônatas, Leila, Luiz, Marcelo, Marcus, Renata, Roberto Araújo, Roberto Rocha e Rosy. Obrigado pelos ótimos momentos juntos, por todo apoio e amizade, muito sucesso para todos vocês.

À Profa. Dra. Fátima de Lourdes dos Santos Nunes Marques, por todo incentivo e apoio durante o mestrado.

Ao Prof. Dr. Helton Hideraldo Bíscaro, pelo incentivo e por despertar meu interesse por pesquisa científica.

Ao Prof. Dr. Esteban Fernandez Tuesta pela importante ajuda durante a análise dos dados.

A todos os meus professores da EACH-USP por serem parte importante da minha formação.

Agradeço à FAPESP, à CAPES, ao CNPq e à USP pelo suporte financeiro. 

Outras vezes ouço passar o vento, e acho que só para ouvir passar o vento vale a pena ter nascido.

(Fernando Pessoa) 



\section{Resumo}

Depuração é a atividade responsável pela localização e correção de defeitos gerados durante o desenvolvimento de programas. A depuração ocorre devido à atividade de teste bem-sucedida, na qual falhas no comportamento do programa são reveladas, indicando a existência de defeitos. Diversas técnicas têm sido propostas para automatizar a tarefa de depuração de programas. Algumas delas utilizam heurísticas baseadas em informações de cobertura obtidas da execução de testes. O objetivo é indicar trechos de código do programa mais suspeitos de conter defeitos. As informações de cobertura mais usadas em depuração automatizada são baseadas no teste estrutural de unidade. A cobertura de integração, obtida por meio da comunicação entre as unidades de um programa, pode trazer novas informações sobre o código executado, possibilitando a criação de novas estratégias para a tarefa de localização de defeitos. Este trabalho apresenta uma nova técnica de localização de defeitos chamada Depuração de programas baseada em Cobertura de Integração (DCI). São apresentadas duas coberturas de integração baseadas nas chamadas de métodos de um programa. Essas coberturas são usadas para a proposição de roteiros de busca dos defeitos a partir dos métodos considerados mais suspeitos. As informações de cobertura de unidade são então utilizadas para a localização dos defeitos dentro dos métodos. A DCI também utiliza uma nova heurística para atribuição de valores de suspeição a entidades de integração estática dos programas como pacotes, classes e métodos, fornecendo também um roteiro para a procura dos defeitos. Os experimentos realizados em programas reais mostram que a DCI permite realizar a localização de defeitos de forma mais eficaz do que o uso de informações de cobertura de unidade isoladamente.

Palavras-chave: Depuração automatizada, localização de defeitos, teste de integração, cobertura de código. 



\section{Abstract}

Debugging is the activity responsible for localizing and fixing faults generated during software development. Debugging occurs due to a successful testing activity, in which failures in the behavior of the program are revealed, indicating the existence of faults. Several techniques have been proposed to automate the debugging tasks, especially the fault localization task. Some techniques use heuristics based on coverage data obtained from the execution of tests. The goal is to indicate program code excerpts more likely to contain faults. The coverage data mostly used in automated debugging is based on whitebox unit testing. Integration coverage data, obtained from the communication between the units of a program, can bring about new information with respect to the executed code, which allows new strategies to the fault localization task to be devised. This work presents a new fault localization technique called Debugging based on Integration Coverage (DIC). Two integration coverages based on method invocations are presented. These coverages are used to propose two search strategies that provides a roadmap to locate faults by investigating the more suspicious methods. The unit coverage information are used to search the faulty statement inside the suspicious methods. The DIC technique also proposes a heuristic that assigns suspiciousness values to static integration entities of the programs, namely, packages, classes, and methods. This heuristic also provides a roadmap to search for the faults. Experiments using real programs show that DIC is more effective to locate faults than solely using unit coverage information.

Keywords: Automated debugging, fault localization, integration testing, code coverage. 



\section{Sumário}

Lista de Figuras

vii

Lista de Tabelas

1 Introdução

1.1 Considerações iniciais . . . . . . . . . . . . . . . . . . . . 1

1.2 Motivação . . . . . . . . . . . . . . . . . . . . . 3

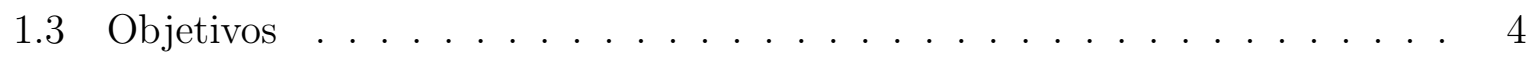

1.4 Organização . . . . . . . . . . . . . . . . . . . . 5

2 Conceitos fundamentais $\quad 7$

2.1 Conceitos de teste de software . . . . . . . . . . . . . . . 7

2.1.1 Defeito, erro, falha e engano . . . . . . . . . . . . . . 7

2.1.2 Caso de teste, conjunto de teste e oráculo . . . . . . . . . . . . 9

2.1.3 Técnicas de teste . . . . . . . . . . . . . . . . . 10

Teste estrutural . . . . . . . . . . . . . . . . . 10

Teste funcional . . . . . . . . . . . . . . . . . . 15

Teste baseado em defeitos . . . . . . . . . . . . . . . . 16

2.1.4 Cobertura de teste . . . . . . . . . . . . . . 16

2.1.5 Fases de teste . . . . . . . . . . . . . . . . 17

Teste de unidade . . . . . . . . . . . . . . . . . . 17

Teste de integração . . . . . . . . . . . . . . . . . . . . . . 17

Teste de sistema . . . . . . . . . . . . . . . . . . . . . 18 
Teste de regressão . . . . . . . . . . . . . . . . . . . . . 18

2.1.6 Teste estrutural de integração . . . . . . . . . . . . . . . . . 18

Defeitos de integração . . . . . . . . . . . . . . . . . . . . 18

Taxonomia para defeitos de integração . . . . . . . . . . . . . . 19

Critérios para teste de integração entre pares de unidades . . . . . . 20

Critérios para teste de integração nível um . . . . . . . . . . . . 22

2.2 Conceitos de depuração baseada em cobertura de código . . . . . . . . . . 25

2.2.1 Depuração . . . . . . . . . . . . . . . . . . . . . 25

2.2.2 Cobertura de código . . . . . . . . . . . . . . . 25

2.2.3 Heurísticas . . . . . . . . . . . . . . . . . . . . . 28

2.3 Considerações finais . . . . . . . . . . . . . . . . . . . . . . 29

3 Depuração automatizada baseada em cobertura de código 31

3.1 Revisão sistemática . . . . . . . . . . . . . . . . . . . . . 31

3.2 Análise das técnicas de depuração baseada em cobertura de código . . . . . 33

3.2.1 Tipos de cobertura de código e sua utilização em depuração . . . . 33

3.2 .2 Heurísticas . . . . . . . . . . . . . . . . . . 36

3.2.3 Técnicas que utilizam informações de integração . . . . . . . . . . . . 40

3.2.4 Benchmarks......................... 41

3.2.5 Programas com defeitos únicos e múltiplos . . . . . . . . . . . . . 44

3.2.6 Métricas . . . . . . . . . . . . . . . . . . 47

3.2.7 Custo de execução . . . . . . . . . . . . . . . . . . . . . . . . 48

3.2.8 Ferramentas de apoio à depuração baseada em cobertura . . . . . . 50

3.3 Considerações finais . . . . . . . . . . . . . . . . . . . . . 51

4 Depuração de programas baseada em cobertura de integração 53

4.1 Hierarquia de código $(\mathrm{HC}) \ldots \ldots \ldots \ldots \ldots$ 
4.2 Coberturas de integração . . . . . . . . . . . . . . . . . . . . 55

4.2 .1 MethodCallPair $(\mathrm{MCP}) \ldots \ldots \ldots \ldots 6$

4.2 .2 MethodCallTriple $(\mathrm{MCT}) \ldots \ldots \ldots$. . . . . . . . . . 57

4.3 Depuração de programas baseada em Cobertura de Integração (DCI) . . 57

$4.3 .1 \mathrm{JaBUTi} / \mathrm{InSS} \ldots \ldots \ldots \ldots . \ldots \ldots$

4.3.2 Programa defeituoso . . . . . . . . . . . . . . . 59

4.3 .3 Conjunto de teste . . . . . . . . . . . . . . . 60

4.3.4 Coberturas de integração e unidade . . . . . . . . . . . . . . 60

4.3 .5 Informações de cobertura . . . . . . . . . . . . . . . . . . 60

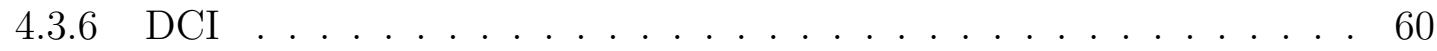

Cálculo dos coeficientes de cobertura . . . . . . . . . . . . 61

Cálculo da suspeição (heurísticas) . . . . . . . . . . . . . . . 62

Classificação dos requisitos . . . . . . . . . . . . . . . . . . . 62

Roteiro de busca por métodos . . . . . . . . . . . . . . . 63

4.3 .7 Programador . . . . . . . . . . . . . . . . . 64

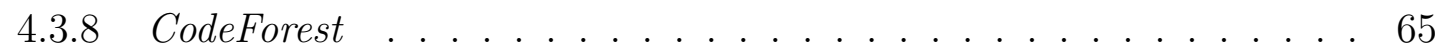

4.4 Localizando o defeito com DCI e CodeForest . . . . . . . . . . . . . . . 66

4.4 .1 Usando R-MCP . . . . . . . . . . . . . . . . . . . . 67

4.4 .2 Usando R-MCT com o valor de suspeição delta . . . . . . . . . . . 69

4.4 .3 Usando a LSN e HC . . . . . . . . . . . . . . . . . . . . . 75

4.5 Considerações finais . . . . . . . . . . . . . . . . . . . . . 78

$\begin{array}{lll}5 & \text { Avaliação experimental } & 79\end{array}$

5.1 Considerações iniciais . . . . . . . . . . . . . . . . . . . . 79

5.2 Desenho experimental . . . . . . . . . . . . . . . . . 79

5.2 .1 Variáveis . . . . . . . . . . . . . . . . . . 80

Variáveis independentes . . . . . . . . . . . . . . . 80 
Variáveis dependentes . . . . . . . . . . . . . . . 81

5.2 .2 Heurísticas . . . . . . . . . . . . . . . . . . 81

5.2 .3 Defeitos de integração . . . . . . . . . . . . . . . . . . 81

5.2 .4 Métricas . . . . . . . . . . . . . . . . . . . . 81

Cliques . . . . . . . . . . . . . . . . . . . . 82

Posição média . . . . . . . . . . . . . . . . . . . . . . . . . . . . . 82

Critérios de parada . . . . . . . . . . . . . . . 83

Tratamentos ...................... 84

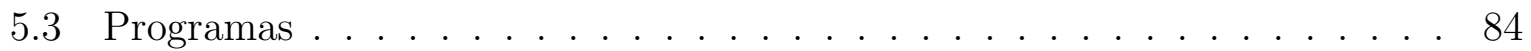

5.4 Instrumentação dos experimentos . . . . . . . . . . . . . . . . . . 86

5.4 .1 Incluindo o defeito no programa . . . . . . . . . . . . 87

5.4.2 Instrumentando e coletando as informações de cobertura . . . . . . 87

5.4.3 Gerando as listas de suspeição e os roteiros de busca com a DCI . . 88

5.5 Condução dos experimentos . . . . . . . . . . . . . . . . . . . . 89

5.6 Resultados . . . . . . . . . . . . . . . . . . . . 90 90

5.7 Sumarização dos resultados . . . . . . . . . . . . . . . . 102

5.8 Análise estatística . . . . . . . . . . . . . . . . . . . . . 112

5.8.1 Procedimentos realizados . . . . . . . . . . . . . . . . . . 113

5.8.2 Teste de hipótese I - R-MCP, R-MCT e LSN com a métrica CL . . 117

Comparação entre R-MCP e LSN . . . . . . . . . . . . . . . . . 117

Comparação entre R-MCT e LSN . . . . . . . . . . . . . . . . 118

Comparação entre R-MCP e R-MCT . . . . . . . . . . . . . . . . 118

5.8.3 Teste de Hipótese II - R-MCP, R-MCT e LSN com a métrica CHC 118

Comparação entre R-MCP e LSN . . . . . . . . . . . . . . . . 118

Comparação entre R-MCT e LSN . . . . . . . . . . . . . . . . 119

Comparação entre R-MCP e R-MCT . . . . . . . . . . . . . . . . . 119 
5.8.4 Teste de Hipótese III - Uso de CHC e CL para R-MCP, R-MCT e $\mathrm{LSN} \ldots \ldots \ldots \ldots \ldots \ldots$

Comparação do uso de CHC e CL para R-MCP . . . . . . . . . . . 119

Comparação do uso de CHC e CL para R-MCT . . . . . . . . . . . 120

Comparação do uso de CHC e CL para LSN . . . . . . . . . . . . . 120

5.8.5 Teste de Hipótese IV - Posição dos métodos defeituosos em R-MCP

e R-MCT . . . . . . . . . . . . . . . . . . . . 120

Comparação da posição dos métodos defeituosos entre R-MCP e R-MCT ...................... 120

5.9 Discussão . . . . . . . . . . . . . . . . . . . . . . . . 121

5.9 .1 Considerações gerais . . . . . . . . . . . . . . . . . . 121

5.9.2 Utilizando a DCI para a localização de defeitos . . . . . . . . . . . 122

5.9 .3 Respondendo às questões de pesquisa . . . . . . . . . . . . . . . . . 124

5.10 Ameaças à validade . . . . . . . . . . . . . . . . . . . . 125

5.11 Considerações finais . . . . . . . . . . . . . . . . . . . . . 127

6 Conclusões $\quad 129$

6.1 Contribuições . . . . . . . . . . . . . . . . . . . . . 131

6.2 Trabalhos futuros . . . . . . . . . . . . . . . . . 131

Referências

Apêndice A - Algoritmos de geração das coberturas MCP e MCT

Apêndice B - Técnicas de depuração automatizada

B.1 Técnicas de depuração . . . . . . . . . . . . . . . . . . . 145

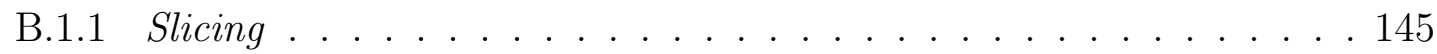

B.1.2 Depuração delta . . . . . . . . . . . . . . . . . . . . . 146

B.2 Dependência de comandos . . . . . . . . . . . . . . . . 146 
B.2.1 Dependência de controle . . . . . . . . . . . . . . . . . 147

B.2.2 Dependência de dados . . . . . . . . . . . . . . . . 147

B.3 Análise de fluxo de informações dinâmica . . . . . . . . . . . . . . . . . . . 147 


\section{Lista de Figuras}

2.1 Método $\max ($ CHAIM; ARAUJO, 2012) . . . . . . . . . . . . . . . . . 8

2.2 Método somaMax. . . . . . . . . . . . . . . . . . . . . . 9

2.3 GFC do método max. . . . . . . . . . . . . . . . . . . . . . . 12

2.4 GFC do método somaMax. . . . . . . . . . . . . . . . . . . . . . 12

2.5 GDU do método $\max \ldots \ldots \ldots \ldots \ldots$

2.6 GDU do método somaMax. . . . . . . . . . . . . . . . . . . . 13

2.7 Grafo $P W D U$ para os métodos somaMax e max. . . . . . . . . . . . . 21

2.8 Grafo IN1P para os métodos somaMax e max. . . . . . . . . . . . . . . 23

4.1 MethodCallPair (MCP). . . . . . . . . . . . . . 56

4.2 MethodCallTriple (MCT). . . . . . . . . . . . . . . 57

4.3 Depuração de programas baseada em Cobertura de Integração (DCI). . . . 58

4.4 R-MCP para o defeito AE_AK_1 do Commons-Math. . . . . . . . . . . . . 64

4.5 Floresta gerada pela CodeForest. . . . . . . . . . . . . . . 66

4.6 Trecho de código que insere o defeito AE_AK_1 do Commons-Math. . . . . 67

4.7 Visão geral da CodeForest gerada para o defeito AE_AK_1 do CommonsMath. . . . . . . . . . . . . . . . . . . . 68

4.8 Visão frontal da CodeForest gerada para o defeito AE_AK_1 do CommonsMath. . . . . . . . . . . . . . . . . . 68

4.9 CodeForest com filtro trimmer em 0,99 para o defeito AE_AK_1 do CommonsMath. . . . . . . . . . . . . . . . . . . . 69

4.10 CodeForest com filtro de busca contendo o termo "getCovariances(" para o defeito AE_AK_1 do Commons-Math. . . . . . . . . . . . . . . . . . . 70

4.11 Detalhe da árvore que contém o defeito AE_AK_1 do Commons-Math. . . . 70 
4.12 Trecho de código que insere o defeito PJH_AK_1 do Ant. . . . . . . . . . . 71

4.13 Visão geral da CodeForest gerada para o defeito PJH_AK_1 do Ant. . . . . 72

4.14 R-MCT para o defeito PJH_AK_1 do Ant. . . . . . . . . . . . . . . . 72

4.15 CodeForest com filtro trimmer em 1 e com o termo "parse(" para o defeito PJH_AK_1 do Ant. . . . . . . . . . . . . . . . . . . 73

4.16 R-MCT para o defeito PJH_AK_1 do Ant com uso do valor de suspeição delta. . . . . . . . . . . . . . . . . . . . 74

4.17 CodeForest com filtro trimmer em 0,97 e com o termo "parse(" para o defeito PJH_AK_1 do Ant. . . . . . . . . . . . . . . . . . . . . . . 74

4.18 Trecho de código que insere o defeito CB_HD_3 do XML-security. . . . . . . 75

4.19 LSN para o defeito CB_HD_3 do XML-security. . . . . . . . . . . . . 76

4.20 Visão geral da CodeForest gerada para o defeito CB_HD_3 do XML-security. 76

4.21 CodeForest com filtro trimmer em 1 para o defeito CB_HD_3 do XMLsecurity . . . . . . . . . . . . . . . . . . 77

4.22 Detalhe do defeito CB_HD_3 do XML-security localizado na CodeForest. 77

5.1 Trecho de código que insere o defeito AE_AK_1 do Commons-Math. . . . . 87

5.2 Lista de suspeição de MCP para o defeito AE_AK_1 do Commons-Math. 89

5.3 R-MCP para o defeito AE_AK_1 do Commons-Math. . . . . . . . . . . . . 90

5.4 Gráfico quantil-quantil para R-MCP usando CL. . . . . . . . . . . . . . . . 114

5.5 Gráfico quantil-quantil para R-MCT usando CL. . . . . . . . . . . . . . 114

5.6 Gráfico quantil-quantil para LSN usando CL. . . . . . . . . . . . . . 115

5.7 Histograma para R-MCP usando CHC . . . . . . . . . . . . . . 115

5.8 Histograma para R-MCT usando CHC . . . . . . . . . . . . . . . 116

5.9 Histograma para LSN usando CHC . . . . . . . . . . . . . . 116 


\section{Lista de Tabelas}

2.1 Requisitos de teste para os critérios Todos Nós e Todos Ramos do método $\max \ldots \ldots \ldots \ldots \ldots$

2.2 Requisitos de teste para os critérios Todas Definições e Todos Usos do

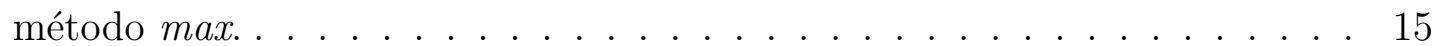

2.3 Taxonomia de defeitos de integração (DELAMARO et al., 2001). . . . . . . . 20

2.4 Requisitos de teste para os critérios Todos Nós Integrados Par-a-Par, Todos Ramos Integrados Par-a-Par e Todos Usos Integrados Par-a-Par para os métodos somaMax e $\max$. . . . . . . . . . . . . . . . . . . . . . . . 22

2.5 Requisitos de teste para os critérios Todos Nós Integrados N1, Todos Ramos Integrados N1 e Todos Usos Integrados N1 para os métodos somaMax e max. 24

2.6 Tabela de cobertura do método $\max . \ldots \ldots$. . . . . . . . . 27

2.7 Conjunto de teste para o método $\max \ldots \ldots \ldots \ldots$. . . . . . 27

3.1 Coberturas utilizadas nos artigos da revisão. . . . . . . . . . . . . . . . . 37

3.2 Heurísticas para a localização de defeitos. . . . . . . . . . . . . . . . . . . 38

3.3 Benchmarks utilizados para avaliação das técnicas. . . . . . . . . . . . . 43

5.1 Tratamentos usados nos experimentos. . . . . . . . . . . . . . . 84

5.2 Programas utilizados para os experimentos. . . . . . . . . . . . . 85

5.3 Detalhes dos programas utilizados para os experimentos. . . . . . . . . . 86

5.4 Computadores usados nos experimentos. . . . . . . . . . . . . . . 86

5.5 Quantidade de cliques para os defeitos do programa Ant. . . . . . . . . . . 92

5.6 Quantidade de cliques para os defeitos do programa Commons-Math. . . . 94

5.7 Quantidade de cliques para os defeitos do programa JTopas. . . . . . . . . 97

5.8 Quantidade de cliques para os defeitos do programa XML-security. . . . . . 97 
5.9 Posições de classificação dos defeitos na lista de suspeição de MCP, MCT e Nós no programa Ant. . . . . . . . . . . . . . . . . . . . . . . . . . . 99

5.10 Posições de classificação dos defeitos na lista de suspeição de MCP, MCT e Nós no programa Commons-Math. . . . . . . . . . . . . . . . . 100

5.11 Posições de classificação dos defeitos na lista de suspeição de MCP, MCT e Nós no programa JTopas. . . . . . . . . . . . . . . . . . . . . . . . 101

5.12 Posições de classificação dos defeitos na lista de suspeição de MCP, MCT e Nós no programa XML-security. . . . . . . . . . . . . . . . . . . . . 101

5.13 Defeitos localizados para R-MCP, R-MCT e LSN sem e com uso de delta. . 104

5.14 Defeitos localizados para R-MCP, R-MCT e LSN sem e com uso de delta. . 104

5.15 Comparação da quantidade de cliques entre R-MCP, R-MCT e LSN. .. . 106

5.16 Quantidade de métodos retornados nos roteiros de busca R-MCP e R-MCT até o método defeituoso. . . . . . . . . . . . . . . . 107

5.17 Quantidade de métodos necessários para localizar o defeito usando R-MCP e R-MCT. . . . . . . . . . . . . . . . . . . . 107

5.18 Quantidade de defeitos em que há redução do número de cliques usando hierarquia de código. . . . . . . . . . . . . . . . . . . . . . . . . . 109

5.19 Porcentagem dos defeitos em que foi necessário usar a suspeição delta e porcentagem dos casos em que uso de delta ajuda a localizar. . . . . . . . . 109

5.20 Posição de classificação dos defeitos não localizados na lista de cobertura de MCP, MCT e Nós. . . . . . . . . . . . . . . . . . . . . . . . . 111

5.21 Quantidade de defeitos de integração em que a cobertura foi mais eficaz. 112

5.22 Quantidade de defeitos de unidade em que a cobertura foi mais eficaz. . . . 112

5.23 Valores $p$ para o teste de Anderson-Darling para R-MCP, R-MCT e LSN. . 113

5.24 Valores $p$ para o teste de Anderson-Darling para Qtde. Métodos e Pos. Média. . . . . . . . . . . . . . . . . . . . . . . . 113

5.25 Valores $p$ obtidos para o teste de hipótese I. . . . . . . . . . . . . . 117

5.26 Valores $p$ obtidos para o teste de hipótese II. . . . . . . . . . . . . . . . . . 118

5.27 Valores $p$ obtidos para o teste de hipótese III. . . . . . . . . . . . . . . 119 


\section{Introdução}

\subsection{Considerações iniciais}

Durante o desenvolvimento de software, existe a preocupação em construir programas que funcionem corretamente, sem a ocorrência de falhas. Tais falhas são manifestações de defeitos inseridos no código pelos desenvolvedores, seja por um erro de compreensão sobre o que uma funcionalidade deve fazer, seja simplesmente por um erro de digitação. Dentro da área da Engenharia de Software, são utilizadas diversas técnicas de teste de software para revelar possíveis falhas existentes. Uma vez manifestadas, deseja-se localizar o defeito que causa a falha observada para corrigir o programa.

A atividade de depuração de programas é responsável pela localização e correção dos defeitos existentes em programas com o objetivo de livrá-los das falhas que foram reveladas durante os testes. A depuração é uma tarefa custosa, geralmente realizada de forma manual (JONES et al., 2007). É entendida como o corolário do teste bem-sucedido uma vez que se inicia a partir de um teste que revela a presença de defeitos (AGRAWAL et al., 1998). A depuração é uma tarefa necessária para garantir a qualidade do programa.

A depuração é sempre iniciada depois de um teste, independente da fase do processo de desenvolvimento. As informações geradas durante os testes são essenciais para o sucesso da depuração. Diversas técnicas têm sido propostas para automatizar a tarefa de depuração, principalmente para a localização de defeitos (JONES et al., 2007; SANTELICES et al., 2009; MASRI, 2010; WONG et al., 2010; NAISH et al., 2010; ABREU et al., 2011; MARIANI et al., 2011; ZHANG et al., 2011). Essas técnicas utilizam heurísticas que indicam valores de desconfiança dos requisitos a partir das informações dinâmicas obtidas na execução de testes. Existem técnicas de localização de defeitos que usam apenas um caso de teste de falha (AGRAWAL et al., 1991; ZELLER, 2002; CLEVE; ZELLER, 2005; GUO et al., 2006; BURGER; ZELLER, 2008) e outras que utilizam informação de cobertura de código de um conjunto de teste (AGRAWAL et al., 1998; JONES et al., 2002; JONES et al., 2007; SANTELICES et al., 2009; ABREU et al., 2011; MASRI, 2010; WONG et al., 2010; YU et al., 2011; ZHANG et 
al., 2011) para identificar trechos do software suspeitos de conter o defeito.

Informações de cobertura de código têm sido utilizadas para reduzir o espaço de busca para localização de defeitos. Diversas técnicas de localização de defeitos usam as informações de cobertura de comandos, analisando os comandos que foram executados ou não pelos casos de teste para inferir aqueles que possuem comportamentos suspeitos (AGRAWAL et al., 1998; JONES et al., 2007; WONG et al., 2010; ABREU et al., 2011). Outras técnicas investigam predicados associados a comandos de desvio de fluxo do código, como if-then-else, while e for (GUO et al., 2006; NAISH et al., 2010; YU et al., 2011; ZHANG et al., 2011). Existem ainda técnicas que utilizam as informações sobre chamadas de métodos executados (MURTAZA et al., 2008; BURGER; ZELLER, 2008; MARIANI et al., 2011; BURGER; ZELLER, 2011) e blocos básicos percorridos (ZHANG et al., 2009a; WANG et al., 2009a; ZHAO et al., 2010). Essas técnicas utilizam diferentes heurísticas para extrair as informações úteis para a localização de defeitos a partir da cobertura de código.

As heurísticas utilizam as informações de cobertura para inferir requisitos (comandos, predicados, blocos ou chamadas de método) mais suspeitos de conterem defeitos. Normalmente, essas heurísticas baseiam-se na frequência de execução de determinados requisitos por casos de teste que são executados corretamente ou incorretamente. A ideia é que requisitos executados com mais frequência por casos de teste de falha têm maior probabilidade de conter defeitos.

As heurísticas mais simples realizam operações de intersecção, substração e união de requisitos. As mais sofisticadas estabelecem uma classificação dos requisitos do programa executados pelos casos de teste. Nessa classificação, os requisitos que ocorrem mais frequentemente em casos de teste que manifestam falhas são classificados com maiores valores de desconfiança do que aqueles que ocorrem com menor frequência. Essa ideia foi inicialmente proposta por Collofello e Cousins (1987) para evitar que um defeito localizado em um trecho do código executado tanto por casos de teste que falham quanto por casos de teste que não falham fosse eliminado nas operações de subtração e interseção. Essa mesma ideia foi retomada posteriormente por Jones et al. (2002), que propuseram a heurística Tarantula.

As heurísticas utilizam normalmente requisitos de teste de unidade, isto é, a cobertura de comandos, nós, ramos e associações definição-uso (adus) intraunidade (procedimentos, funções ou métodos) para localizar defeitos. Uma questão relevante é: o uso de informações de cobertura de integração, baseada na comunicação entre as unidades de um programa, pode trazer informações que auxiliem o processo de busca por defeitos? 
O objetivo deste trabalho é investigar como as informações de requisitos de cobertura de integração podem ser utilizadas para melhorar a localização de defeitos por meio do desenvolvimento de uma técnica baseada em cobertura de integração.

\subsection{Motivação}

Diversas pesquisas vêm sendo realizadas com o objetivo de desenvolver técnicas para automatizar a tarefa de depuração de software. O teste de integração, por testar a comunicação entre as unidades existentes, pode levar à identificação de falhas não reveladas pelo teste de unidade (DELAMARO et al., 2001). No entanto, essa técnica de teste tem sido pouco explorada pelos trabalhos que estudam ou propõem técnicas para localização de defeitos. Assim, foram utilizadas as relações de integração entre as unidades exercitadas durante o teste de um programa, chamadas de cobertura de integração, para verificar sua eficácia na tarefa de localização automatizada de defeitos. Além disso, investigou-se como as informações de cobertura podem ser contextualizadas para guiar o programador na busca pelo defeito.

A atividade de depuração demanda uma significativa parcela do tempo total dispendido durante o desenvolvimento de programas (JONES et al., 2007; SANTELICES et al., 2009). Dessa forma, justifica-se a busca por técnicas que automatizem a depuração como forma de diminuir o tempo do processo de desenvolvimento. Para atingir esse objetivo, tais técnicas devem ser aplicáveis à indústria de software para uso em programas reais ${ }^{1}$, que podem conter uma quantidade desconhecida de defeitos. Que seja de nosso conhecimento, as técnicas de localização de defeitos existentes ainda não apresentam resultados que demonstrem ser possível utilizá-las em programas reais. Uma evidência disso são os experimentos realizados por tais técnicas (GUO et al., 2006; MURTAZA et al., 2008; XIE et al., 2010; YU et al., 2011; ZHANG et al., 2011), que utilizam programas (benchmarks) pequenos para avaliação, contendo um único defeito inserido no programa para a realização de experimentos.

Outra lacuna identificada nos trabalhos relacionados com depuração automatizada é a ausência de análise dos tipos de defeitos que determinadas técnicas conseguem identificar com maior ou menor eficácia. Alguns trabalhos apontam esse fato, indicando que as técnicas de teste que exercitam diferentes características dos programas conseguem reve-

\footnotetext{
${ }^{1}$ Usa-se o termo "programa real" para programas desenvolvidos para uso prático, contendo a partir de 5.000 linhas de código, em oposição a programas simples desenvolvidos para provas de conceito e programas contendo uma quantidade pequena de linhas de código.
} 
lar diferentes falhas existentes (SANTELICES et al., 2009; MASRI, 2010). No entanto, essa relação entre taxonomia de defeito e técnica/heurística de localização tem sido negligenciada até o presente momento, já que os trabalhos analisados não utilizam nenhum tipo de classificação para os defeitos dos programas usados como benchmarks para a realização de experimentos. O trabalho de Delamaro et al. (2001) propõe uma taxonomia para defeitos de integração, que será apresentada no próximo capítulo.

Portanto, a motivação desta pesquisa está em utilizar cobertura de integração para a depuração automatizada de software. Além disso, o uso de uma taxonomia de defeitos de integração pode indicar para quais defeitos a cobertura de integração é mais aplicável. O uso de programas reais nos experimentos possibilita avaliar quais são as vantagens e limitações para esse tipo de programa. Com isso, espera-se contribuir para aproximar a depuração automatizada de sua finalidade principal, que é permitir seu uso na indústria de software.

\subsection{Objetivos}

O objetivo principal deste projeto de pesquisa é avaliar se a cobertura de integração e a contextualização da informação de cobertura podem colaborar para a depuração automatizada. Pretende-se investigar se o uso dessas informações, aplicadas a heurísticas de localização de defeitos, consegue revelar defeitos existentes em programas. Assim, os seguintes objetivos específicos para este trabalho foram definidos:

- Propor uma técnica que utilize informações de cobertura de integração para localização de defeitos;

- Avaliar o uso de informações de cobertura de integração contextualizadas para a localização de defeitos;

- Avaliar a aplicação da cobertura de integração em heurísticas de localização de defeitos existentes;

- Identificar defeitos de integração nos programas usados para experimentos. Para isso, será utilizada a taxonomia de defeitos de integração definida por Delamaro et al. (2001); e

- Realizar experimentos em programas reais. O uso de um ou mais programas reais e de grande porte permitirá verificar a eficácia do uso de informações de integração em programas mais próximos da realidade existente na indústria de software. 
A técnica proposta, chamada Depuração de programas baseada em Cobertura de Integração (DCI), utiliza informações estáticas e dinâmicas de integração para indicar roteiros de busca para a localização de defeitos. Usa-se então as informações de cobertura de unidade para examinar as unidades dentro dos métodos considerados mais suspeitos. Os experimentos realizados com a DCI mostram que o uso de informações de cobertura de integração em conjunto com as informações de cobertura de unidade contribui para a tarefa de localização de defeitos com maior eficácia em relação ao uso somente de informações de cobertura de unidade. Foram utilizados programas reais para a execução dos experimentos.

\subsection{Organização}

No Capítulo 2 são apresentados os conceitos básicos relacionados com as áreas de teste de software e depuração automatizada. O Capítulo 3 traz um levantamento bibliográfico sobre depuração automatizada, indicando o atual estado da arte. No Capítulo 4 é apresentada a técnica DCI, que propõe o uso de informações de cobertura de integração para depuração automatizada. No Capítulo 5 são descritos os experimentos realizados para a validação da técnica DCI e são feitas a análise e a discussão dos resultados obtidos. Por fim, o Capítulo 6 apresenta as conclusões, contribuições e possíveis trabalhos futuros. 



\section{Conceitos fundamentais}

Neste capítulo são apresentados os conceitos mais frequentemente usados no contexto da depuração automatizada. A Seção 2.1 traz os conceitos relacionados com teste de software, que servem como base para as atividades de depuração automatizada. Na Seção 2.2 são apresentados diversos conceitos sobre a área de depuração automatizada.

\subsection{Conceitos de teste de software}

Esta seção apresenta conceitos da área de teste de software que são utilizados pelas técnicas de depuração automatizada. É a partir das informações obtidas durante a execução dos testes que se torna possível identificar a existência de falhas e iniciar a busca por defeitos.

\subsubsection{Defeito, erro, falha e engano}

Um defeito é um passo, processo ou definição de dados incorretos, inserido no programa durante a codificação (DELAMARO et al., 2007, 1-7). O defeito é a consequência de um engano cometido por um desenvolvedor. Diferentes motivos podem levar o desenvolvedor a cometer um engano, como o entendimento incorreto sobre o que uma funcionalidade deve fazer, o uso de uma variável em um local errado ou a exclusão indevida de um comando, entre outros. Um erro é um estado inconsistente ou inesperado na execução de um programa gerado a partir de um defeito. Por exemplo, um operador de comparação errado em um comando if que gera um desvio de fluxo incorreto. Esse estado inconsistente pode levar a uma falha, que é um comportamento inesperado em um programa percebido por quem o executa (DELAMARO et al., 2007, 1-7). Portanto, a manifestação de uma falha indica que em algum lugar do programa existe um defeito, possibilitando o início da atividade de depuração.

Para exemplificar alguns dos conceitos apresentados neste capítulo, serão usados os 
métodos max e somaMax, escritos em Java e apresentados nas Figuras 2.1 e 2.2, respectivamente. A coluna L indica a linha dos comandos dos métodos. O método max, apresentado por Chaim e Araujo (2012), retorna o maior valor do array de inteiros dentro do tamanho definido pela variável length. Esse método possui um defeito na linha de comando 2, que realiza um pré-incremento na variável $i$ antes de atribuir o valor da posição inicial do array. Dessa forma, se o maior valor estiver na primeira posição do array, ocorrerá uma falha na saída do método, que não retornará o valor correto. Outra falha pode ocorrer se o método receber um array contendo uma única posição, o que irá gerar uma exceção do tipo ArrayIndexOutOfBoundsException. A correção para o comando é mostrada em negrito na mesma linha.

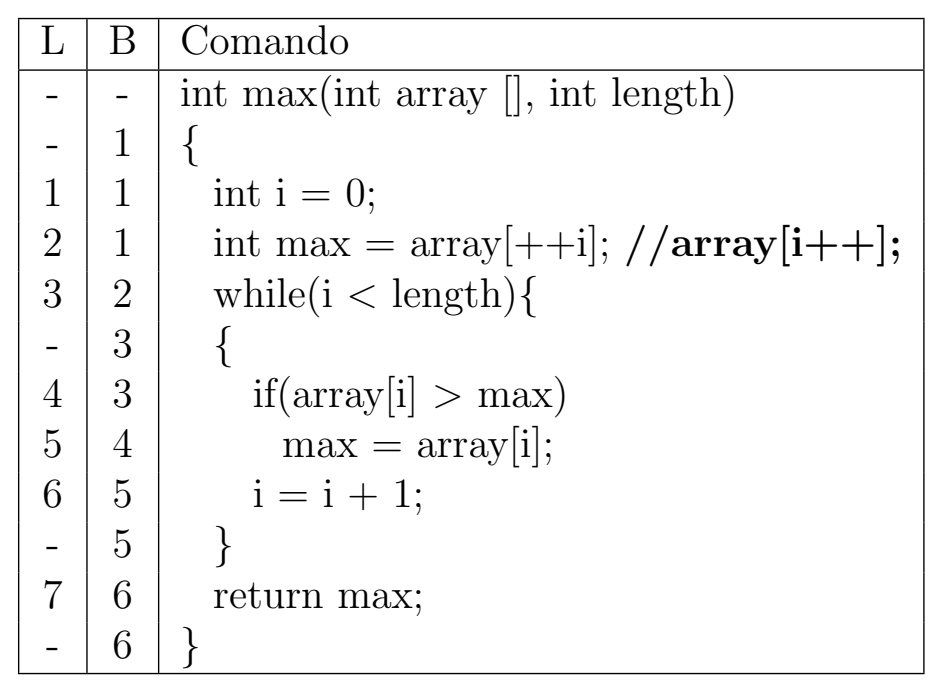

Figura 2.1 - Método max (CHAIM; ARAUJO, 2012).

O método somaMax será utilizado para exemplificar conceitos relacionados ao teste de integração. Esse método recebe dois arrays de inteiros retornando o valor da soma entre o maior valor de cada array, usando o método max para selecionar os maiores inteiros. Para simplificar o exemplo, considera-se que o método somaMax não pode receber arrays nulos. Existe um defeito no comando da linha 7, que está passando o tamanho do array1 (array1.length) ao invés do tamanho do array2 para o segundo parâmetro do método max. A correção do comando 7 é mostrada em negrito na Figura 2.2. Esse defeito pode levar a três situações distintas: se o tamanho dos arrays for o mesmo, não ocorrerá nenhuma falha relacionada com esse defeito; se o tamanho do array1 for maior que o tamanho do array2, ocorrerá uma falha que levará a uma exceção do tipo ArrayIndexOutOfBoundsException; se o tamanho do array1 for menor que o tamanho do array2 e o maior inteiro de array2 estiver em uma posição maior que o tamanho de array1, o método max não retornará o maior valor de array2, causando uma falha. 


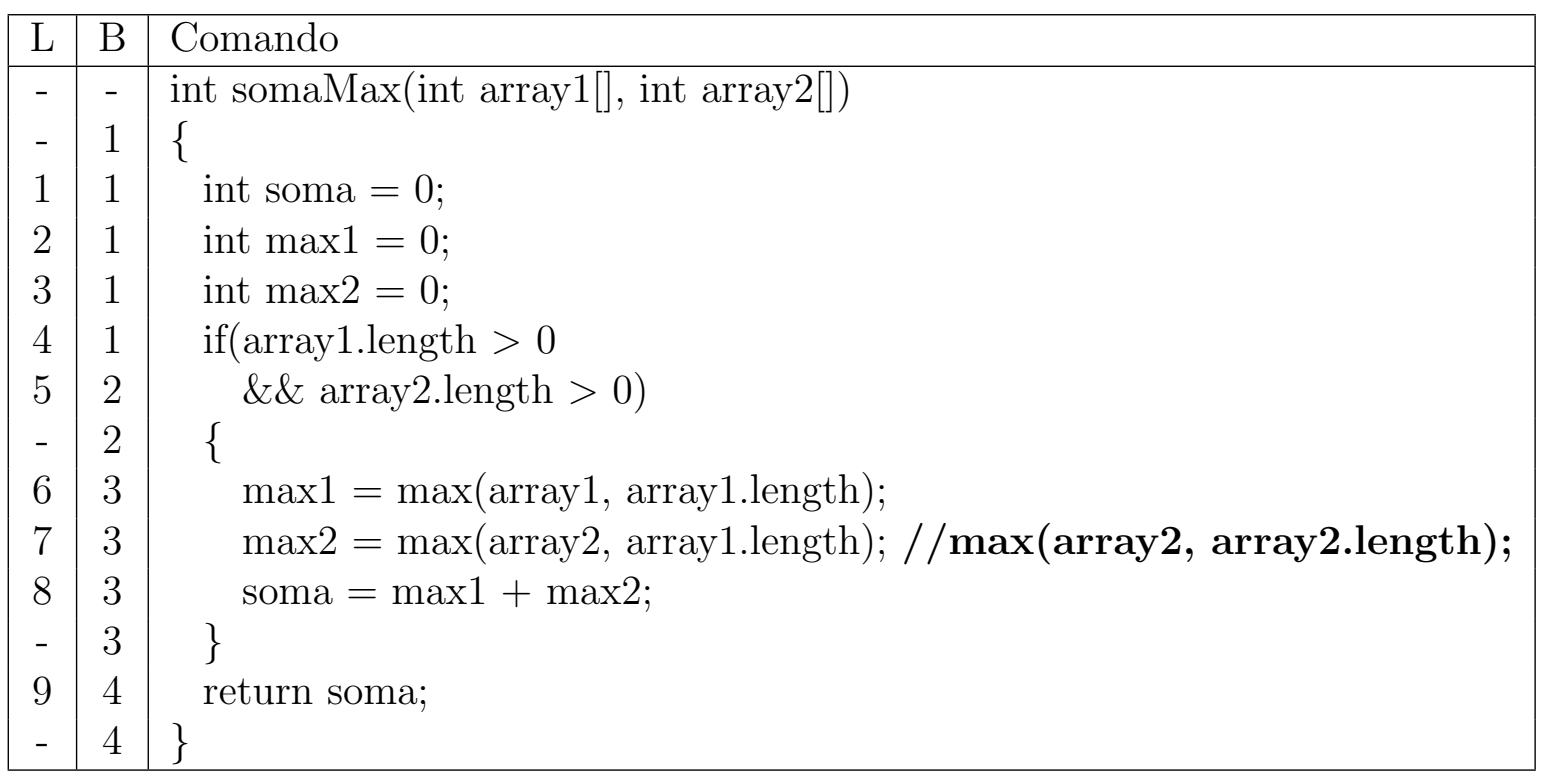

Figura 2.2 - Método somaMax.

\subsubsection{Caso de teste, conjunto de teste e oráculo}

Um caso de teste é formado pelas entradas e o resultado de saída esperado para aquele teste (DELAMARO et al., 2007, 1-7). Um conjunto de teste é formado pelos casos de teste existentes para o programa que será testado. As falhas podem ser reveladas pela execução de um conjunto de teste. Com base no resultado de saída esperado é possível determinar se um caso de teste foi executado corretamente (caso de teste de sucesso), com resultado igual ao esperado; ou incorretamente (caso de teste de falha), com resultado diferente do esperado. Cada caso de teste pode executar diferentes trechos do programa e ter um resultado correto ou incorreto. Essas informações podem ser usadas para indicar partes do código que possuam maior possibilidade de conter defeitos.

A identificação da falha depende do conhecimento sobre qual é o comportamento esperado de um programa (ou de um trecho do programa), o que geralmente é determinado por intervenção humana. No contexto de teste de software, o oráculo é responsável por verificar o resultado esperado de saída dos casos de teste (DELAMARO et al., 2010). O oráculo é necessário para determinar quando um caso de teste é executado com sucesso ou falha, sendo fundamental para as técnicas de localização que fazem uso da informação de execução dos testes.

Por exemplo, o método max da Figura 2.1 pode ser testado com um caso de teste $t_{1}$ $=\langle([5,2,4], 3), 5\rangle$, no qual "[5,2,4]" e "3" são o valor de entrada do array e o tamanho do array, respectivamente, e "5" é o valor de saída esperado. Quando o caso de teste é executado no método, o valor de saída obtido é "4", diferente do esperado. O oráculo 
considera então que houve uma falha, sendo este um exemplo de caso de teste de falha.

\subsubsection{Técnicas de teste}

As técnicas de teste são usadas para verificar diferentes aspectos do programa, servindo para revelar falhas em seu funcionamento e para otimizar a quantidade de testes a serem realizados. Essas técnicas permitem avaliar se um programa apresenta falhas, podendo ser usadas por diferentes tipos de testadores, desde desenvolvedores interessados no código até pessoas que possuem conhecimento apenas sobre as funcionalidades que o programa deve realizar, como analistas e o próprio usuário. As técnicas de teste também permitem sistematizar a atividade de teste de programas, tornando o processo repetível e controlado.

Cada técnica possui um conjunto de critérios de teste que são usados para determinar as características do programa que serão testadas, indicando quais requisitos de teste devem ser cobertos para atender a um determinado critério a ser utilizado. Um requisito de teste é coberto quando há pelo menos um caso de teste que o atende. Um conjunto de teste é considerado adequado ou $C$-adequado quando satisfaz todos os requisitos que compõem um critério de teste $C$ (DELAMARO et al., 2010).

Por exemplo, se um critério de teste diz que todos os comandos de um método devem ser testados, cada comando será um requisito de teste. O conjunto de teste será adequado se cada comando desse método for coberto por pelo menos um caso de teste do conjunto. Cada critério pode levar à manifestação de diferentes falhas no programa testado, de acordo com as características definidas por esse critério, implicando maior ou menor custo de execução dos testes.

\section{Teste estrutural}

Teste estrutural é uma técnica que utiliza informações da estrutura do código (fonte ou objeto) do programa para a realização dos testes (DELAMARO et al., 2010). O teste estrutural possibilita que os testadores exercitem as estruturas do código de acordo com seu fluxo de execução, como comandos percorridos ou variáveis utilizadas. Entre os critérios para o teste estrutural, tem-se os critérios baseados no fluxo de controle, que investigam os caminhos tomados por uma determinada execução, e os critérios baseados no fluxo de dados, que identificam as definições e usos das variáveis de um programa durante a execução. 
A estrutura do código é representada por um grafo de fluxo de controle (GFC), cujos nós representam blocos básicos, ligados pelos ramos (ou arestas) do grafo. Os blocos básicos são formados pelos comandos que são executados de forma sequencial, em que a execução do primeiro comando acarreta a execução dos demais comandos do bloco (DELAMARO et al., 2007, 47-76). Os comandos de desvio determinam os ramos do GFC, ou seja, controlam o fluxo de execução do programa. Nas Figuras 2.1 e 2.2, a coluna B representa os blocos básicos dos métodos max e somaMax, respectivamente. As Figuras 2.3 e 2.4 contêm os GFCs de max e somaMax, respectivamente. Esse grafo pode ser estendido para conter informações sobre a definição e uso de variáveis que ocorrem no programa, chamado de grafo definição-uso (GDU). A relação entre a definição e o uso de uma variável é conhecida como associação definição-uso (adu) (DELAMARO et al., 2010). As Figuras 2.5 e 2.6 representam, respectivamente, os GDUs dos métodos max e somaMax.

A definição de uma variável ocorre quando um comando pode realizar uma modificação no valor dessa variável (DELAMARO et al., 2010). Por exemplo, o comando int $i=0$; do método $\max$ (Figura 2.1) define um valor para a variável $i$. O uso de uma variável referese às referências feitas a essa variável em que seu valor não é modificado (DELAMARO et al., 2010). O uso de variáveis é chamado de uso predicativo (p-uso) quando está associado a comandos condicionais, por exemplo, o comando while $(i<$ length) do método max (Figura 2.1) faz uso predicativo da variável $i$. O uso de variáveis que não for p-uso é chamado de uso computacional (c-uso). Um exemplo é o comando max = array[i], que faz uso computacional das variáveis array e $i$.

Uma adu requer que exista um caminho livre de definição entre a definição e o uso da variável em questão. Um caminho livre de definição é aquele no qual a variável não é redefinida entre a definição e o uso de tal variável (DELAMARO et al., 2010). No GDU, os p-usos são associados aos ramos do grafo, enquanto os c-usos são associados aos nós. Assim, a representação da adu na qual ocorre um c-uso é $D=(d, u, x)$, que representa um requisito de teste de fluxo de dados em que $d$ e $u$ são os nós nos quais ocorre a definição e o uso da variável $x$, respectivamente. Em uma adu na qual ocorre um p-uso, o requisito é representado por $D=\left(d,\left(u^{\prime}, u\right), x\right)$, em que $\left(u^{\prime}, u\right)$ representa o ramo no qual ocorre o uso da variável $x$ definida em $d$.

A partir dos grafos que representam o programa, pode-se definir os critérios de teste que determinam as características que serão testadas. Entre os critérios baseados no fluxo de controle tem-se os critérios Todos Nós e Todos Ramos. Dois dos critérios baseados no fluxo de dados são o critério Todas Definições e o critério Todos Usos. 


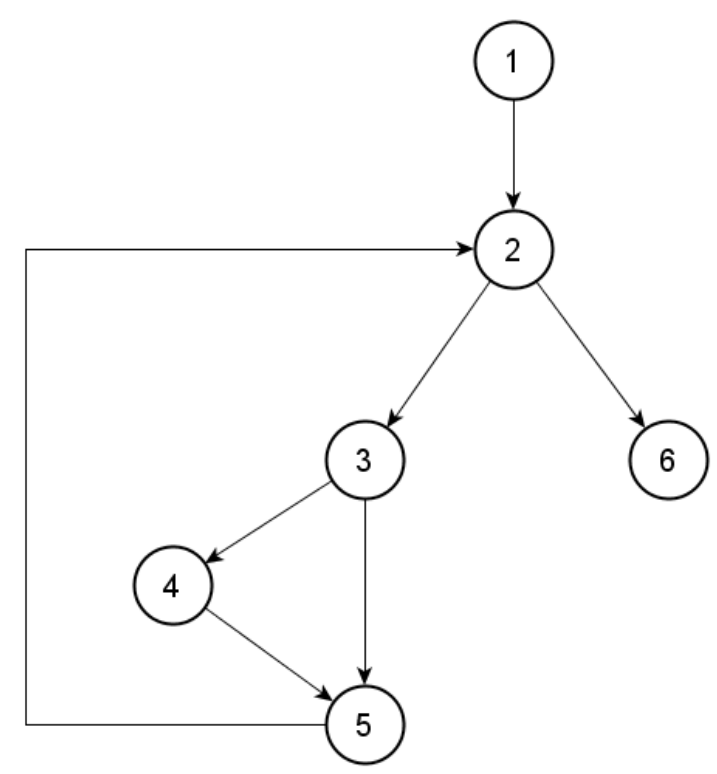

Figura 2.3 - GFC do método max.

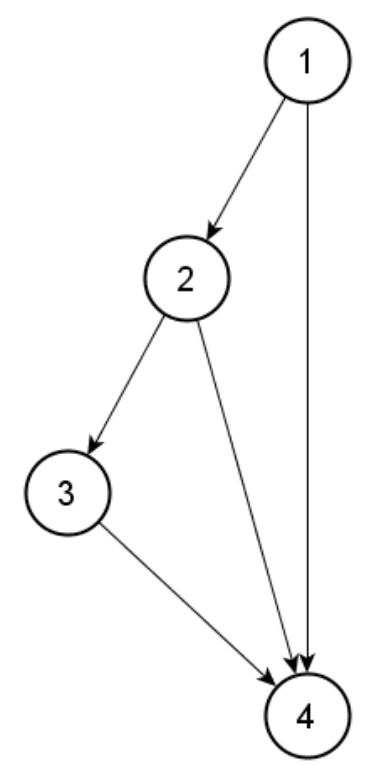

Figura 2.4 - GFC do método somaMax. 


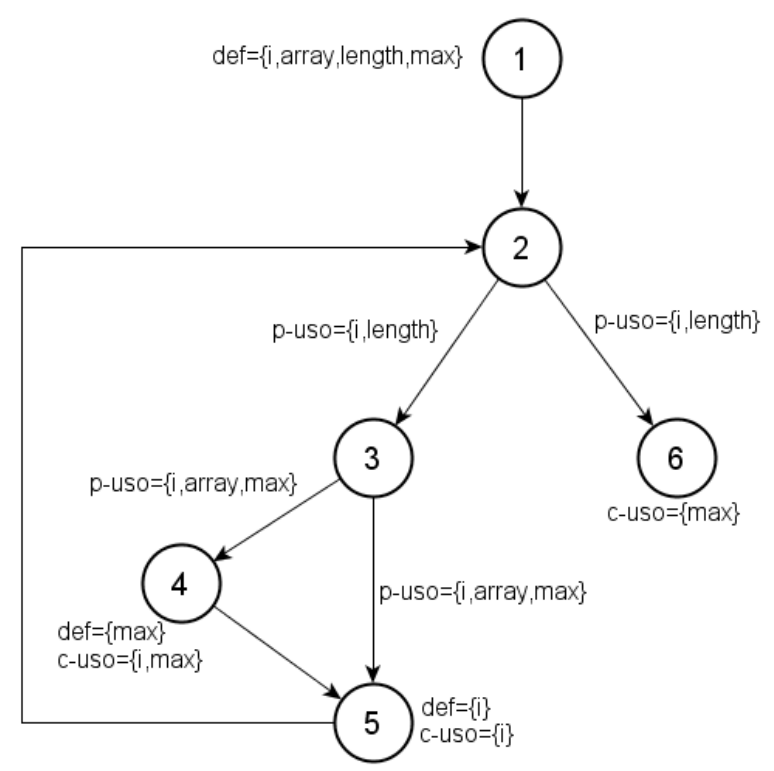

Figura 2.5 - GDU do método max.

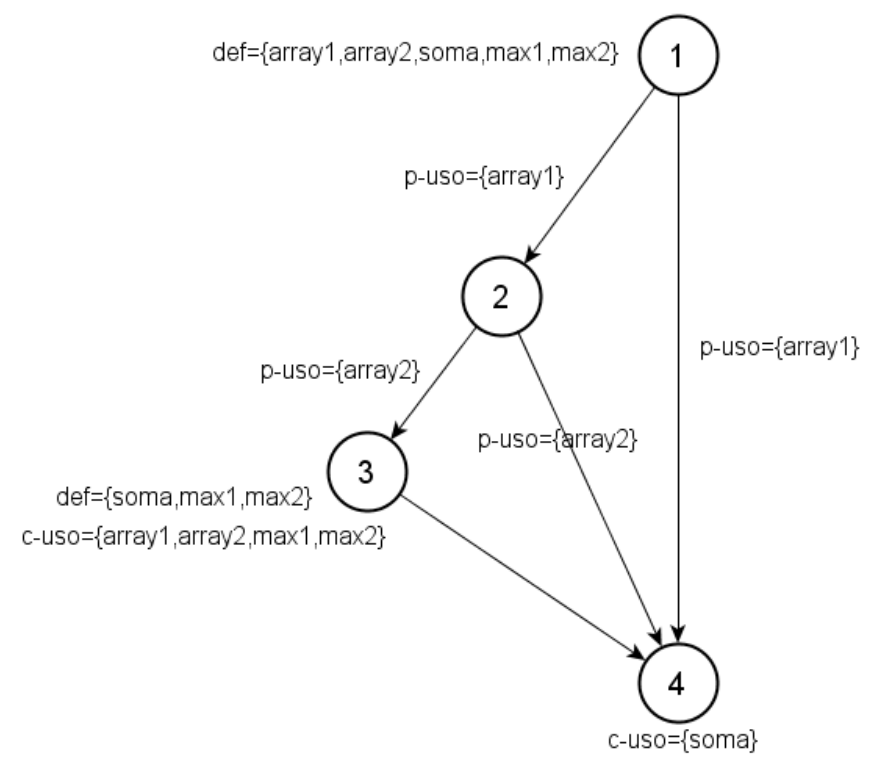

Figura 2.6 - GDU do método somaMax. 
Critério Todos Nós: requer que o conjunto de teste percorra todos os nós do GFC pelo menos uma vez (DELAMARO et al., 2007, 47-76).

Critério Todos Ramos: todos os ramos existentes entre os nós do GFC devem ser visitados pelo conjunto de teste (DELAMARO et al., 2007, 47-76). Esse critério atende também ao critério Todos Nós visto que, ao passar por todos os ramos, consequentemente todos os nós são percorridos.

Critério Todas Definições: o conjunto de teste deve percorrer todos os trechos de código nos quais ocorre uma definição de variável e um uso em um caminho livre de definição, podendo ser um c-uso ou um p-uso (DELAMARO et al., 2007, 47-76). Existem diferentes soluções possíveis para gerar os requisitos que atendem a esse critério, visto que se pode escolher qualquer um dos usos existentes para cada definição.

Critério Todos Usos: para atender a esse critério, todos os usos posteriores à definição de uma variável em um caminho livre de definição devem ser percorridos, e não apenas o uso seguinte (DELAMARO et al., 2007, 47-76). Ou seja, todas adus devem ser percorridas. Esse critério engloba o critério Todas Definições, já que qualquer uso escolhido em Todas Definições será percorrido.

Utilizando o método max como exemplo, a Tabela 2.1 mostra os requisitos necessários para atender aos critérios Todos Nós e Todos Ramos, enquanto a Tabela 2.2 mostra os requisitos necessários para atender aos critérios Todas Definições e Todos Usos.

Os critérios Todas Definições e Todos Usos são computacionalmente caros, principalmente o critério Todos Usos, exigindo um maior tempo para execução e maior espaço de armazenamento das informações geradas em comparação com os critérios Todos Ramos e Todos Nós, resultando em maior sobrecarga de execução quando da análise de cobertura desses critérios (SANTELICES et al., 2009).

Tabela 2.1 - Requisitos de teste para os critérios Todos Nós e Todos Ramos do método $\max$.

\begin{tabular}{|c|c|}
\hline Todos Nós & Todos Ramos \\
\hline 1 & $(1,2)$ \\
\hline 2 & $(2,3)$ \\
\hline 3 & $(2,6)$ \\
\hline 4 & $(3,4)$ \\
\hline 5 & $(3,5)$ \\
\hline 6 & $(4,5)$ \\
\hline & $(5,2)$ \\
\hline
\end{tabular}


Tal fato pode ser exemplificado pelas Tabelas 2.1 e 2.2. Pode-se ver que o total de requisitos necessários para atender ao critério Todos Usos é maior em relação aos demais critérios. Além disso, os critérios baseados em fluxo de dados guardam, além dos nós e ramos percorridos, as variáveis envolvidas. No grafo da Figura 2.5, pode-se ver que o nó número 1, que contém a definição de 4 variáveis, origina 4 requisitos para o critério Todas Definições e 14 requisitos para o critério Todos Usos. Consequentemente, o uso desses critérios traz informações diferentes em relação a Todos Ramos e Todos Nós, visto que considera a relação entre as variáveis no código e não somente o fluxo tomado por um determinado caso de teste.

\section{Teste funcional}

O teste funcional baseia-se nas informações de entrada e saída dos testes sobre as funcionalidades do programa (DELAMARO et al., 2007, 9-25). A partir da execução dos valores de entrada fornecidos, o resultado de saída é avaliado pelo oráculo, determinando se tal funcionalidade retorna ou não o valor esperado. Sua principal diferença para o teste estrutural é que não é necessário ter conhecimento sobre o código do programa. Entre os critérios de teste funcional mais utilizados estão o Particionamento em Classes de Equivalência (PCE) e Análise do Valor Limite (AVL).

Particionamento em Classes de Equivalência (PCE): esse critério divide o domínio de entrada em classes de equivalência, que são identificadas a partir intervalos ou conjuntos de valores que tenham o mesmo comportamento no domínio. Dessa forma, basta testar um dos possíveis valores de uma determinada classe, diminuindo a quantidade de entradas necessárias para a atividade de teste (DELAMARO et al., 2007, 9-25).

Tabela 2.2 - Requisitos de teste para os critérios Todas Definições e Todos Usos do método max.

\begin{tabular}{|c|c|c|c|}
\hline Todas Definições & Todos Usos & Todos Usos & Todos Usos \\
\hline$(1,(2,6), \mathrm{i})$ & $(1,(2,3), \mathrm{i})$ & $(1,4$, array $)$ & $(4,6, \max )$ \\
\hline$(1,(3,4), \max )$ & $(1,(2,6), \mathrm{i})$ & $(1,(2,3)$, length $)$ & $(5,(2,3), \mathrm{i})$ \\
\hline$(1,(2,3)$, length $)$ & $(1,(3,4), \mathrm{i})$ & $(1,(2,6)$, length $)$ & $(5,(2,6), \mathrm{i})$ \\
\hline$(1,6, \max )$ & $(1,(3,5), \mathrm{i})$ & $(1,(3,4), \max )$ & $(5,(3,4), \mathrm{i})$ \\
\hline$(4,6, \max )$ & $(1,4, \mathrm{i})$ & $(1,(3,5), \max )$ & $(5,(3,5), \mathrm{i})$ \\
\hline$(5,(2,3), \mathrm{i})$ & $(1,5, \mathrm{i})$ & $(1,6, \max )$ & $(5,4, \mathrm{i})$ \\
\hline & $(1,(3,4)$, array $)$ & $(4,(3,4), \max )$ & $(5,5, \mathrm{i})$ \\
\hline & $(1,(3,5)$, array $)$ & $(4,(3,5), \max )$ & \\
\hline
\end{tabular}


Análise do Valor Limite (AVL): esse critério explora os valores limites dos intervalos do domínio de entrada. O AVL costuma ser usado em conjunto com o PCE, só que explorando os valores imediatamente acima e abaixo dos limites identificados (DELAMARO et al., 2007, 9-25).

\section{Teste baseado em defeitos}

O teste baseado em defeitos é uma técnica de teste que utiliza a inserção de defeitos no código para revelar falhas. Para isso, são criadas versões do programa a ser testado contendo defeitos típicos que ocorrem durante o desenvolvimento (DELAMARO et al., 2010). Os respectivos conjuntos de teste são então executados nas versões defeituosas geradas. Espera-se que o conjunto de teste revele falhas tanto relativas aos defeitos inseridos, bem como novas falhas. Essa técnica pode ser usada tanto para revelar falhas quanto para avaliar a qualidade de conjuntos de teste. Para o teste baseado em defeitos, um dos critérios utilizados é o teste de mutação.

Teste de Mutação ou Análise de Mutantes: para esse critério de teste são criadas versões modificadas (mutadas) do código de interesse na qual uma ou mais linhas são substituídas por defeitos por meio do uso de operadores de mutação. Os operadores de mutação definem as regras para modificação dos programas, como a troca de sinais em operações ou exclusão de comandos. Essas versões mutantes são então executadas pelo conjunto de teste e, caso o mutante apresente um resultado incorreto, ele é considerado morto (DELAMARO et al., 2010). Dessa forma, procura-se obter um conjunto de teste que consiga matar todos os mutantes para atender a esse critério.

O Teste de Mutação pode ser usado tanto para revelar falhas em um programa quanto para avaliar se o número de mutantes mortos pelo conjunto de teste é suficiente. No entanto, a técnica tem sido usada para outras atividades, como gerar versões defeituosas de programas para criar benchmarks (ALI et al., 2009; XIE et al., 2011) ou então para sugerir correções para possíveis defeitos no código (DEBROY; WONG, 2010).

\subsubsection{Cobertura de teste}

A cobertura de teste tem o objetivo de avaliar a adequação de um conjunto de teste aos requisitos de teste definidos, indicando os requisitos que foram satisfeitos por um dado caso de teste ou conjunto de teste (ZHANG et al., 2010). A cobertura de teste é aplicada 
aos critérios de diferentes técnicas de teste, como o teste estrutural, teste funcional ou teste baseado em defeitos.

Para o teste estrutural, a cobertura de teste refere-se a requisitos como nós, ramos ou adus satisfeitos para um conjunto de teste. Tipicamente, a cobertura de teste pode ser avaliada como uma porcentagem dos requisitos satisfeitos em relação ao total de requisitos estabelecidos pelo critério de teste. Essa porcentagem pode indicar a necessidade de criação de novos casos de teste para aumentar a cobertura e, consequentemente, testar mais trechos do programa.

\subsubsection{Fases de teste}

As fases de teste são utilizadas para verificar a existência de falhas em diferentes momentos do processo de desenvolvimento do programa, o que diminui a complexidade da atividade de teste (DELAMARO et al., 2007, 1-7). Por exemplo, uma falha pode ser revelada durante o teste em uma unidade do programa ou então durante os testes de comunicação entre unidades.

\section{Teste de unidade}

O teste de unidade é a etapa de teste na qual se avalia partes individuais do programa, como um método, um módulo ou uma classe, dependendo do que for definido como unidade. O objetivo nessa fase é testar a unidade de código na busca por possíveis defeitos antes de integrá-la com as demais unidades. Na abordagem utilizada neste trabalho, unidade é um método, um procedimento ou uma função.

O teste de unidade pode ser realizado individualmente pelos programadores para avaliar o funcionamento do código implementado, de forma independente das demais unidades existentes. São normalmente realizados pelos desenvolvedores logo após concluída a codificação da unidade (DELAMARO et al., 2007, 1-7).

\section{Teste de integração}

O teste de integração é a etapa de teste que analisa a comunicação entre as unidades existentes em um determinado programa, com ênfase na estrutura do programa (DELAMARO et al., 2007, 1-7). Durante essa etapa, espera-se verificar a existência de falhas ocorridas na troca de mensagens entre as unidades. Essa etapa costuma ser realizada após os testes de unidades. Portanto, as falhas reveladas durante o teste de integração 
podem estar relacionadas a erros em chamada de métodos, assim como passagens e retorno de valores entre métodos. O teste de integração costuma ser realizado pela equipe de desenvolvedores.

\section{Teste de sistema}

Durante o teste de sistema procura-se verificar se todos os requisitos funcionais ou não funcionais definidos para o programa são atendidos (DELAMARO et al., 2007, 1-7). Costuma ser realizado após o teste de integração e pode envolver testadores e usuários.

\section{Teste de regressão}

Essa etapa de teste é realizada durante a manutenção do programa. Após as modificações feitas, podem ser introduzidos novos defeitos ao código, o que indica a necessidade de novos testes que mostrem que as mudanças não apresentam falhas e que as funcionalidades anteriores continuam funcionando (DELAMARO et al., 2007, 1-7).

\subsubsection{Teste estrutural de integração}

Um dos principais objetivos deste projeto de pesquisa é realizar a depuração automatizada usando informações de integração. Para isso, serão descritas técnicas que têm sido propostas para realizar o teste de integração. Nesta seção, serão mostradas as características dos defeitos de integração. Em seguida, é apresentada uma taxonomia desenvolvida para identificar defeitos de integração. Também serão apresentados três critérios de teste para a realização de teste de integração entre pares de unidades e um modelo de grafo proposto para representar a integração entre pares de unidades. Por fim, serão mostrados três critérios para o teste de integração entre uma unidade e todas as unidades que são diretamente chamadas por ela e um modelo de grafo que representa essa integração.

\section{Defeitos de integração}

Os defeitos de integração são aqueles presentes na comunicação entre as unidades existentes em um programa. Esses defeitos ocasionam erros que podem aparecer na invocação de uma unidade a partir de outra, nos valores retornados pela unidade chamada ou ainda por meio de variáveis globais compartilhadas entre as unidades que estão se comunicando (DELAMARO et al., 2001; DELAMARO et al., 2010). Os defeitos de integração 
podem também ser causados por enganos nos formatos de entrada e saída, sequência incorreta de chamada a subrotinas e incompreensão de valores de parâmetros (HARROLD et al., 1992).

Os defeitos de integração geralmente pertencem às unidades (funções, procedimentos ou métodos), mas podem ser exercitados somente durante o teste de integração. Por exemplo, os métodos somaMax (Figura 2.2) e max (Figura 2.1) podem ter sido escritos por programadores diferentes. Como o método somaMax faz chamadas ao método max, o programador responsável por escrever somaMax poderia utilizar um objeto mock (SAFF; ERNST, 2004) para simular a comunicação com o método max durante os testes de unidade de somaMax. Assim, falhas na comunicação entre os métodos poderiam não ser reveladas durante os testes de unidade, ocorrendo somente durante o teste de integração.

\section{Taxonomia para defeitos de integração}

Delamaro et al. (2001) apresentaram uma taxonomia para identificar defeitos de integração, mostrada na Tabela 2.3. São propostas três categorias para defeitos envolvendo a troca de mensagens entre duas unidades $F$ e $G$, em que $F$ realiza uma chamada a $G$ passando e recebendo valores. Esses valores podem ser parâmetros, passados por valor ou por referência, variáveis globais ou o valor retornado pela unidade $G$. A passagem de valores incorretos entre as unidades pode ocasionar uma falha observável em uma das unidades. Lemos et al. (2009) estendem a taxonomia de defeitos de integração apresentada por Delamaro et al. (2001) para o contexto de comunicação entre pares de unidades em programas orientados a aspectos e orientados a objetos em Java.

Um exemplo de defeito de integração pode ser visto entre os métodos max (Figura 2.1) e somaMax (Figura 2.2). Suponha que um caso de teste $t_{1}=\langle([1,2,4],[5,3,2]), 9\rangle$ seja executado no método somaMax e que esse método não contenha defeito. Na primeira chamada ao método max, o defeito será executado, porém não leva à ocorrência de um erro. Devido à ordem dos inteiros em array1 o valor retornado pelo método max para a variável max1 é igual a 4, que é o valor correto. Na segunda chamada ao método max, o defeito será novamente executado, gerando um erro e retornando um valor incorreto para a variável max2, que receberá o valor 3 ao invés de 5. Dessa forma, o valor na variável soma será 7, e não 9 como seria o resultado esperado, gerando uma saída incorreta (falha). De acordo com a taxonomia de defeitos de integração, esse defeito pode ser classificado como pertencente à categoria $c$. 
Tabela 2.3 - Taxonomia de defeitos de integração (DELAMARO et al., 2001).

\begin{tabular}{|c|l|}
\hline Categoria & Descrição \\
\hline$a$ & $\begin{array}{l}\text { A unidade } G \text { recebe da unidade } F \text { valores incorretos em sua entrada, } \\
\text { causando uma falha em } G\end{array}$ \\
\hline$b$ & $\begin{array}{l}\text { A unidade } G \text { recebe da unidade } F \text { valores incorretos em sua entrada, } \\
\text { devolvendo valores incorretos a } F, \text { gerando uma falha em } F\end{array}$ \\
\hline$c$ & $\begin{array}{l}\text { A unidade } G \text { recebe valores corretos de } F, \text { porém retorna valores in- } \\
\text { corretos para } F, \text { causando uma falha em } F\end{array}$ \\
\hline
\end{tabular}

\section{Critérios para teste de integração entre pares de unidades}

Lemos et al. (2009) definiram três critérios de teste específicos para integração entre pares de unidades, dois baseados nos critérios de fluxo de controle Todos Nós e Todos Ramos e um baseado no critério de fluxo de dados Todos Usos.

O grafo PairWise Def-Use (PWDU), ou grafo definição-uso par-a-par, foi proposto por Lemos et al. (2009) para implementar a técnica de teste de integração par-a-par. O objetivo é integrar os grafos definição-uso das unidades utilizando bytecode Java. Esse grafo é baseado no grafo definição-uso orientado a aspectos (Aspected-Oriented Def-Use - AODU) (LEMOS et al., 2007), que representa unidades de código também baseado em bytecodes para código orientado a objetos e orientado a aspectos. O PWDU integra o par de unidades AODUs que interagem. A unidade que faz a chamada do método é nomeada como unidade base e a que recebe o fluxo de controle recebe o nome de unidade integrada. Os nós integrados são os que pertencem à unidade integrada. Os ramos integrados conectam dois nós integrados, enquanto os ramos de integração representam um fluxo entre um nó base e um nó integrado.

A representação do grafo é feita da seguinte forma: ramos regulares, de base e integrados, são representados por linhas simples contínuas; desvios de fluxo para tratamento de exceção são representados por linhas tracejadas; nós integrados são representados com o prefixo "i." no rótulo do nó; nós de chamada são representados por círculos duplos nos nós; e nós de saída são representados por nós em negrito. Os rótulos dos nós representam a primeira instrução bytecode de cada bloco. O grafo PWDU pode conter as informações das definições e usos necessárias para a representação de fluxo de dados entre a unidade base e a integrada, com os p-usos nos ramos e os c-usos nos nós. Apenas as variáveis que são definidas em um método e usadas no outro, chamadas de variáveis de comunicação, são representadas no grafo. Como os programas analisados neste projeto de pesquisa são do paradigma orientado a objetos, a notação referente à orientação a aspectos não será 
apresentada.

Um exemplo do grafo PWDU é apresentado na Figura 2.7, utilizando os métodos max e somaMax. No exemplo, optou-se por usar o número do bloco do código fonte Java ao invés do número do bytecode. Para o exemplo, o nó 3 do método somaMax foi dividido em $3 a, 3 b$ e $3 c$ referente às linhas de comando 6, 7 e 8, respectivamente, devido aos comandos 6 e 7 serem nós de chamada. O grafo mostra a integração para a chamada de método na linha 6. A integração que ocorre na linha 7 seria realizada de forma semelhante.

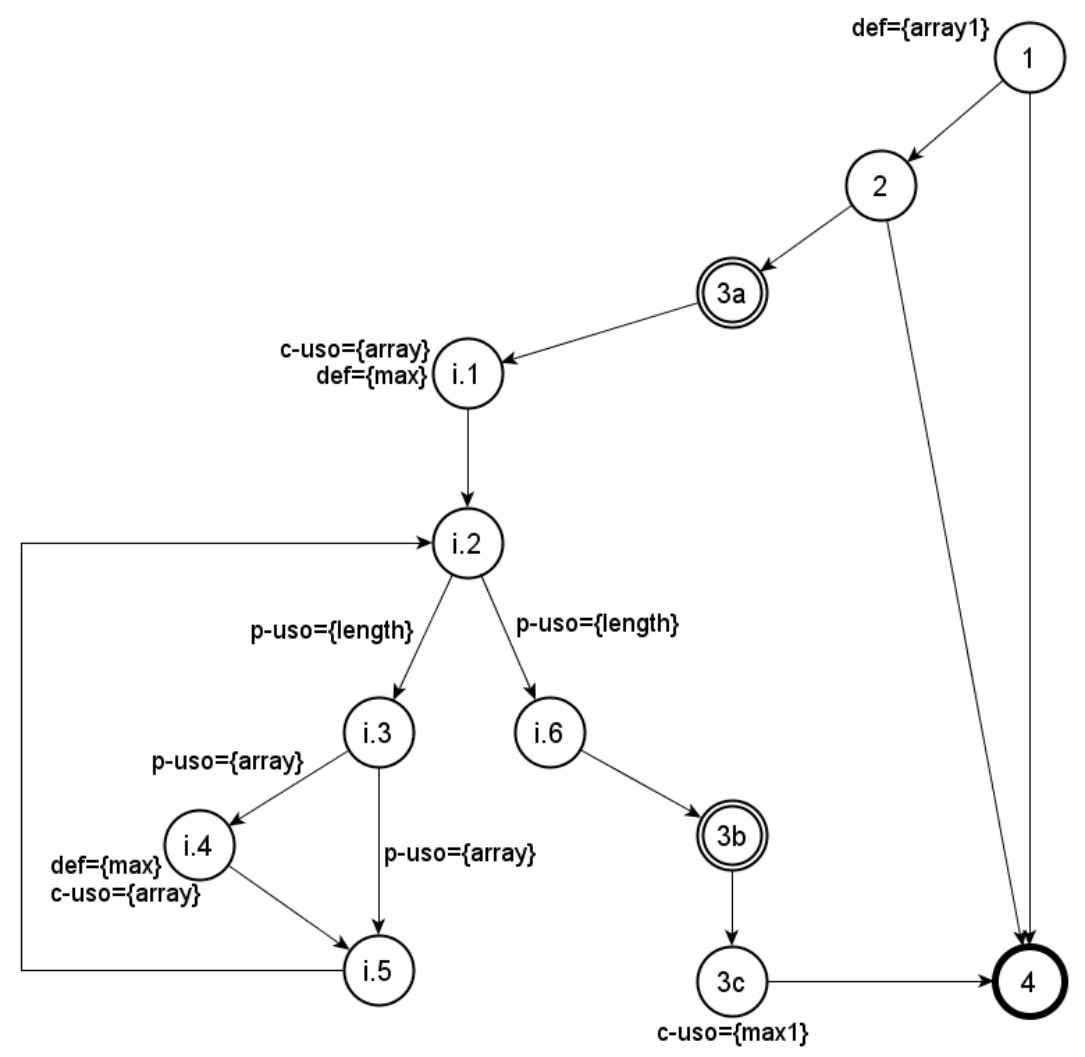

Figura 2.7 - Grafo PWDU para os métodos somaMax e max.

A seguir, são descritos os critérios definidos para integração entre pares de unidades. Esses critérios consideram as estruturas que pertencem à unidade integrada, que dão origem aos requisitos que atendem a esses critérios.

Todos Nós Integrados Par-a-Par (all-pairwise-integrated-nodes): requer que todos os nós integrados do grafo PWDU sejam exercitados pelo menos uma vez pelo conjunto de teste.

Todos Ramos Integrados Par-a-Par (all-pairwise-integrated-edges): exige que cada ramo integrado existente no grafo seja exercitado ao menos uma vez pelo conjunto de teste. 
Todos Usos Integrados Par-a-Par (all-pairwise-integrated-uses): requer que cada adu entre as variáveis de comunicação seja percorrida pelo conjunto de teste.

Como exemplo, a Tabela 2.4 mostra os requisitos do grafo da Figura 2.7 para os critérios Todos Nós Integrados Par-a-Par, Todos Ramos Integrados Par-a-Par e Todos Usos Integrados Par-a-Par, representados pelas colunas Nós, Ramos e Usos, respectivamente.

Tabela 2.4 - Requisitos de teste para os critérios Todos Nós Integrados Par-a-Par, Todos Ramos Integrados Par-a-Par e Todos Usos Integrados Par-a-Par para os métodos somaMax e max.

\begin{tabular}{|c|c|c|}
\hline Nós & Ramos & Usos \\
\hline i.1 & (i.1,i.2) & $(1, \mathrm{i} .1$, array 1$)$ \\
\hline i.2 & (i.2,i.3) & $(1,(\mathrm{i} .2, \mathrm{i} .3)$, array 1$)$ \\
\hline i.3 & $($ i. 2, i. 6$)$ & $(1,($ i. 2, i. 6$)$, array 1$)$ \\
\hline i. 4 & (i. 3, i. 4$)$ & $(1,($ i. 3, i. 4$)$, array 1$)$ \\
\hline i. 5 & $($ i. 3, i. .5$)$ & $(1,(\mathrm{i} .3, \mathrm{i} .5)$, array 1$)$ \\
\hline i. 6 & $(\mathrm{i} .4, \mathrm{i} .5)$ & $(1$, i. 4, array 1$)$ \\
\hline & (i. 5, i. 2$)$ & $(\mathrm{i} .4,3 \mathrm{c}, \max )$ \\
\hline
\end{tabular}

\section{Critérios para teste de integração nível um}

Neves (2010) propôs três critérios de teste de integração nível um para programas orientados a objetos e a aspectos. O teste nível um, no contexto de orientação a objetos, refere-se à interação que ocorre entre um método com todos os outros métodos que interagem diretamente com o primeiro (NEVES, 2010). Dos critérios propostos, dois são baseados nos critérios de fluxo de controle Todos Nós e Todos Ramos e um é baseado no critério de fluxo de dados Todos Usos.

Para representar esse modelo de integração foi elaborado um grafo chamado $I N 1 P$, que é formado pelos grafos AODU de cada unidade da interação, utilizando a mesma notação apresentada na subseção anterior. Como o grafo IN1P pode ser composto pelos grafos de mais de duas unidades, os rótulos dos nós integrados recebem um prefixo com um número inteiro seguido por ":", em que cada número inteiro refere-se a um método chamado. A unidade que faz a invocação das outras unidades é nomeada como unidade chamadora e as demais são consideradas as unidades chamadas. Para o paradigma orientado a objetos, tais unidades são os métodos do programa. Todos os métodos chamados pelo método chamador são representados como nós de integração e ramos de integração. 
O grafo IN1P também contém as informações de fluxo de dados para determinar as adus. Um exemplo do grafo IN1P é apresentado na Figura 2.8, considerando as duas chamadas que o método somaMax faz ao método max. Utilizou-se o número dos nós do código ao invés do número das linhas do bytecode. O nó 3 do método somaMax foi dividido em $3 a$, $3 b$ e $3 c$ referente às linhas de comando 6,7 e 8 , respectivamente, devido aos comandos 6 e 7 serem nós de chamada.

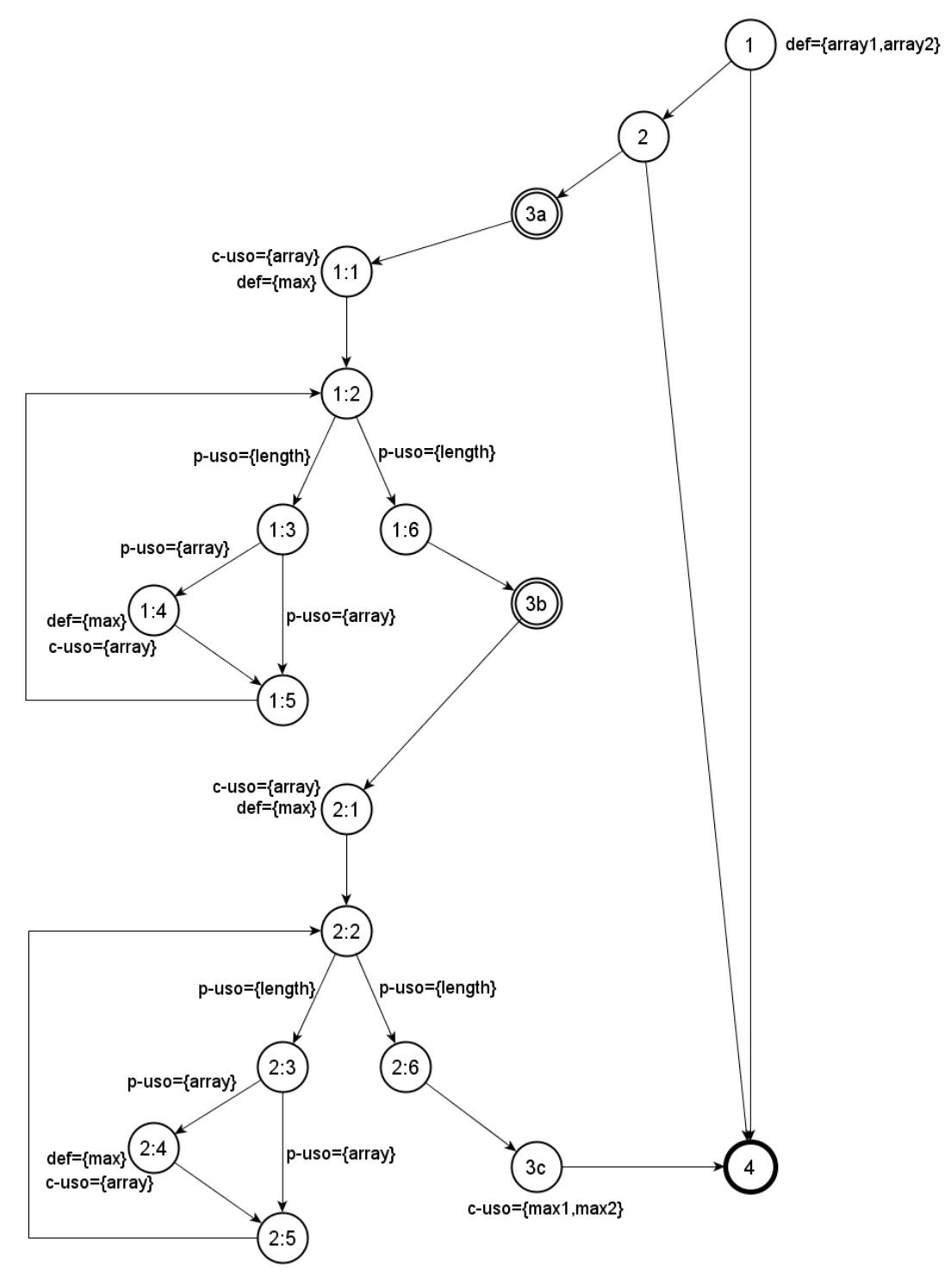

Figura 2.8 - Grafo IN1P para os métodos somaMax e max.

Os critérios para o teste de integração nível um são apresentados a seguir.

Todos Nós Integrados N1: requer que todos os nós integrados do grafo IN1P sejam exercitados por algum caso de teste.

Todos Ramos Integrados N1: para esse critério, cada ramo integrado do grafo IN1P deve 
ser percorrido ao menos uma vez por algum caso de teste.

Todos Usos Integrados N1: requer que todas as adus existentes entre as variáveis de comunicação das unidades chamadora e chamadas sejam exercitadas ao menos uma vez por algum caso de teste. Ou seja, as variáveis definidas em um método chamador e usadas nos métodos chamados; e as variáveis definidas nos métodos chamados e usadas no método chamador devem ser percorridas.

A Tabela 2.5 mostra os requisitos o grafo da Figura 2.8 para os critérios Todos Nós Integrados N1, Todos Ramos Integrados N1 e Todos Usos Integrados N1, representados pelas colunas Nós, Ramos e Usos, respectivamente.

Tabela 2.5 - Requisitos de teste para os critérios Todos Nós Integrados N1, Todos Ramos Integrados $N 1$ e Todos Usos Integrados $N 1$ para os métodos somaMax e $\max$.

\begin{tabular}{|c|c|c|}
\hline Nós & Ramos & Usos \\
\hline $1: 1$ & $(1: 1,1: 2)$ & $(1,1: 1$, array1 $)$ \\
\hline $1: 2$ & $(1: 2,1: 3)$ & $(1,(1: 2,1: 3)$, array1 $)$ \\
\hline $1: 3$ & $(1: 2,1: 6)$ & $(1,(1: 2,1: 6)$, array1 $)$ \\
\hline $1: 4$ & $(1: 3,1: 4)$ & $(1,(1: 3,1: 4)$, array1 $)$ \\
\hline $1: 5$ & $(1: 3,1: 5)$ & $(1,(1: 3,1: 5)$, array1 $)$ \\
\hline $1: 6$ & $(1: 4,1: 5)$ & $(1,1: 4$, array1 $)$ \\
\hline $2: 1$ & $(1: 5,1: 2)$ & $(1: 4,3 \mathrm{c}$, max $)$ \\
\hline $2: 2$ & $(2: 1,2: 2)$ & $(1,2: 1$, array2 $)$ \\
\hline $2: 3$ & $(2: 2,2: 3)$ & $(1,(2: 2,2: 3)$, array2 $)$ \\
\hline $2: 4$ & $(2: 2,2: 6)$ & $(1,(2: 2,2: 6)$, array2 $)$ \\
\hline $2: 5$ & $(2: 3,2: 4)$ & $(1,(2: 3,2: 4)$, array2 $)$ \\
\hline $2: 6$ & $(2: 3,2: 5)$ & $(1,(2: 3,2: 5)$, array2 $)$ \\
\hline & $(2: 4,2: 5)$ & $(1,2: 4$, array2 $)$ \\
\hline & $(2: 5,2: 2)$ & $(2: 4,3 c$, max $)$ \\
\hline
\end{tabular}

Os critérios definidos por Neves (2010) diferenciam-se dos critérios propostos por Lemos et al. (2009) por analisar todas as interações diretas entre um método e os métodos que são chamados pelo primeiro ao invés de analisar somente um par de métodos. Essa diferença faz com que que o número de requisitos gerados seja maior para os critérios de teste de integração nível um, uma vez que cobre mais estruturas do código. 


\subsection{Conceitos de depuração baseada em cobertura de código}

A seguir são apresentados conceitos relativos à área de depuração automatizada baseada em cobertura de código. Embora alguns conceitos como instrumentação e cobertura de código também façam parte da área de teste de software, optou-se por colocá-los nesta seção devido à relação entre tais conceitos e as atividades de localização de defeitos que usam informações de cobertura de código.

\subsubsection{Depuração}

A depuração pode ser definida como o processo que envolve a localização e a correção de defeitos existentes em um programa (ARAKI et al., 1991). A atividade de depuração é inerente ao desenvolvimento de software. Uma vez identificada uma falha existente em um programa, seja por meio da execução de testes seja durante o uso do programa, devese localizar e corrigir o defeito causador da falha observada. Geralmente, a depuração é feita de forma manual pelos programadores que, a partir da execução de casos de teste que falham, colocam breakpoints em linhas de comando para verificar os valores presentes em variáveis ou então os fluxos de desvios do programa com o objetivo de localizar o defeito. Outro procedimento comum realizado por programadores para depurar programas é imprimir em tela os valores presentes em variáveis na tentativa de identificar comportamentos incorretos do programa (JONES et al., 2007).

Diferentes técnicas foram propostas para apoiar a depuração de programas. Esta dissertação tem por objetivo contribuir para o estado da arte das técnicas de depuração baseadas em cobertura de código. Por isso, os conceitos utilizados para esse tipo de depuração são apresentados em detalhes a seguir. Outras técnicas de depuração são apresentadas no Apêndice B

\subsubsection{Cobertura de código}

Cobertura de código pode ser definida como o conjunto de estruturas de código de um programa que são percorridas pelos testes. Também é conhecida como espectro de programas (ABREU et al., 2008a; NAISH et al., 2009; XIE et al., 2010). Está associada com a execução dinâmica das estruturas pelo conjunto de teste utilizado. A cobertura de código pode representar diferentes características do programa. A cobertura de comandos, por 
exemplo, indica quais comandos foram executados (ou cobertos) pelos casos de teste executados.

Entre as possíveis coberturas de código, tem-se a cobertura de comandos, a cobertura de predicados, a cobertura de blocos, a cobertura de adus e a cobertura DIFA, apresentada no Apêndice B.

A cobertura de comandos identifica os comandos percorridos por um caso de teste ou por um conjunto de teste. Está associada ao fluxo de controle de execução.

A cobertura de blocos básicos refere-se também aos comandos executados pelos testes, só que agrupados em seus blocos básicos. A diferença em relação à cobertura de comandos está na granularidade do conjunto, visto que um bloco pode conter um ou mais comandos.

A cobertura de predicados indica os comandos predicados que foram percorridos pelo conjunto de teste. Um predicado é uma expressão booleana referente a alguma propriedade do sistema presente em algum ponto do programa (ZHANG et al., 2009b). Comandos predicados são aqueles associados a uma condição que é verificada durante a execução e na qual pode ocorrer um desvio no fluxo de controle, como comandos if ou while.

A cobertura de adus indica as adus percorridas durante a execução dos testes, representando o fluxo de dados entre nós, ramos e variáveis envolvidos na execução (CHAIM et al., 2003).

A cobertura DIFA representa as relações de dependência dinâmica entre fluxos de informação das variáveis executadas pelos testes, envolvendo dependência de controle e de dados (MASRI, 2010).

Na depuração, as informações de cobertura são usadas para verificar os comandos que são executados por casos de teste de sucesso e de falha. Diversas técnicas utilizam heurísticas baseadas na frequência de execução de blocos, ramos, predicados e adus para avaliar aqueles mais suspeitos de conter defeitos (JONES et al., 2007; WONG et al., 2008a; SANTELICES et al., 2009; MASRI, 2010; WONG et al., 2010; YU et al., 2011; ZHANG et al., 2011). Para exemplificar o uso de cobertura de código em depuração, será utilizada a cobertura de comandos para localizar o defeito contido no programa max da Figura 2.1.

As informações de cobertura de código podem ser representadas por meio de uma matriz $C$, conforme mostrado na Tabela 2.6. A coluna L indica as linhas de comando do 
Tabela 2.6 - Tabela de cobertura do método max.

\begin{tabular}{|c||c|c|c|c|c|c|c|c|c|c|}
\hline $\mathrm{L}$ & $t_{1}$ & $t_{2}$ & $t_{3}$ & $t_{4}$ & $t_{5}$ & $c_{00}$ & $c_{10}$ & $c_{01}$ & $c_{11}$ & $H_{1}$ \\
\hline 1 & $\bullet$ & $\bullet$ & $\bullet$ & $\bullet$ & $\bullet$ & 0 & 3 & 0 & 2 & 0.5 \\
\hline 2 & $\bullet$ & $\bullet$ & $\bullet$ & $\bullet$ & $\bullet$ & 0 & 3 & 0 & 2 & 0.5 \\
\hline 3 & $\bullet$ & $\bullet$ & $\bullet$ & $\bullet$ & & 0 & 3 & 1 & 1 & 0.33 \\
\hline 4 & $\bullet$ & $\bullet$ & $\bullet$ & $\bullet$ & & 0 & 3 & 1 & 1 & 0.33 \\
\hline 5 & $\bullet$ & $\bullet$ & $\bullet$ & $\bullet$ & & 0 & 3 & 1 & 1 & 0.33 \\
\hline 6 & $\bullet$ & $\bullet$ & $\bullet$ & $\bullet$ & & 0 & 3 & 1 & 1 & 0.33 \\
\hline 7 & $\bullet$ & $\bullet$ & $\bullet$ & $\bullet$ & & 0 & 3 & 1 & 1 & 0.33 \\
\hline- & $\mathrm{S}$ & $\mathrm{S}$ & $\mathrm{S}$ & $\mathrm{F}$ & $\mathrm{F}$ & - & - & - & - & - \\
\hline
\end{tabular}

Tabela 2.7 - Conjunto de teste para o método max.

\begin{tabular}{|l|l|}
\hline \multicolumn{2}{|c|}{ Conjunto de teste } \\
\hline$t_{1}$ & $\langle([1,2,3], 3), 3\rangle$ \\
\hline$t_{2}$ & $\langle([5,5,5], 3), 5\rangle$ \\
\hline$t_{3}$ & $\langle([2,10,1], 3), 10\rangle$ \\
\hline$t_{4}$ & $\langle([4,2,3], 3), 4\rangle$ \\
\hline$t_{5}$ & $\langle([4], 1), 4\rangle$ \\
\hline
\end{tabular}

método max, as colunas $t_{1}$ a $t_{5}$ representam os casos de teste. Os casos de teste para esse exemplo são mostrados na Tabela 2.7. Um comando que é executado por um caso de teste recebe o símbolo "•". As colunas $c_{00}, c_{01}, c_{10}$ e $c_{11}$ trazem os coeficientes de cobertura, explicados no parágrafo seguinte. Na última linha, abaixo das colunas de $t_{1}$ a $t_{5}$ estão os resultados de execução dos casos de teste, "S" para os casos de teste de sucesso e "F" para os casos de teste de falha.

Os coeficientes de cobertura servem para indicar quantas vezes um comando foi ou não executado pelos casos de teste de sucesso e de falha. São utilizados pelas heurísticas para calcular o valor de desconfiança para cada comando. Cada valor na matriz $C$ pode ser representado por $c_{i j}$, em que $i$ vale 0 se o comando não foi executado pelo caso de teste e vale 1 se o comando foi executado pelo caso de teste; $j$ vale 0 se o caso de teste é de sucesso e 1 se é de falha. Dessa forma, $c_{00}$ é a quantidade de vezes em que o comando não foi executado por um caso de teste de sucesso, $c_{01}$ indica a quantidade de vezes que ele não foi executado por um caso de teste de falha, $c_{10}$ representa a quantidade de vezes que o comando foi executado por um caso de teste de sucesso e $c_{11}$ é a quantidade de vezes que ele foi executado por um caso de teste de falha (ABREU et al., 2011). 


\subsubsection{Heurísticas}

As heurísticas de localização de defeitos são usadas para extrair informações sobre os resultados de execução dos testes e, com isso, indicar valores de desconfiança (ou suspeição) para os requisitos do programa avaliado. Requisitos são as unidades analisadas; podem ser comandos, predicados, blocos básicos, adus ou DIFA, entre outras.

Em geral, as heurísticas avaliam a frequência de execução de requisitos nos casos de teste executados utilizando os coeficientes de cobertura para calcular os valores de desconfiança. A ideia é que um requisito executado muitas vezes por casos de teste de falha possui maior probabilidade de indicar um defeito. Da mesma forma, quanto mais vezes um requisito for executado em casos de teste de sucesso, menor a chance de ele conter defeitos. A partir dos requisitos com maior índice de desconfiança calculados, as técnicas de localização de defeitos classificam os requisitos em ordem decrescente de desconfiança, retornando uma lista com os requisitos mais suspeitos no topo para que os programadores possam localizar o defeito.

Para exemplificar as técnicas de localização baseadas em heurísticas, será apresentada a técnica Tarantula (JONES et al., 2002) em conjunto com a cobertura de comandos. Outras técnicas relevantes são detalhadas no próximo capítulo. A Tarantula foi uma das primeiras heurísticas propostas para localização de defeitos. Ela realiza um cálculo da frequência de execução dos comandos em casos de teste de sucesso e de falha para calcular sua desconfiança. Sua fórmula é mostrada na equação 2.1 :

$$
H_{(T)}=\frac{\frac{c_{11}}{c_{11}+c_{01}}}{\frac{c_{11}}{c_{11}+c_{01}}+\frac{c_{10}}{c_{10}+c_{00}}}
$$

$H_{(T)}$ refere-se ao valor de desconfiança do comando $c$ para a heurística Tarantula. O cálculo é realizado para cada comando executável, cujo numerador calcula a quantidade de vezes que o comando foi executado em casos de teste de falha $\left(c_{11}\right)$ pelo total de casos de teste de falha $\left(c_{11}+c_{10}\right)$ e o denominador soma essa mesma razão com a quantidade de vezes que o comando foi executado em casos de teste de sucesso $\left(c_{10}\right)$ pelo total de casos de teste de sucesso $\left(c_{10}+c_{00}\right)$.

Assim, quanto maior a frequência em que um comando for executado pelos casos de teste de falha, maior será o valor de desconfiança desse comando. Isso vai depender da frequência com que o comando é executado em casos de teste de sucesso, de forma inversamente proporcional. O valor de suspeição obtido varia entre 0 (menos suspeito) e 
1 (mais suspeito). A Tabela 2.6 mostra um exemplo da aplicação da heurística Tarantula no método max para um conjunto de teste com cinco casos de teste. Na última linha, $S$ representa o resultado dos casos de teste de sucesso e $F$ os casos de teste de falha. A coluna $H_{1}$ representa o valor de desconfiança obtido no cálculo da Tarantula para os coeficientes de cobertura. O comando defeituoso (2) obteve o maior valor de desconfiança, assim como o comando 1. Portanto, entre os comandos mais suspeitos encontra-se o defeito.

Uma limitação das heurísticas é a correção coincidente. Um comando defeituoso pode ser executado por um caso de teste sem que ocorra uma falha, o que é conhecido como correção coincidente (WANG et al., 2009b). Tal fato pode ocorrer para determinados valores utilizados como entrada em um caso de teste, de forma que não ocorra um erro na execução. Alguns defeitos podem ser mais difíceis de localizar por não manifestarem falha para a maioria dos casos de teste executados, influenciando os valores de desconfiança obtidos para o comando defeituoso quando se utiliza uma heurística. Alguns estudos realizados apontam que a correção coincidente influencia o desempenho das técnicas de localização de defeitos (WANG et al., 2009b; MASRI et al., 2009; MASRI; ASSI, 2010; ABREU et al., 2011), diminuindo a eficácia de tais técnicas.

Um exemplo de correção coincidente pode ser visto no método max (Figura 2.1). Se max receber um array $a=[1,2,3]$, o comando defeituoso será executado, mas não ocorrerá falha porque o maior inteiro está na última posição do array, que é percorrida pelo método, retornando o valor correto, que é 3 .

\subsection{Considerações finais}

Neste capítulo, foram apresentados os principais conceitos e técnicas de teste de software que fornecem informações necessárias para a atividade de depuração automatizada assim como conceitos de depuração automatizada que são utilizados nas técnicas apresentadas no próximo capítulo. 



\section{Depuração automatizada baseada em cobertura de código}

Este capítulo traz um levantamento bibliográfico sobre a área de depuração automatizada baseada em cobertura de código. Para aprofundar os conhecimentos sobre o estado da arte das técnicas de localização de defeitos, foi feita uma revisão sistemática, que será apresentada na Seção 3.1. Em seguida, na Seção 3.2, são discutidas as principais características das técnicas que têm sido propostas para a realização de depuração automatizada. Na Seção 3.3 são apresentadas as considerações finais sobre o levantamento realizado.

\subsection{Revisão sistemática}

Foi realizada uma revisão sistemática sobre técnicas para depuração automatizada baseada em cobertura de código. O principal objetivo foi ampliar os conhecimentos sobre os trabalhos realizados na área por meio da identificação das características que envolvem a localização de defeitos, as estratégias propostas, os experimentos realizados e os resultados obtidos. Para conduzir a revisão foram elaboradas as seguintes questões de pesquisa:

1. Quais são as técnicas e métodos existentes que utilizam informações de teste estrutural para auxiliar a depuração automatizada de programas?

2. Quais técnicas de depuração automatizada realizam experimentos em programas contendo múltiplos defeitos?

3. Quais técnicas de depuração automatizada realizam experimentos em programas reais?

4. As técnicas de depuração automatizada usam informações de teste estrutural de integração? 
Para realizar a pesquisa, foram escolhidas os termos "fault localization" (localização de defeitos) e "code coverage" (cobertura de código), utilizados em conjunto. Esses termos foram definidos depois de uma pesquisa exploratória para a identificação dos termos mais relevantes aos trabalhos da área. Outras condições utilizadas para a revisão foram trabalhos recentes, a partir de 2006, e que estivessem escritos em inglês ou português. Os critérios de inclusão e exclusão utilizados para a seleção de artigos na revisão são descritos a seguir.

Critérios de inclusão:

1. Trabalhos que utilizem informações de cobertura de código para depuração automatizada.

2. Trabalhos que proponham novas técnicas para realizar depuração automatizada.

3. Trabalhos que façam a comparação entre técnicas de depuração automatizada existentes.

4. Trabalhos que analisem ou proponham melhorias para as informações usadas pelas técnicas de depuração automatizada.

5. Trabalhos que avaliem o uso prático de técnicas de depuração automatizada.

Critérios de exclusão:

1. Trabalhos que proponham técnicas e métodos de teste estrutural não aplicados à depuração.

2. Trabalhos cujo texto não esteja completamente disponível.

3. Trabalhos que não apresentem validação experimental da proposta.

As bases científicas utilizadas para a pesquisa foram as bibliotecas digitais $A C M D i$ gital Library (Association for Computing Machinery), IEEE Xplore Digital Library (Institute of Eletronical and Eletronics Engineerings) e SpringerLink. Também foi utilizada a base eletrônica indexada SciVerse Scopus.

A pesquisa realizada com os termos definidos nas bases citadas retornou 128 artigos, excluindo-se os artigos que estavam presentes em mais de uma base. Após a aplicação dos critérios de inclusão e exclusão foram selecionados 43 artigos. Foram incluídos 4 artigos 
relacionados com o tema da pesquisa realizada, por sugestão do orientador do projeto, que não retornaram na pequisa com os termos mencionados. Portanto, no total foram incluídos 47 trabalhos na revisão sistemática.

Dentre os artigos selecionados na revisão sistemática, são discutidos no levantamento bibliográfico os trabalhos que possuem maior relevância para a tarefa de depuração automatizada. De acordo com o interesse deste projeto, levou-se em consideração principalmente os trabalhos que utilizam técnicas de localização de defeitos com os melhores resultados quanto à eficácia de localização, com base nos experimentos realizados; técnicas que possam ser aplicadas utilizando informações de teste estrutural de integração; trabalhos que abordam a tarefa de depuração em programas reais e contendo múltiplos defeitos; técnicas que visem reduzir custos de execução; e trabalhos que apresentem uma comparação entre as técnicas existentes. O levantamento bibliográfico inclui também outros artigos que serviram para a realização da pesquisa exploratória e de áreas relacionadas com os temas de interesse já citados.

\subsection{Análise das técnicas de depuração baseada em cobertura de código}

A tarefa de depuração automatizada envolve diversos aspectos que possibilitam sua realização e, consequentemente, influenciam seu desempenho. Com o objetivo de apresentar os principais progressos e desafios existentes para a área de depuração baseada em cobertura de código, esta seção apresenta um levantamento bibliográfico dividido em tópicos que abordam as suas características principais.

\subsubsection{Tipos de cobertura de código e sua utilização em depuração}

As coberturas mais usadas pelas técnicas de depuração são a cobertura de comandos (JONES et al., 2007; DEAN et al., 2009; WONG et al., 2010; XIE et al., 2010; ABREU et al., 2011) e a cobertura de predicados (GUO et al., 2006; ZHANG et al., 2009b; NAISH et al., 2010). Alguns trabalhos utilizam a cobertura de blocos básicos (ZHANG et al., 2009a; ZHAO et al., 2010) e outros a cobertura de chamada de métodos ou funções (BURGER; ZELLER, 2011; MARIANI et al., 2011). Além desses, existem técnicas que utilizam uma combinação entre diferentes coberturas e outros que propõem suas próprias coberturas (MURTAZA et al., 2008; SANTELICES et al., 2009; XU et al., 2011; YU et al., 2011). 
Jones et al. (2007) utilizam cobertura de comandos para a localização de defeitos em programas com defeitos múltiplos. Wong et al. (2010) aplicam a cobertura de comandos a um conjunto de heurísticas que atribui diferentes pesos para os casos de teste de sucesso.

Guo et al. (2006) utilizam cobertura de predicados para comparar uma execução de falha com todas as execuções de sucesso, buscando identificar a execução de sucesso mais similar à execução de falha. Essa similaridade é medida pela semelhança entre os comandos predicados que foram executados em ambas execuções, levando em consideração também a ordem em que tais comandos foram executados. Uma vez identificada a execução de sucesso mais similar, é gerado um relatório de diferenças entre as duas execuções contendo os predicados que foram executados apenas pela execução de falha.

Naish et al. (2010) propuseram uma técnica que obtém informações de predicados a partir do espectro de cobertura de comandos. Os autores argumentam que a cobertura de predicados fornece mais informações sobre a execução porque acrescentam o resultado da execução, indicando o fluxo tomado pelo código. Xu et al. (2011) apresentaram uma cobertura chamada KBC - Key Block Chains ou Cadeia de Blocos Chave. Cada KBC contém no máximo um predicado cujo resultado da execução é verdadeiro. Assim, todos os blocos executados sequencialmente onde não houver um predicado avaliado como verdadeiro durante uma execução farão parte do mesmo KBC.

Zhang et al. (2009b) realizaram um estudo estatístico do comportamento de distribuição dos predicados relevantes para a ocorrência de falhas. Utilizando testes de normalidade, mostraram que o modelo de distribuição normal não pode ser assumido pelas técnicas, visto que tais distribuições normais não são uma característica constante para esses predicados. Nos experimentos realizados, cerca de $40 \%$ dos predicados não possuem esse tipo de distribuição.

Em outro trabalho, Zhang et al. (2009a) usam a cobertura de blocos básicos para propor uma técnica que calcula os blocos mais suspeitos de conter um defeito propagando os valores de desconfiança entre blocos que estão relacionados através de ramos. Uma abordagem semelhante, também utilizando cobertura de blocos, foi adotada por Zhao et al. (2010), atribuindo pesos para os ramos executados por casos de teste de sucesso e falha como forma de identificar blocos propensos a conter defeitos e blocos com maior possibilidade de ausência de defeitos.

Burger e Zeller (2011) utilizam a cobertura de métodos para obter informações das interações ocorridas entre métodos durante a execução de um caso de teste de falha. Essas informações são utilizadas para obter um conjunto mínimo de interações que sejam 
relevantes à falha, usando depuração delta (ver Apêndice B) e slicing (ver Apêndice B) para procurar pelo defeito.

Mariani et al. (2011) apresentam uma técnica de localização de defeitos que usa cobertura de métodos para obter informações de integração entre requisitos que dão origem a modelos de interação a partir da execução de casos de teste de sucesso. Esses modelos são comparados às execuções de casos de teste de falha para indicar chamadas de método mais prováveis de conter defeitos.

Alguns trabalhos determinam suas coberturas específicas (MURTAZA et al., 2008; SANTELICES et al., 2009; YU et al., 2011). Santelices et al. (2009) fizeram um estudo comparando o desempenho de diferentes coberturas para a localização de defeitos baseadas em fluxo de controle e de dados. Foram propostas três abordagens de cobertura que utilizam uma combinação das coberturas de comandos, ramos e adus para calcular o valor de desconfiança, das quais a abordagem conhecida como avg-SBD obteve melhor eficácia para a localização de defeitos que as demais coberturas. A avg-SBD calcula a média de desconfiança obtida pelas coberturas de comandos, ramos e adus. A comparação entre as coberturas mostrou que cada uma delas retorna diferentes resultados para os mesmos testes. No entanto, não foi feita uma análise sobre os defeitos e características dos programas que são melhor identificados pelas diferentes coberturas.

Murtaza et al. (2008) apresentaram uma técnica chamada MiniEPI que utiliza cobertura de chamada de funções sobre a execução de casos de teste de falha para realizar um mapeamento de padrões de sequência dessas chamadas de funções (nomeadas como episódios). A MiniEPI indica uma função suspeita de conter o defeito. A partir desse resultado, o programador deve então verificar a função indicada para localizar o defeito.

Yu et al. (2011) apresentaram uma técnica de localização de defeitos chamada LOUPE, que utiliza dois modelos de cobertura, baseados em dependência de controle e dependência de dados (ver Apêndice B). Os modelos são integrados com os maiores valores de suspeição dos comandos para obter a melhor classificação para localização de defeitos. O resultado dos experimentos mostram que LOUPE teve melhor eficácia de localização para diferentes tipos de defeitos em relação às técnicas comparadas. No entanto, o custo de geração das dependências dinâmicas, em especial de dados, é alto.

Masri (2010) propõe uma heurística similar à Tarantula para a cobertura DIFA considerando os objetos (variáveis) definidos e utilizados no fluxo de controle para indicar fluxos suspeitos de conter defeitos. De acordo com os experimentos realizados, a técnica consegue capturar defeitos presentes em ramos e adus, além de outros defeitos considera- 
dos complexos, que podem estar em locais distantes de onde ocorre a falha no fluxo de execução. Embora a técnica nem sempre obtenha a mesma eficácia de localização que o uso de cobertura de ramos e adus, ela consegue apontar os defeitos que são capturados ou pela cobertura de ramos ou pela cobertura de adus, além de possuir uma eficácia superior à cobertura de comandos. A técnica apresentada é capaz de lidar com a integração entre métodos, por meio do mapeamento dos objetos associados aos comandos de diferentes métodos. A principal desvantagem da técnica é seu custo de execução, tanto em relação ao tempo de execução quanto em relação ao espaço de armazenamento.

A maioria das técnicas de localização de defeitos não faz referências de forma explícita ao critério utilizado na seleção dos casos de teste. Geralmente, as técnicas possuem conjuntos de teste que cobrem todos os comandos (JONES et al., 2007; DEAN et al., 2009; WONG et al., 2010; ABREU et al., 2011) ou seja, o critério Todos Nós é atendido; enquanto outras técnicas usam conjuntos que cobrem todos predicados (GUO et al., 2006; ZHANG et al., 2009b; NAISH et al., 2010; YU et al., 2011).

Ali et al. (2009) fizeram um estudo sobre características que podem influenciar a localização de defeitos. Foi comparado o efeito da utilização de casos de teste com máxima cobertura e com um conjunto de casos de teste gerados aleatoriamente, mostrando que, com significância estatística de $0,1 \%$, o uso de cobertura máxima é relevante. Assim, a verificação das porcentagens de cobertura dos programas utilizados nos experimentos pode colaborar para melhorar a cobertura do conjunto de testes ou, pelo menos, indicar que são suficientes para o seu uso.

A cobertura de código possibilita a obtenção de diferentes informações a partir da execução dos conjuntos de teste, colaborando para a identificação de diferentes tipos de defeitos, como visto em (SANTELICES et al., 2009; MASRI, 2010; YU et al., 2011). A maioria das técnicas de depuração automatizada adota apenas um tipo de cobertura, o que pode ser melhorado por meio da utilização de diferentes coberturas. A identificação de diferentes tipos de defeitos que são localizados de forma mais eficaz pelas diversas coberturas também pode colaborar para uma melhor utilização de coberturas mais adequadas para diferentes programas. A Tabela 3.1 mostra as coberturas utilizadas pelos trabalhos apresentados nesta subseção.

\subsubsection{Heurísticas}

Como descrito na subseção anterior, as coberturas de código contribuem para a localização de defeitos quando associadas a heurísticas. O papel das heurísticas é indicar 
Tabela 3.1 - Coberturas utilizadas nos artigos da revisão.

\begin{tabular}{|l|l|}
\hline Artigo & Cobertura \\
\hline Guo et al. (2006) & Predicados \\
\hline Jones et al. (2007) & Comandos \\
\hline Murtaza et al. (2008) & Chamada de Funções (Episódios) \\
\hline Dean et al. (2009) & Comandos \\
\hline Zhang et al. (2009a) & Blocos \\
\hline Zhang et al. (2009b) & Predicados \\
\hline Santelices et al. (2009) & Comandos, Ramos e Adus combinados \\
\hline Wong et al. (2010) & Comandos \\
\hline Zhao et al. (2010) & Blocos \\
\hline Masri (2010) & DIFA \\
\hline Xie et al. (2010) & Comandos \\
\hline Naish et al. (2010) & Predicados obtidos por Comandos \\
\hline Abreu et al. (2011) & Comandos \\
\hline Burger e Zeller (2011) & Chamada de Métodos \\
\hline Mariani et al. (2011) & Chamada de Métodos \\
\hline Xu et al. (2011) & KBC \\
\hline Yu et al. (2011) & Dependência de Controle e Dados \\
\hline
\end{tabular}

o grau de desconfiança dos requisitos do programa. Nesta subseção, são discutidas as heurísticas mais promissoras utilizadas na localização de defeitos.

Além da Tarantula (JONES et al., 2002), apresentada na Seção 2.2.3, outras heurísticas têm sido propostas para a tarefa de depuração automatizada utilizando cobertura de código. A Tabela 3.2 apresenta as fórmulas dessas heurísticas. Abreu et al. (2007) propuseram a utilização do coeficiente de similaridade Ochiai, originalmente utilizado na área de biologia molecular, e do coeficiente de Jaccard, como heurísticas de localização de defeitos. Os resultados dos experimentos realizados indicam maior eficácia dessas heurísticas em relação à Tarantula. A heurística Zoltar (SÁNCHEZ, 2007) é uma variação do coeficiente de Jaccard que atribui menor peso a comandos que são raramente executados em casos de teste de falha e frequentemente executados em casos de teste de sucesso.

A heurística conhecida como Wong3, proposta por Wong et al. (2007), parte do princípio de que os primeiros casos de teste de sucesso fornecem mais informações relevantes para a descoberta de falhas que os casos de teste de sucesso seguintes. Dessa forma, o cálculo de Wong3 é dado pelo total de vezes que o comando foi executado pelos casos de teste de falha $\left(c_{11}\right)$ menos a quantidade de vezes em que ele foi executado por casos de teste de sucesso $\left(c_{10}\right)$. No entanto, os casos de teste de sucesso são divididos em três grupos, atribuindo maior peso aos casos de teste do primeiro grupo (que contém dois casos de teste), um peso intermediário para o segundo grupo (contendo dez casos de teste) 
de comandos. No entanto, o programador precisa verificar os comandos que apresentam dependência de controle dos predicados suspeitos. Entre as heurísticas que usam informações de cobertura de predicados estão a Nearest Neighbor (NN) (RENIERIS; REISS, 2003) e a Control Flow (CF) (GUO et al., 2006). Elas comparam uma execução de falha com todas as execuções de sucesso. Apenas os predicados do caso de teste de falha que tomaram fluxo diferente dos casos de teste de sucesso são considerados suspeitos.

As heurísticas baseadas em informações de cobertura realizam cálculos simples, podendo ser aplicadas com baixo custo computacional. No entanto, tais heurísticas não fazem uso de informações sobre as características dos comandos que estão sendo executados, baseando-se somente nos coeficientes de cobertura. Alguns trabalhos recentes têm proposto heurísticas que utilizam mais informações do código, acrescentando tais informações ao cálculo de desconfiança dos comandos como forma de melhorar a eficácia na indicação dos comandos mais suspeitos.

Naish et al. (2009) apresentaram uma abordagem que atribui pesos diferentes para casos de teste de falha de acordo com a quantidade de comandos presentes. Quanto menor a quantidade de comandos presente em um caso de teste de falha maior o seu peso. Essa abordagem pode então ser utilizada com diferentes heurísticas de localização de defeitos para o cálculo da desconfiança dos comandos. Nesse mesmo trabalho, os autores realizam experimentos com várias heurísticas diferentes. Dentre elas, o coeficiente de Kulczynski (chamado de Kulczynski2, mostrado na Tabela 3.2), obteve um dos melhores resultados nos experimentos realizados em programas contendo dois defeitos. Zhang et al. (2009a) apresentaram uma heurística que realiza a propagação de valores de desconfiança de um bloco sucessor para seu bloco antecessor por meio dos ramos que os relacionam. O valor de desconfiança de cada bloco é calculado pela soma de frações dos valores de desconfiança dos blocos que o sucedem.

Debroy e Wong (2011) apontam a equivalência existente entre diferentes heurísticas por meio de simplificações algébricas em suas fórmulas, mostrando que algumas heurísticas classificam os comandos de um programa na mesma posição relativa na lista de comandos suspeitos, produzindo classificações idênticas. Assim, pode-se evitar o uso de heurísticas equivalentes para comparação em experimentos ou ainda é possível verificar se uma nova heurística proposta é equivalente a alguma já existente, evitando trabalho desnecessário.

Outros trabalhos fazem experimentos comparando a eficácia de diversas heurísticas propostas para localização de defeitos (LEE et al., 2009; WONG et al., 2010; NAISH et al., 2011). De forma geral, os resultados obtidos nesses trabalhos indicam que algumas 
heurísticas apresentam melhores resultados de eficácia de localização, com valores muito semelhantes entre elas (Ochiai, Zoltar, Wong3, Jaccard). Esse fato indica a necessidade de novas abordagens que possibilitem melhorias significativas para a eficácia de localização de defeitos.

Uma constatação feita durante o levantamento é que nenhuma delas utiliza informações sobre o tipo de comando executado, exceção feita às heurísticas de comandos predicados, que analisam o resultado de execução das condições e não se os comandos são condicionais ou de laço, por exemplo. Uma possível estratégia para obter mais avanços na elaboração de heurísticas é utilizar mais informações do código para melhorar a eficácia de localização.

\subsubsection{Técnicas que utilizam informações de integração}

Existem alguns trabalhos de depuração automatizada que utilizam informações sobre a integração entre unidades dos programas para realizar a depuração automatizada. Mariani et al. (2011) apresentam uma técnica de localização de defeitos que utiliza informações de integração entre requisitos sem a necessidade do código fonte chamada Behavior Capture and Test (BCT). Para isso, a técnica cria modelos de entrada e saída e interação entre métodos (representados por máquinas de estado finitos) a partir da execução de casos de teste de sucesso e compara tais modelos com a execução de casos de teste de falha para obter informações sobre comportamentos diferentes (anomalias) dessas execuções.

Essa técnica gera grafos de anomalias que são conjuntos de chamadas de métodos e valores de variáveis que explicam as falhas observadas, indicando os locais suspeitos de conter defeito. Nos experimentos realizados, a técnica não conseguiu localizar defeitos para os benchmarks maiores utilizados. Os autores atribuem os resultados obtidos ao fato de tais programas possuírem métodos grandes, o que influencia a quantidade de comandos que necessitam ser verificados pelo desenvolvedor. Os testes foram realizados com programas contendo apenas um defeito. A técnica apresenta uma abordagem que utiliza informações sobre chamadas de métodos e variáveis utilizadas. Porém, não foi verificado se o teste de integração pode resultar na localização defeitos diferentes daqueles localizados por técnicas que fazem uso de informações de teste unitário. A técnica não utiliza informações sobre os comandos existentes nos métodos capturados.

Burger e Zeller $(2008,2011)$ propuseram uma técnica que grava em registros (logs) as interações realizadas em chamadas de métodos a partir de um determinado requisito, ou conjunto de classes, utilizando um único caso de teste de falha. Em seguida, usando slicing dinâmico e depuração delta, os registros são reproduzidos para minimizar as interações 
realizadas (sobre chamadas de métodos), resultando em um conjunto de interações relevantes à falha. Como apenas um caso de teste de falha é necessário para a realização de todo o processo, a técnica dispensa assim a etapa de geração de conjuntos de casos de teste com cobertura variada. Os resultados obtidos com a técnica causaram uma redução significativa no espaço de busca para os programas analisados, retornando poucas interações consideradas suspeitas. A técnica foi aplicada a um programa de uso real contendo um único defeito, reduzindo a quantidade de interações de 187.532 para 20 apenas (BURGER; ZELLER, 2008). No entanto, devido à quantidade de processamentos realizados, a técnica possui um alto custo de execução.

O trabalho proposto por Murtaza et al. (2008), descrito na Subseção 3.2 .1 também utiliza chamadas de função, indicando funções suspeitas de conter defeitos. Masri (2010) indica que a cobertura DIFA possui relações de dependência interprocedimentais, o que possibilita realizar experimentos com tal abordagem para obter informações de cobertura de integração. No entanto, os experimentos realizados não explicitam o uso de integração entre os métodos.

As estratégias apresentadas utilizam informações de integração com foco nas interações entre unidades considerando chamadas de métodos, procedimentos ou funções. Essas técnicas retornam um conjunto de chamadas que podem ser relevantes para localizar o defeito. O trabalho de localização dos comandos que contém defeitos dentro dos métodos indicados pelas técnicas é feito de forma manual. A exceção é o trabalho de Masri (2010), que analisa comandos e variáveis obtidas pela cobertura DIFA.

Os trabalhos de Murtaza et al. (2008) e de Mariani et al. (2011) não fazem referências ao custo de execução das técnicas propostas, enquanto os trabalhos de Burger e Zeller (2008, 2011) e Masri (2010) possuem um elevado custo de execução. Os experimentos realizados com essas técnicas usaram benchmarks contendo defeitos únicos, de forma que, apenas pelos artigos, não é possível avaliar suas eficácias em programas contendo defeitos múltiplos.

\subsubsection{Benchmarks}

Existem alguns programas que são recorrentemente utilizados como benchmarks pelas técnicas de depuração automatizada. Esses programas geralmente possuem diversas versões, cada uma contendo um defeito diferente. Os benchmarks utilizados nos experimentos das técnicas de localização de defeitos são, em sua maioria, programas pequenos, formados por algumas centenas de linhas executáveis. Os mais utilizados são os pro- 
gramas do conjunto Siemens (tcas, schedule, schedule2, replace, tot_info, print_tokens e print_tokens2) e os programas do conjunto Unix (Col, Cal, Uniq, Spline, Checked e Tr) (GUO et al., 2006; SANTELICES et al., 2009; LEE et al., 2009; XIE et al., 2010; ZHANG et al., 2011). Os programas dos conjuntos Siemens e Unix possuem defeitos semeados para a realização de experimentos. Os benchmarks acima citados possuem conjuntos de teste grandes, contendo milhares de casos de teste.

No entanto, o uso de programas desse porte não possibilita que os experimentos assemelhem-se a ambientes que contenham programas reais, que são o objetivo principal das técnicas desenvolvidas. Dessa forma, os resultados obtidos pelas técnicas de localização de defeitos não podem ser extrapolados para programas desenvolvidos na indústria de software.

Alguns trabalhos recentes estão utilizando como benchmarks programas maiores e de uso real, contendo algumas milhares de linhas de código executáveis (WONG et al., 2008b; MASRI, 2010; XU et al., 2011; MARIANI et al., 2011). Como exemplo desses benchmarks temse o gcc, grep, gzip, make, NanoXML e o Ant (DO et al., 2005). Os programas citados estão disponíveis em um repositório chamado SIR (Software-artifact Infrastructure Repository ou Repositório de Infraestrutura de artefatos de Programas), que foi desenvolvido com o objetivo de servir como base para a realização de experimentos de pesquisa controlados para a área de Engenharia de Software, especialmente para teste de software (DO et al., 2005). Outro benchmark utilizado é o Space, que possui defeitos reais identificados durante o desenvolvimento, contendo aproximadamente 10.000 linhas de código. A Tabela 3.3 apresenta a quantidade de linhas executáveis e casos de teste existentes dos programas citados.

A maioria dos benchmarks existentes contém um defeito por versão, o que pode dificultar o uso prático das técnicas propostas. Uma alternativa para a realização de experimentos foi apresentada por Naish et al. (2009). Os autores propuseram um modelo simples de programa, contendo uma estrutura de comandos condicionais, para avaliar o desempenho de diversas heurísticas de localização de defeitos. O uso do modelo simplificou a etapa de preparação dos experimentos, reduzindo o tempo necessário para testes e trazendo uma contribuição baseada em execução teórica. Uma vantagem dessa abordagem é que o ambiente de testes pode ser melhor controlado. Porém, esse modelo é composto de uma sequência de comandos condicionais, o que não representa programas desenvolvidos em ambientes reais. 
Tabela 3.3 - Benchmarks utilizados para avaliação das técnicas.

\begin{tabular}{|l||l|r|r|r|}
\hline Programa & Descrição & Versões & LOC & Testes \\
\hline tcas & Detector de colisões & 41 & 173 & 1608 \\
\hline schedule2 & Agendador de prioridades & 10 & 374 & 2710 \\
\hline schedule & Agendador de prioridades & 9 & 412 & 2650 \\
\hline replace & Substituição de padrões & 32 & 564 & 5542 \\
\hline tot_info & Comparador de informações & 23 & 565 & 1052 \\
\hline print_tokens2 & Analisador léxico & 10 & 570 & 4115 \\
\hline print_tokens & Analisador léxico & 7 & 726 & 4130 \\
\hline Space & Configurador de antenas & 35 & 9564 & 13585 \\
\hline Col & Formatador de texto & 30 & 308 & 156 \\
\hline Cal & Calendário & 20 & 202 & 162 \\
\hline Uniq & Analisador de linhas duplicadas & 17 & 143 & 431 \\
\hline Spline & Interpolador de curvas & 13 & 338 & 700 \\
\hline Checked & Analisador de delimitadores & 20 & 102 & 166 \\
\hline Tr & Tradutor de caracteres & 11 & 137 & 870 \\
\hline gcc & Compilador C & 1 & 95218 & 9495 \\
\hline grep & Analisador de padrões & 75 & 15633 & 809 \\
\hline gzip & Compactador de arquivos & 15 & 6582 & 217 \\
\hline make & Compilador de arquivos & 21 & 179827 & 150 \\
\hline NanoXML & Analisador de XML & Automatizador de construções & 7646 & 217 \\
\hline Ant & & 1043 \\
\hline
\end{tabular}

Uma possível solução para diminuir o tempo de criação de benchmarks é gerar defeitos por meio do teste de mutação. Ali et al. (2009) analisaram a geração de versões defeituosas por mutação em comparação ao uso de defeitos reais; os resultados mostram que o uso de programas com defeitos gerados por mutação é adequado à localização de defeitos, assemelhando-se a aplicação de defeitos reais.

Os mesmos benchmarks costumam ser usados em diversos experimentos para localização de defeitos. Ao utilizar frequentemente esses mesmos programas como benchmarks, as técnicas podem obter resultados enviesados, já que podem não ser testados em programas com diferentes características. Esse fato indica a necessidade de construção de novos benchmarks, com tamanhos diferentes e defeitos variados. Assim, o uso desses benchmarks nos experimentos permite verificar o comportamento das técnicas diante 
de programas com diferentes características, e pode colaborar para avaliar a eficácia de localização de um modo mais abrangente.

Naish et al. (2009) citam a falta de benchmarks contendo múltiplos defeitos como uma dificuldade para a realização de experimentos sob tais condições. Esse fato pode ser comprovado pelos trabalhos que realizam experimentos com defeitos múltiplos, que geram versões contendo dois ou mais defeitos a partir das versões contendo defeitos únicos, utilizando uma combinação desses defeitos (JONES et al., 2007; DEAN et al., 2009; NAISH et al., 2009; WONG et al., 2010; ABREU et al., 2011). Dentro do nosso conhecimento, não existe, por exemplo, um benchmark que contenha explicitamente defeitos de integração.

\subsubsection{Programas com defeitos únicos e múltiplos}

Um programa real geralmente contém uma quantidade desconhecida de defeitos que podem ser localizados e corrigidos pelos desenvolvedores após a observação de falhas. Dado que o conjunto de teste tenha uma cobertura satisfatória, diz-se que o programa é livre de falhas quando as correções feitas em tal programa façam com que as falhas manifestadas não ocorram mais (JONES et al., 2007). Ou seja, os casos de teste de falha passam a apresentar o comportamento esperado. Isso não garante que novos casos de teste não possam revelar outras falhas, de modo que o termo refere-se às falhas que foram identificadas. Assim, não se pode garantir com certeza absoluta que um programa não contém defeitos. Além disso, um programa real costuma ser atualizado, o que torna possível a ocorrência de novos enganos, gerando consequentemente novos defeitos.

A maioria das técnicas de localização de defeitos realiza experimentos em benchmarks contendo um único defeito por versão (GUO et al., 2006; MURTAZA et al., 2008; BURGER; ZELLER, 2008; SANTELICES et al., 2009; MASRI, 2010; XIE et al., 2010; NAISH et al., 2010; MARIANI et al., 2011; YU et al., 2011) chamados de programas com defeitos únicos. Tal condição pode facilitar a realização de experimentos, mas distancia os resultados obtidos pelas técnicas analisadas das situações enfrentadas na prática por programas reais. A utilização de programas contendo somente defeitos únicos nos experimentos não garante que heurísticas que apresentem melhores resultados quanto à eficácia sob tais condições obtenham a mesma performance em programas com uma quantidade desconhecida de defeitos.

Alguns trabalhos mais recentes têm mostrado preocupação com essa questão, realizando experimentos com benchmarks contendo mais de um defeito, ou programas com defeitos múltiplos (NAISH et al., 2009; WONG et al., 2010; LEE et al., 2010). Esses traba- 
lhos costumam utilizar as mesmas técnicas experimentadas em programas com defeitos simples em programas com defeitos múltiplos. Os resultados apresentados mostram que essas técnicas perdem eficácia na presença de defeitos múltiplos.

Outros estudos desenvolvem técnicas específicas para depuração em programas contendo defeitos múltiplos (JONES et al., 2007; DEAN et al., 2009; ABREU et al., 2011). Uma abordagem proposta para programas contendo múltiplos defeitos é apresentada em Jones et al. (2007); a técnica proposta realiza o agrupamento de casos de teste de falha de acordo com uma medida de similaridade utilizando clusterização hierárquica aglomerativa. Os casos de teste similares pertencem ao mesmo grupo, conhecidos como fault focusing clusters (grupos focados em defeitos), o que indica que estão relacionados com o mesmo defeito. Uma vantagem dessa abordagem é a possibilidade de utilizar diferentes heurísticas de localização de defeitos após a geração dos clusters. Embora os custos de execução não sejam explicitados no artigo, o procedimento de obtenção dos fault focusing clusters exige uma grande quantidade de cálculos, o que indica que podem ter um custo de execução alto.

O trabalho apresentado por Dean et al. (2009) propõe uma abordagem para localização de defeitos baseada em um framework de programação linear para múltiplos defeitos. A técnica identifica um conjunto pequeno de linhas com máxima desconfiança que explica coletivamente todos os casos de teste de falha. Embora apresente resultados gerais melhores que Tarantula, Jaccard e outras técnicas comparadas, a técnica foi desenvolvida para múltiplos defeitos, o que não acontece com as técnicas utilizadas na comparação.

Abreu et al. (2011) propuseram uma técnica de localização para programas com múltiplos defeitos, chamada Zoltar-M. A técnica é baseada em Model-Based Diagnosis (MBD), que são modelos lógicos de observação. O MBD é construído sobre proposições lógicas a partir de resultados dinâmicos de execução. Esses modelos geram grupos de comandos relacionados com a falha. Os resultados indicam que a técnica é mais eficaz do que heurísticas como Tarantula e Ochiai. Além disso, é proposta uma técnica para localizar defeitos únicos, chamada Zoltar-S, mais eficaz para localização de defeitos que as heurísticas comparadas. De acordo com os autores, a técnica demanda um alto custo computacional.

Uma dificuldade na existência de defeitos múltiplos em um mesmo programa está na influência que um comando defeituoso pode exercer sobre outro comando defeituoso. Debroy e Wong (2009) realizaram um estudo sobre a interferência existente entre defeitos em um mesmo programa. Os efeitos observados podem ir desde um defeito inibir a falha 
causada por outro defeito até a execução de dois comandos existentes por um mesmo caso de teste levar à revelação de uma falha que não apareceria se apenas um dos comandos fosse executado. Os resultados obtidos no experimento realizado indicam que em $67 \%$ dos programas ocorre algum tipo de interferência. Com isso, as técnicas que abordam programas contendo múltiplos defeitos devem levar em consideração a existência de interferência entre os defeitos em um programa, o que pode afetar a eficácia de localização.

Alguns defeitos podem ocorrer devido à combinação de linhas de comando, o que é conhecido como defeitos únicos em múltiplas linhas (WONG et al., 2010). Geralmente, as heurísticas de localização de defeitos não são propostas para identificar essa situação e os benchmarks existentes carecem de defeitos que possibilitem testar tal condição.

Outra questão que pode dificultar a eficácia de localização das heurísticas são os comandos não defeituosos que são sempre executados durante os testes, em especial aqueles que são frequentemente executados nos casos de teste de falha. Esses comandos tendem a ser classificados com altos valores de suspeição mesmo não contendo qualquer defeito, o que irá fazer com que sejam verificados por quem for analisar os resultados da classificação, aumentando a quantidade de comandos que deverão ser verificados.

O trabalho de Masri et al. (2009) faz uma análise de fatores que influenciam a localização de defeitos baseada em cobertura, propondo quatro cenários que representam dificuldades para as heurísticas avaliadas e executando um conjunto de casos de teste para avaliar qual é a porcentagem de ocorrência desses fatores durante a realização de testes. Dois cenários tratam de correção coincidente, um terceiro cenário está relacionado com a presença de defeitos únicos em múltiplas linhas e outro verifica a influência de sequências de comandos que são executados somente em casos de teste de falha. Os resultados obtidos nos experimentos mostram que a ocorrência de correção coincidente atinge em média $56 \%$ dos defeitos presentes nos programas avaliados.

Alguns trabalhos recentes têm mostrado preocupação com a presença de múltiplos defeitos, realizando experimentos e propondo novas técnicas para esses programas. No entanto, as técnicas propostas até agora apresentam alto custo de execução, enquanto as heurísticas que não foram concebidas considerando defeitos múltiplos têm sua eficácia reduzida diante de tais programas. Mais estudos são necessários para melhorar o desempenho de localização de programas com defeitos múltiplos. A construção de benchmarks contendo diversos defeitos por versão pode colaborar para a realização de experimentos. A realização de novos experimentos sobre fatores que influenciam os defeitos existentes, como correção coincidente, defeitos em múltiplas linhas, entre outros fatores que podem 
interferir no desempenho das técnicas de depuração automatizada também pode colaborar para o desenvolvimento de novas técnicas para defeitos múltiplos.

\subsubsection{Métricas}

As métricas são usadas para avaliar a eficácia das classificações realizadas pelas técnicas de localização de defeitos durante os experimentos. Geralmente indicam a posição relativa na qual o comando defeituoso foi classificado em relação ao total de comandos do código. Esses valores são apresentados como o custo de localização que um desenvolvedor tem para identificar o comando defeituoso a partir da lista de comandos suspeitos gerada por uma determinada técnica.

A métrica mais utilizada pelas técnicas de localização é a EXAM score, que indica a porcentagem de comandos que precisou ser verificada até o comando defeituoso ser alcançado (JONES et al., 2007; WONG et al., 2008b; ZHANG et al., 2009a; MASRI, 2010; NAISH et al., 2010; MARIANI et al., 2011). Essa métrica é uma variação da métrica score, utilizada em outros trabalhos (WONG et al., 2007; ABREU et al., 2008b; ALI et al., 2009; WANG et al., 2009a) e que mede a porcentagem de código que não precisa ser verificada até atingir o comando defeituoso. O uso dessas métricas permite comparar o desempenho de diferentes técnicas. Existem também outras métricas propostas para contextos mais específicos, relacionadas com custo de execução ou precisão de localização (DEAN et al., 2009; MASRI et al., 2009; DEBROY; WONG, 2011).

Uma questão a respeito de métricas como a EXAM score é a suposição de que o desenvolvedor é capaz de localizar o comando defeituoso apresentado na lista de classificação imediatamente ao vê-lo, o que é conhecido como situação de detecção perfeita (WONG et al., 2010), fato que pode não ocorrer na prática. Caso o desenvolvedor não consiga identificar o comando defeituoso ao investigá-lo, mais comandos serão examinados, o que irá alterar a eficácia da técnica medida. O uso dessas métricas também supõe que o desenvolvedor irá examinar os comandos na ordem em que eles aparecem classificados.

Parnin e Orso (2011) realizaram experimentos com um grupo de desenvolvedores utilizando a heurística Tarantula. Esse trabalho mostra que, na prática, os desenvolvedores não costumam seguir a ordem exata na qual os comandos estão classificados. Os desenvolvedores costumam levar em conta outras características do programa defeituoso ao examiná-lo. Por exemplo, seu entendimento sobre o código, modo como a falha ocorre ou sobre o histórico de modificações (CHAIM et al., 2003; NAISH et al., 2009; PARNIN; ORSO, 2011). 
Outro apontamento que foi feito em relação ao uso de classificação de comandos é que as técnicas costumam avaliar a posição relativa do comando defeituoso para medir a eficácia das técnicas (PARNIN; ORSO, 2011). No entanto, em um programa contendo 100.000 linhas de código executável, se a técnica retornar o comando defeituoso dentro de $1 \%$ dos comandos mais suspeitos, poderá ser necessário verificar cerca de 1.000 linhas, o que é inviável na prática. Além disso, os comandos classificados não possuem nenhuma relação entre si, o que dificulta sua utilização (CHAIM et al., 2003; PARNIN; ORSO, 2011). Assim, utilizar apenas o valor do EXAM score pode não indicar a eficácia real de localização. Segundo Parnin e Orso (2011), as técnicas devem focar na posição absoluta ao invés da posição relativa, ou seja, o comando defeituoso deve retornar entre os primeiros da lista para que as técnicas sejam usadas em ambientes de desenvolvimento reais.

Naish et al. (2009) apresentaram uma técnica de classificação incremental que calcula a posição dos comandos classificados considerando que outros comandos classificados acima dele (com maior valor de desconfiança) não são defeituosos. Como o cálculo da classificação incremental é computacionalmente custoso, devido à necessidade de recalcular tal classificação a partir de cada comando, é sugerida uma estratégia para calcular uma porcentagem dos comandos mais suspeitos. Outra estratégia utilizada pelos autores é recalcular a classificação a cada comando verificado pelo programador. Essa classificação incremental atualiza o comando a ser verificado de forma que, caso um comando classificado em uma posição mais inferior precise ser verificado, é porque os comandos com desconfiança maior não continham o defeito.

\subsubsection{Custo de execução}

O custo de execução das técnicas de localização de defeitos pode ser dividido em vários aspectos. Em geral, dado um programa contendo um defeito, é necessário primeiro instrumentá-lo, o que permitirá atender aos critérios de cobertura da técnica e colher as informações de execução dos conjuntos de teste. O custo de execução do código instrumentado varia de acordo com os critérios que devem ser atendidos. Os critérios baseados em informações de fluxo de dados em geral têm custo de execução mais elevado em comparação aos critérios baseados em fluxo de controle, embora possam trazer informações diferentes sobre os testes realizados, colaborando para a localização de defeitos diferentes (SANTELICES et al., 2009; MASRI, 2010; YU et al., 2011).

Devido ao custo de execução de cobertura de adus, Santelices et al. (2009) utilizaram uma técnica para obter a cobertura de adus a partir da cobertura de ramos, proposta 
anteriormente pelos autores (SANTELICES; HARROLD, 2007). Essa cobertura aproximada tem desempenho de localização inferior à cobertura exata de adus. Porém, os resultados obtidos mostram que a aproximação de adus combinada com as coberturas de comandos e ramos tem desempenho de localização superior ao uso somente da cobertura de ramos, com custo computacional semelhante entre as duas abordagens.

Outro aspecto envolvido no custo de localização está relacionado é o cálculo de desconfiança dos requisitos analisados. Esse custo está relacionado com a quantidade de cálculos e processamentos que as técnicas fazem para chegar aos valores de desconfiança. A maioria das técnicas baseadas nas informações dos coeficientes de cobertura realizam cálculos simples (JONES et al., 2002; GUO et al., 2006; ABREU et al., 2008b; WONG et al., 2010; NAISH et al., 2011), enquanto técnicas que fazem uso de slicing e depuração delta podem ter um custo mais elevado (BURGER; ZELLER, 2008; DIMITROV; ZHOU, 2009; BURGER; ZELLER, 2011). Já o custo de ordenação dos comandos calculados não costuma ser citado, o que indica que não deve ter influência no desempenho das técnicas.

Murtaza et al. (2008) apresentaram a técnica MiniEPI (ver Subseção 3.2.1), que possui baixo custo computacional por analisar somente chamadas de funções. No entanto, a partir do resultado indicado pela técnica, o programador deve verificar a função indicada para buscar pelo defeito, o que pode ocasionar um custo maior para quem for utilizá-la.

O tamanho dos benchmarks e dos conjuntos de teste pode influenciar o desempenho das técnicas de localização de defeitos. No entanto, os trabalhos na área não costumam analisar essa questão. Os trabalhos que analisam programas de diferentes tamanhos não fazem uma comparação dos custos de execução das técnicas sob tal ponto de vista. Outro fator que pode influenciar os custos é a quantidade de defeitos presente nos benchmarks, assim como as características desses defeitos. Novos estudos podem ajudar a compreender melhor essas questões.

O trabalho realizado por Wong et al. (2010) avalia a influência da quantidade de casos de teste executados para verificar qual é a contribuição que estes trazem para a localização de defeitos. Os resultados indicam que os primeiros casos de teste são mais relevantes para a localização dos defeitos, o que sugere a possibilidade de utilizar menos casos de teste para a tarefa de depuração, diminuindo a sobrecarga de execução e a necessidade de gerar uma quantidade elevada de casos de teste, reduzindo o custo da tarefa de testes.

As técnicas de depuração automatizada desenvolvidas até o momento para localizar defeitos múltiplos também apresentam alto custo de execução (JONES et al., 2007; DEAN et al., 2009; ABREU et al., 2011). O custo de localização dos defeitos pelos desenvolvedores 
também deve ser analisado, visto que a situação de detecção perfeita não ocorre na prática (WONG et al., 2010; PARNIN; ORSO, 2011), o que pode dificultar a adoção das técnicas de localização propostas. Portanto, existem muitos fatores que influenciam o custo de execução das técnicas de depuração automatizada, o que mostra que há muito a se fazer para a obtenção de técnicas que possam ser usadas na indústria de software.

\subsubsection{Ferramentas de apoio à depuração baseada em cobertura}

As técnicas de depuração automatizada dependem de ferramentas para realizar as tarefas de localização de defeitos. Os trabalhos da área utilizam ferramentas desenvolvidas em pesquisas anteriores, ou desenvolvem suas próprias ferramentas para atender às necessidades específicas do projeto. Para obter as informações sobre a cobertura dos testes, são utilizadas ferramentas para realizar a instrumentação e fornecer as informações de cobertura do programa a ser analisado de acordo com o critério de teste ou cobertura adotados. Entre essas ferramentas, pode-se citar: The Aristotle Analysis System (ARISTOTLE..., 2007), $\chi$ Suds (XSUDS..., 1998), gcov (GCOV..., 1999) e Clover (CLOVER, 2012).

Outra ferramenta utilizada para avaliar a cobertura de código é a JaBUTi (Java Bytecode Understanding and Testing) (VINCENZI et al., 2005). A JaBUTi é uma ferramenta de teste estrutural para programas feitos em Java ou compilados para a Java Virtual Machine. A análise do código é feita sobre o bytecode, o que dispensa a necessidade de acesso ao código-fonte Java. A partir do bytecode é gerado um GDU do programa analisado, o que permite o uso de critérios tanto de teste baseados no fluxo de controle como no fluxo de dados de programas.

A JaBUTi faz a instrumentação do bytecode de programas para atender aos critérios disponíveis e executa os conjuntos de teste, permitindo analisar a cobertura de código atingida. Além disso, ela implementa heurísticas baseadas na subtração de requisitos de teste exercitados por diferentes casos de teste para auxiliar a localização de defeitos.

O framework InSS (Instrumentation Strategies Simulator) (ARAUJO et al., 2011) é utilizado para a simulação de execução de programas instrumentados, a partir de grafos de entrada e dos nós visitados durante os testes. O InSS pode ser utilizado para obter a cobertura dos testes e assim auxiliar a localização de defeitos. Existem também as ferramentas que realizam o cálculo de desconfiança, permitindo até mesmo implementar diferentes heurísticas existentes. Esses programas de localização de defeitos utilizam as informações sobre as estatísticas de cobertura, realizando o cálculo das heurísticas e a classificação dos comandos suspeitos. Entre as utilizadas estão a Tarantula (JONES et al., 
2002), a $\chi$ Debug (WONG et al., 2007) e a Zoltar (JANSSEN et al., 2009).

Outras ferramentas utilizadas para contextos específicos são a Jimple (VALLEE-RAI; HENDREN, 1998) e a BCEL (BCEL..., 2003), para permitir a manipulação de bytecodes Java; e a SLOCCount (SLOCCOUNT, 2011) para contar a quantidade de linhas executáveis dos benchmarks. Em muitos trabalhos são desenvolvidas ferramentas específicas para implementar as técnicas propostas (BURGER; ZELLER, 2008; MASRI, 2010), enquanto outros trabalhos não fazem referências às ferramentas utilizadas ou criadas.

\subsection{Considerações finais}

Neste capítulo, foram apresentados trabalhos que realizam depuração automatizada usando informações de cobertura de código. Esses trabalhos foram discutidos levando em consideração às características da atividade de depuração automatizada, e as soluções propostas para os problemas enfrentados para a realização dessa atividade. Foram abordadas também algumas das necessidades existentes para o desenvolvimento de técnicas que consigam obter melhores resultados de localização de defeitos.

A depuração automatizada de programas necessita de abordagens que possibilitem seu uso com baixo custo computacional, em programas com grande quantidade de código e com características de implementação variadas. As técnicas devem ser eficazes na presença de defeitos múltiplos e fornecer informações relevantes sobre os defeitos para os desenvolvedores que as utilizarão.

Foi visto que a maioria das técnicas propostas utilizam informações vindas do teste de unidade, não levando em consideração que informações de cobertura de integração podem auxiliar a localização de defeitos. As técnicas apresentadas que utilizam informações de integração indicam métodos ou funções que possivelmente contêm defeitos, mas não analisam os comandos das unidades que interagem. Dessa forma, cabe ao desenvolvedor o trabalho de procurar o comando defeituoso dentro dos métodos apontados.

O trabalho proposto por Masri (2010) utiliza a cobertura DIFA, que captura informações de integração entre métodos, mas os experimentos realizados não explicitam o uso dessas informações de integração. A maioria das técnicas apresentadas possui alto custo de execução. Os experimentos realizados com essas técnicas usaram benchmarks contendo apenas defeitos únicos.

Considerando alguns dos desafios apresentados nesta seção, nesta dissertação pretende- 
se investigar se o uso de coberturas de integração e de informações de integração sobre os requisitos de unidade auxiliam a localização de defeitos. Outra questão a ser avaliada é a eficácia de localização da técnica que será proposta para programas reais. No próximo capítulo, será apresentada a técnica de depuração automatizada baseada em informações de cobertura de integração. 


\section{Depuração de programas baseada em cobertura de integração}

Neste trabalho, é proposto o uso de informações de integração em conjunto com as informações de cobertura de unidade para realizar a tarefa de localização de defeitos. Pretende-se avaliar se o acréscimo de informações de integração pode aumentar a eficácia de localização de defeitos.

A automatização do processo de depuração vem sendo proposta por diversos trabalhos, e a principal abordagem utilizada é o uso de informações de cobertura de código obtidas a partir dos testes automatizados. Entre as técnicas propostas, nota-se predominantemente o uso de informações do teste de unidade para indicar trechos mais suspeitos do código analisado por meio de diferentes heurísticas (JONES et al., 2002; WONG et al., 2007; NAISH et al., 2009). Portanto, são aplicáveis a métodos, procedimentos ou funções dos programas de forma isolada. O uso de cobertura de integração pode trazer novas informações para a depuração automatizada, uma vez que a comunicação entre unidades pode indicar novas formas de procurar pelo comando defeituoso.

Embora existam progressos na área de depuração automatizada, as técnicas baseadas em heurísticas com cobertura de unidade não têm apresentado resultados satisfatórios para tornar seu uso possível na indústria de software, visto que a maioria das técnicas propostas não apresentam experimentos em programas reais. Um estudo de Parnin e Orso (2011), realizado com um grupo de programadores mostra que, ao procurar por um defeito usando uma lista de classificação de comandos mais suspeitos, esses programadores não seguem a ordem indicada na classificação quando não conseguem localizar o defeito entre as primeiras posições.

As melhorias obtidas pelas técnicas de localização de defeitos consideradas mais eficazes (WONG et al., 2007; SÁNCHEZ, 2007; NAISH et al., 2009) consistem da diminuição 
de valores nas métricas de esforço em relação às demais técnicas existentes, geralmente avaliadas em programas de pequeno porte. Por exemplo, Naish et al. (2011) realizaram um experimento com diversas heurísticas utilizando os programas do conjunto Siemens. Para o programa tcas, que possui 173 linhas de código, as heurísticas mais eficazes para localização de defeitos foram Zoltar, Kulczynski2 e Wong3; o esforço de localização (EXAM score) foi de $9,90 \%, 9,94 \%$, e 10,11\%, respectivamente. Outras heurísticas como Ochiai, Jaccard e Tarantula, obtiveram 10,66\%, 10,77\% e 10,80\%, respectivamente. Considerando que alguns benchmarks usados contêm centenas de linhas de código, essas diferenças de porcentagem podem significar uma redução pequena na quantidade de linhas a serem examinadas de uma técnica em relação à outra.

Além disso, o uso dos mesmos benchmarks para experimentação, a maioria contendo uma quantidade pequena de linhas de código e apenas defeitos únicos, pode levar as heurísticas a apresentar desempenhos de localização semelhantes. Por sua vez, a aplicação das técnicas de localização em outros programas, com uma quantidade maior de linhas de código, que contenham vários defeitos e características diversas, pode levar a resultados diferentes dos obtidos até o presente momento, indicando situações em que as heurísticas apresentem melhor desempenho.

Esta dissertação apresenta uma técnica de depuração automatizada que utiliza informações de cobertura de integração chamada Depuração de programas baseada em Cobertura de Integração (DCI). A DCI é composta de duas abordagens baseadas em informações de integração. A primeira usa informações estáticas de integração a partir da hierarquia do código para indicar a ordem de verificação de nós com um mesmo valor de suspeição, servindo como uma heurística de localização. A hierarquia do código é a estrutura à qual cada requisito de unidade pertence. Por exemplo, um nó em um programa escrito em Java pode pertencer a um determinado método, que está em uma classe, que por sua vez está dentro de um pacote.

A segunda abordagem usa informações dinâmicas de integração, obtidas a partir de duas coberturas de integração propostas neste trabalho, para gerar uma lista de métodos ordenados por valor de suspeição, servindo como um roteiro dos métodos que devem ser examinados na busca pelo código defeituoso. As coberturas de integração, que baseiam-se na relação entre os métodos que são executados, são usadas em conjunto com a cobertura de unidade de Nós para indicar comandos mais suspeitos de conter defeitos.

As coberturas de integração são obtidas usando as ferramentas JaBUTi e InSS. A DCI pode utilizar heurísticas diferentes para indicar comandos mais suspeitos de conter 
defeitos. Foram realizados experimentos com programas de uso real para avaliar a eficácia de localização da DCI. A seguir, a DCI é apresentada em detalhes, bem como exemplos de uso da técnica.

\subsection{Hierarquia de código (HC)}

A hierarquia de código (HC) foi elaborada para este trabalho de mestrado com o objetivo de adicionar contexto à localização de defeitos. A ideia foi utilizar informações estáticas de integração dos requisitos de cobertura de unidade para servir como uma heurística de busca que sugere uma ordem de investigação pelo defeito. Cada requisito coberto é agrupado de acordo com a sua hierarquia no código do programa, ou seja, um nó, aresta ou adu é classificado de acordo com o método, a classe e o pacote ao qual pertence. Cada método, classe e pacote recebe dois valores: um valor de suspeição, que corresponde ao maior valor de suspeição entre os requisitos que possui; e a quantidade de requisitos que possui esse maior valor de suspeição.

Assim, a hierarquia de código adiciona mais informações para a localização de defeitos, indicando quais pacotes, classes e métodos possuem uma quantidade maior de requisitos contendo altos valores de suspeição.

Por exemplo, uma classe $A$ possui 2 nós classificados com o valor de suspeição 0,99 , que é o maior valor entre todos os requisitos dessa classe, enquanto uma classe $B$ possui 4 nós com esse mesmo valor, também o maior valor entre os requisitos da classe $B$. A classe $A$ recebe o valor de suspeição 0,99 e a quantidade de requisitos é igual a 2 , enquanto a classe $B$ possui o mesmo valor de suspeição, porém a quantidade de requisitos é 4 . O programador pode realizar a busca pelo defeito começando pela classe $B$, que possui mais requisitos com valor de suspeição 0,99. Na Seção 4.4 é mostrado um exemplo de uso da hierarquia de código.

\subsection{Coberturas de integração}

Para a realização deste trabalho, propõe-se o uso de cobertura de integração com foco em informações de fluxo de controle, por meio da comunicação entre os métodos que são exercitados durante os testes. O principal objetivo é verificar se é possível obter informações relevantes à depuração a partir de comunicação entre os métodos de um programa. 
Na proposta inicial deste projeto, pretendia-se trabalhar com os critérios de teste de integração propostos por (LEMOS et al., 2009) e (NEVES, 2010). Durante testes realizados com a ferramenta que implementa essas abordagens, chamada JaBUTi/AJ, verificouse não ser possível utilizá-la para extrair a cobertura desses critérios para os programas usados nos experimentos.

Além disso, verificou-se que, para a técnica de localização de defeitos, é preciso obter a cobertura de integração dos testes executados, mesmo que os testes não sejam C-adequados a um determinado critério de teste de integração. Assim, é possível utilizar os testes já existentes nos programas usados na avaliação. A seguir, são descritas as duas coberturas implementadas.

\subsubsection{MethodCallPair (MCP)}

A cobertura MethodCallPair (MCP) representa os pares de métodos que são exercitados durante a execução dos testes. Esse par é formado pelo método chamador e pelo método chamado e suas respectivas classes, formando um requisito de cobertura de integração. Com isso, pode-se coletar as informações dos pares de método que foram executados durante os casos de teste de sucesso e falha para indicar aqueles mais suspeitos de conter defeitos. A Figura 4.1 ilustra um requisito da cobertura MCP, em que o metodoA da classe $A$ invoca o metodo $B$ da classe $B$.

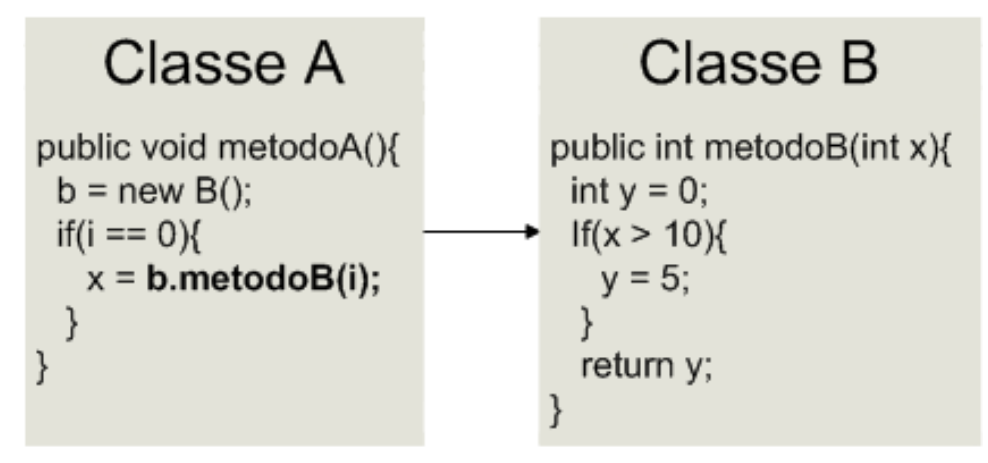

\section{$<$ A.metodoA, B.metodoB $>$}

Figura 4.1 - MethodCallPair (MCP). 


\subsubsection{MethodCallTriple (MCT)}

De forma semelhante à MCP, a cobertura MethodCallTriple (MCT) representa as triplas de métodos formadas durante a execução do programa. Um método chamador contém uma chamada para um método intermediário que, por sua vez, invoca um método chamado. O objetivo é verificar se o acréscimo de um nível de chamada, em relação à MCP, melhora a identifição dos métodos mais suspeitos. A Figura 4.2 apresenta a cobertura MCT, na qual o metodo $A$ da classe $A$ invoca o metodo $B$ da classe $B$ e este chama o metodo $C$ da classe $C$.

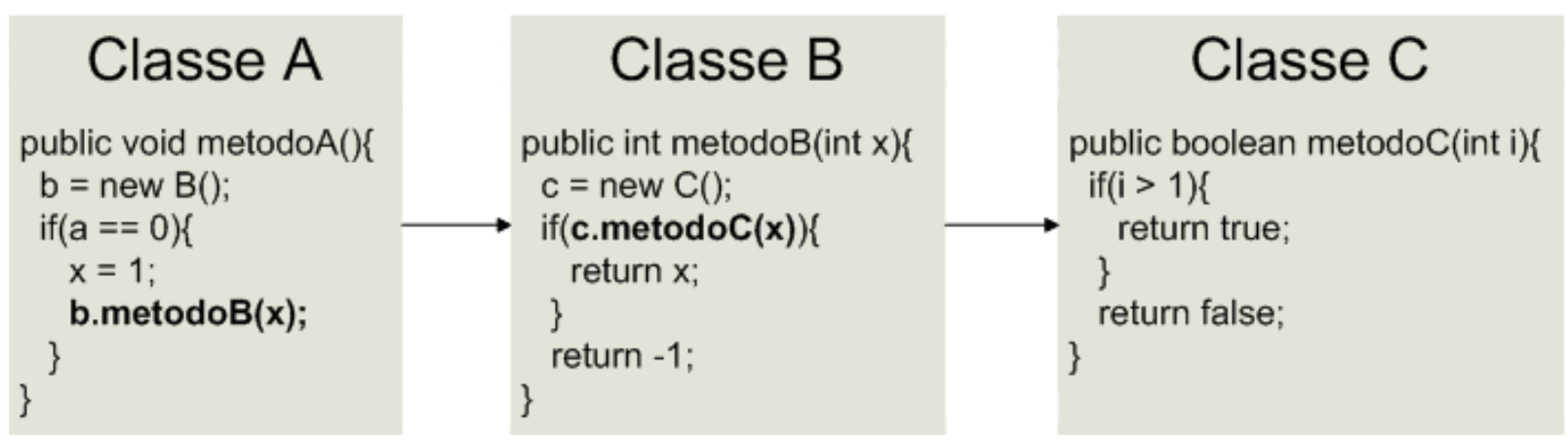

\section{$<$ A.metodoA, B.metodoB , C.metodoC>}

Figura 4.2 - MethodCallTriple (MCT).

\subsection{Depuração de programas baseada em Cobertura de Integração (DCI)}

Para avaliar o uso das informações de cobertura de integração para depuração automatizada, este trabalho apresenta a técnica chamada Depuração de programas baseada em Cobertura de Integração (DCI). A DCI é composta pelas coberturas de integração MCP e MCT, descritas na seção anterior, e a cobertura de unidade de Nós, que são extraídas a partir da execução dos testes de um programa. A partir das coberturas obtidas, a DCI calcula a suspeição dos requisitos por meio de heurísticas e faz a classificação desses requisitos.

A DCI gera a lista de suspeição e a hierarquia de código para coberturas de unidade. A hierarquia de código serve como um guia para indicar a ordem na qual pacotes, classes, métodos e requisitos de unidade são verificados na busca por defeitos. Já para as 
coberturas de integração, DCI gera a lista de suspeição e o roteiro de busca. O roteiro de busca é utilizado para examinar métodos mais suspeitos de conter defeitos, podendo ser usado em conjunto com a lista de suspeição de requisitos de unidade para indicar os comandos pertencentes a esses métodos com maior possibilidade de conter defeitos. Dessa forma, pode-se combinar cobertura de integração com cobertura de unidade para refinar a localização de defeitos. A Figura 4.3 mostra o processo de utilização da técnica DCI.

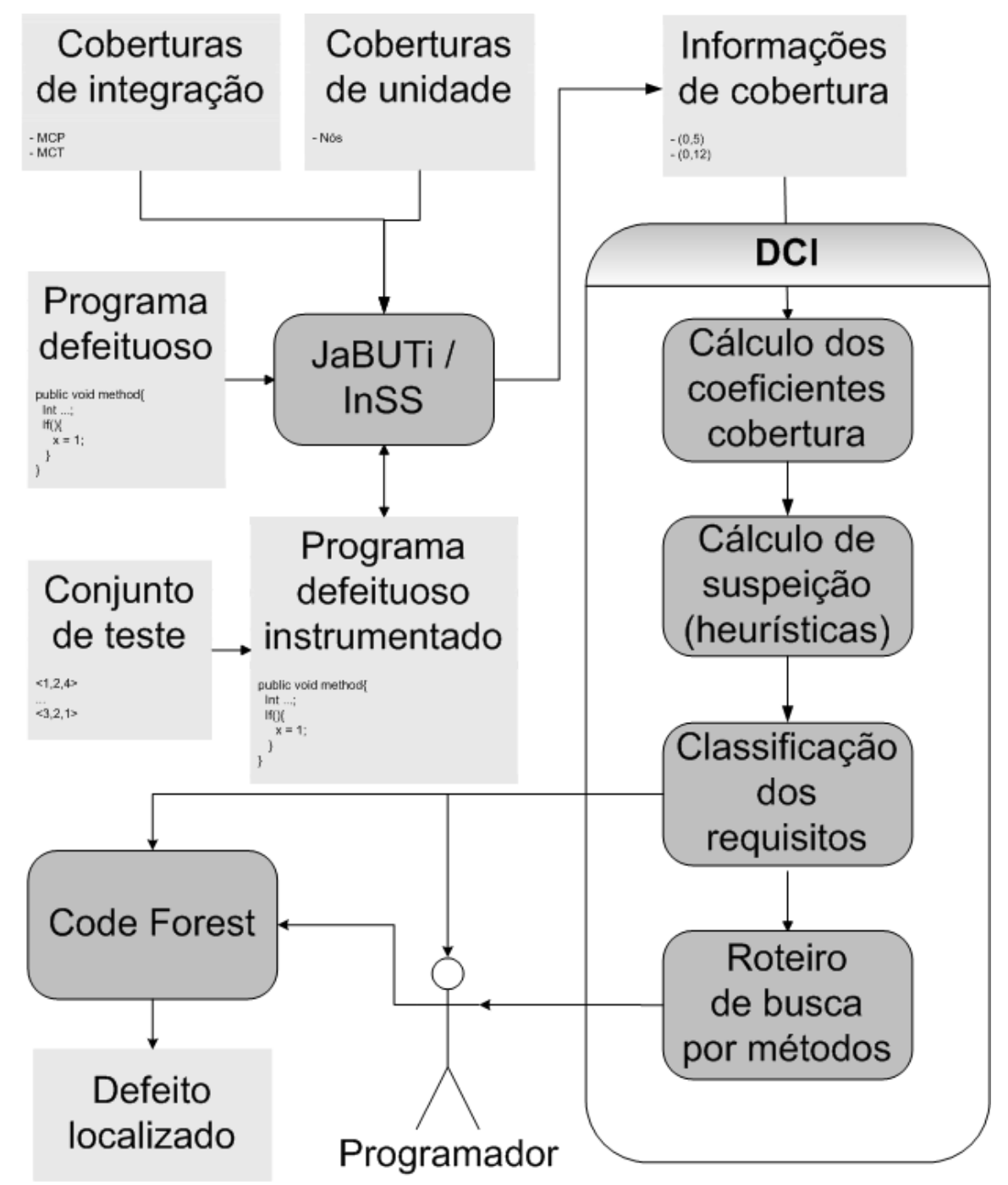

Figura 4.3 - Depuração de programas baseada em Cobertura de Integração (DCI).

\subsubsection{JaBUTi / InSS}

A Java Bytecode Understanding and Testing (JaBUTi) (VINCENZI et al., 2005) é uma ferramenta de teste estrutural para programas feitos em Java ou compilados para códigoobjeto Java. A análise do código é feita sobre o bytecode, o que dispensa a necessidade de acesso ao código-fonte Java. A partir do código-objeto é gerado um GDU do programa 
analisado, o que permite o uso de critérios tanto de teste baseados no fluxo de controle como no fluxo de dados de programas. A JaBUTi faz a instrumentação do código-objeto de programas para atender aos critérios disponíveis e executa os conjuntos de teste, permitindo analisar a cobertura de código atingida.

O framework chamado Instrumentation Strategies Simulator (InSS) (ARAUJO et al., 2011) simula a execução de um programa instrumentado para avaliar estratégias de coberturas em tempo de execução. Para simular a execução de um programa instrumentado o InSS recebe como entrada grafos de fluxo de dados gerados pela JaBUTi e um fluxo de nós representando o fluxo de execução do programa. O InSS instrumenta o códigoobjeto Java de modo que sempre que o nó de um método em particular é percorrido, essa informação é passada para o InSS.

A simulação do InSS funciona da seguinte forma. Toda vez que o primeiro nó de um novo método é recebido a partir do fluxo de nós, o grafo de fluxo de controle do método é carregado. Um objeto é criado para representar o novo método lido com suas pontas de prova (instrumentação inserida nos nós). Conforme os nós são percorridos, as pontas de prova são executadas e a partir daí pode-se realizar a análise desejada. O InSS possui estratégias implementadas para instrumentar as coberturas de Nós, Ramos e Adus (ARAUJO et al., 2011). As coberturas MCP e MCT foram implementadas neste trabalho e os algoritmos para calculá-las estão descritos no Apêndice A.

O InSS fornece como saída arquivos serializados que representam os requisitos que foram exercitados para cada caso de teste. Dessa forma, é possível avaliar os requisitos percorridos em um caso de teste que resultou em falha ou sucesso. Os arquivos gerados para as coberturas de integração e para as coberturas de unidade são usados como entrada para a ferramenta DCI. Na Figura 4.3, os arquivos serializados são indicados pelo bloco "Informações de cobertura".

\subsubsection{Programa defeituoso}

O bloco "Programa defeituoso" da Figura 4.3 representa o programa a ser avaliado usando a DCI. Para este projeto foram selecionados programas escritos na linguagem Java. No entanto, a técnica pode ser utilizada para programas escritos em outras linguagens. 


\subsubsection{Conjunto de teste}

A técnica foi desenvolvida para utilizar casos de teste escritos utilizando a biblioteca JUnit (GAMMA; BECK, 1999), a partir dos quais são obtidas as informações de cobertura. É necessário que exista pelo menos um caso de teste de sucesso e um caso de teste de falha para tornar possível o uso das heurísticas de localização. O bloco "Conjunto de teste" representa os testes dos programas que utilizam a biblioteca JUnit; considera-se cada método da classe de teste como um caso de teste.

\subsubsection{Coberturas de integração e unidade}

As coberturas de integração MCP e MCT, descritas na Seção 4.2, foram desenvolvidas utilizando o framework InSS para obter informações de integração. Os Algoritmos 6 e 7 , descritos no Apêndice A, apresentam o processo de extração das informações de cobertura de integração no InSS. A partir da instrumentação feita pelo InSS foi possível extrair as informações da sequência de chamadas de métodos suspeitas ocorrida durante a execução de cada teste. O bloco "Coberturas de integração" representa os programas Java utilizados pelo InSS para extrair as coberturas MCP e MCT.

Araujo et al. (2011) implementaram diversas coberturas de unidade (Nós, Ramos e Adus) utilizando o InSS. O bloco "Coberturas de unidade" representa os programas fornecidos ao InSS para obter as respectivas coberturas. A cobertura de Nós foi a cobertura de unidade utilizada neste trabalho, mas quaisquer das outras poderiam ter sido utilizadas.

\subsubsection{Informações de cobertura}

As informações de cobertura são os arquivos gerados pelo InSS contendo os requisitos que foram percorridos durante os testes. O InSS gera um arquivo para cada caso de teste executado, incluindo também o resultado da execução (sucesso ou falha).

\subsubsection{DCI}

A técnica DCI foi desenvolvida para possibilitar a indicação de trechos de código mais suspeitos de conter defeitos. Para isso, recebe como entrada os arquivos serializados gerados pelo InSS e tem como saída a lista de suspeição de requisitos.

O Algoritmo 1 descreve de maneira geral o funcionamento da técnica. Ele recebe 
como entrada os arquivos de cobertura (requisitos cobertos em um dado caso de teste) que serão analisados, a cobertura (Nós, Ramos, Adus, MCP ou MCT), a heurística (e.g., Tarantula, Ochiai, Wong3) e o tipo de classificação que será gerada. As etapas da técnica DCI são detalhadas a seguir.

Algoritmo 1: Gera as listas de suspeição de acordo com a cobertura e tipo de classificação selecionada.

Entrada: ArquivosDeCobertura, Cobertura, Heuristica, TipoDeClassificacao

Saída: ListasDeSuspeicao

para cada Arquivo em ArquivosDeCobertura faça

se Arquivo = falha então

- atualizaCasosDeTesteDeFalha();

criaMatrizDeCobertura(Arquivo) ; // Algoritmo 2

ListaDeRequisitos $\leftarrow$ atualizaRequisitos();

calculaSuspeição(ListaDeRequisitos, Heuristica) ; // Algoritmo 3

classificaRequisitos (ListaDeRequisitos, TipoDeClassificacao) ; // Algoritmo 4

geraListasDeSuspeição(Cobertura);

exportaListasDeSuspeição();

retorna ListaDeSuspeicao

\section{Cálculo dos coeficientes de cobertura}

As informações de cobertura são coletadas para armazenar a frequência de execução de cada requisito para os casos de teste de sucesso ou falha, gerando a matriz de coeficientes de cobertura de requisitos conforme descrito na Seção 2.2 .

O Algoritmo 2 mostra como é criada a matriz de coeficientes de cobertura de cada um dos requisitos a partir de um arquivo de cobertura, isto é, dos dados de cobertura de um caso de teste.

Algoritmo 2: Gera a matriz com os coeficientes de cobertura.

Entrada: ArquivoDeCobertura - cobertura dos requisitos para um caso de teste

Saída: MatrizDeCobertura

para cada Requisito em ArquivoDeCobertura faça

se Requisito existe então

L atualizaMatrizDeCobertura(Requisito);

senão

insereMatrizDeCobertura(Requisito);

retorna MatrizDeCobertura 


\section{Cálculo da suspeição (heurísticas)}

A suspeição de cada requisito é calculada de acordo com a heurística escolhida. Foram implementadas as heurísticas DRT (CHAIM et al., 2003), Jaccard, Kulczynski, McCon, Minus, Ochiai, $O^{p}$, Tarantula, Zoltar e Wong3.

A matriz de coeficientes de cobertura gerada pelo Algoritmo 2 é usada pelo Algoritmo 3 para calcular o valor de suspeição de cada requisito.

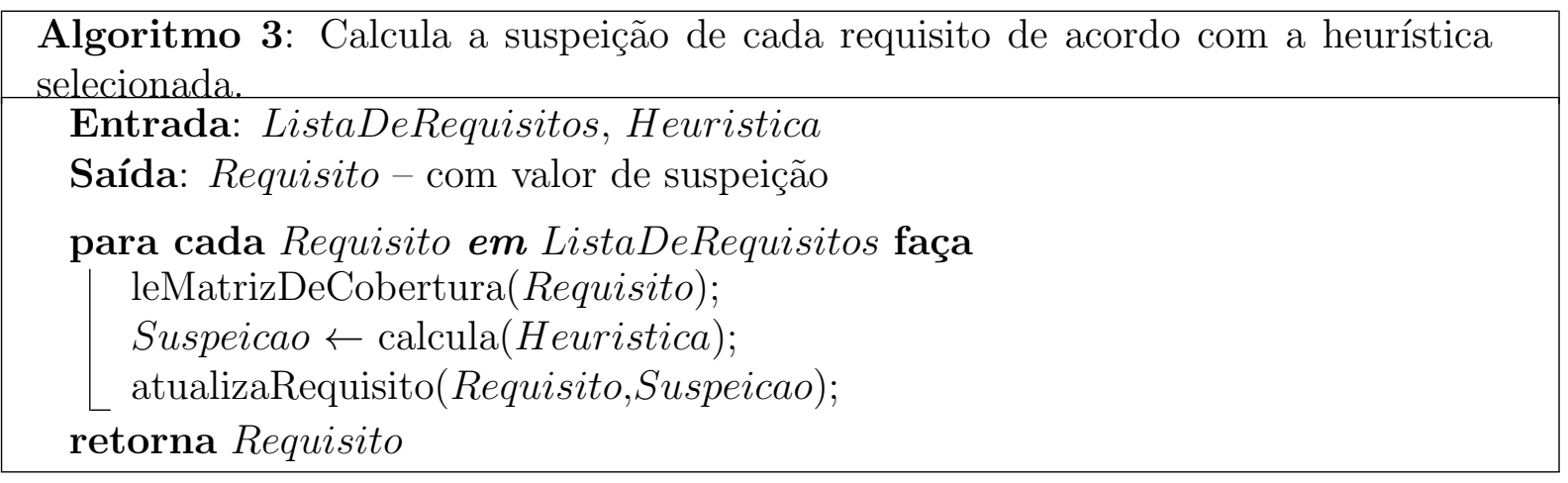

\section{Classificação dos requisitos}

A partir dos valores de suspeição obtidos, os requisitos são classificados de duas maneiras: pela lista de suspeição ou pela hierarquia de código.

Lista de suspeição: Neste tipo de classificação os requisitos são listados em ordem decrescente de valor de suspeição. Requisitos com mesmo valor de suspeição são ordenados alfabeticamente da seguinte forma: para as coberturas de integração, pelo nome da classe, o que inclui o nome do pacote e o índice do método; para coberturas de unidade, além das ordenações anteriores, o número identificador do requisito é também utilizado na ordenação.

Hierarquia de código: Para esta classificação os requisitos são agrupados de acordo com o pacote, a classe e o método ao qual pertencem, sendo atribuídos os valores de suspeição e o número de requisitos com tal valor para cada pacote, classe e método, conforme explicado na Seção 4.1.

O Algoritmo 4 descreve as classificações de requisitos fornecidas pela DCI. A lista de suspeição pode ser gerada para as coberturas de unidade e integração, enquanto que a classificação por hierarquia de código pode ser gerada apenas para coberturas de unidade. 
A DCI fornece como saída listas de requisitos contendo os valores de suspeição de acordo com a classificação escolhida. Pode-se gerar os arquivos no formato $X M L$ ou $C S V$. Para a classificação por hierarquia de código, o Algoritmo 4 representa apenas a ordenação por pacotes, mas o procedimento para ordenação por classes e métodos é semelhante.

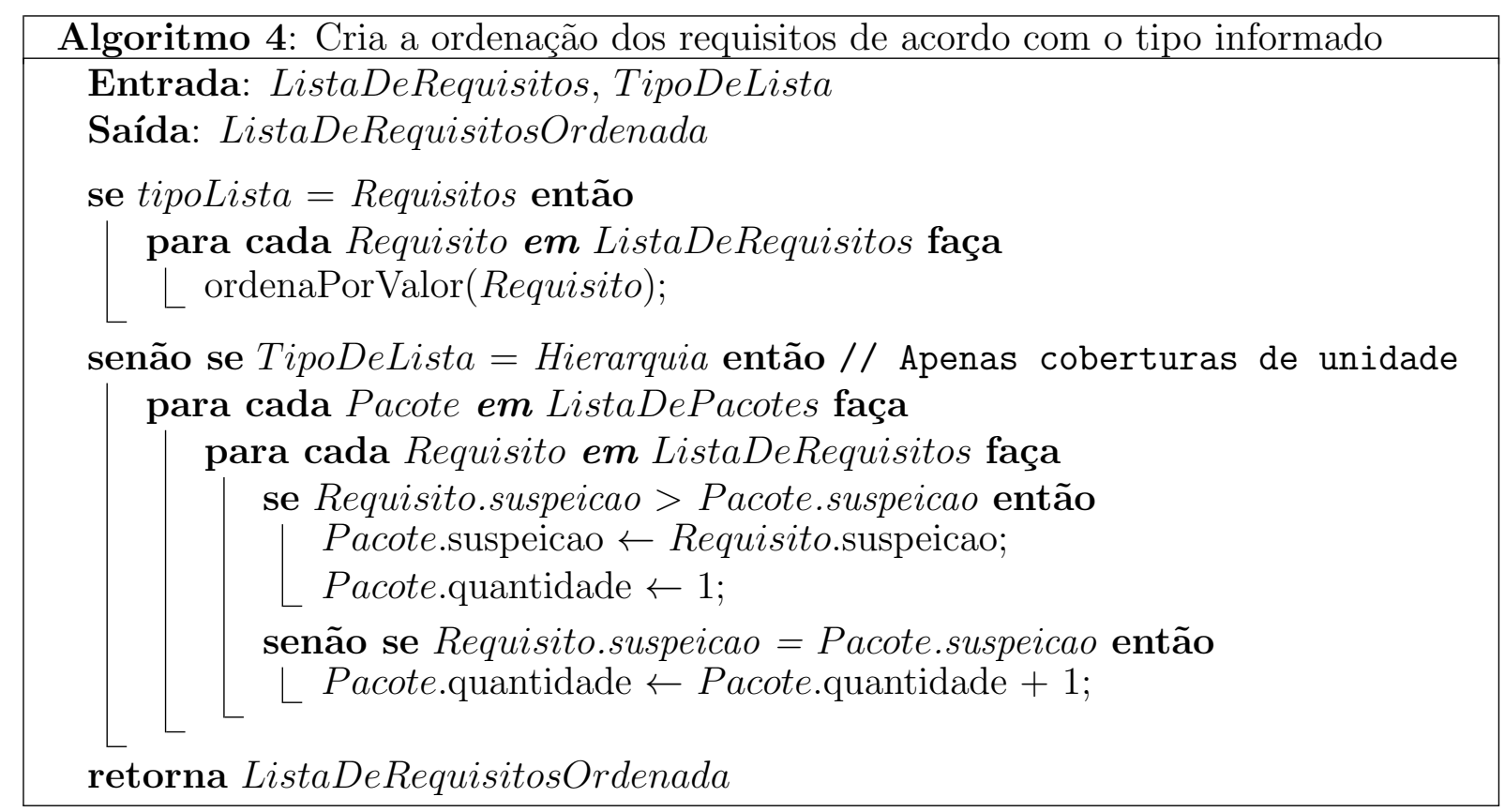

\section{Roteiro de busca por métodos}

A ideia do roteiro de busca por métodos é simplificar o uso da lista de requisitos das coberturas de integração. Utilizando a lista ordenada por suspeição de MCP ou MCT para procurar pelo defeito, o programador verificaria o primeiro requisito (par ou tripla), começando pelo método chamador, passando pelo método intermediário (no caso de MCT) e terminando pelo método chamado. Ao examinar os requisitos seguintes (pares ou triplas), métodos que já foram visitados podem aparecer novamente. O roteiro de busca por métodos tem por finalidade evitar que o programador tenha que examinar métodos que já foram verificados antes, simplificando o processo de localização de defeitos.

Portanto, o roteiro de busca por métodos é uma lista gerada a partir da lista de suspeição de MCP ou MCT, de acordo com a cobertura escolhida. Cada requisito da lista de suspeição é verificado, começando pelo método chamador, indo para o método intermediário, no caso da cobertura MCT, e em seguida para o método chamado. Se o método ainda não está presente no roteiro de busca, ele é então incluído nesse roteiro com o valor de suspeição do requisito ao qual pertence. Dessa forma, o roteiro de busca por métodos contém cada um dos métodos da lista de requisitos de MCP ou MCT com o seu 
maior valor de suspeição. O roteiro de busca baseado na lista de suspeição de MCP será chamado de $R$-MCP e o roteiro de busca gerado a partir da lista de suspeição de MCT será nomeado como $R-M C T$. Um exemplo do R-MCP é mostrado na Figura 4.4.

\begin{tabular}{l|r}
\hline R-MCP & \multicolumn{1}{c}{ suspeição } \\
\hline getCovariances( & 0,9985037 \\
\hline getAllParameters( & 0,9985037 \\
\hline getMeasurements( & 0,9985037 \\
\hline EstimatedParameter( & 0,997012 \\
\hline getName( & 0,9960199 \\
\hline solve( & 0,9955246 \\
\hline buildMessage( & 0,9955246 \\
\hline MathException( & 0,9955246 \\
\hline EstimationException( & 0,9955246 \\
\hline updateJacobian( & 0,9950298 \\
\hline GaussNewtonEstimator( & 0,9930556 \\
\hline estimate( & 0,9930556 \\
\hline SimpleEstimationProblem( & 0,9930556 \\
\hline getUnboundParameters( & 0,9930556 \\
\hline addParameter( & 0,9930556 \\
\hline addMeasurement( & 0,9930556
\end{tabular}

Figura 4.4 - R-MCP para o defeito $A E_{-} A K_{-} 1$ do Commons-Math.

O roteiro de busca por métodos serve como um guia para que o programador possa investigar o código na busca pelo defeito. O roteiro de busca é combinado com a lista de suspeição de Nós (que será chamada de $L S N$ ) para possibilitar a localização dos defeitos investigando os nós que pertencem ao método que está sendo verificado.

O Algoritmo 5 mostra como é gerado o roteiro de busca por métodos. O algoritmo recebe como entrada a lista de suspeição de MCP ou MCT e armazena o nome de cada método do par ou tripla e seu respectivo valor de suspeição. Cada vez que um novo método é percorrido na lista de requisitos, ele é armazenado com o valor de suspeição do requisito. Como a lista de requisitos está ordenada por valor de suspeição, cada método armazenado no roteiro de busca possui o seu maior valor de suspeição obtido pela DCI. Um exemplo de uso do roteiro de busca é apresentado na Seção 4.4.

\subsubsection{Programador}

O programador tem um papel fundamental na tarefa de localização de defeitos. A DCI indica os roteiros de busca, assim como os trechos de código mais suspeitos de conter defeitos dentro dos métodos. Porém, a avaliação para determinar se existe o 


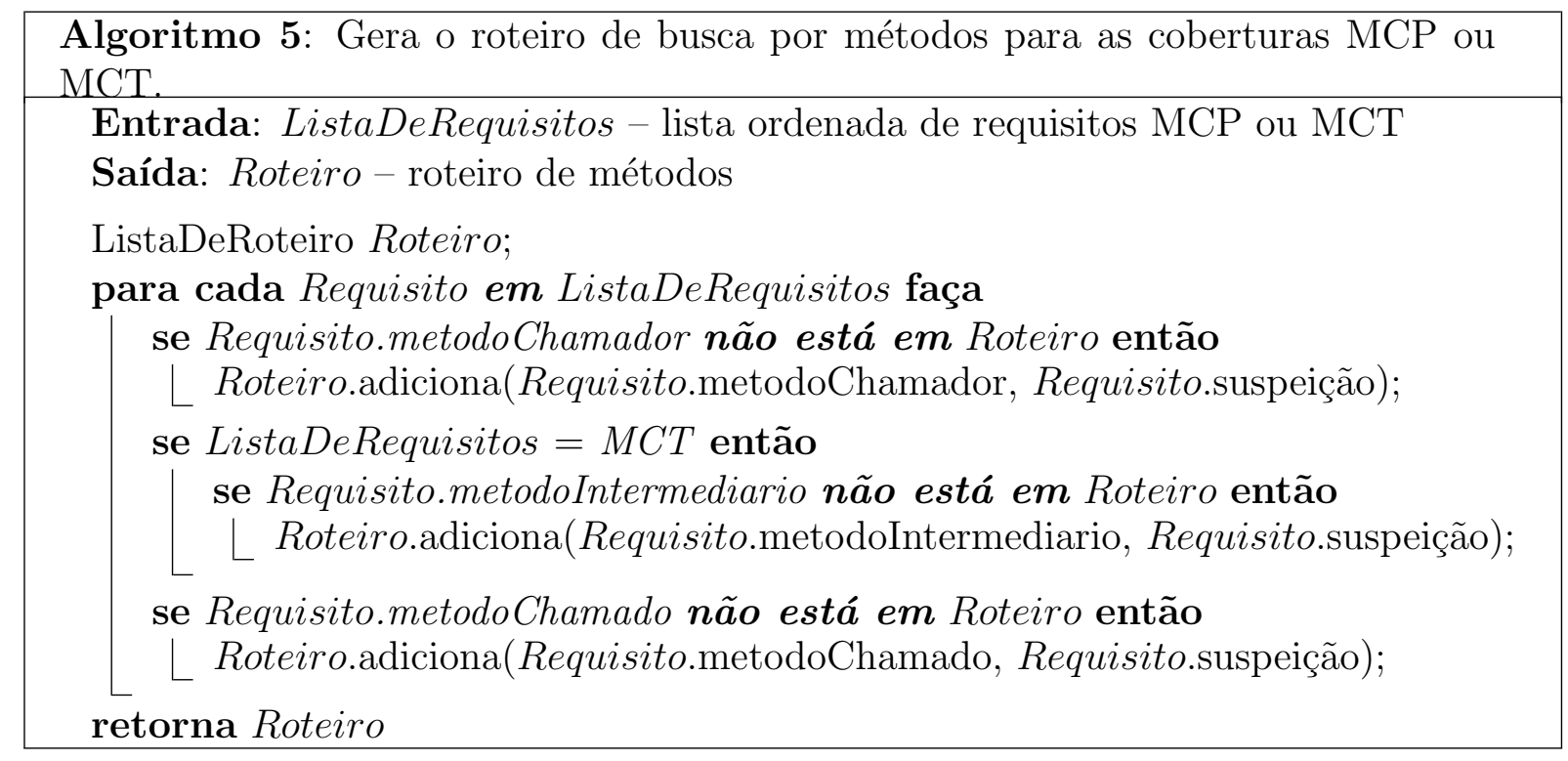

defeito continua sendo uma tarefa predominantemente humana. A partir dos resultados fornecidos pela DCI, o programador procura o defeito, inspecionando os métodos do roteiro e as lista de suspeição de Nós de cada método visitado. Outra possibilidade é o programador usar a CodeForest, que é apresentada a seguir.

\subsubsection{CodeForest}

A CodeForest (MUTTI et al., 2012) é uma ferramenta de visualização de informações de depuração que está em fase de desenvolvimento. A CodeForest usa uma metáfora de representação do código na qual o programa é uma floresta de código. As classes são representadas como árvores da floresta, os métodos são os galhos da árvore e os nós de cada método são suas folhas.

As árvores, galhos e folhas possuem valores de suspeição, obtidos a partir das listas ordenadas por hierarquia de código que são geradas pela DCI. A construção das árvores na floresta é feita posicionando as árvores mais suspeitas na frente da floresta, da direita para a esquerda. Os galhos com maior suspeição são ordenados de baixo para cima alternando entre os lados da árvore. As folhas com maior valor são ordenadas da parte interna para a parte externa dos galhos, alternando entre a parte superior e inferior do galho.

A Figura 4.5 mostra uma floresta construída pela CodeForest. A árvore em torno da elipse azul representa a classe com o maior valor de suspeição. O galho classificado como mais suspeito está circulado em branco. 


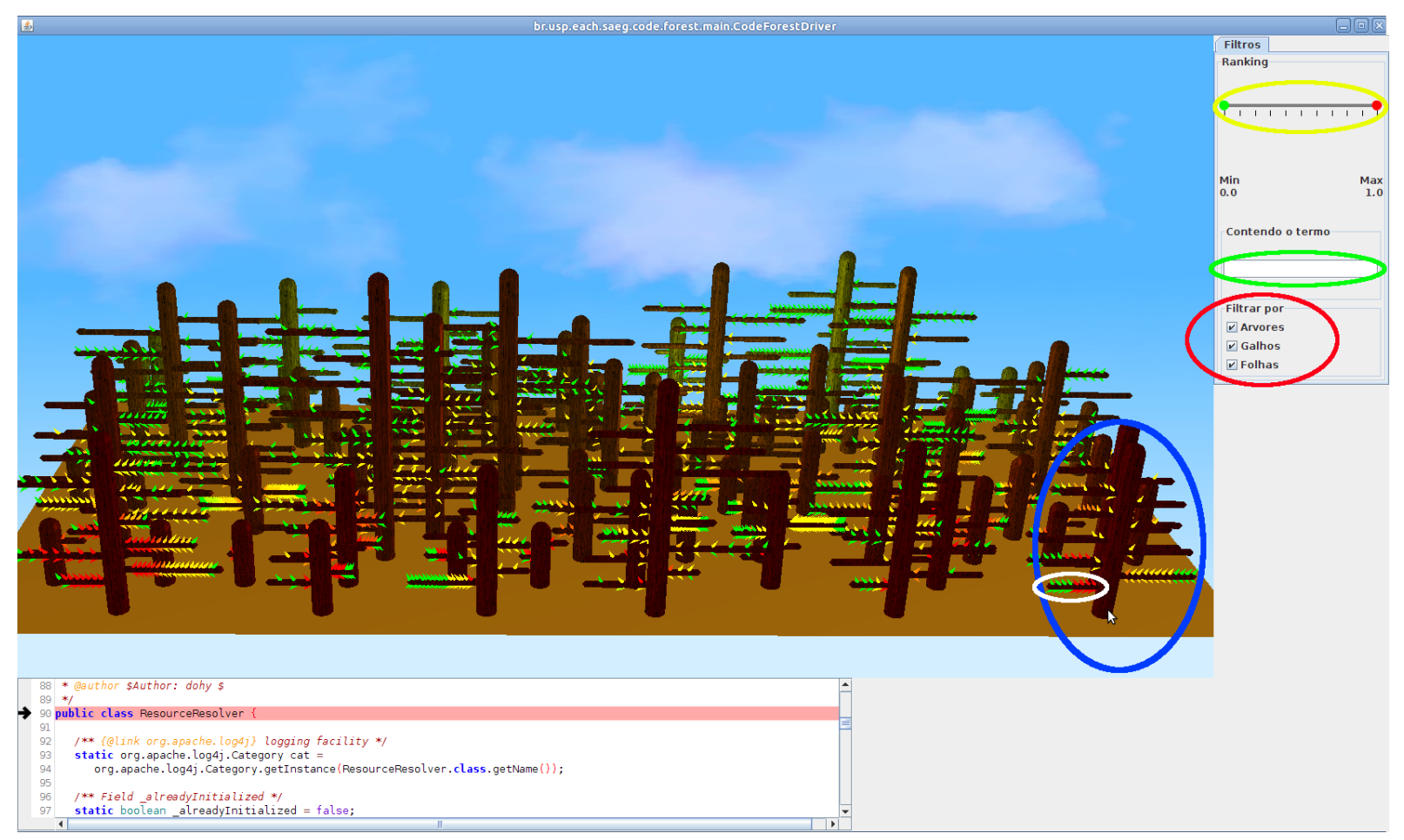

Figura 4.5 - Floresta gerada pela CodeForest.

As árvores mais suspeitas recebem uma coloração mais escura. As cores das folhas variam entre vermelho (com maior valor de suspeição), passando pelo laranja e amarelo até chegar ao verde (folhas contendo menor valor de suspeição).

A CodeForest possui um filtro que permite visualizar partes da floresta que contenham apenas uma determinada faixa de valores desejada, diminuindo a carga visual necessária para o avaliador. Esse filtro é chamado trimmer. Existe um outro filtro para realizar busca por termo (textual), que retorna partes de floresta relacionadas com o termo pesquisado. Também é possível definir o nível em que esses filtros são utilizados (folhas, galhos e/ou árvores). A ferramenta possibilita visualizar o código da classe, método ou nó associado a cada objeto de representação, clicando sobre o objeto desejado.

Na Figura 4.5, o trimmer aparece envolvido pela elipse amarela. O filtro de busca por termo é destacado pela elipse verde, enquanto o filtro de níveis está circulado em vermelho.

\subsection{Localizando o defeito com DCI e CodeForest}

Para ilustrar o funcionamento da técnica proposta, serão apresentados alguns exemplos de uso da DCI para defeitos que foram examinados durante a fase de validação da 
ferramenta. São mostrados o uso do roteiro de busca de métodos e da lista de suspeição de Nós para localizar defeitos utilizando a CodeForest. Os procedimentos para incluir um defeito, instrumentar um programa e gerar as listas de suspeição são mostrados na Seção 5.4 .

\subsubsection{Usando R-MCP}

Para esse exemplo, será usado o defeito nomeado como $A E_{-} A K_{-} 1$, que pode ser visto na Figura 4.6. Esse defeito está presente na classe AbstractEstimator do programa CommonsMath (COMMONS-MATH, 2012) (apresentado na Seção 5.3) e consiste em atribuir um valor incorreto a uma variável local do método getCovariances, podendo fazer com que esse método retorne o valor incorreto no array do tipo double que é retornado pelo método. Inicialmente, a CodeForest gera a floresta contendo todo o código do programa, conforme mostrado nas Figuras 4.7 e 4.8 .

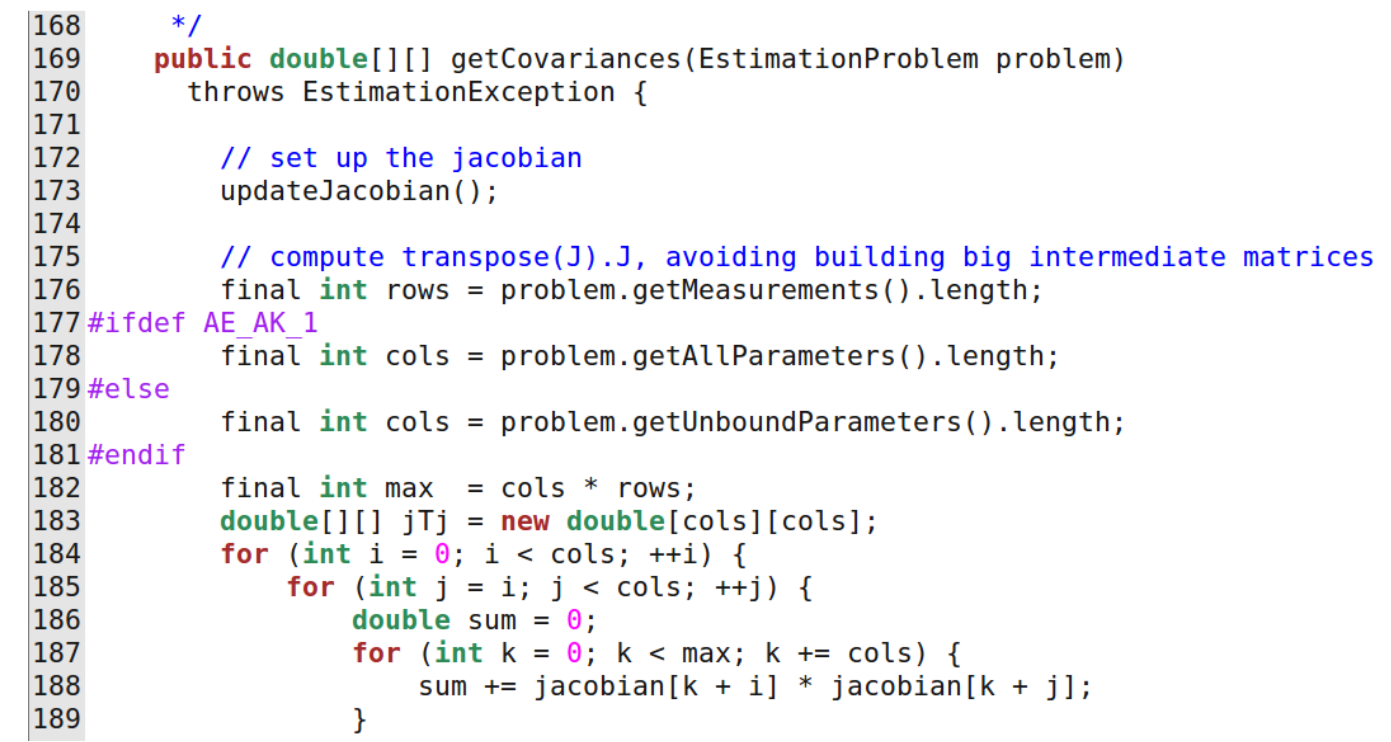

Figura 4.6 - Trecho de código que insere o defeito AE_AK_1 do Commons-Math.

Usando R-MCP, que pode ser visto na Figura 4.4, ajusta-se o valor mínimo do trimmer (o círculo que fica do lado esquerdo do filtro) para 0,99, que é o valor de suspeição do primeiro método do roteiro. Isso faz com que a floresta apresente somente árvores e galhos que contenham valor de suspeição entre 0,99 e 1, considerando que a precisão decimal da CodeForest é de dois dígitos. A Figura 4.9 mostra a floresta com o valor 0,99 no filtro trimmer.

Ao incluir o nome do método no filtro de busca por termo, a CodeForest retorna apenas as folhas do galho que representa o método defeituoso com o valor de suspeição 


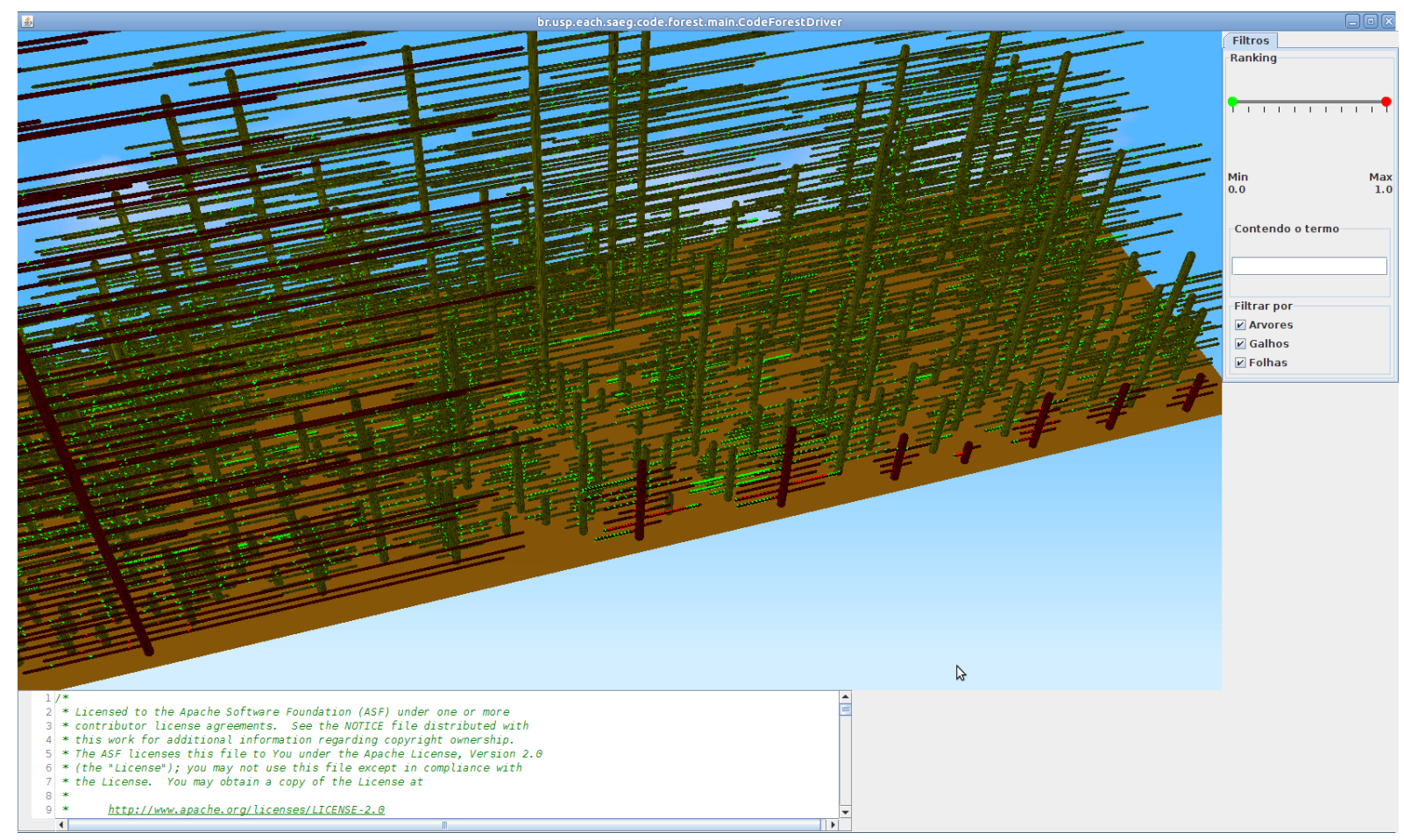

Figura 4.7 - Visão geral da CodeForest gerada para o defeito AE_AK_1 do CommonsMath.

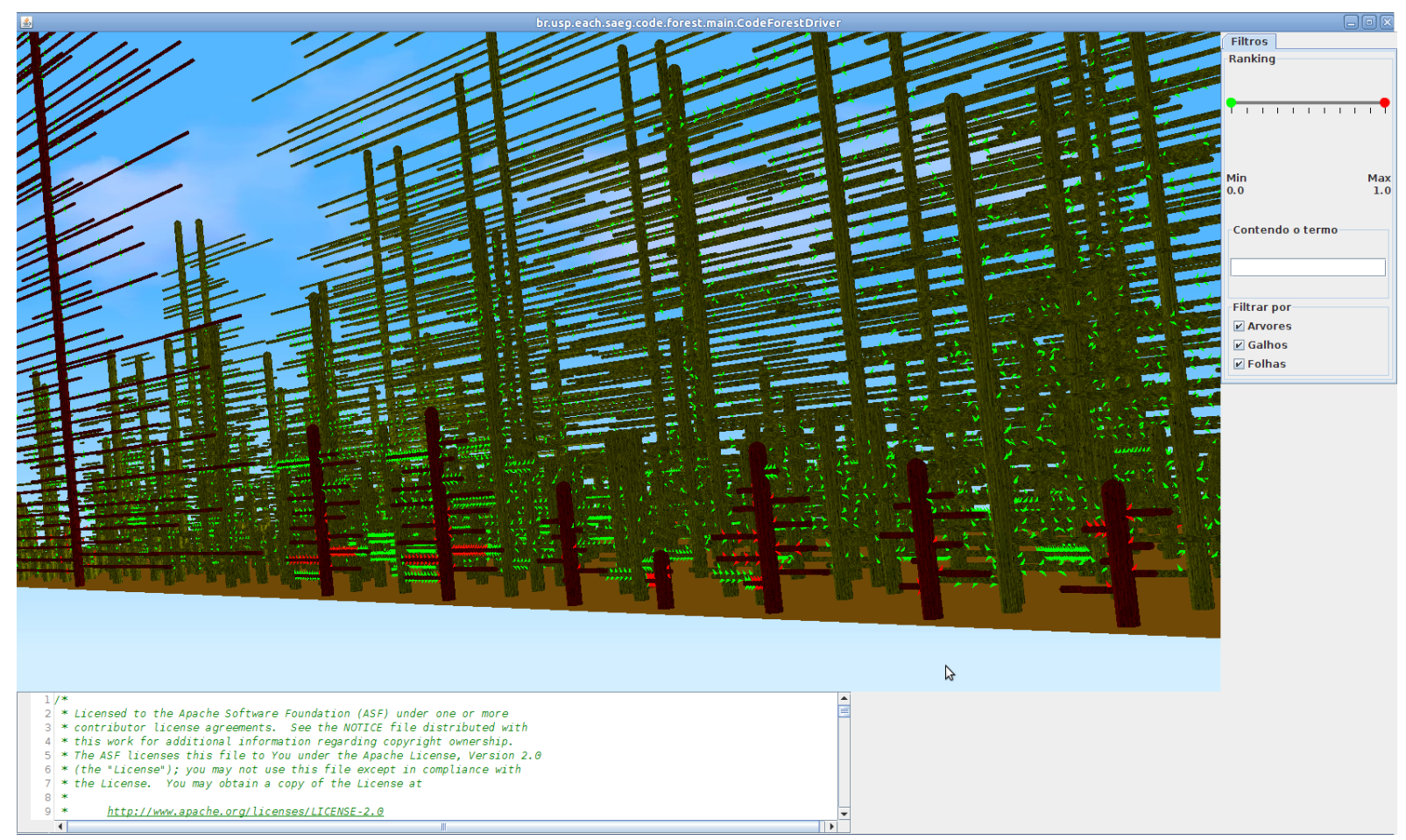

Figura 4.8 - Visão frontal da CodeForest gerada para o defeito AE_AK_1 do CommonsMath. 


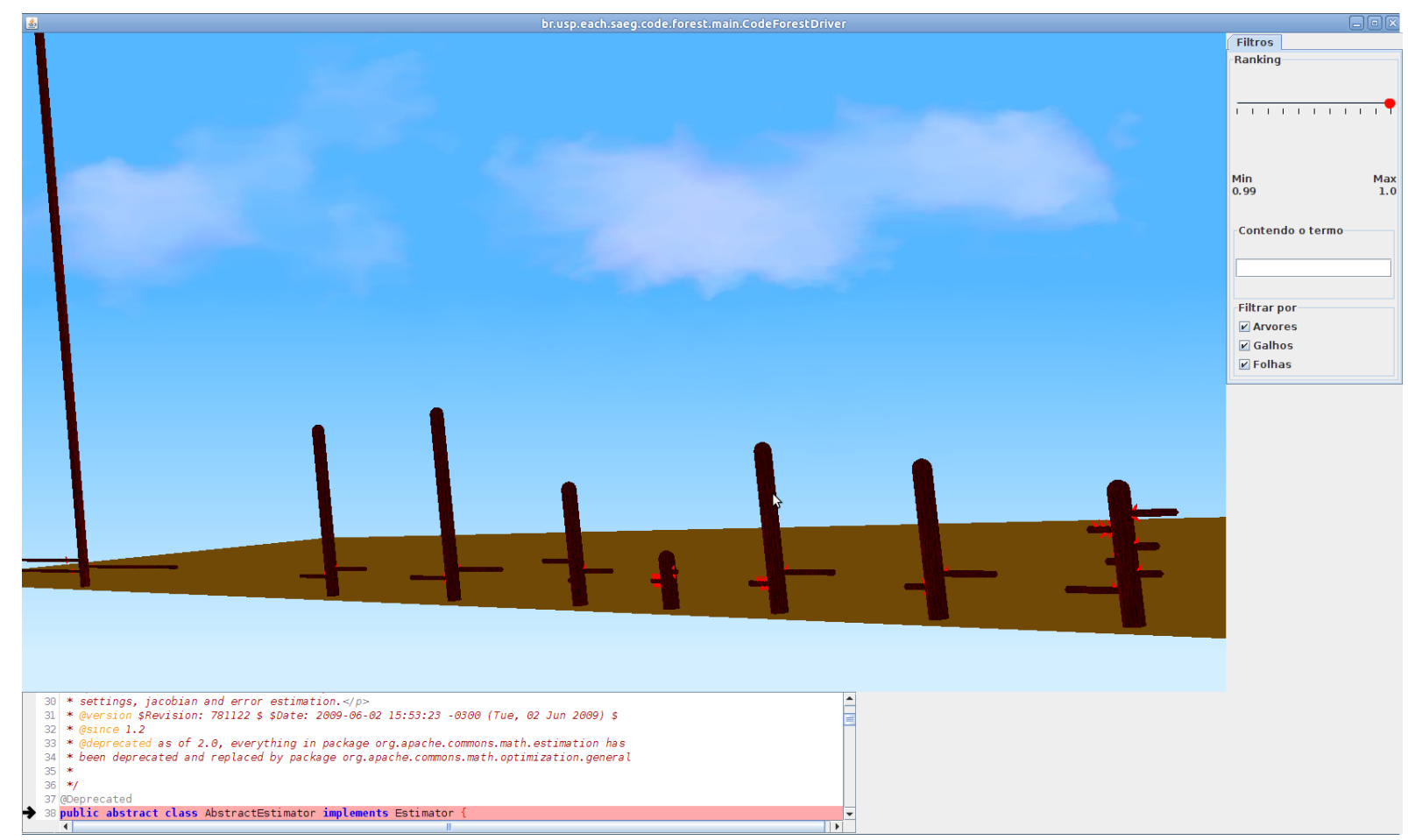

Figura 4.9-CodeForest com filtro trimmer em 0,99 para o defeito $A E_{-} A K_{-} 1$ do Commons-Math.

selecionado e as folhas que contenham o nome do método procurado e o valor de suspeição determinado, conforme mostrado na Figura 4.10.

A Figura 4.11 mostra a árvore que contém o galho defeituoso e as folhas que contém o valor de suspeição selecionado. Dessa forma, considerando o uso de R-MCP com a lista LSN, o programador precisa clicar no máximo em 7 folhas para chegar ao defeito. Seguindo a ordenação sugerida pela CodeForest, que é baseada na hierarquia de código da DCI, ou seja, R-MCP com HC, o programador necessita clicar apenas na primeira folha do galho para chegar ao nó defeituoso.

\subsubsection{Usando R-MCT com o valor de suspeição delta}

Devido à existência de requisitos de unidade com diferentes valores dentro de um método, foi adotado um valor de suspeição variável para o roteiro de busca por métodos, chamado valor de suspeição delta. A ideia é possibilitar a localização de requisitos de unidade que tenham valor de suspeição inferior ao valor do método ao qual pertencem.

Este exemplo serve para mostrar o uso do valor de suspeição delta. O defeito PJH_AK_1, mostrado na Figura 4.12, está na versão 1 do programa Ant (DO et al., 2005), que será apresentado no Capítulo 5. Após a coleta das coberturas e geração das listas de sus- 


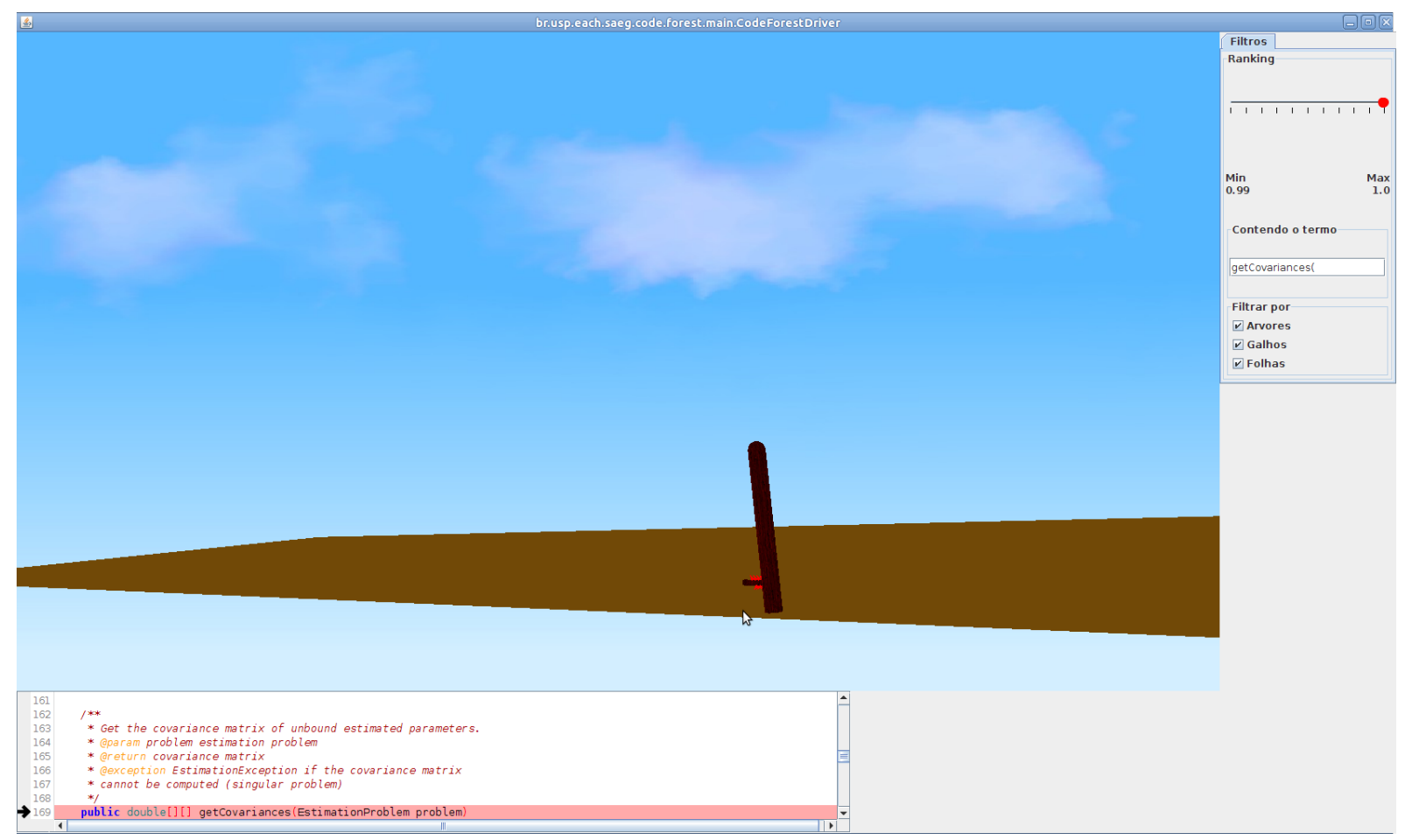

Figura 4.10 - CodeForest com filtro de busca contendo o termo "getCovariances(" para $o$ defeito AE_AK_1 do Commons-Math.

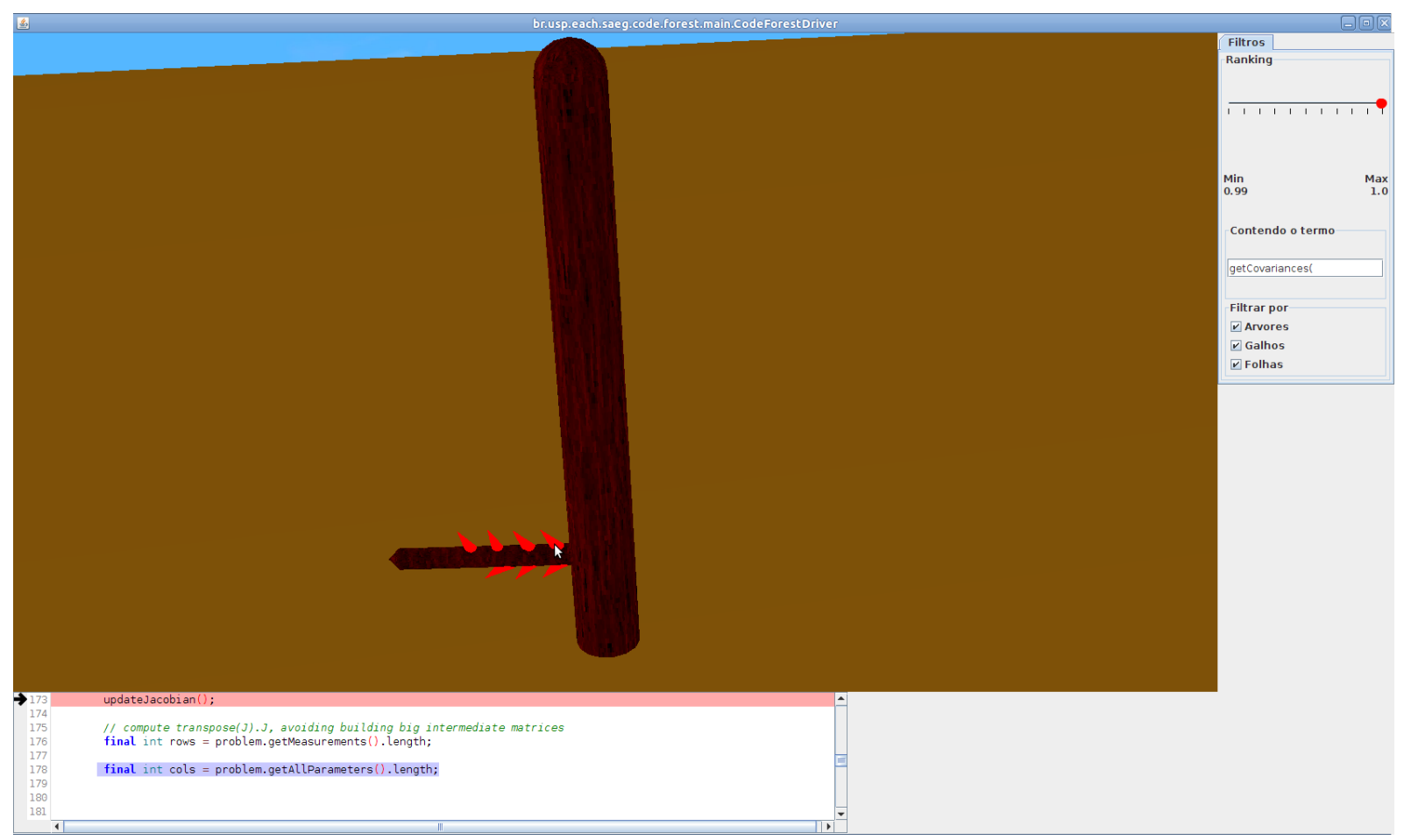

Figura 4.11 - Detalhe da árvore que contém o defeito AE_AK_1 do Commons-Math. 


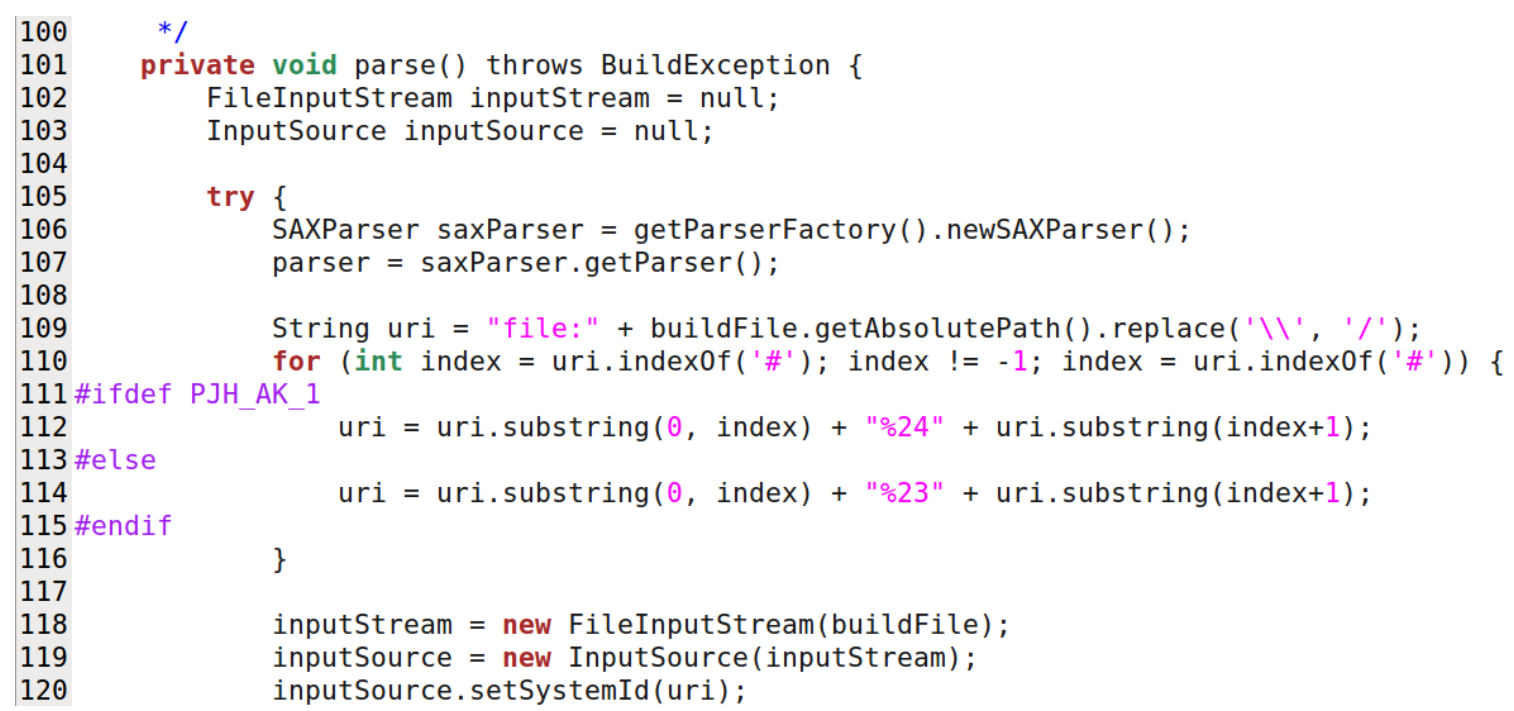

Figura 4.12 - Trecho de código que insere o defeito PJH_AK_1 do Ant.

peição, a floresta gerada para esse defeito é mostrada na Figura 4.13. Usando R-MCT, pode-se ver na Figura 4.14 que o método defeituoso, chamado parse, pertencente à classe ProjectHelper, foi classificado na quinta posição do roteiro, com valor de suspeição 1.0.

Buscando pelo defeito nos quatro métodos acima de parse não foi necessário realizar nenhum clique. Ao serem examinados na CodeForest, esses métodos não retornaram nenhuma árvore, de forma que foram desconsiderados para a quantidade de métodos percorridos até a localização do defeito. Ao pesquisar pelo método parse no filtro de busca por termo mantendo o valor de suspeição do trimmer em 1.0, a floresta mostra uma única árvore com um galho e três folhas, como pode ser visto na Figura 4.15.

Embora o galho retornado represente o método defeituoso, nenhuma das três folhas presentes refere-se ao nó que contém o defeito. Assim, foram necessários realizar três cliques sem que o defeito fosse localizado. O programador pode continuar procurando pelo defeito usando o roteiro de busca, mas não irá localizá-lo porque o método que contém o defeito já foi examinado.

Essa situação ocorre porque o valor de suspeição do nó defeituoso é 0,9857 , obtido da lista ordenada por hierarquia de código. Dessa forma, o defeito não é localizado utilizando o roteiro porque o valor de suspeição do método defeituoso é maior que o valor de suspeição do nó defeituoso. Durante os experimentos, observou-se a ocorrência de outros casos como este. Dessa forma, foi proposto o uso de um valor de suspeição delta, definido como uma faixa de $97 \%$ a $100 \%$ do valor de suspeição de cada método do roteiro de busca. Esse valor é definido na Equação 4.1. 


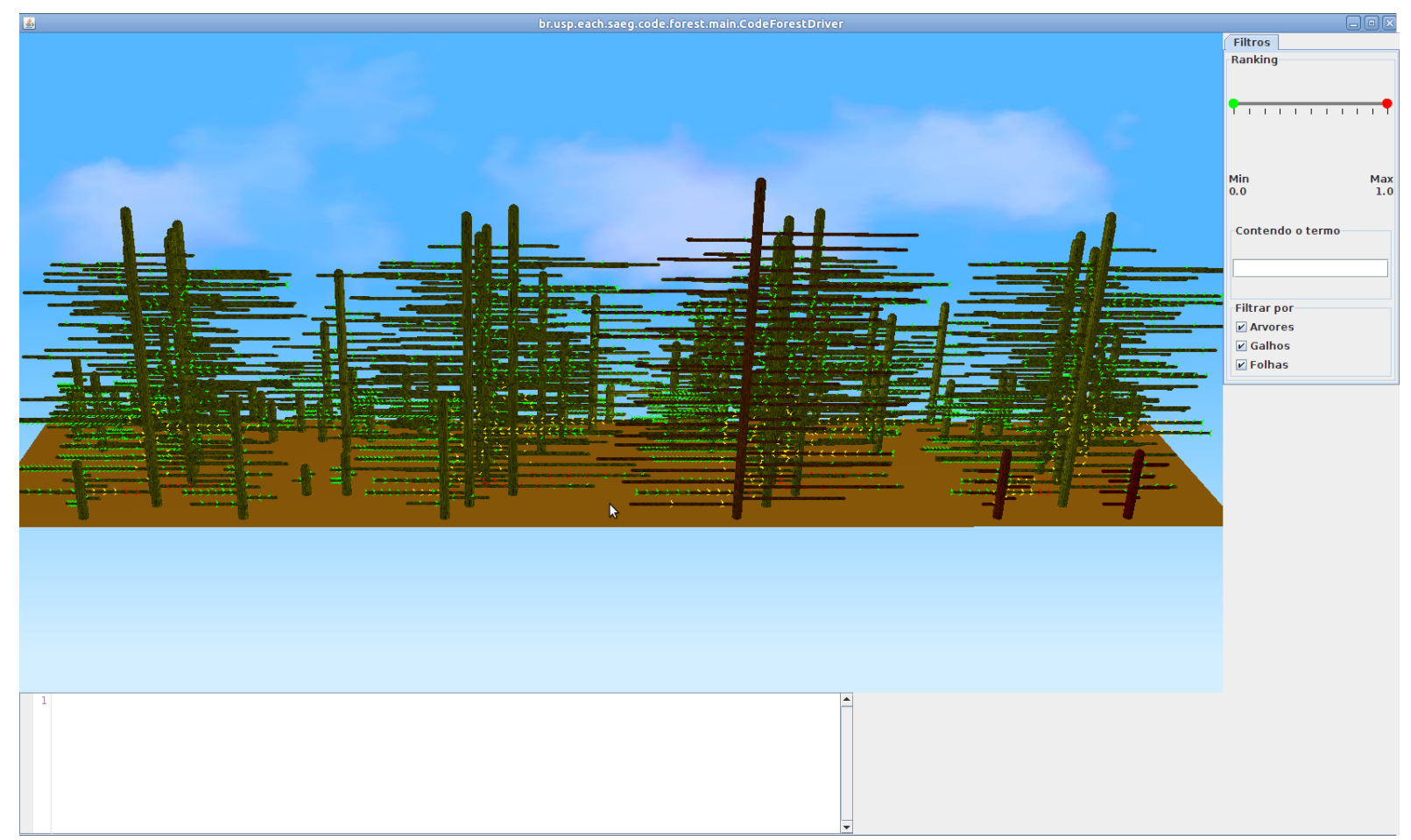

Figura 4.13 - Visão geral da CodeForest gerada para o defeito PJH_AK_1 do Ant.

\begin{tabular}{|c|c|}
\hline R-MCT & suspeição \\
\hline fireMessageLogged( & 1,0 \\
\hline fireMessageLoggedEvent( & 1,0 \\
\hline getMessage( & 1,0 \\
\hline configureProject( & 1,0 \\
\hline parse( & 1,0 \\
\hline BuildException( & 1,0 \\
\hline resolveEntity( & 0,9718309859 \\
\hline $\log ($ & 0,9718309859 \\
\hline access $\$ 300($ & 0,9718309859 \\
\hline access $\$ 400$ ( & 0,9718309859 \\
\hline setAttribute( & 0,9583333333 \\
\hline set( & 0,9583333333 \\
\hline setMessage( & 0,9583333333 \\
\hline runTarget( & 0,9517241379 \\
\hline execute( & 0,9517241379 \\
\hline init( & 0,9517241379 \\
\hline
\end{tabular}

Figura 4.14 - R-MCT para o defeito PJH_AK_1 do Ant. 


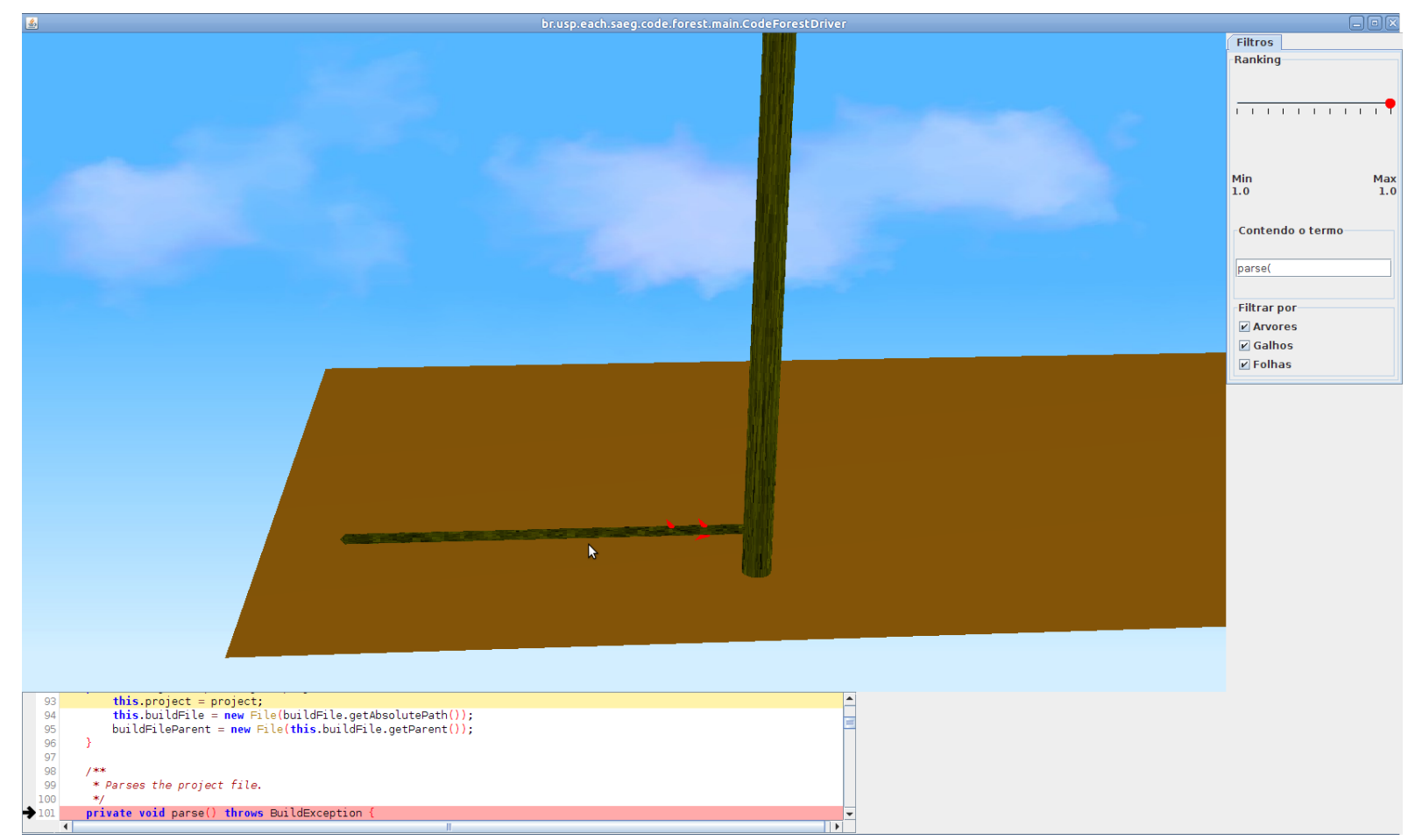

Figura 4.15 - CodeForest com filtro trimmer em 1 e com o termo "parse(" para o defeito PJH_AK_1 do Ant.

$\operatorname{suspeição~} \operatorname{delta}(x)=\operatorname{suspeição~do~método~} * 0,97 \leq x \leq$ suspeição do método

Usando o valor de suspeição delta, os métodos do roteiro de busca possuem uma variação de valores de suspeição entre em $97 \%$ e 100\% do valor original, como mostrado na Figura 4.16. O valor de suspeição delta foi definido arbitrariamente, com base em observações realizadas durante a fase preliminar dos experimentos. Ao procurar o defeito, usa-se agora o valor delta (97\%) para o valor mínimo no filtro trimmer e mantém-se o valor máximo do trimmer no valor de suspeição original (100\%). Os quatro métodos classificados acima do método defeituoso continuam retornando a floresta vazia, não sendo necessário realizar nenhum clique.

Ao buscar pelo método defeituoso, a floresta retorna apenas uma árvore e um galho, como ocorria antes sem o uso do valor delta. No entanto, agora o galho contém quatro folhas, uma a mais do que sem o uso do delta, conforme mostrado na Figura 4.17. Essa folha contém o nó defeituoso, que está dentro do valor delta, entre 0,97 e 1,0. Assim, são necessários quatro cliques para chegar ao defeito usando o valor de suspeição delta. 


\begin{tabular}{ll} 
R-MCT & suspeição delta \\
fireMessageLogged( & $0.97-1.0$ \\
\hline fireMessageLoggedEvent( & $0.97-1.0$ \\
\hline getMessage( & $0.97-1.0$ \\
\hline configureProject( & $0.97-1.0$ \\
\hline parse( & $0.97-1.0$ \\
\hline BuildException( & $0.97-1.0$ \\
\hline resolveEntity( & $0.9426-0.9718$ \\
\hline log( & $0.9426-0.9718$ \\
\hline access $\$ 300($ & $0.9426-0.9718$ \\
\hline access $\$ 400($ & $0.9426-0.9718$ \\
\hline setAttribute( & $0.9296-0.9583$ \\
\hline set( & $0.9296-0.9583$ \\
\hline setMessage( & $0.9296-0.9583$ \\
\hline runTarget( & $0.9232-0.9517$ \\
\hline execute ( & $0.9232-0.9517$ \\
init( & $0.9232-0.9517$
\end{tabular}

Figura 4.16 - R-MCT para o defeito PJH_AK_1 do Ant com uso do valor de suspeição delta.

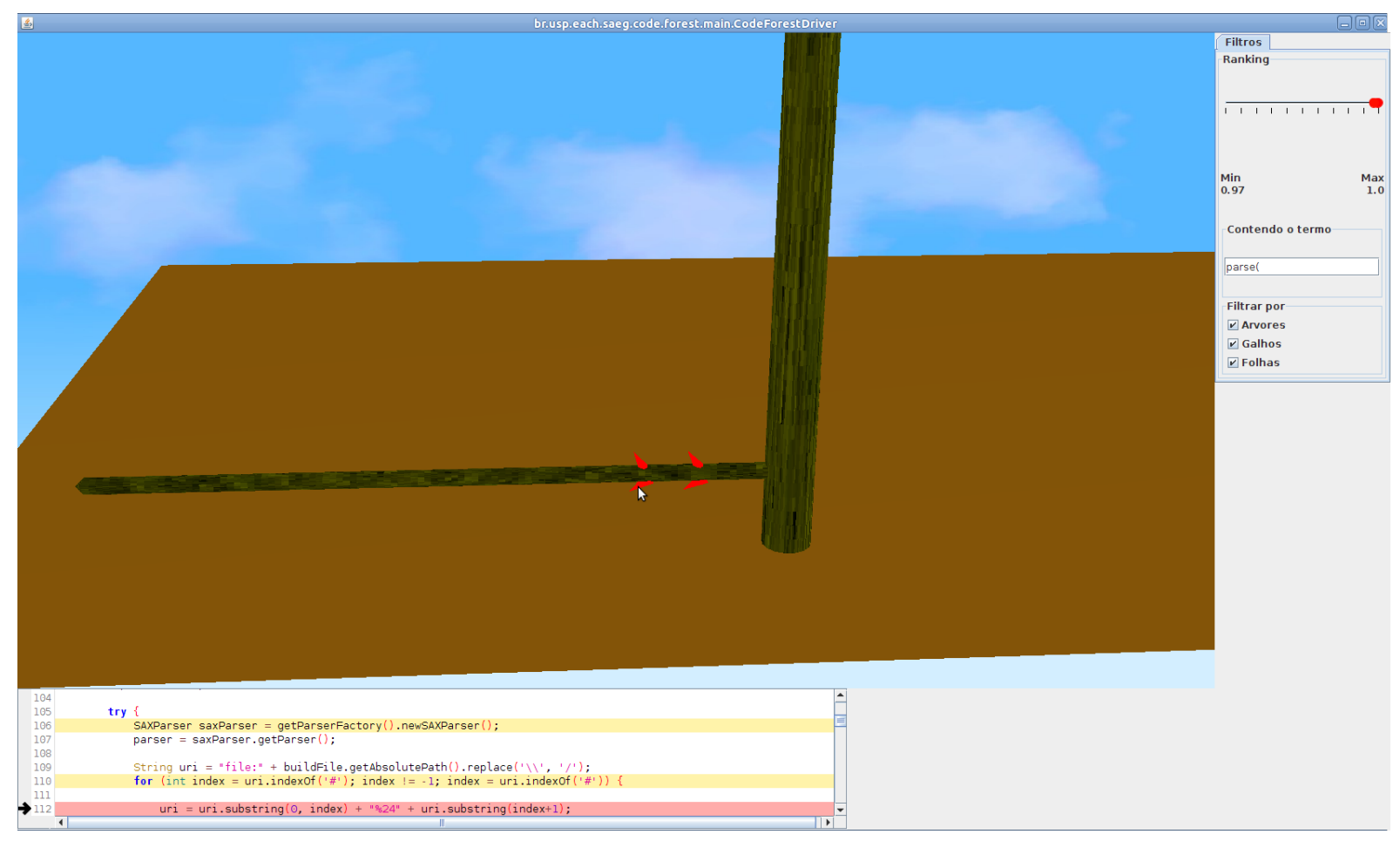

Figura 4.17 - CodeForest com filtro trimmer em 0,97 e com o termo "parse(" para o defeito PJH_AK_1 do Ant. 


\subsubsection{Usando a LSN e HC}

Para este exemplo foi utilizado o defeito CB_HD_3, visto na Figura 4.18. O defeito pertence ao programa XML-security (DO et al., 2005), que será comentado no Capítulo 5. O defeito pertence ao método outputPItoWriter da classe CanonicalizerBase.

A lista de Nós ordenada por valor de suspeição será usada para localizar o defeito. A Figura 4.19 mostra um trecho da LSN que contém o nó defeituoso. As colunas da lista indicam, respectivamente, o nome da classe, o identificador do método, o nome do método, a linha de início do nó, o valor de suspeição e a posição de classificação na lista. O nó defeituoso inicia na linha 613 e vai até a linha 618 da classe e foi classificado na posição 24 da lista de Nós. Portanto, usando LSN para procurar pelo defeito sem a CodeForest, o programador inspeciona 24 nós para localizar o defeito.

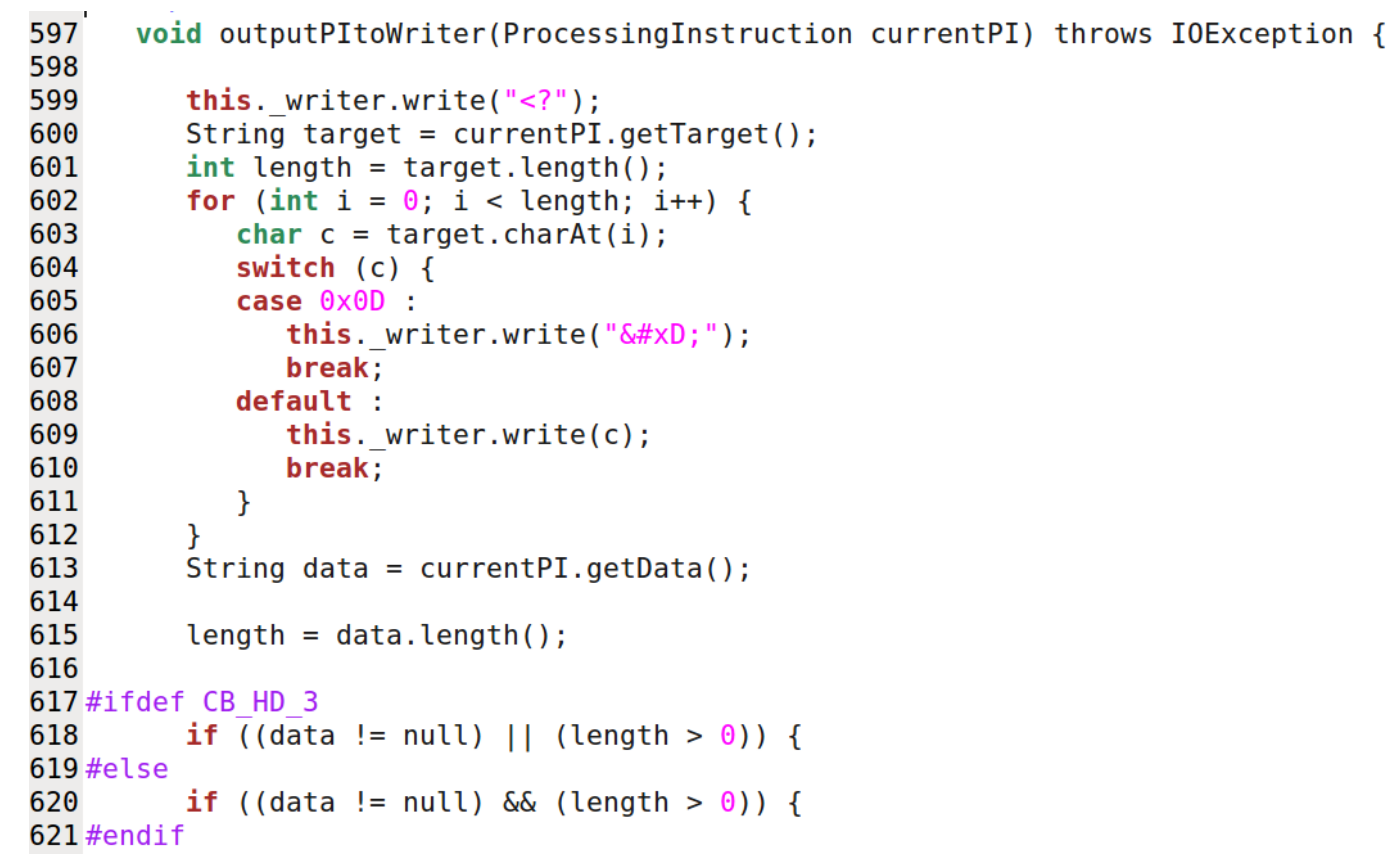

Figura 4.18 - Trecho de código que insere o defeito $C B_{-} H D_{-} 3$ do XML-security.

A Figura 4.20 mostra uma visão geral da CodeForest para esse defeito. Com a CodeForest, o programador pode selecionar o trimmer com o valor máximo de suspeição 1. A floresta é reduzida como visto na Figura 4.21.

Mesmo havendo uma grande redução na quantidade de árvores e galhos, a quantidade de Nós presente na floresta da Figura 4.21 é de 29 folhas, o que significa que o programador pode ter que examinar essas 29 folhas até chegar ao defeito.

Utilizando HC, o programador examina a floresta seguindo a ordem sugerida pela CodeForest, e precisa efetuar 16 cliques até localizar o defeito. A Figura 4.22 mostra uma 
imagem aproximada do local que contém a folha defeituosa, circulada em azul. Para esse defeito, o uso de HC reduz a quantidade de cliques necessários para localizar o defeito de 29 para 16 na CodeForest.

\begin{tabular}{|c|c|c|c|c|}
\hline & método & linha & \multicolumn{2}{|c|}{ suspeição posição } \\
\hline CanonicalizerBase & 2canonicalizeSubTree(Node) & 212 & 1,0 & 7 \\
\hline CanonicalizerBase & 6canonicalizeXPathNodeSet(Node) & 444 & 1,0 & 8 \\
\hline CanonicalizerBase & 6canonicalizeXPathNodeSet(Node) & 445 & 1,0 & 0 \\
\hline CanonicalizerBase & 6canonicalizeXPathNodeSet(Node) & 448 & 1,0 & 10 \\
\hline CanonicalizerBase & 6canonicalizeXPathNodeSet(Node) & 451 & 1,0 & 11 \\
\hline CanonicalizerBase & 6canonicalizeXPathNodeSet(Node) & 454 & 1,0 & 12 \\
\hline CanonicalizerBase & 8outputPItoWriter(ProcessingInstruction) & 593 & 1,0 & 13 \\
\hline CanonicalizerBase & 8outputPItoWriter(ProcessingInstruction) & 622 & 1,0 & 14 \\
\hline CanonicalizerBase & 8outputPItoWriter(ProcessingInstruction) & 624 & 1,0 & 15 \\
\hline CanonicalizerBase & 8outputPItoWriter(ProcessingInstruction) & 625 & 1,0 & 16 \\
\hline CanonicalizerBase & 8outputPItoWriter(ProcessingInstruction) & 634 & 1,0 & 17 \\
\hline CanonicalizerBase & 8outputPItoWriter(ProcessingInstruction) & 624 & 1,0 & 18 \\
\hline CanonicalizerBase & 8outputPItoWriter(ProcessingInstruction) & 640 & 1,0 & 19 \\
\hline CanonicalizerBase & 8outputPItoWriter(ProcessingInstruction) & 598 & 1,0 & 20 \\
\hline CanonicalizerBase & 8outputPItoWriter(ProcessingInstruction) & 599 & 1,0 & 21 \\
\hline CanonicalizerBase & 8outputPItoWriter(ProcessingInstruction) & 608 & 1,0 & 22 \\
\hline CanonicalizerBase & 8outputPItoWriter(ProcessingInstruction) & 598 & 1,0 & 2 \\
\hline CanonicalizerBase & 8outputPItoWriter(ProcessingInstruction) & 613 & 1,0 & 2 \\
\hline Manifest & 9verifyReferences(boolean) & 359 & 1,0 & 25 \\
\hline Reference & 27 verify() & 840 & 1,0 & 26 \\
\hline
\end{tabular}

Figura 4.19 - LSN para o defeito $C B_{-} H_{-} 3$ do XML-security.

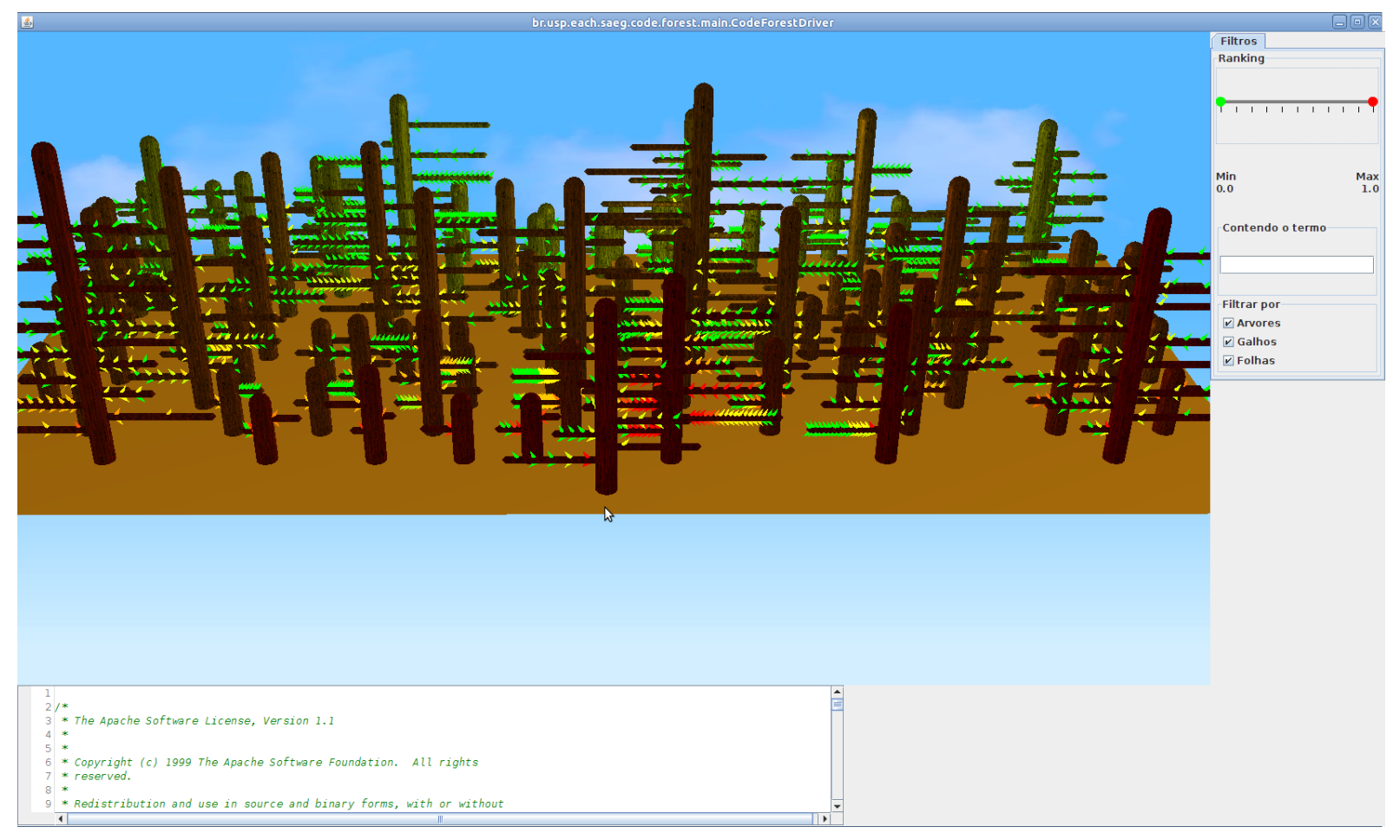

Figura 4.20 - Visão geral da CodeForest gerada para o defeito CB_HD_3 do XMLsecurity. 


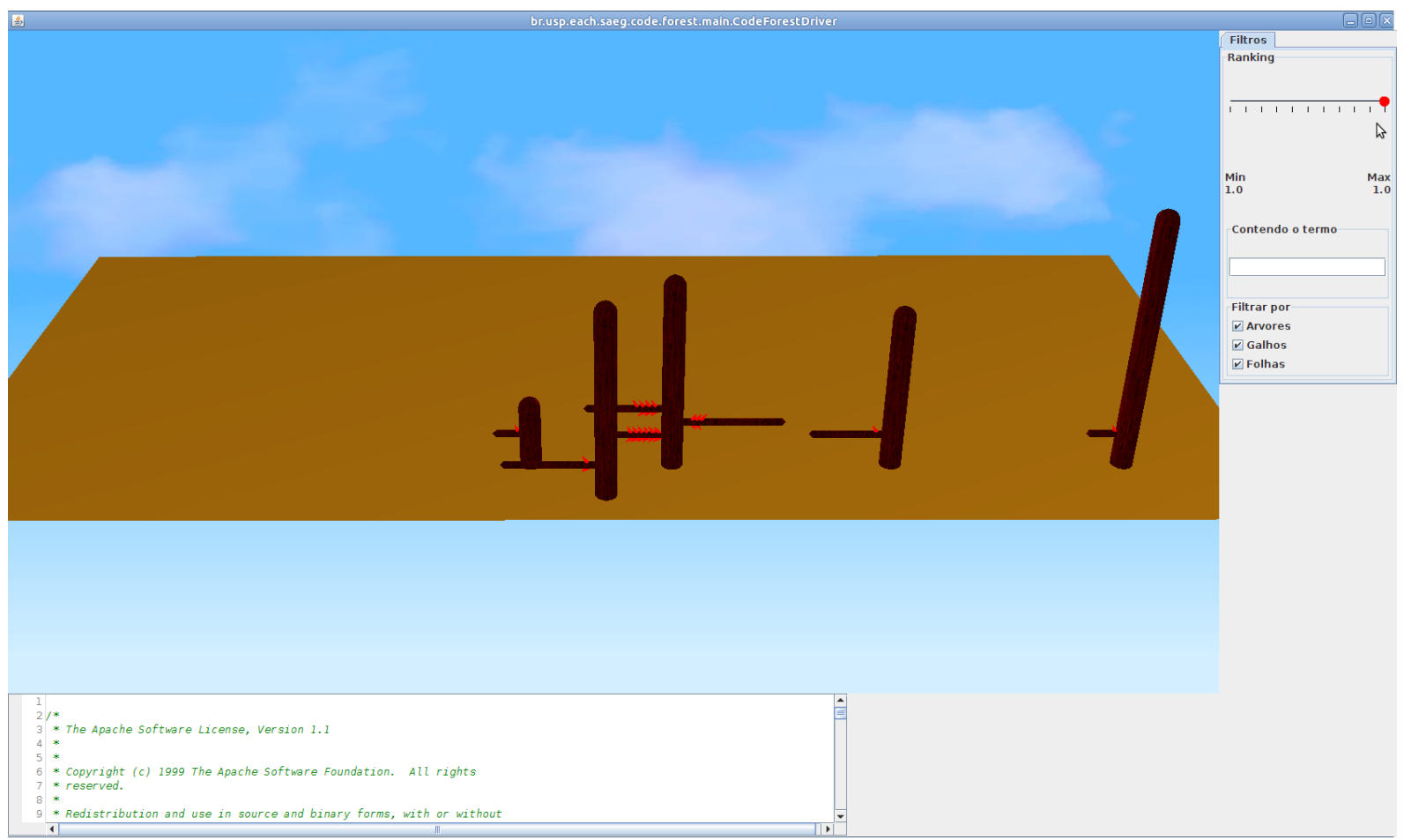

Figura 4.21 - CodeForest com filtro trimmer em 1 para o defeito CB_HD_3 do XMLsecurity.

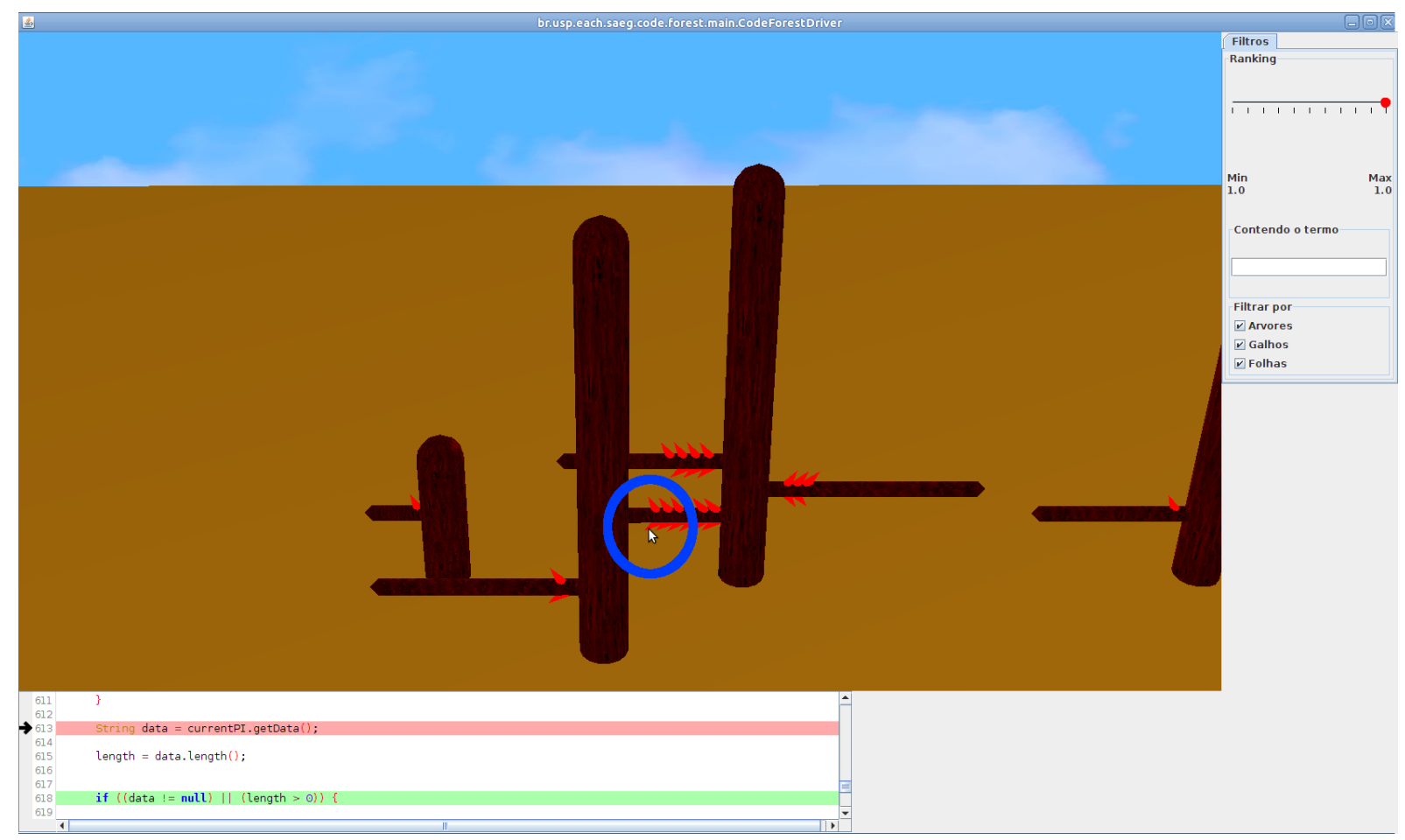

Figura 4.22 - Detalhe do defeito CB_HD_3 do XML-security localizado na CodeForest. 


\subsection{Considerações finais}

Neste capítulo foi apresentada a técnica Depuração de programas baseada em Cobertura de Integração, desenvolvida durante este trabalho. Foram também descritas as etapas de funcionamento da DCI, suas diferentes possibilidades de uso, os componentes desenvolvidos e as ferramentas utilizadas para o funcionamento da técnica.

A DCI fornece informações para a localização de defeitos baseada na lista de suspeição de Nós (LSN). Fornece também a classificação por hierarquia de código (HC), que é baseada em informações de integração estática do código. HC pode acrescentar contexto à busca, indicando quais são os pacotes, classes e métodos que contém mais nós suspeitos ao invés de simplesmente indicar quais são esses nós organizados por ordem de suspeição. Com HC pode-se reduzir a quantidade de nós a serem verificados para localizar o defeito.

As coberturas MCP e MCT podem colaborar para a tarefa de localização de defeitos acrescentando informações dinâmicas de integração sobre o código por meio da indicação de pares e triplas de chamadas de método mais suspeitos de conter o defeito. O uso do roteiro de busca, construído a partir das listas de suspeição de MCP e MCT, também pode reduzir a quantidade de código a ser verificado, servindo como um guia para a procura por defeitos baseado nos métodos que possuem maiores valores de suspeição.

O uso do roteiro de busca em conjunto com as informações sobre os nós mais suspeitos podem ajudar a refinar os resultados obtidos, permitindo investigar os nós pertencentes a cada método. R-MCP e R-MCT podem se beneficiar da ordenação sugerida pela classificação HC ou então utilizar a classificação LSN. O roteiro de busca pode ainda utilizar o valor de suspeição delta para melhorar a localização dos requisitos de unidade, permitindo que requisitos com valores de suspeição próximos aos valores dos métodos apontados pelo roteiro sejam localizados. No capítulo seguinte, são detalhados os experimentos realizados para avaliar e validar a técnica proposta. 


\section{Avaliação experimental}

\subsection{Considerações iniciais}

Este capítulo apresenta os experimentos realizados para avaliação e validação da técnica DCI. O objetivo é verificar se o uso da DCI traz melhorias para a eficácia de localização de defeitos nos programas avaliados, comparando os resultados obtidos entre as coberturas MCP, MCT e Nós com o uso dos roteiros R-MCP e R-MCT e a lista LSN. A eficácia de localização usando a classificação baseada na organização por hierarquia de código também é avaliada.

A Seção 5.2 explica os critérios para elaboração, condução e validação dos experimentos. Na Seção 5.3 são apresentados os programas escolhidos para a realização dos experimentos e suas principais características. A Seção 5.4 descreve o processo de inclusão de defeitos, instrumentação dos programas e geração das listas de suspeição com a DCI, enquanto a Seção 5.5 detalha a condução dos experimentos. Os resultados obtidos são apresentados na Seção 5.6. Na Seção 5.7 os resultados são sumarizados para comparar as abordagens. A Seção 5.8 detalha os procedimentos estatísticos utilizados para avaliar as hipóteses geradas para validação da técnica DCI. A Seção 5.9 apresenta a discussão dos resultados obtidos e a Seção 5.10 traz as ameaças à validade identificadas.

\subsection{Desenho experimental}

Para avaliar o desempenho da técnica DCI, são descritas as características dos experimentos realizados para responder às seguintes questões de pesquisa:

1. DCI é mais eficaz para a localização de defeitos do que a cobertura de unidade?

2. DCI é mais eficaz para a localização de defeitos de integração do que a cobertura de unidade? 
3. O uso do roteiro de busca por métodos pode tornar a localização de defeitos mais eficaz?

4. O acréscimo de informações estáticas de integração sobre os requisitos de unidade pode tornar a localização de defeitos mais eficaz?

5. A técnica DCI é eficaz para localizar defeitos em programas reais?

6. O uso do valor de suspeição delta melhora a localização de defeitos?

\subsubsection{Variáveis}

As variáveis independentes e dependentes relacionadas com as questões de pesquisa são apresentadas a seguir.

\section{Variáveis independentes}

Roteiros de busca: os roteiros de busca R-MCP e R-MCT, assim como a lista LSN, são utilizados para examinar o código em busca dos defeitos. Quando necessário, a busca pode ser feita usando do valor de suspeição delta.

Programas: cada programa possui características próprias, como quantidade de defeitos, quantidade de linhas de código e número de casos de teste. Os programas usados são descritos na Seção 5.3.

Defeitos: foram avaliados os defeitos que apresentaram falhas durante a execução dos testes nos programas utilizados. Os defeitos foram executados separadamente, criando-se uma versão defeituosa do programa para cada defeito a ser experimentado. Tais defeitos podem apresentar características diversas como, por exemplo, alterar o fluxo de execução do programa ou então atribuir um valor incorreto em uma chamada de método.

Heurísticas: cada heurística possui um modo diferente de calcular a suspeição dos requisitos, podendo classificá-los em posições diferentes em relação a outros requisitos. Os experimentos foram executados usando a heurística Tarantula.

Tipo de defeito: os defeitos existentes podem causar erros de integração de acordo com os critérios definidos por Delamaro et al. (2001). Os demais defeitos foram considerados como sendo de unidade. 
Ordem de classificação dos requisitos: o modo como os requisitos são ordenados na lista de classificação também pode influenciar a busca pelo defeito, indicando quais requisitos podem ser examinados primeiro. A busca pelos defeitos são feitas com e sem o uso de HC, em que o uso de HC representa a ordenação sugerida pela CodeForest. A busca sem o uso de HC significa que a investigação pela floresta é feita aleatoriamente.

\section{Variáveis dependentes}

Cliques: representa a quantidade de nós que precisam ser verificados até atingir o nó defeituoso.

$\boldsymbol{E X} \boldsymbol{A} \boldsymbol{M}$ score: percentual de esforço necessário de nós que precisam ser verificados até chegar ao nó defeituoso.

\subsubsection{Heurísticas}

Das heurísticas implementadas na DCI, utilizou-se a heurística Tarantula. A Tarantula foi escolhida por ser a heurística mais utilizada para experimentos em diversos trabalhos de localização de defeitos.

\subsubsection{Defeitos de integração}

Neste trabalho, considera-se como defeitos de integração os defeitos que causam erros de integração, conforme definido por Delamaro et al. (2001) e apresentado na Tabela 2.3 do Capítulo 2, página 20. Cada defeito usado nos experimentos foi avaliado para identificar se manifestam um erro de integração. Os defeitos que podem ou não manifestar um erro de integração foram considerados como sendo de integração. Assim, os defeitos existentes foram separados em dois grupos: defeitos de integração ou defeitos de unidade.

\subsubsection{Métricas}

A seguir são apresentadas as métricas utilizadas para avaliar a eficácia de localização do experimento. 


\section{Cliques}

Para avaliação da técnica DCI, foi proposta a métrica de quantidade de cliques para localizar o defeito usando a CodeForest. Cada clique significa que um nó é examinado na busca pelo defeito. Os experimentos foram feitos para avaliar o uso das abordagens de integração estática e dinâmica que compõem a DCI.

Para a abordagem estátisca de integração, comparou-se a quantidade de cliques necessária para localizar o defeito usando a hierarquia de código, que foi nomeada como $C H C$, com a quantidade de cliques usando a lista de suspeição de nós, nomeada como $C L$. O objetivo é avaliar se a hierarquia de código aumenta a eficácia de localização, possibilitando responder à questão de pesquisa 5 .

A métrica CL pode ser vista como a procura pelo defeito sem uso das informações de HC, ou seja, de forma aleatória entre os comandos de mesmo nível de suspeição, na qual o defeito pode ser localizado tanto no primeiro quanto no último clique. Já a métrica CHC segue a organização sugerida pela CodeForest, obtida da ordenação por hierarquia de código.

Os roteiros de busca de métodos R-MCP e R-MCT utilizam a lista de suspeição de Nós para procurar pelo defeito dentro dos métodos. A eficácia de localização de R-MCP e R-MCT é comparada com os valores de suspeição da lista de Nós isoladamente.

A vantagem de avaliar a localização usando a métrica de cliques é a possibilidade de mensurar a quantidade absoluta de esforço, o que permite estabelecer uma quantidade fixa de requisitos a serem examinados independentemente da quantidade de código existente no programa avaliado. Um estudo feito por Parnin e Orso (2011) sobre o uso de uma ferramenta de depuração com programadores indica que diversos deles deixaram de usar a ferramenta ao perceberem que havia uma grande quantidade de falsos positivos (comandos não defeituosos) na lista de comandos suspeitos.

\section{Posição média}

A métrica EXAM score é mais usada pelos trabalhos que lidam com depuração automatizada (JONES et al., 2007; MASRI et al., 2009; SANTELICES et al., 2009). EXAM score é conhecida também como esforço de localização e indica a porcentagem de código que precisa ser verificada até chegar ao comando defeituoso. O valor é obtido dividindo a posição na qual o comando defeituoso é classificado pelo total de comandos da lista de suspeição. 
Para possibilitar uma comparação entre a métrica de cliques, proposta neste trabalho, com a métrica EXAM score, são utilizados, ao invés da porcentagem obtida em EXAM score, a posição média em que o comando retornou na lista ordenada por ordem de suspeição da cobertura de Nós. Dessa forma, pode-se comparar diretamente a quantidade de código a ser examinada usando um valor absoluto. Por exemplo, se o requisito defeituoso tem valor de suspeição 1 e foi classificado na posição 20 da lista, considerando que os requisitos de 1 a 30 tenham valor de suspeição 1, a posição média do comando defeituoso é igual 15 .

A escolha pela posição média deve-se ao fato de que o requisito defeituoso pode estar na primeira ou na última posição de classificação para um determinado valor de suspeição. Os requisitos com mesmo valor de suspeição são ordenados por ordem alfabética. Com o uso da posição média tenta-se diminuir a influência dessa ordenação alfabética sobre a posição dos comandos com mesmo valor de suspeição.

\section{Critérios de parada}

Foram estabelecidos dois critérios de parada para medir a eficácia de localização de defeito. Considerando a quantidade de cliques, o esforço máximo de localização estabelecido foi de 70 cliques, para R-MCP R-MCT e LSN. A quantidade máxima de métodos a serem examinados usando os roteiros de busca de R-MCP e R-MCT foi definida em 20 métodos.

A ideia é atribuir ao programador um "orçamento" para localizar o defeito, independente da quantidade de requisitos retornados na lista. Dessa forma, pretende-se que a tarefa de depuração seja realizada mantendo o interesse do programador.

Para o critério de 20 métodos, são considerados apenas os métodos que retornam pelo menos um nó quando pesquisados na CodeForest. Caso a busca pelo nó defeituoso ultrapasse a quantidade definida para a técnica usada, o defeito será considerado como tendo ultrapassado o limite (LT) ou então não localizado (NL). A diferença entre $N L$ e $L T$ é que em $N L$ o defeito pode não ter sido localizado mesmo sem atingir os limites máximos estabelecidos porque o requisito defeituoso não está presente entre as folhas retornadas na floresta para determinados valores utilizados nos filtros. Para os casos em que for utilizado o valor de suspeição delta, os critérios de parada continuam sendo os mesmos. 


\section{Tratamentos}

Os experimentos realizados consideram a localização de defeitos usando os roteiros de busca R-MCP e R-MCT, a lista LSN. Para cada um desses roteiros, pode-se usar HC através da métrica CHC ou então a métrica CL. Além disso, quando o defeito não for localizado utilizando o valor de suspeição, utiliza-se o valor de suspeição delta. A Tabela 5.1 mostra as possíveis combinações usadas para os experimentos.

Tabela 5.1 - Tratamentos usados nos experimentos.

\begin{tabular}{|c|c|c|c|}
\hline \multirow{2}{*}{ Roteiro } & \multirow{2}{*}{ Suspeição } & \multicolumn{2}{|c|}{ Métrica } \\
\cline { 3 - 4 } & & CHC & CL \\
\hline \multirow{2}{*}{ R-MCP } & Sem Delta & R-MCP + CHC & R-MCP + CL \\
\cline { 2 - 4 } & Com Delta & R-MCP + CHC + Delta & R-MCP + CL + Delta \\
\hline \multirow{2}{*}{ R-MCT } & Sem Delta & R-MCT + CHC & R-MCT + CL \\
\cline { 2 - 4 } & Com Delta & R-MCT + CHC + Delta & R-MCT + CL + Delta \\
\hline \multirow{2}{*}{ LSN } & Sem Delta & LSN + CHC & LSN + CL \\
\cline { 2 - 4 } & Com Delta & LSN + CHC + Delta & LSN + CL + Delta \\
\hline
\end{tabular}

\subsection{Programas}

Foram selecionados quatro programas para a realização dos experimentos, de acordo com os seguintes critérios: programas de código aberto, escritos em linguagem Java; programas reais, ou seja, programas que sejam utilizados para realizar atividades em situações reais, e não apenas para realizar experimentos científicos; programas contendo uma quantidade mínima de 5000 linhas de código; programas contendo casos de teste JUnit; programas contendo defeitos que causam erros de integração.

Seguindo esses critérios, foram selecionados os programas Ant, Commons-Math, JTopas e XML-security. A única exceção aos critérios adotados é o programa JTopas, cujas versões 1 e 2 têm aproximadamente 2.000 linhas de código cada. Os programas Ant, JTopas e XML-Security foram retirados do repositório SIR (DO et al., 2005), que possui diversos programas contendo defeitos em uma estrutura preparada para a realização de experimentos. Esses três programas retirados do SIR contêm defeitos semeados.

O programa Ant é um construtor de aplicações utilizado por programadores da linguagem Java e possui defeitos em oito versões diferentes no repositório SIR. O programa Commons-Math reúne diversas funcionalidades para realizar cálculos de problemas comuns em matemática e estatística. O Commons-Math foi obtido do repositório $S V N$ do projeto do programa (COMMONS-MATH, 2012). O programa contém defeitos reais, que 
foram identificados por um estagiário do Núcleo de Apoio à Pesquisa em Software Livre (NAPSOL) (NAPSOL, 2012). O programa foi estruturado de forma semelhante aos programas existentes no SIR, contendo três versões diferentes.

O programa JTopas é um analisador de texto usado para verificar a estrutura de arquivos em formatos como HTML e XML. Foram usados defeitos das três versões disponíveis no SIR. O XML-security implementa assinaturas digitais e criptografia para o formato XML, contendo três versões com defeitos.

A Tabela 5.2 apresenta a descrição dos programas utilizados. A coluna Qtde. Defeitos traz o total de defeitos de cada programa utilizado nos experimentos. A coluna Defeito indica se os defeitos do programa são reais ou semeados.

Tabela 5.2 - Programas utilizados para os experimentos.

\begin{tabular}{|l||l|c|l|}
\hline Programa & Descrição & Qtde. Defeitos & Defeito \\
\hline Ant & Construtor de aplicações Java & 19 & Semeados \\
\hline Commons-Math & Biblioteca de funções matemáticas & 20 & Reais \\
\hline JTopas & Analisador de texto & 4 & Semeados \\
\hline XML-Security & Biblioteca de assinaturas digitais XML & 13 & Semeados \\
\hline
\end{tabular}

A Tabela 5.3 traz os detalhes das versões dos programas. A coluna Versão indica a versão utilizada do programa: o número fora dos parênteses representa a referência para cada versão criada para o repositório SIR e o valor entre parênteses indica a versão correspondente do programa. A coluna Linhas indica a quantidade de linhas de código do programa, excluindo-se as linhas em branco e os comentários. A contagem das linhas de código foi feita usando o programa cloc (DANIAL, 2012). A coluna Defeitos indica a quantidade de defeitos da versão que foi utilizadas nos testes. A coluna Casos de Teste indica a quantidade de métodos de teste usada em cada versão.

No programa Ant, por exemplo, o número de linhas de código varia entre 25.834 na primeira versão utilizada e 80.420 na oitava versão. A quantidade de métodos de teste também é crescente, variando de 141 na primeira versão para 851 na oitava. A quantidade de defeitos varia entre 1 e 4 dependendo da versão do Ant. Vale ressaltar que os programas Ant, JTopas e XML-security possuem uma quantidade de defeitos maior que descrita na Tabela 5.2. No entanto, foram utilizados nos experimentos apenas os defeitos que apresentaram falha em pelo menos um método de teste. 
Tabela 5.3 - Detalhes dos programas utilizados para os experimentos.

\begin{tabular}{|c||l|c|c|c|}
\hline Programa & Versão & Linhas & Defeitos & Casos de testes \\
\hline \multirow{5}{*}{ Ant } & $1(1.3)$ & 25834 & 2 & 141 \\
\cline { 2 - 5 } & $2(1.4)$ & 39719 & 2 & 150 \\
\cline { 2 - 5 } & $3(1.4 .1)$ & 39797 & 2 & 219 \\
\cline { 2 - 5 } & $4(1.5)$ & 61853 & 4 & 304 \\
\cline { 2 - 5 } & $5(1.5 .2)$ & 63846 & 4 & 535 \\
\cline { 2 - 5 } & $6(1.5 .3-1)$ & 63554 & 1 & 544 \\
\cline { 2 - 5 } & $7(1.6$ beta) & 80357 & 3 & 649 \\
\cline { 2 - 5 } & $8(1.6$ beta2) & 80420 & 1 & 851 \\
\hline \multirow{5}{*}{ Commons-Math } & $1(1.2)$ & 16485 & 5 & 1167 \\
\cline { 2 - 5 } & $2(2.0)$ & 38234 & 12 & 2003 \\
\cline { 2 - 5 } & $3(2.1)$ & 39991 & 3 & 2114 \\
\hline \multirow{5}{*}{ JTopas } & $1(0.4)$ & 1895 & 2 & 22 \\
\cline { 2 - 5 } & $2(0.5 .1)$ & 2087 & 1 & 31 \\
\cline { 2 - 5 } & $3(0.6)$ & 5428 & 1 & 31 \\
\hline \multirow{5}{*}{ Xml-Security } & $1(1.0 .4)$ & 18302 & 5 & 92 \\
\cline { 2 - 5 } & $2(1.0 .5 \mathrm{D} 2)$ & 18968 & 6 & 84 \\
\cline { 2 - 5 } & $3(1.0 .71)$ & 16861 & 2 & 94 \\
\hline
\end{tabular}

\subsection{Instrumentação dos experimentos}

Esta seção apresenta os recursos utilizados para a realização dos experimentos e os procedimentos para incluir um defeito, instrumentar o programa, coletar as informações de cobertura e gerar as listas de suspeição e os roteiros de busca.

Os experimentos foram conduzidos utilizando os computadores descritos na Tabela 5.4, que indica as configurações de hardware e software dos equipamentos. Atividades como a geração das versões defeituosas dos programas, o uso do InSS para coletar as coberturas e da DCI para gerar as listas de suspeição foram feitas usando os quatro computadores citados.

Tabela 5.4 - Computadores usados nos experimentos.

\begin{tabular}{|l|c|c|l|}
\hline Processador & Arquitetura & Memória & Sistema operacional \\
\hline Intel Core2Duo E8400 & 32 bits & 4 GB & Ubuntu 11.04 \\
\hline Intel Core2Duo T6400 & 64 bits & 4 GB & Ubuntu 10.04 \\
\hline Intel Core2Duo E5400 & $32 \mathrm{bits}$ & $2 \mathrm{~GB}$ & Debian GNU Linux 6.0.2 \\
\hline Intel Xeon E5310 & $32 \mathrm{bits}$ & $8 \mathrm{~GB}$ & Ubuntu 12.04 \\
\hline
\end{tabular}




\subsubsection{Incluindo o defeito no programa}

Para ilustrar as etapas de inclusão de um defeito até a geração das listas de suspeição e roteiros de busca, será usado o defeito AE_AK_1 do programa Commons-Math. O programa segue a estrutura de diretórios proposta por Do et al. (2005) do repositório SIR. O defeito é incluído no programa a partir de uma diretiva de compilação da linguagem $\mathrm{C}$ que substitui a linha correta pela linha defeituosa e gera o arquivo Java da respectiva classe.

A Figura 5.1 mostra o trecho de código que é alterado quando o defeito é incluído, com o conteúdo dentro da diretiva "\#ifdef $A E_{-} A K_{-} 1$ ”, na linha 178, que é o código defeituoso, substituindo o conteúdo da linha 180.

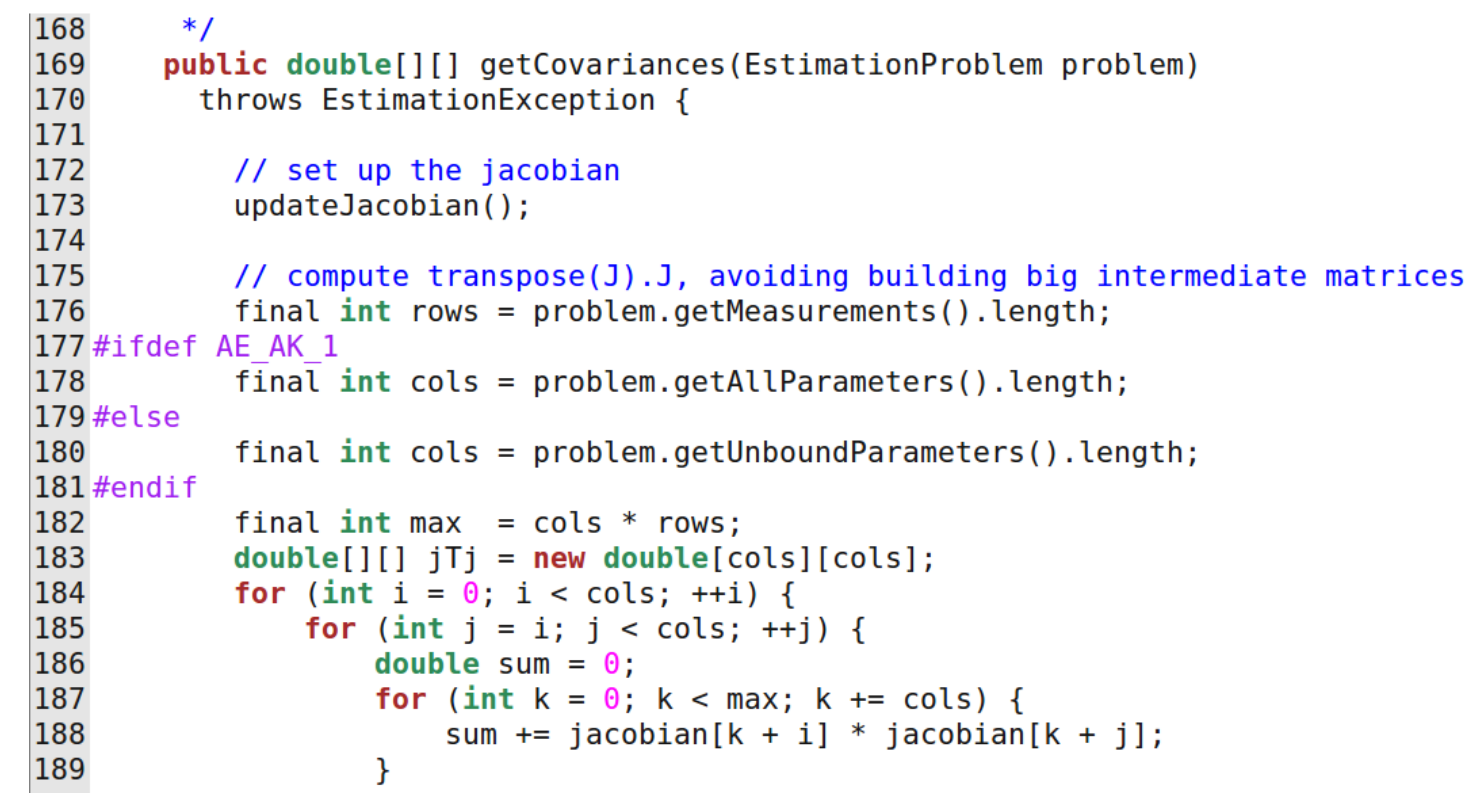

Figura 5.1 - Trecho de código que insere o defeito AE_AK_1 do Commons-Math.

O defeito AE_AK_1, apresentado na Seção 4.4, pertence à versão 2.0 do CommonsMath. Essa versão possui um conjunto de testes contendo 222 classes de testes JUnit, totalizando 2003 métodos de teste. Esse defeito causa uma falha no método de teste testBoundParameters da classe GaussNewtonEstimatorTest. Todos os outros 2002 métodos são executados com sucesso.

\subsubsection{Instrumentando e coletando as informações de cobertura}

O programa é instrumentado com o InSS. Para isso, é feita uma chamada por linha de comando para o InSS gerar a versão instrumentada do código-objeto do programa, indicando o diretório das classes originais e o diretório de destino. A chamada para 
a instrumentação é mostrada abaixo, passando o caminho das classes originais, após a opção -instrument e o caminho no qual serão geradas as classes instrumentadas -dest.

\$INSS_HOME/bin/instrumenter -instrument /home/commons-math/classes -dest /home/commons-math/instr

Em seguida, geram-se os arquivos $G X L$, um formato que armazena o grafo de fluxo de dados dos métodos do programa em estrutura semelhante ao XML (ARAUJO et al., 2011). A chamada de geração dos arquivos GXL é apresentada a seguir, indicando o caminho das classes originais, após a opção -file e o caminho no qual os arquivos serão criados -dest.

\$INSS_HOME/bin/defuse -file/home/commons-math/classes -dest /home/commons-math/gxl

O código instrumentado é executado para cada classe de teste e o InSS coleta os requisitos executados para cada uma das coberturas, gerando os arquivos com as informações de cobertura e o resultado da execução para cada método de teste.

\subsubsection{Gerando as listas de suspeição e os roteiros de busca com a DCI}

A partir dos arquivos de cobertura gerados pelo InSS, a DCI gera as listas de suspeição de cada cobertura, de acordo com a heurística escolhida, e também gera os roteiros de busca por método R-MCP e R-MCT. A lista de Nós ordenada por hierarquia de código é utilizada como entrada para a ferramenta CodeForest. Um exemplo de chamada da DCI é mostrado a seguir, que nesse caso gera uma lista de suspeição da cobertura MCP. O parâmetro - $r$ indica o diretório que contém os arquivos de cobertura, -rt informa o tipo de cobertura, - $h r$ indica a heurística a ser usada, -c informa o diretório das classes originais e -lt é o tipo de lista a ser gerada. O valor requirement indica que é a lista de classificação de requisitos por valor de suspeição. Um roteiro de busca pode ser gerado de forma semelhante.

\$DCI_HOME/dci_mcp -r /test/cov_mcp -rt mcp -hr tarantula -c/home/commons-math/classes -lt requirement

A Figura 5.2 mostra um trecho da lista de suspeição em XML gerada por DCI. Para o defeito AE_AK_1 (Figura 5.1), usando a heurística Tarantula, o método defeituoso está presente no requisito MCP classificado na primeira posição da lista, destacado em vermelho, com valor de suspeição de aproximadamente 0,9985. Ao gerar os roteiros de busca R-MCP e R-MCT, o método que contém o código defeituoso aparece na primeira 
posição em ambos casos, apresentando o maior valor de suspeição. Dessa forma, ao seguir o roteiro sugerido, o método defeituoso seria o primeiro a ser verificado tanto para R-MCP quanto para R-MCT. A Figura 5.3 mostra um trecho do roteiro R-MCP, obtido a partir da lista de suspeição mostrada na Figura 5.2.

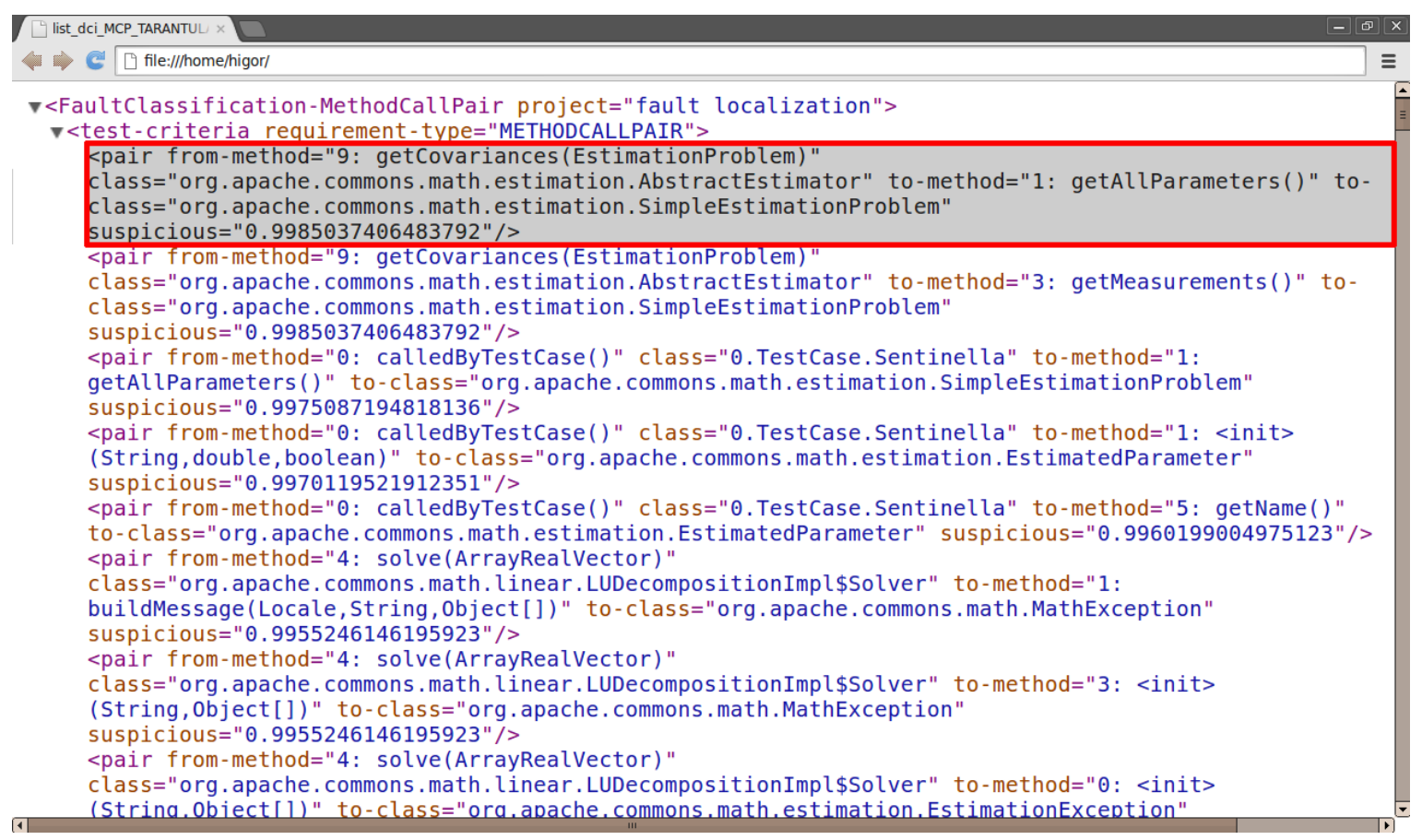

Figura 5.2 - Lista de suspeição de MCP para o defeito AE_AK_1 do Commons-Math.

\subsection{Condução dos experimentos}

Os experimentos foram realizados utilizando o seguinte procedimento. Foram avaliados os defeitos existentes em cada versão dos programas. Cada defeito foi executado para identificar a existência de casos de teste que geravam falhas. Os defeitos que manisfetaram ao menos uma falha foram utilizados nos experimentos. Os experimentos foram executados usando a versão 1.6 do Java Development Kit (JDK), exceto pelo programa Ant, para o qual foi necessário usar a versão 1.4 do Java.

Usando o InSS, cada versão defeituosa foi instrumentada e em seguida foram gerados os arquivos de cobertura de MCP, MCT e Nós. Alguns casos de teste falharam para uma determinada cobertura e para outra não. Isso ocorreu porque em algumas situações os testes geravam resultados aleatórios, enquanto em outros casos ocorreu estouro de memória durante a geração das coberturas. Os testes que geraram resultados diferentes entre as coberturas foram excluídos. Para algumas versões dos programas, houve testes que falhavam mesmo executando a versão original (sem defeito) do código. Esses testes 


\begin{tabular}{l|r}
\hline R-MCP & \multicolumn{1}{c}{ suspeição } \\
\hline getCovariances( & 0,9985037 \\
\hline getAllParameters( & 0,9985037 \\
\hline getMeasurements( & 0,9985037 \\
\hline EstimatedParameter( & 0,997012 \\
\hline getName( & 0,9960199 \\
\hline solve( & 0,9955246 \\
\hline buildMessage( & 0,9955246 \\
\hline MathException( & 0,9955246 \\
\hline EstimationException( & 0,9955246 \\
\hline updateJacobian( & 0,9950298 \\
\hline GaussNewtonEstimator( & 0,9930556 \\
\hline estimate( & 0,9930556 \\
\hline SimpleEstimationProblem( & 0,9930556 \\
\hline getUnboundParameters( & 0,9930556 \\
\hline addParameter( & 0,9930556 \\
\hline addMeasurement( & 0,9930556
\end{tabular}

Figura 5.3 - R-MCP para o defeito $A E_{-} A K_{-} 1$ do Commons-Math.

foram excluídos durante a geração das listas de suspeição de todas as coberturas para não influenciar a classificação dos comandos.

A partir dos arquivos de cobertura foram geradas as listas de suspeição. Cada versão defeituosa dos programas, assim como seus arquivos de cobertura e listas de suspeição foram armazenados em um diretório de testes. Para automatizar o processo de condução dos experimentos, foram criados scripts para realizar as etapas descritas acima, desde a inserção do defeito até o armazenamento dos resultados.

Em seguida, cada defeito foi examinado utilizando os roteiros de busca, as listas de suspeição e a CodeForest. Os resultados foram armazenados para análise do desempenho das técnicas.

\subsection{Resultados}

Nesta seção são apresentados os resultados obtidos durante a execução dos experimentos. A Tabela 5.5 mostra a quantidade de cliques necessários para localizar cada defeito no programa Ant com a CodeForest. As linhas com fundo cinza indicam a quantidade de cliques realizados para os defeitos em que foi necessário o uso do valor de suspeição delta. A coluna Defeito traz a descrição do defeito, a coluna Versão refere-se à versão do programa, enquanto a coluna Int. indica se o defeito é de integração $(S)$ ou não $(N)$. As colunas em Suspeição trazem os valores de suspeição do defeito para R-MCP, R-MCT e LSN usando a heurística Tarantula. 
As colunas $C L$ referem-se à metrica de cliques na CodeForest sem uso da hierarquia de código para R-MCP, R-MCT e LSN. Da mesma forma, as colunas em $C H C$ referemse à métrica de cliques usando a hierarquia de código para R-MCP, R-MCT e LSN. As colunas em Qtde. Métodos referem-se à quantidade de métodos contendo folhas que foram usados seguindo os roteiros de busca R-MCP e R-MCT até chegar ao método defeituoso. O valor $N L$ indica os casos em que o defeito não foi localizado usando a cobertura. O valor $L T$ indica os casos em que a quantidade máxima de cliques (70) ou métodos (20) foi ultrapassada.

A Tabela 5.6 mostra as quantidades de cliques para a localização dos defeitos do programa Commons-Math, seguindo a mesma organização da Tabela 5.5. De modo semelhante, a Tabela 5.7 refere-se ao programa JTopas e a Tabela 5.8 ao programa XMLsecurity.

Na Tabela 5.5, pode-se ver que o defeito $C L J_{-} H D_{-} 1$ necessitou de 10 cliques usando R-MCP e R-MCT e 22 cliques para LSN considerando a busca sem uso da hierarquia (CL). Já com o uso da organização por hierarquia de código (CHC) foram necessários 4 cliques para LSN e os mesmos 10 cliques para R-MCP e R-MCT. Foi necessário realizar a busca em 6 métodos nos roteiros de busca R-MCP e R-MCT usando a CodeForest. Para esse defeito, R-MCP e R-MCT tiveram desempenho idêntico. LSN teve uma redução na quantidade de cliques usando a hierarquia de código, e superou R-MCP e R-MCT utilizando essa abordagem de integração. Para esse defeito, não foi necessário o uso de delta.

O defeito $P J_{-} H D_{-2}$ não foi localizado usando a CodeForest sem o uso da suspeição delta. Na Tabela 5.5, pode-se ver que com o uso da suspeição delta sem a hierarquia de código, são necessários 32 cliques usando LSN, enquanto com o uso de R-MCP e R-MCT são necessários no máximo 18 e 19 cliques, respectivamente. Já com o uso da hierarquia, o número de cliques necessários para localizar o defeito é 17 para R-MCP, 18 para R-MCT e 20 para LSN. O número de métodos pesquisados para R-MCP e R-MCT não aumentou devido ao uso do valor de suspeição delta.

Já o defeito $A C L \_H D \_2$ não foi localizado por R-MCP, R-MCT ou LSN mesmo com o uso da suspeição delta, e o método defeituoso retornado R-MCP ultrapassou o limite estabelecido. 


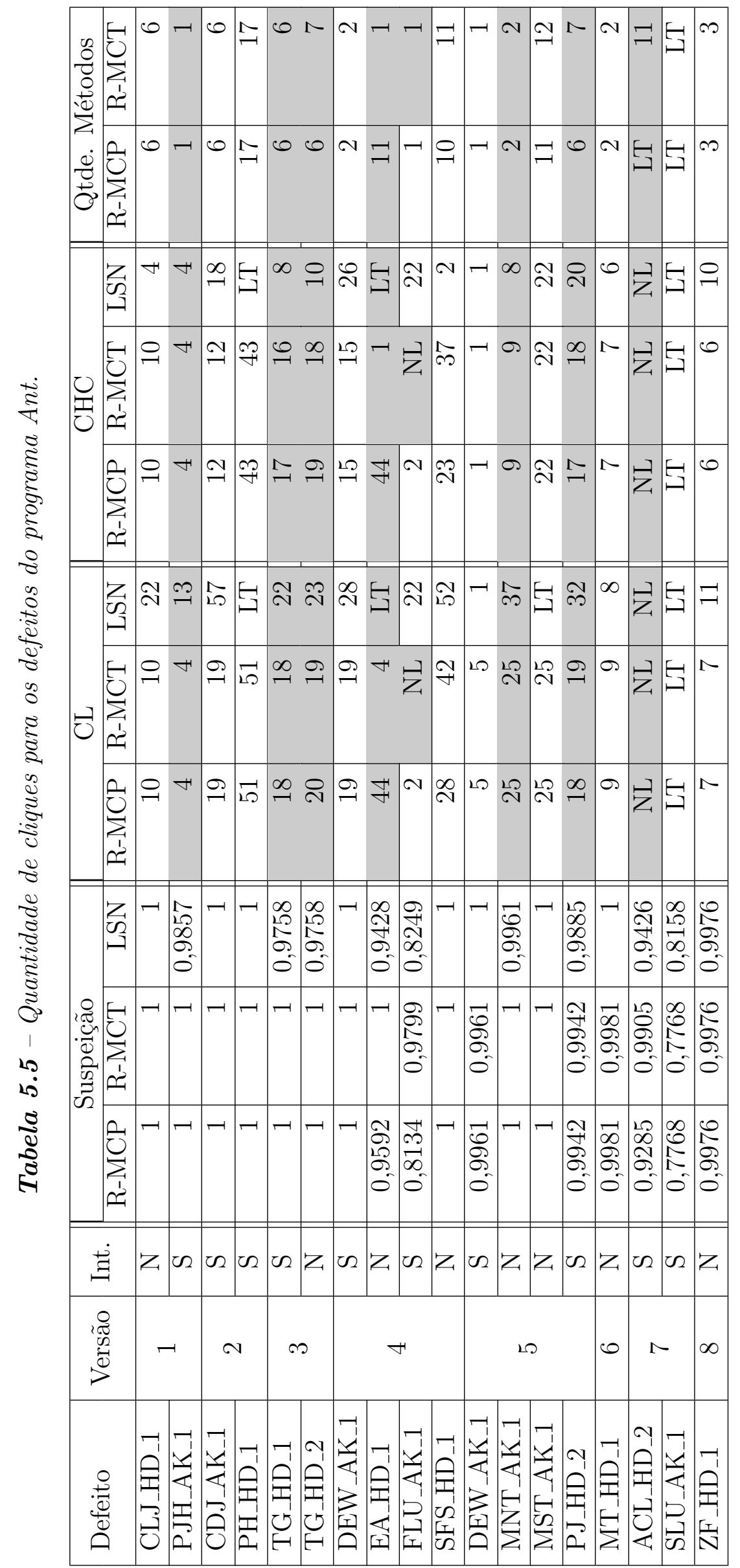


Para o programa Commons-Math, a maioria dos defeitos foi localizado sem a necessidade de usar o valor delta. Olhando a Tabela 5.6, o defeito $C_{-} A K_{-} 1$ necessitou de 6 cliques para R-MCP e R-MCT, e 9 cliques com LSN para a métrica CL. Com CHC, R-MCP, R-MCT e LSN necessitaram de exatos 4 cliques para localizar o defeito. Nos roteiros de busca por métodos, o método defeituoso retornou na segunda posição tanto para R-MCP quanto para R-MCT.

Para o defeito $A B I_{-} A K_{-}$, na mesma Tabela 5.6, R-MCP e R-MCT tiveram desempenho semelhante, ambos necessitando de 39 cliques para CL e 38 cliques para CHC. LSN obteve uma redução na quantidade de cliques usando a métrica CHC (37 cliques) tanto em comparação com CL, que ultrapassa o limite estabelecido, quanto em relação a R-MCP e R-MCT.

Pode-se ainda observar na Tabela 5.6 que os defeitos $M U_{-} A K_{-} 2$ e $M U_{-} A K_{-} 3$ possuem mais de um comando defeituoso, presentes em métodos diferentes. Para esses defeitos considerou-se a localização de cada um dos nós que apresentou o defeito separadamente.

O defeito $M U_{-} A K_{-} 5$ não foi localizado por R-MCP, R-MCT ou LSN. Para esse defeito o uso da suspeição delta possibilitou a localização para R-MCP e R-MCT, como pode ser visto na Tabela 5.6, necessitando de 25 cliques para R-MCP e R-MCT com a métrica CL e 24 cliques para ambos usando CHC. O método defeituoso aparece na primeira posição nos roteiros de busca de R-MCP e R-MCT. Já usando LSN, o comando defeituoso não é atingido mesmo com o uso da suspeição delta. 


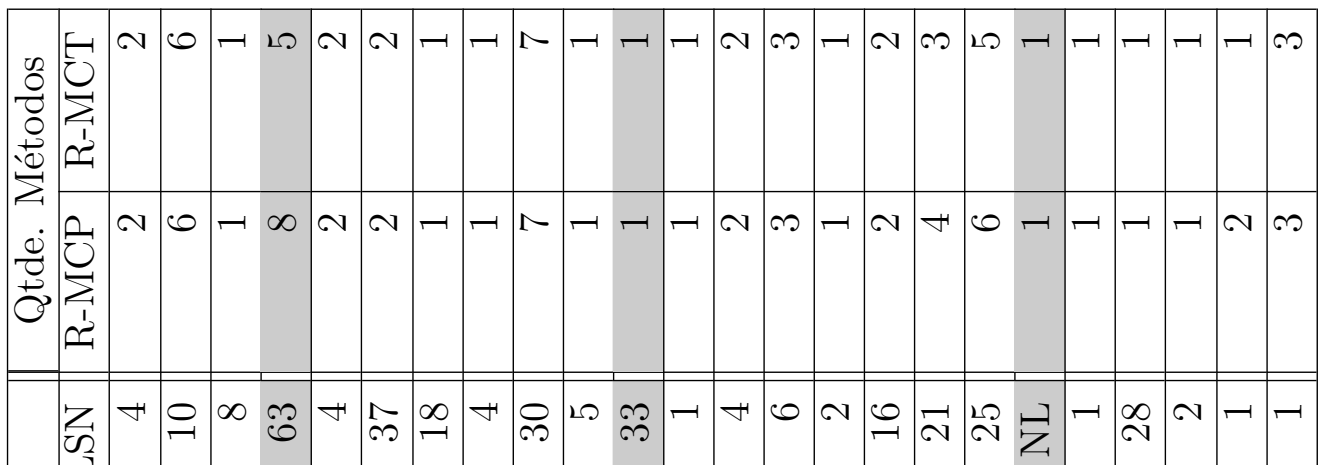

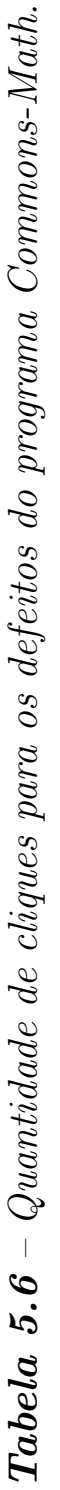

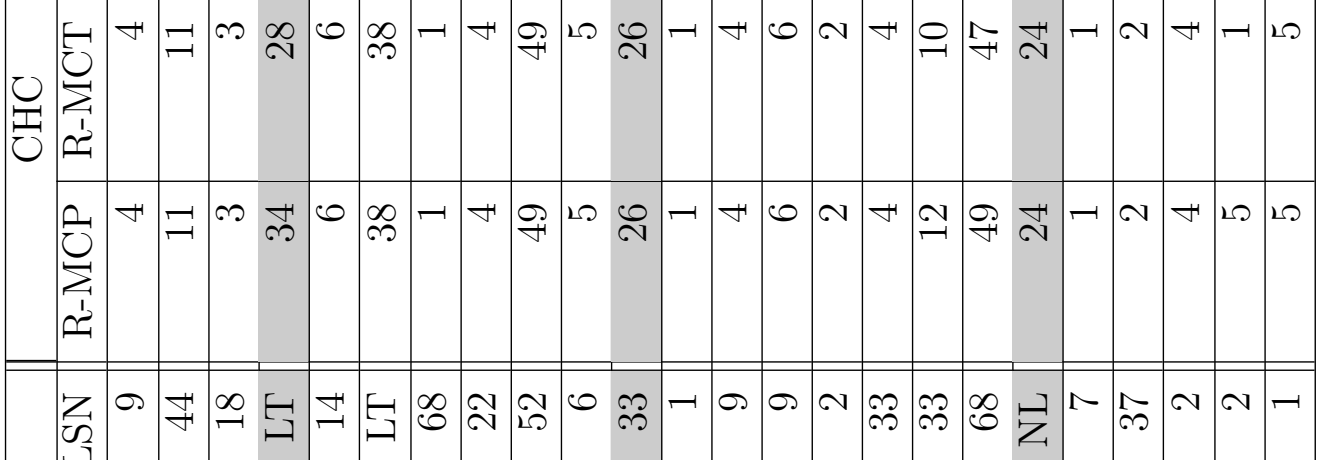

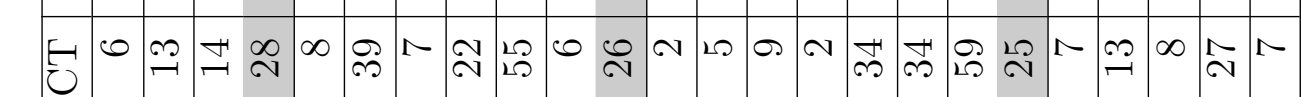
$\circlearrowright \sum_{\substack{1 \\ \infty}}^{\infty}$

లు 定

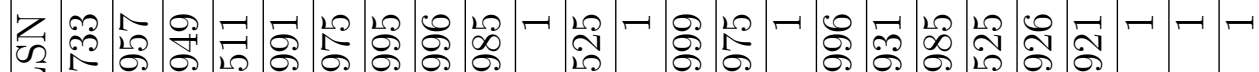

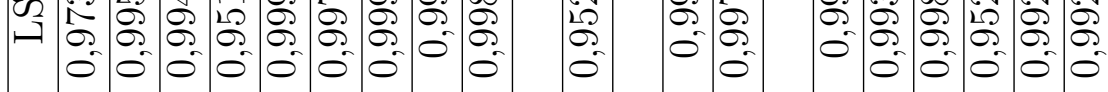

身

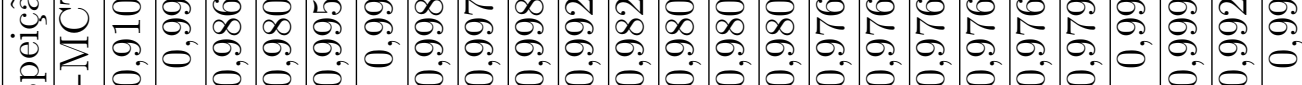
离

D H H

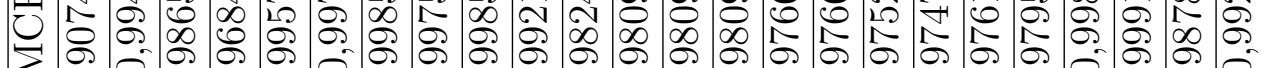

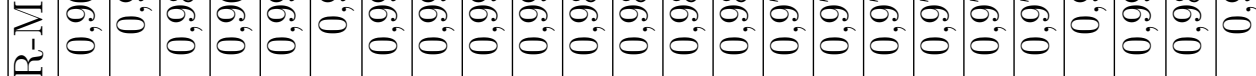

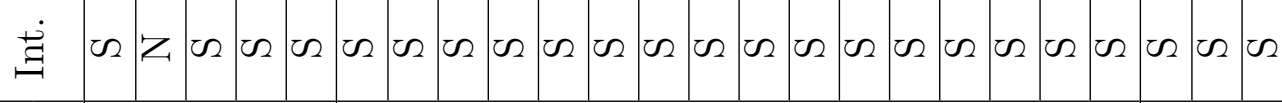

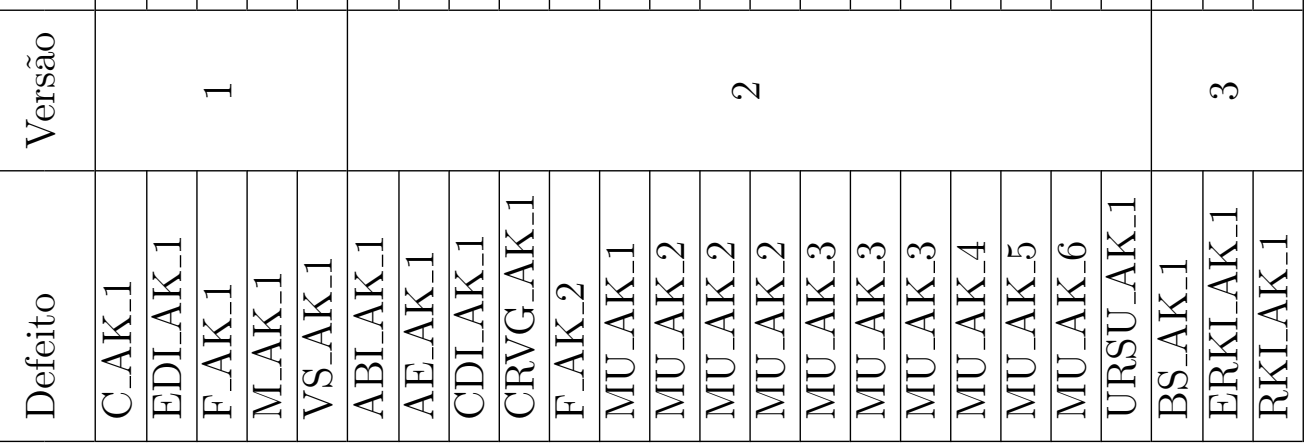


O programa JTopas apresentou uma quantidade menor de defeitos que manifestaram falhas nos casos de teste. A Tabela 5.7 mostra, por exemplo, o defeito FAULT_4, que para R-MCP e R-MCT foi localizado com 37 com CL, enquanto para LSN foram necessários 58 cliques para chegar ao nó defeituoso. Usando a métrica CHC, R-MCP, R-MCT e LSN precisaram de 34 cliques para chegar ao defeito, sem necessidade de usar o valor de suspeição delta.

O defeito FAULT_1 apresenta uma particularidade. Observando a Tabela 5.7, podese ver que o defeito não foi localizado por R-MCP, R-MCT ou LSN, mesmo com o uso da suspeição delta. Esse defeito ocorre no construtor da classe defeituosa, tratando-se da ausência de uma chamada explícita ao construtor da superclasse "super()" da qual a classe defeituosa é herdeira. O InSS sempre inicia a instrumentação no construtor após a chamada à superclasse, de modo que esse nó não é instrumentado. Nesse caso, embora o defeito não seja localizado, R-MCP e R-MCT conseguem retornar o método suspeito entre os 4 primeiros sem uso da suspeição delta e entre os 6 primeiros usando delta. Esse é o ponto mais próximo que se pode chegar desse defeito usando a instrumentação do InSS.

O programa XML-security apresentou a maior quantidade de defeitos que não foram localizados entre os quatro programas. Para a maioria dos defeitos, a quantidade de cliques para a localização superou o limite estabelecido mesmo sem o uso do delta. Na Tabela 5.8, o defeito CE_HD_3 necessitou de 66 cliques para R-MCP e R-MCT com CL, enquanto LSN precisou 2 cliques. Com CHC, LSN precisou dos mesmos 2 cliques e tanto R-MCP quanto R-MCT tiveram uma redução no número de cliques, cada uma necessitando de 10 cliques para encontrar o defeito. Foi necessário pesquisar 2 métodos tanto para R-MCP quanto para R-MCT até localizar o defeito.

O defeito $C N C_{-} A K_{-} 1$ foi localizado por R-MCP e R-MCT necessitando de 2 cliques com CL e de apenas 1 clique usando CHC. Para LSN, o limite de cliques foi excedido usando CL, enquanto com o uso de CHC foi possível a localização do defeito com 25 cliques, como pode ser visto na Tabela 5.8.

Na Tabela 5.8, o defeito $R F \_H D \_2$ ultrapassou a quantidade de cliques para R-MCP, R-MCT e LSN, tanto com CL como com CHC, e mesmo com o uso da suspeição delta. Também ultrapassou o limite de métodos estabelecido para R-MCP e R-MCT. A lista de suspeição da cobertura de Nós mostra que existem 488 nós classificados com suspeição máxima, o que pode indicar a incapacidade de localizar o defeito com essa quantidade de requisitos com o mesmo valor considerando o critério de parada estabelecido. 
O defeito $X U_{-} H D_{-}$, na Tabela 5.8, foi localizado apenas com R-MCP. A quantidade de cliques necessária foi de 70, tanto para CL quanto para CHC. Para R-MCT o defeito não foi localizado, mesmo usando a suspeição delta. Para a cobertura de Nós, o limite de cliques foi ultrapassado. A diferença entre R-MCP e R-MCT para esse defeito deve-se ao valor no qual o método defeituoso foi classificado. Como em R-MCT o método retornou com valor de suspeição maior que a suspeição do nó defeituoso, ele não é identificado usando a busca pela CodeForest mesmo com o uso da suspeição delta, como visto na Tabela 5.8. A diferença entre os valores de suspeição do método em R-MCT e do nó defeituoso é maior que o estabelecido para a suspeição delta. O método foi classificado em R-MCP com valor de suspeição inferior ao valor do nó, de forma que, ao usar os filtros, o nó é retornado entre as folhas e o defeito é localizado.

No programa XML-security, os defeitos $C B \_H D \_2$ e CNC_AK_1 ocorrem na atribuição de valor a constantes pertencentes às suas respectivas classes defeituosas. Para localizar o defeito, foram considerados como defeituosos os nós presentes em métodos que usam essas constantes, e não diretamente o local onde está o defeito. 

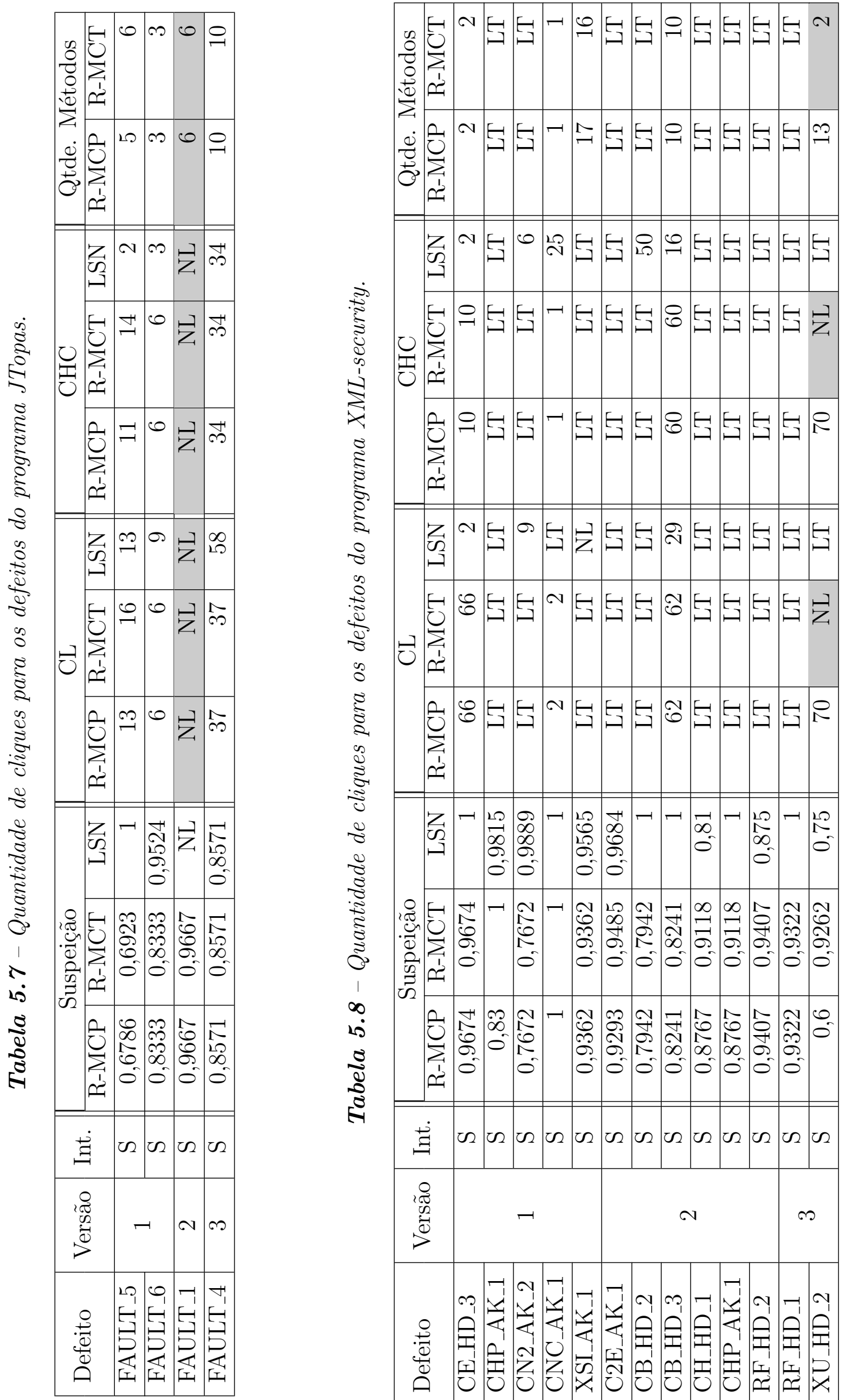

ص

苔

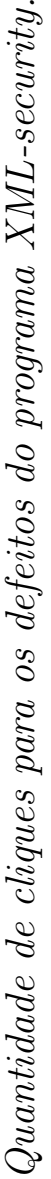

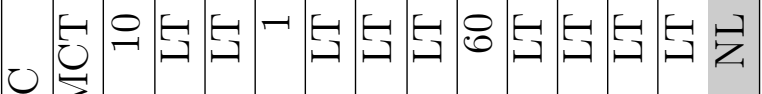

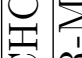

0

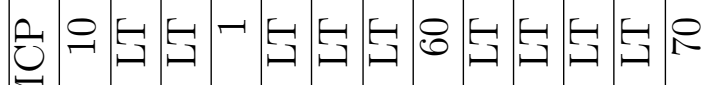

ح'

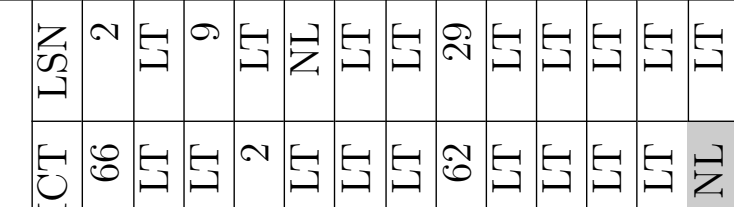

0 حـ

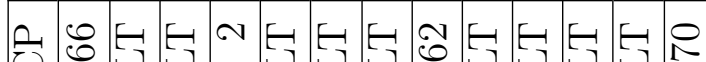

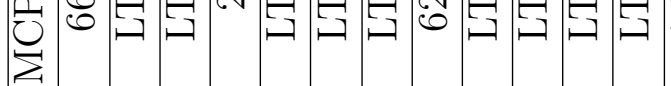

ح.

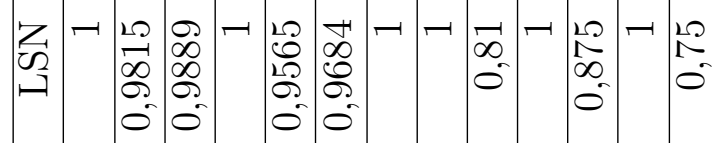

禹值

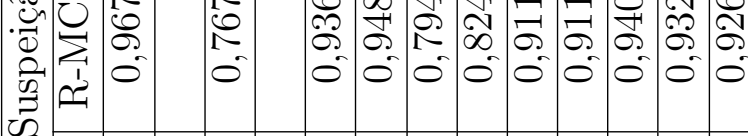

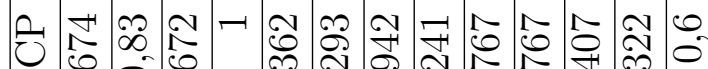

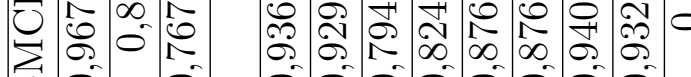

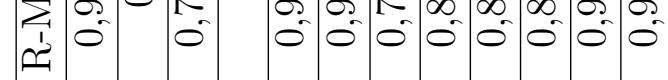

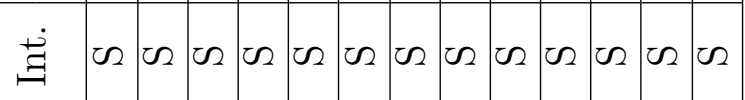

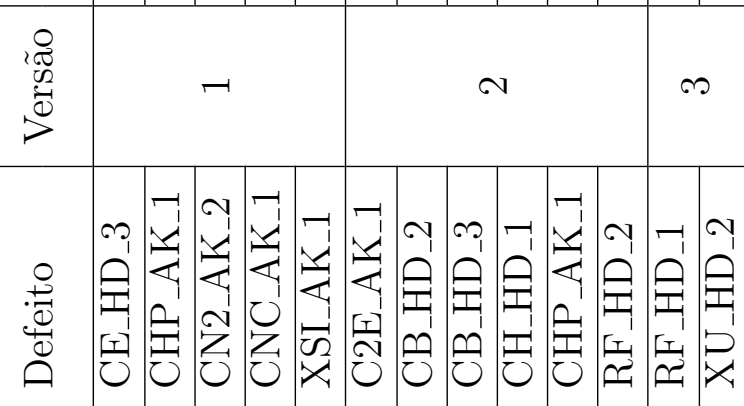


As Tabelas 5.9, 5.10, 5.11 e 5.12, apresentam as posições de classificação dos defeitos nas listas ordenadas por valor de suspeição de MCP, MCT e Nós para os programas Ant, Commons-Math, JTopas e XML-security, respectivamente. As colunas MCP, MCT e Nós em Posição absoluta indicam as posições exatas de classificação para cada defeito em cada uma das coberturas, enquanto as colunas MCP, MCT e Nós em EXAM score abs. representam a porcentagem de esforço para localizar os defeitos considerando a quantidade de requisitos que foi executada durante os testes para cada cobertura. As colunas seguintes, em Posição média e EXAM score médio apresentam os valores de classificação para os defeitos considerando as posições médias em relação aos requisitos que possuem o mesmo valor de suspeição que o requisito defeituoso.

De modo geral, pode-se observar na Tabela 5.9 que para a maioria dos defeitos do programa Ant, os requisitos das três coberturas estão classificados em posições inferiores ao critério de parada estabelecido para a quantidade de cliques, tanto em relação à posição absoluta quanto à posição média. A mesma situação ocorre para o programa CommonsMath e JTopas, como visto nas Tabelas 5.10 e 5.11, respectivamente. Já o programa XML-security apresenta mais defeitos em que os requisitos estão classificados acima do limite de cliques, fato que pode ter influência no desempenho de localização inferior para os defeitos desse programa. 


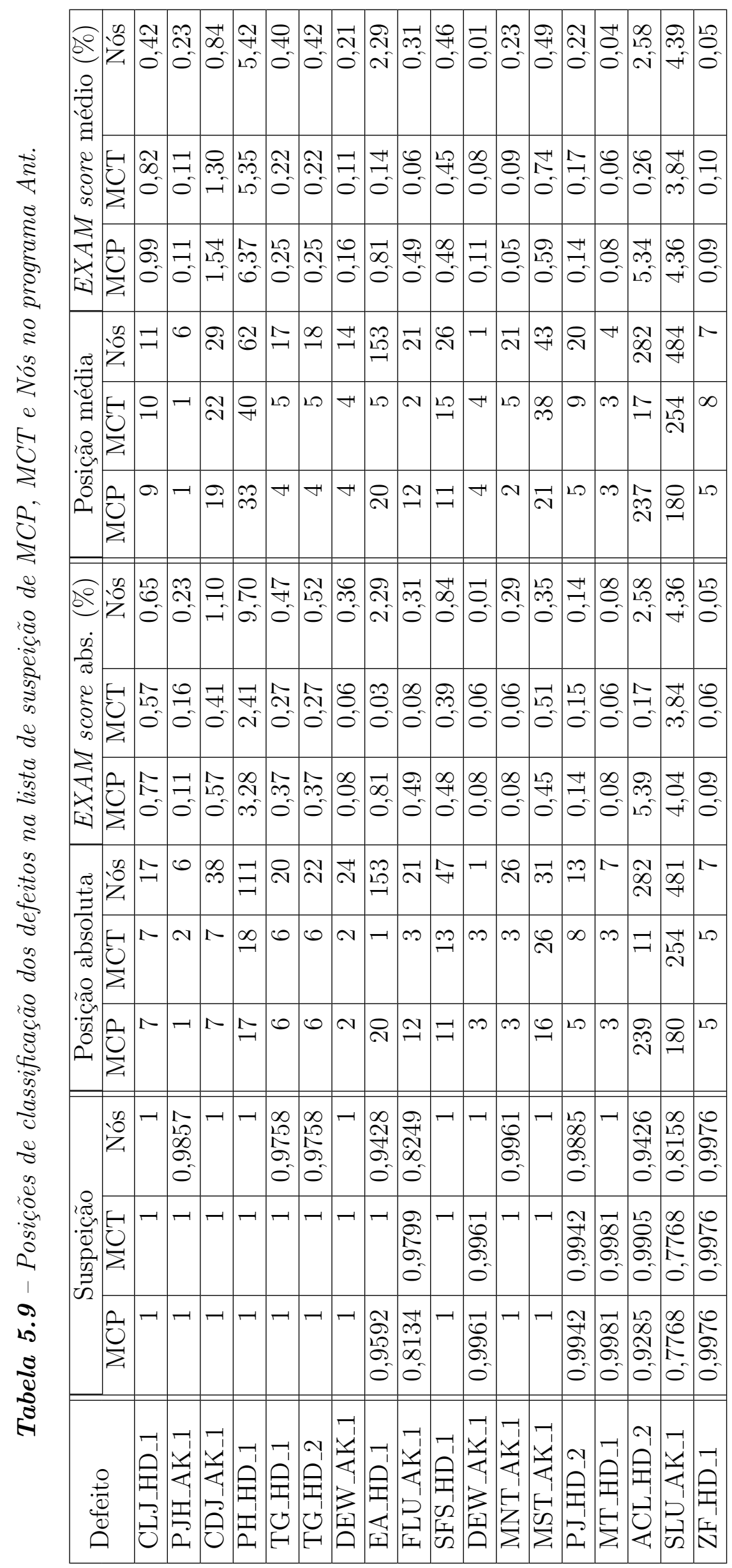




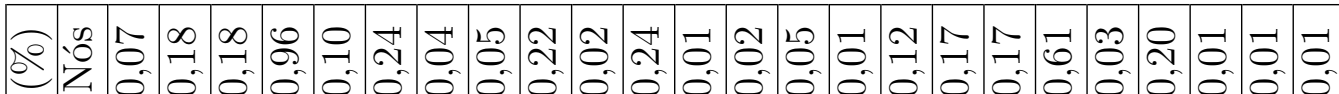
है $\stackrel{\circ}{-}$

$\Xi$

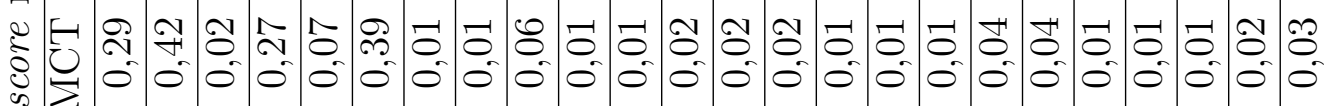

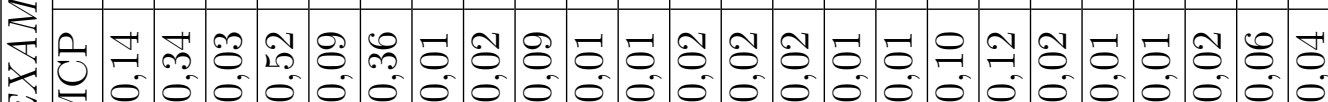

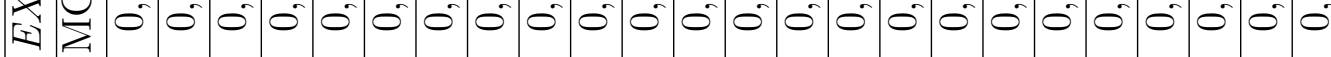

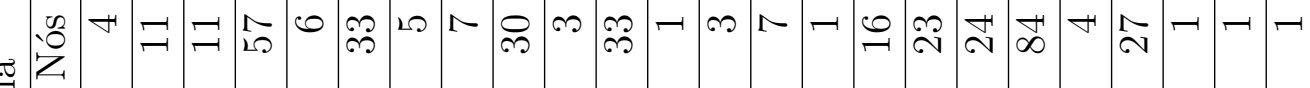
西

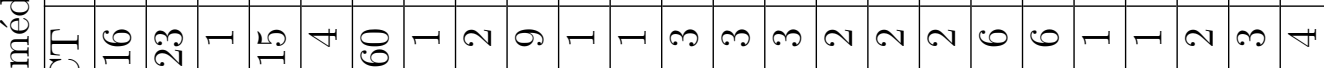

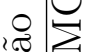

.

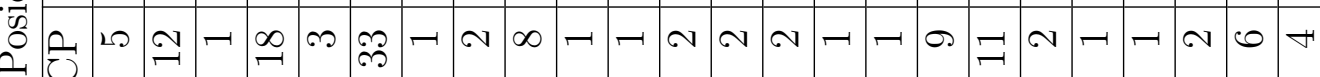

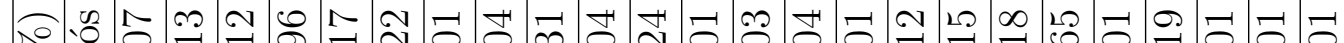

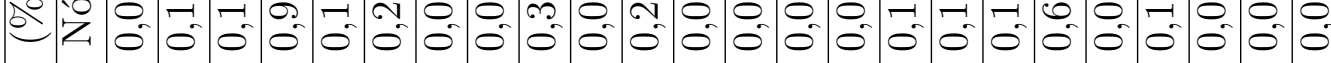
$\frac{\dot{2}}{\tilde{\sigma}}$

\&

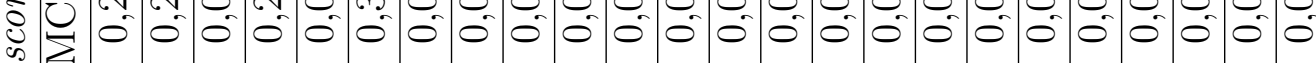
草

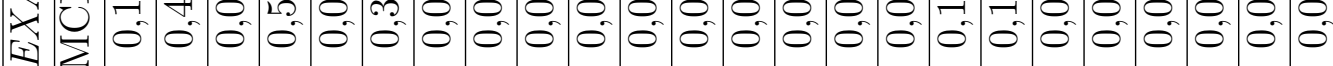

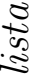

ఏ

is

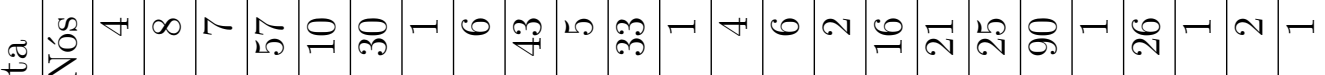
西

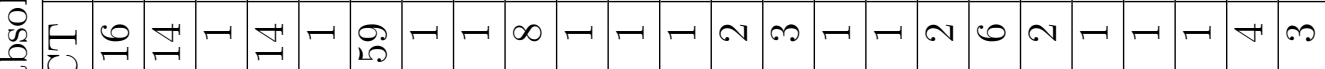
$\sum$

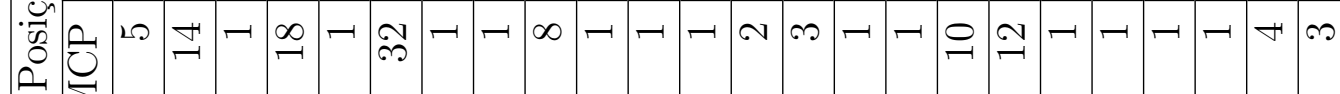

:

ע

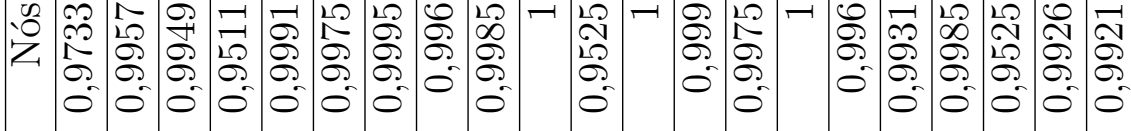
㐘 莕

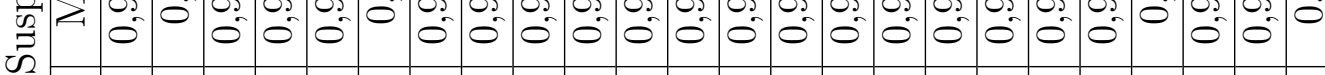

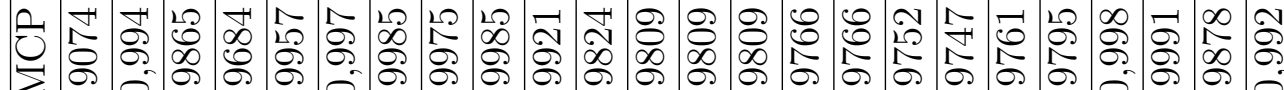

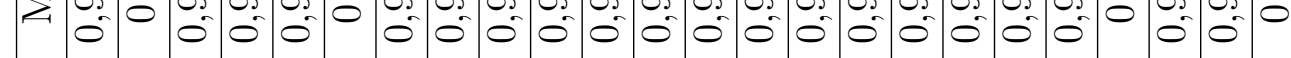

$\frac{7}{2}$

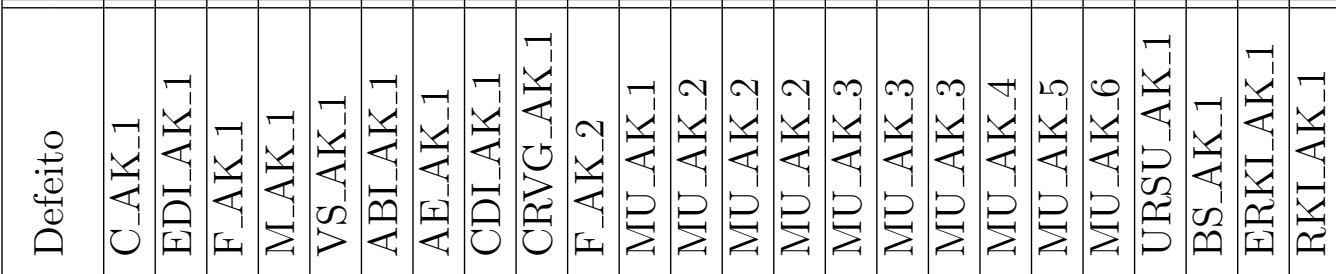




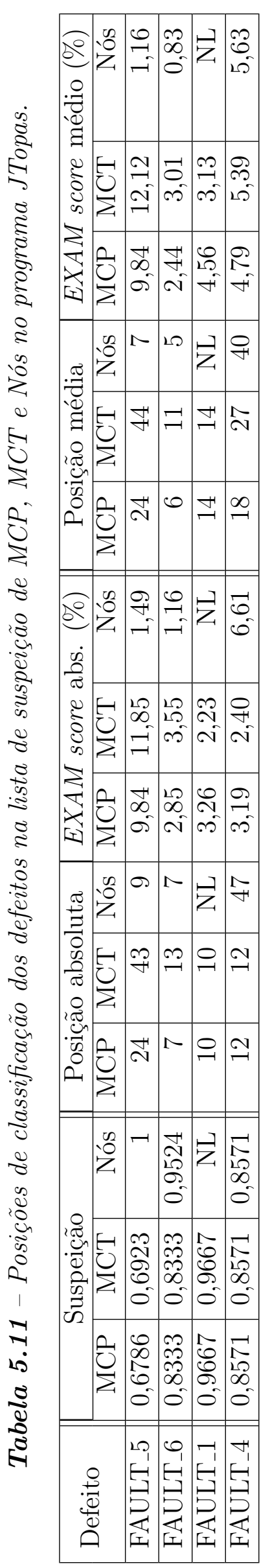

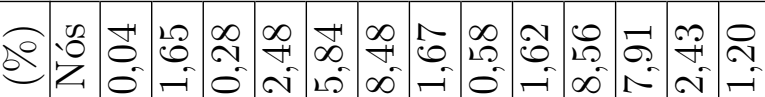
ㅇ

(1)

7

$\exists$

ป

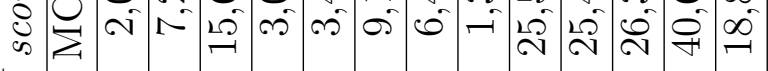

$\Sigma$

Н

住

溮

$\because$

寻代ন

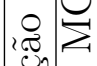

党

$\sum$

(2)

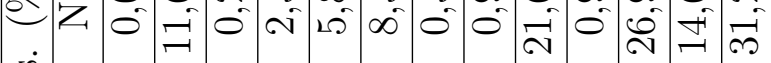

$\frac{\dot{0}}{\sigma}$

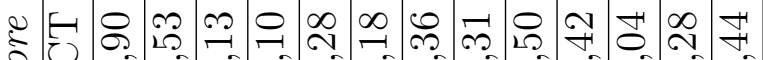

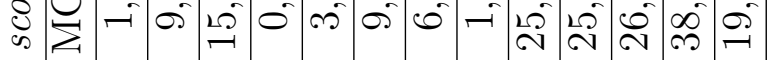

$\Sigma$

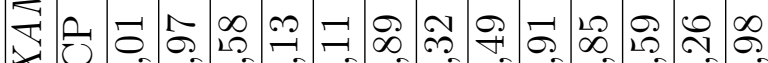

过 $\quad$ 代

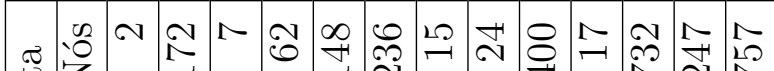

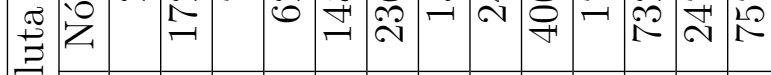

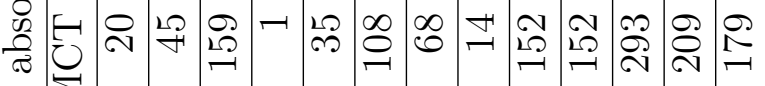

之

崩 总

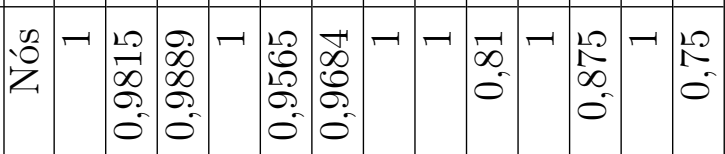

我然

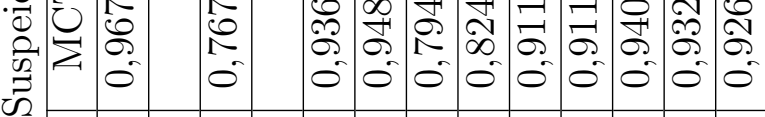

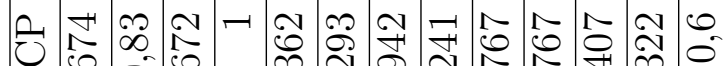

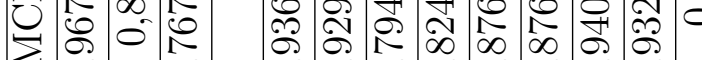

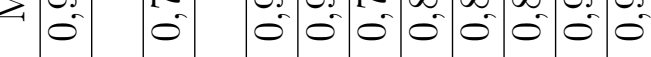

$\frac{\sqrt{3}}{\frac{8}{8}}$

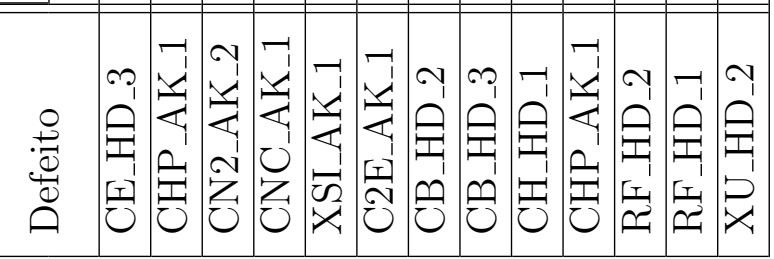




\subsection{Sumarização dos resultados}

Com base nos resultados obtidos durante a execução dos experimentos, é apresentada uma análise do desempenho da técnica DCI para as variáveis avaliadas neste trabalho. O objetivo é realizar uma comparação entre o uso dos roteiros de busca R-MCP e R-MCT e da lista de suspeição LSN quanto à sua eficácia de localização de defeitos, e relacionar esse desempenho com o uso da abordagem de hierarquia de código, por meio das métricas CL e CHC.

Verificou-se também se o uso do valor de suspeição delta foi capaz de auxiliar a localização dos defeitos que não foram identificados diretamente pelas coberturas e a relação entre a eficácia de localização usando as coberturas para os defeitos classificados como sendo de integração e de unidade.

A Tabela 5.13 apresenta a quantidade de defeitos localizados para R-MCP, R-MCT e LSN considerando os defeitos em que não foi necessário o uso do valor delta e os casos em que ocorreu o uso de delta. As colunas $C L$ e $C H C$ indicam, respectivamente, a quantidade de defeitos localizados sem uso da hierarquia de código e com o uso da hierarquia para R-MCP, R-MCT e LSN. Para cada programa são apresentadas a quantidade de defeitos (linha Qtde.) e a porcentagem em relação ao total de defeitos do programa (linha \%). A linha Total mostra a quantidade e a porcentagem dos defeitos localizados somando-se todos os programas.

Para R-MCP no programa Commons-Math foram localizados 17 defeitos dos 20 existentes sem uso do valor de suspeição delta, tanto com CL quanto com CHC. Os outros 3 defeitos foram localizados usando o valor de suspeição delta. R-MCT obteve esse mesmo resultado, enquanto para LSN só foi possível atingir todos os defeitos usando o valor delta e CHC.

No programa XML-security, com CL e sem uso da suspeição delta, R-MCP possibilitou a localização de 4 defeitos, enquanto R-MCT e LSN atingiram 3 dos 13 defeitos existentes. Já usando CHC, para LSN tornou possível identificar 5 defeitos e não houve alteração nas quantidades localizadas para R-MCP e R-MCT. O uso da suspeição delta não possibilitou a localização de nenhum dos outros defeitos do XML-security. Já os programas Ant e Commons-Math tiveram um acréscimo na quantidade de defeitos localizados de até $33 \%$ e $15 \%$, respectivamente.

A Tabela 5.14 mostra o total de defeitos localizados por R-MCP, R-MCT e LSN para os programas avaliados somando os defeitos localizados sem o uso da suspeição delta e 
com o uso de delta, seguindo a mesma estrutura da Tabela 5.13. Os defeitos presentes em mais de uma linha foram considerados apenas uma vez nas Tabelas 5.13 e 5.14.

Para o programa Ant, R-MCP permitiu localizar mais defeitos de acordo com os critérios estabelecidos: 16 dos 18 defeitos (ou 88,89\%) foram localizados, independente do uso de CL ou CHC; com R-MCT foram localizados 15 defeitos tanto com CL como com CHC e para LSN foram localizados 13 defeitos com CL e 14 defeitos usando CHC.

Para o programa Commons-Math, todos os defeitos foram localizados usando R-MCP e R-MCT. Já para LSN usando a métrica CL, foram localizados 17 dos 20 defeitos, e para LSN com CHC todos os 20 defeitos foram localizados. Dos quatro programas avaliados, o XML-security foi o que teve uma menor quantidade de acertos: no melhor caso, 38,46\% (5 dos 13 defeitos) com LSN e CHC e, no pior caso, 23,08\% (3 dos 13 defeitos) usando R-MCT e LSN, ambas com a CL, e R-MCT com CHC.

Pode-se observar na Tabela 5.14 que o uso da hierarquia de código permitiu aumentar o número de defeitos localizados somente para a lista LSN. Considerando a quantidade total de defeitos, o uso de R-MCP permitiu localizar o maior número de defeitos, 43 dos 55 existentes $(78,18 \%)$, tanto usando CL quanto usando CHC. 


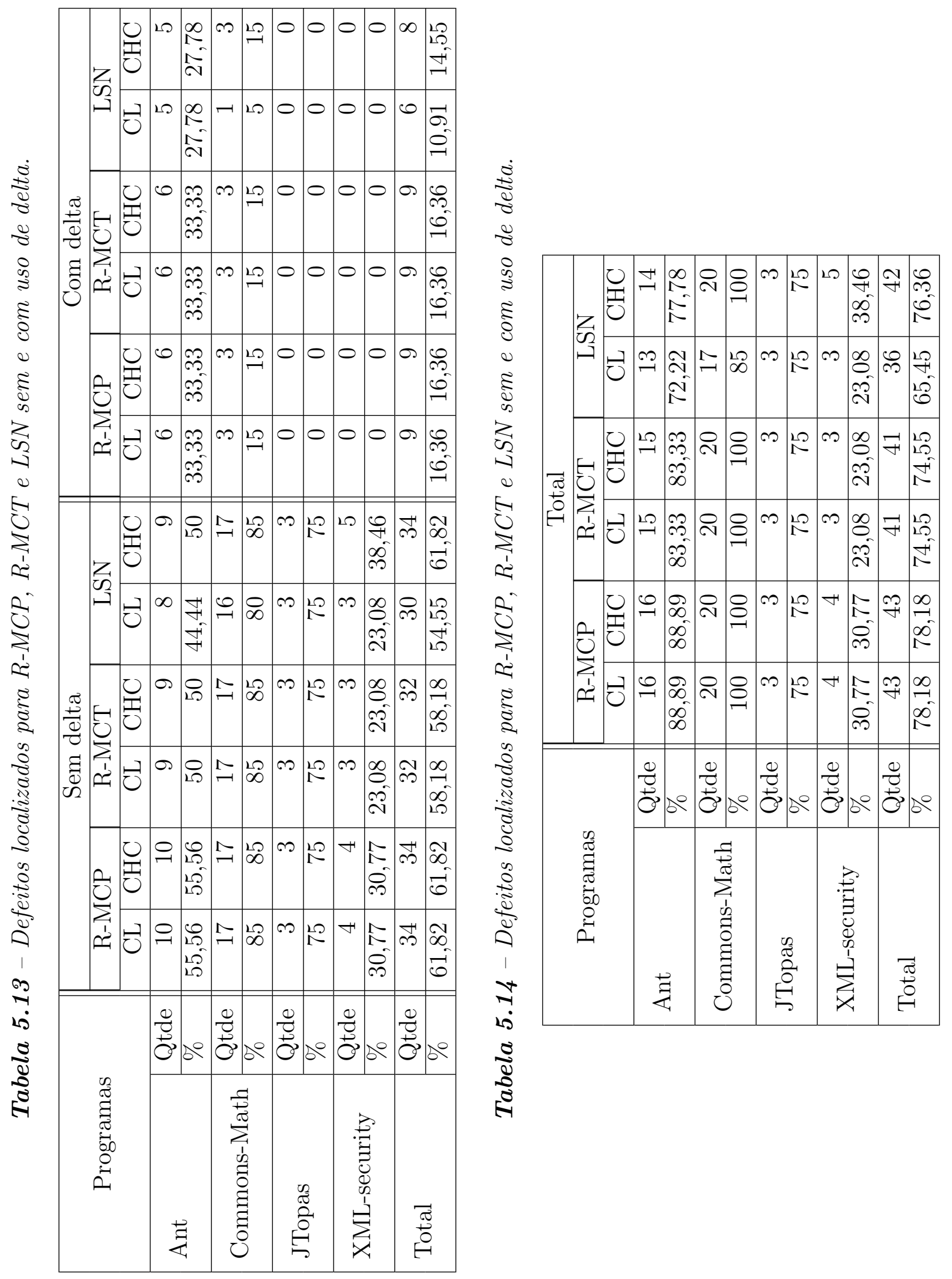


A Tabela 5.15 traz uma comparação entre a quantidade de vezes em que R-MCP e R-MCT conseguem localizar o defeito com uma quantidade de cliques menor, igual ou maior em relação LSN (R-MCP x LSN e R-MCT x LSN) e entre si (R-MCP x R-MCT), considerando o uso das métricas CL e CHC. A comparação é feita para cada um dos programas e para o total de defeitos localizados por pelo menos uma das técnicas com ou sem o uso da suspeição delta. Os defeitos que ocorrem em mais de uma linha foram incluídos separadamente.

Considerando todos os programas, tanto na comparação de R-MCP com LSN como na comparação entre R-MCT e LSN, R-MCP e R-MCT tiveram uma quantidade maior de defeitos que necessitaram de menos cliques usando CL. Já usando CHC, LSN tem uma quantidade maior de defeitos que precisaram de menos cliques para serem localizados em comparação com R-MCP e R-MCT. Na comparação entre R-MCP e R-MCT, a maioria dos defeitos precisou da mesma quantidade de cliques, o que indica a semelhança do uso desses dois roteiros para a maioria dos defeitos. 


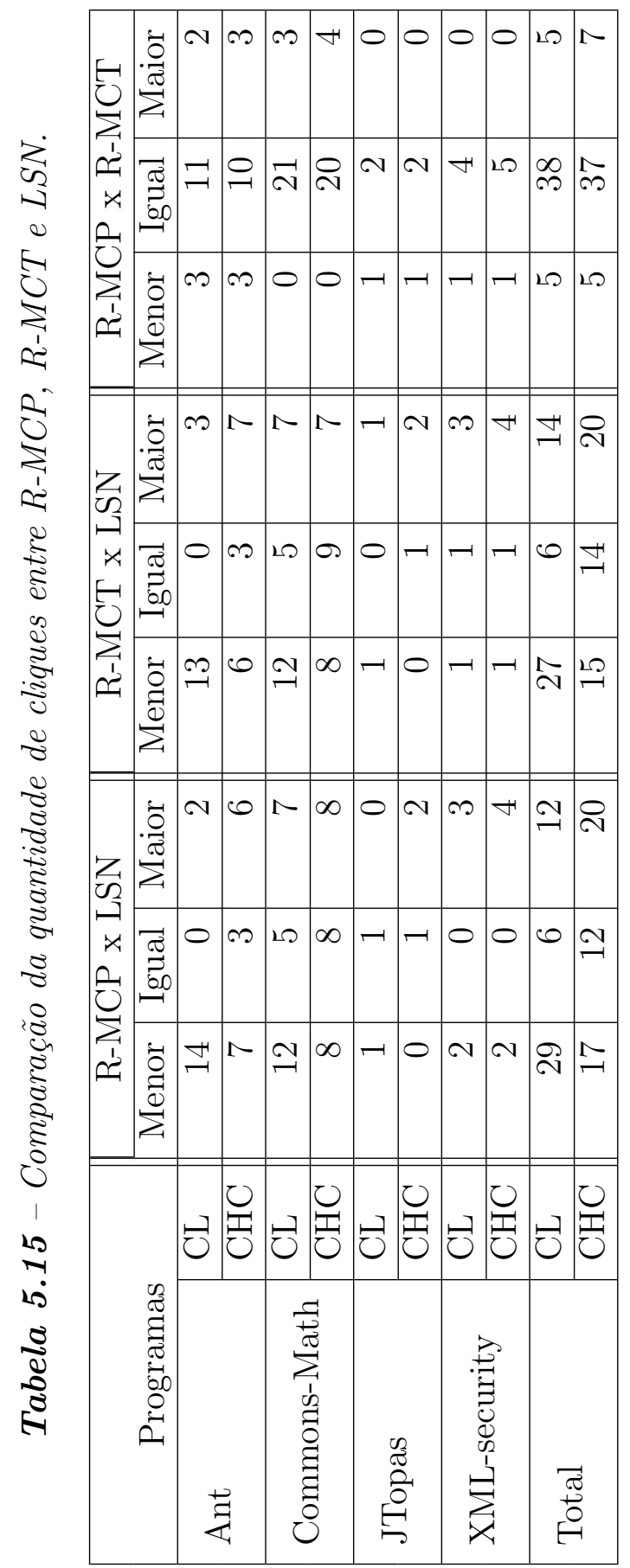


Outra forma de comparar o desempenho de localização entre R-MCP e R-MCT é verificar a posição do método defeituoso no roteiro de busca das duas coberturas. A Tabela 5.16 compara a quantidade de vezes em que a posição do método defeituoso foi superior, igual ou inferior entre os roteiros de busca R-MCP e R-MCT para cada programa e para o total de defeitos.

Tabela 5.16 - Quantidade de métodos retornados nos roteiros de busca $R$-MCP e $R$ MCT até o método defeituoso.

\begin{tabular}{|l||r|r|r|}
\hline \multirow{2}{*}{ Programas } & \multicolumn{3}{|c|}{ Métodos R-MCP x R-MCT } \\
\cline { 2 - 4 } & Superior & Igual & Inferior \\
\hline Ant & 3 & 11 & 2 \\
\hline Commons-Math & 0 & 20 & 4 \\
\hline JTopas & 1 & 2 & 0 \\
\hline XML-security & 0 & 4 & 2 \\
\hline Total & 4 & 37 & 8 \\
\hline
\end{tabular}

No total, em 8 dos defeitos o roteiro R-MCT classificou o método defeituoso em uma posição inferior em relação a R-MCP, contra 4 defeitos em que a R-MCP traz o método defeituoso em posição inferior a R-MCT. Para 37 defeitos, os dois roteiros retornam o método defeituoso na mesma posição.

A Tabela 5.17 apresenta a quantidade de métodos que foram examinados para localizar os defeitos com R-MCP e R-MCT. O resultado foi dividido por faixa de valores até o limite de número de métodos estabelecido. Estão sendo considerados apenas os casos em que o defeito foi localizado utilizando pelo menos um dos roteiros.

Pode-se observar que a maioria dos defeitos foi localizada examinando no máximo 5 métodos, tanto para R-MCP quanto para R-MCT. A faixa entre 6 e 10 métodos também possui uma grande quantidade de defeitos localizados. Apenas um dos defeitos precisou de até 20 métodos para ser localizado para ambos roteiros. R-MCP e R-MCT apresentaram resultados semelhante para todas as faixas de valores.

A Tabela 5.18 mostra a quantidade de defeitos em que há redução do número de cliques usando hierarquia de código. A comparação é feita para R-MCP, R-MCT e LSN para todos os programas avaliados. A coluna Qtde é a quantidade de defeitos em que

Tabela 5.17 - Quantidade de métodos necessários para localizar o defeito usando $R$ $M C P$ e $R-M C T$.

\begin{tabular}{|l||r|r|r|r|}
\hline Roteiro & Até 5 & $6-10$ & $11-15$ & $16-20$ \\
\hline R-MCP & 30 & 12 & 3 & 1 \\
\hline R-MCT & 31 & 10 & 2 & 1 \\
\hline
\end{tabular}


houve redução, a coluna Defeito (\%) indica a porcentagem dos defeitos em que houve redução com relação a todos os defeitos de cada programa. A coluna Redução (\%) mostra a porcentagem de cliques reduzidos até a localização do defeito para cada programa usando HC. Os defeitos em múltiplas linhas foram considerados separadamente. Para os defeitos em que o número de cliques ultrapassou o limite, foi considerado o valor do limite mais um (71).

No programa Commons-Math, o uso da HC reduziu o número de cliques em 95,83\% dos defeitos, com uma diminuição média de 36,19\% da quantidade de cliques. Para o programa Ant, R-MCT obteve uma redução para 13 defeitos (72,22\%), com uma diminuição de 21,75\% no número de cliques necessários para localizar o defeito. LSN obteve a maior redução da porcentagem de cliques necessários para localizar os defeitos em todos os programas. Os resultados obtidos indicam que o uso da $\mathrm{HC}$ reduz a quantidade de cliques necessária para atingir o comando defeituoso.

A Tabela 5.19 mostra a porcentagem de defeitos em que foi necessário usar o valor de suspeição delta, independente de ocorrer a localização do defeito. Esta tabela também indica a porcentagem em que o uso da suspeição delta possibilita a localização do defeito, considerando somente os defeitos em que o valor delta foi usado. A coluna Qdte. indica a quantidade de defeitos e a coluna \% indica a porcentagem de defeitos.

Com R-MCT no programa Ant, em 8 (44\%) defeitos a suspeição delta foi usada. Desses defeitos, 6 (75\%) foram localizados. No programa Commons-Math, o valor de suspeição delta foi usado para a localização de três defeitos. Para R-MCP e R-MCT, esses três defeitos foram localizados com delta, enquanto para LSN dois dos três defeitos foram encontrados. Já para os programas JTopas (para R-MCP, R-MCT e LSN) e XMLsecurity (para R-MCT) apenas um defeito usou o valor delta, porém o defeito não foi localizado para esses dois programas. 

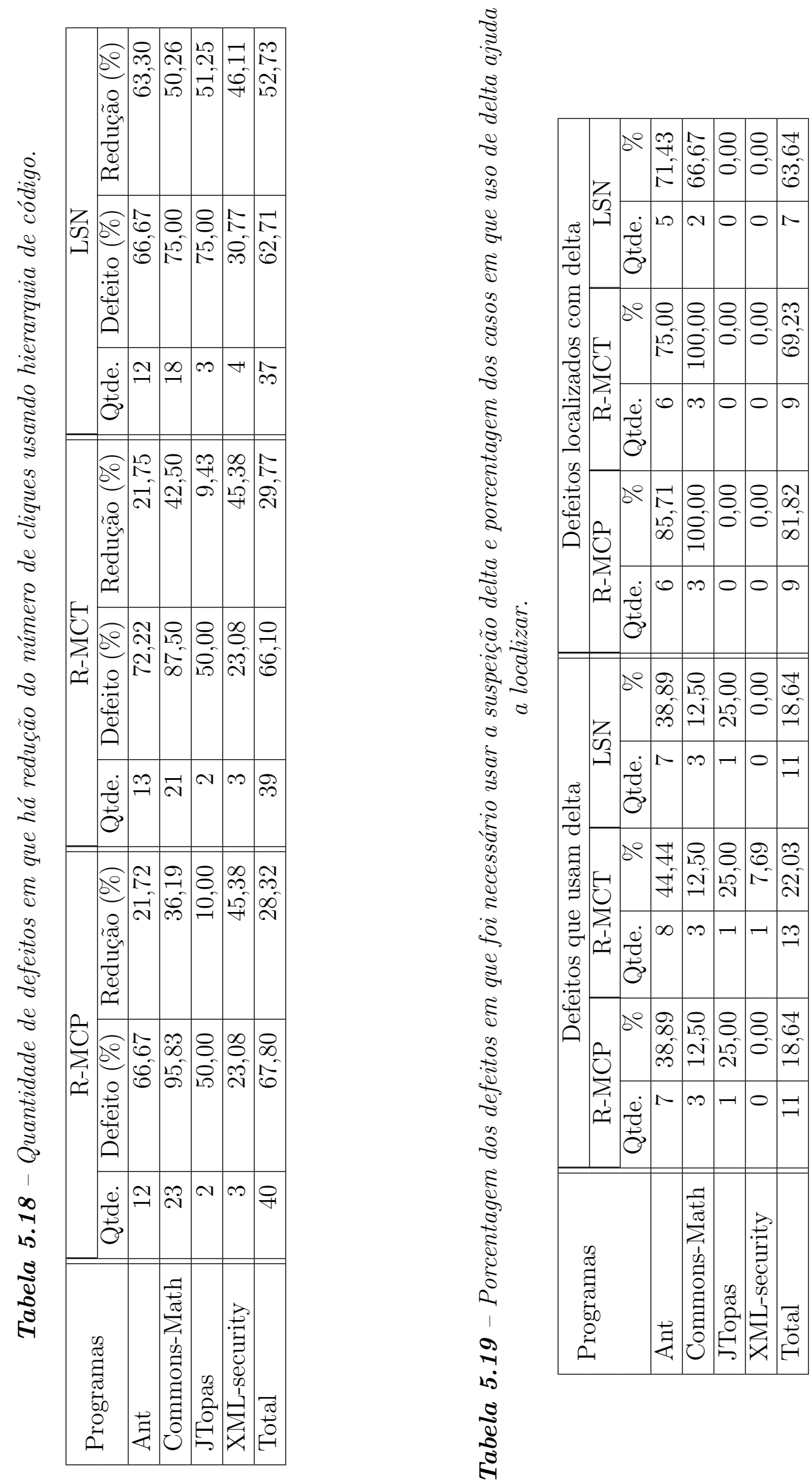
Para tentar compreender o motivo pelo qual alguns dos defeitos avaliados não foram localizados, foram observadas as posições de classificação nas listas de suspeição das coberturas MCP, MCT e Nós, separadamente para os defeitos que não foram localizados por R-MCP, R-MCT ou LSN e pelos defeitos que foram localizados por pelo menos um entre R-MCP, R-MCT e LSN. A Tabela 5.20 mostra a posição média de classificação dos defeitos que não foram localizados por R-MCP, R-MCT ou LSN. A penúltima linha apresenta a média da posição de classificação dos requisitos defeituosos que não foram localizados para as listas de suspeição das coberturas MCP, MCT e Nós. A última linha traz a média da posição dos requisitos defeituosos que foram localizados nas listas das três coberturas.

Pode-se observar que a média da posição do comando defeituoso na lista de Nós é superior tanto para os defeitos localizados quanto para aqueles não localizados, o que é explicado pela quantidade maior de requisitos que são retornados por essa lista em comparação com as listas de MCP e MCT. As médias obtidas pelos comandos defeituosos nas listas de MCP e MCT apresentaram resultados parecidos, com uma diferença da média entre defeitos localizados e não localizados de aproximadamente 100 posições. Já a diferença entre a média entre defeitos localizados e não localizados na lista de cobertura de Nós é de aproximadamente 280 posições.

Vale ressaltar que para o defeito FAULT_1, do programa JTopas, o nó defeituoso não está presente na lista de suspeição por não ser coberto pelo InSS, de forma que não poderia ser localizado.

A Tabela 5.20 indica que existe uma relação entre o posicionamento do comando defeituoso nas listas de classificação, mostrado nas colunas MCP, MCT e Nós, e a eficácia de localização de R-MCP, R-MCT e LSN, especialmente considerando os limites estabelecidos para a localização de defeitos estabelecidos neste trabalho. Um defeito como o RF_HD_2 do programa XML-security retornou na posição 757 da lista de Nós e poderia necessitar dessa mesma quantidade de cliques para localizar o defeito. 
Tabela 5.20 - Posição de classificação dos defeitos não localizados na lista de cobertura de MCP, MCT e Nós.

\begin{tabular}{|c|c|c|c|c|}
\hline \multirow{2}{*}{ Defeito } & \multirow{2}{*}{ Programa } & $\mathrm{MCP}$ & $\mathrm{MCT}$ & Nós \\
\hline & & Pos. Média & Pos. Média & Pos. Média \\
\hline ACL_HD_2 & \multirow{2}{*}{ Ant } & 237 & 17 & 282 \\
\hline SLU_AK_1 & & 180 & 254 & 484 \\
\hline FAULT_1 & JTopas & 14 & 14 & NL \\
\hline CHP_AK_1 & \multirow{7}{*}{ XML-security } & 59 & 34 & 172 \\
\hline XSI_AK_1 & & 20 & 37 & 147 \\
\hline C2E_AK_1 & & 86 & 108 & 235 \\
\hline CH_HD_1 & & 134 & 152 & 400 \\
\hline CHP_AK_1 & & 134 & 152 & 160 \\
\hline RF_HD_2 & & 177 & 296 & 757 \\
\hline RF_HD_1 & & 167 & 222 & 210 \\
\hline \multicolumn{2}{|c|}{ Média (Não localizados) } & 120,80 & 128,60 & 316,33 \\
\hline \multicolumn{2}{|c|}{ Média (Localizados) } & 22,98 & 18,39 & 36,31 \\
\hline
\end{tabular}

Para analisar a influência do tipo de defeito com relação aos roteiros R-MCP, RMCT e a lista LSN, foram avaliadas a quantidade de defeitos que R-MCP, R-MCT e LSN conseguiram localizar com um número menor de cliques. A Tabela 5.21 apresenta a quantidade de defeitos de integração em que R-MCP, R-MCT e LSN necessitaram de menos cliques usando CL e CHC. A Tabela 5.22 traz a mesma comparação para defeitos de unidade.

A coluna Qtde. indica a quantidade de defeitos em que R-MCP, R-MCT e LSN precisaram de menos cliques e a coluna \% mostra o percentual em relação ao total de defeitos de integração ou unidade. Foram considerados os defeitos que foram localizados com e sem o uso da suspeição delta. Para os casos em que R-MCP, R-MCT ou LSN obtiveram o mesmo número mínimo de cliques, ambos foram considerados como tendo o menor número de cliques.

Na Tabela 5.21, usando CL, R-MCP precisou de menos cliques para 25 defeitos entre os 40 defeitos de integração, o que representa 62,50\% do total. R-MCT obteve 23 defeitos em que precisou de um menor número de cliques com CL, enquanto LSN obteve 17 defeitos para essas condições. Usando CHC, R-MCP e R-MCT precisam de menos cliques para 23 defeitos, e LSN teve uma quantidade menor de cliques para 25 defeitos. 
Na Tabela 5.22, dos 9 defeitos existentes, R-MCP teve um menor número de cliques em 6 usando CL, enquanto para R-MCT esta situação ocorreu para 7 defeitos e para LSN em apenas 1 defeito. Usando CHC, R-MCP teve 2 defeitos com menos cliques e R-MCT e LSN tiveram 4 defeitos com menor número de cliques.

Pelos resultados apresentados nas Tabelas 5.21 e 5.22, não há evidências de que o tipo de defeito seja identificado de modo mais eficaz por R-MCP, R-MCT ou LSN.

Tabela 5.21 - Quantidade de defeitos de integração em que a cobertura foi mais eficaz.

\begin{tabular}{|l||r|r|r|r|}
\hline \multirow{2}{*}{ Roteiro } & \multicolumn{2}{|c|}{ CL } & \multicolumn{2}{c|}{ CHC } \\
\cline { 2 - 5 } & Qtde. & $\%$ & Qtde. & $\%$ \\
\hline R-MCP & 25 & 62,50 & 23 & 57,50 \\
\hline R-MCT & 23 & 57,50 & 23 & 57,50 \\
\hline LSN & 17 & 42,50 & 25 & 62,50 \\
\hline
\end{tabular}

Tabela 5.22 - Quantidade de defeitos de unidade em que a cobertura foi mais eficaz.

\begin{tabular}{|l||r|r|r|r|}
\hline \multirow{2}{*}{ Roteiro } & \multicolumn{2}{|c|}{ CL } & \multicolumn{2}{c|}{ CHC } \\
\cline { 2 - 5 } & Qtde. & $\%$ & Qtde. & $\%$ \\
\hline R-MCP & 6 & 66,67 & 2 & 22,22 \\
\hline R-MCT & 7 & 77,78 & 4 & 44,44 \\
\hline LSN & 1 & 11,11 & 4 & 44,44 \\
\hline
\end{tabular}

\subsection{Análise estatística}

Esta seção apresenta os procedimentos e resultados da análise estatística realizada para responder às questões de pesquisa referentes a este projeto. O objetivo desta análise é verificar se existem diferenças significativas na eficácia de localização entre os roteiros de busca R-MCP e R-MCT e a lista LSN, considerando os casos em que R-MCP, R-MCT e LSN usam a hierarquia de código e os casos em que essa heurística de busca não é utilizada. Também é feita uma comparação entre a quantidade de métodos indicados por R-MCP e R-MCT. 


\subsubsection{Procedimentos realizados}

Foram considerados os defeitos localizados por pelo menos um entre R-MCP, R-MCT e LSN. Para os casos em que R-MCP, R-MCT ou LSN não localizaram o defeito ou ultrapassaram o limite estabelecido foi atribuído o valor do limite do número de cliques mais um (71). Não ocorreu nenhum caso em que foi necessário usar esse ajuste para a quantidade de métodos examinados. O programa utilizado para realizar a análise estatística foi o $R$, versão 2.15.2 (GENTLEMAN; IHAKA, 2012).

Para escolher o modelo de teste estatístico mais adequado para os dados a serem analisados, foi utilizado o teste de hipótese de distribuição normal de Anderson-Darling. Este teste verifica se uma amostra de dados possui uma determinada distribuição (ENGINEERING..., 2012). Para todos os dados obtidos nos experimentos, com significância estatística de 1\%, é possível afirmar que esses dados não possuem uma distribuição normal.

A Tabela 5.23 mostra os valores p obtidos pelo teste de Anderson-Darling para as amostras de quantidades de cliques obtidas para R-MCP, R-MCT e LSN usando CL e CHC. A Tabela 5.24 mostra os valores $p$ para as posições dos métodos defeituosos obtidos de R-MCP e R-MCT (Qtde. Métodos) e para as posições médias dos defeitos nas listas de suspeição de Nós (Pos. Média).

Outras formas de verificar se os dados possuem distribuição normal são o gráfico quantil-quantil e o histograma. As Figuras 5.4, 5.5 e 5.6 apresentam os gráficos quantilquantil para as quantidades de cliques usando CL para R-MCP, R-MCT e LSN. Os pontos nesses gráficos representam as amostras de cliques, que não acompanham a linha teórica que representa a distribuição normal. As Figuras 5.7, 5.8 e 5.9 mostram os histogramas das quantidades de cliques para R-MCP, R-MCT e LSN usando CHC, cujas distribuições esparsas indicam que os dados analisados não possuem distribuição normal.

Tabela 5.23 - Valores p para o teste de Anderson-Darling para $R$-MCP, R-MCT e LSN.

\begin{tabular}{|l||r|r|r|r|r|r|}
\hline \multirow{2}{*}{ Anderson-Darling } & \multicolumn{3}{c|}{ CL } & \multicolumn{3}{c|}{ CHC } \\
\cline { 2 - 7 } & R-MCP & R-MCT & LSN & R-MCP & R-MCT & LSN \\
\hline Valor $p$ & $4.066 \mathrm{e}-06$ & $7.846 \mathrm{e}-07$ & $1.024 \mathrm{e}-05$ & $6.598 \mathrm{e}-10$ & $2.228 \mathrm{e}-10$ & $1.653 \mathrm{e}-09$ \\
\hline
\end{tabular}

Tabela 5.24 - Valores p para o teste de Anderson-Darling para Qtde. Métodos e Pos. Média.

\begin{tabular}{|l||r|r|r|}
\hline \multirow{2}{*}{ Anderson-Darling } & \multicolumn{2}{|c|}{ Qtde. Métodos } & Pos. Média \\
\cline { 2 - 4 } & R-MCP & R-MCT & Nós \\
\hline Valor $p$ & $1.205 \mathrm{e}-08$ & $5.043 \mathrm{e}-10$ & $2.2 \mathrm{e}-16$ \\
\hline
\end{tabular}




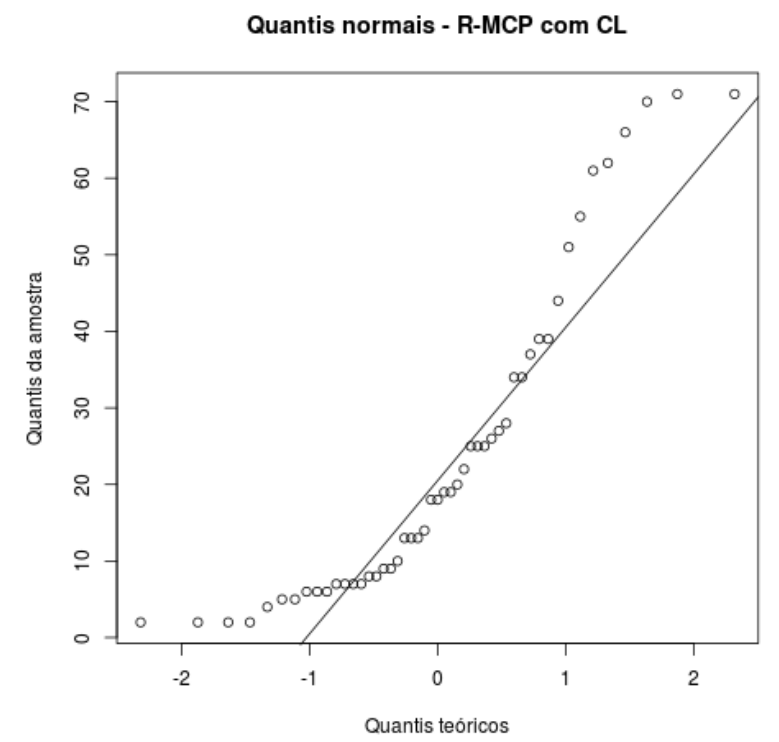

Figura 5.4 - Gráfico quantil-quantil para R-MCP usando $C L$.

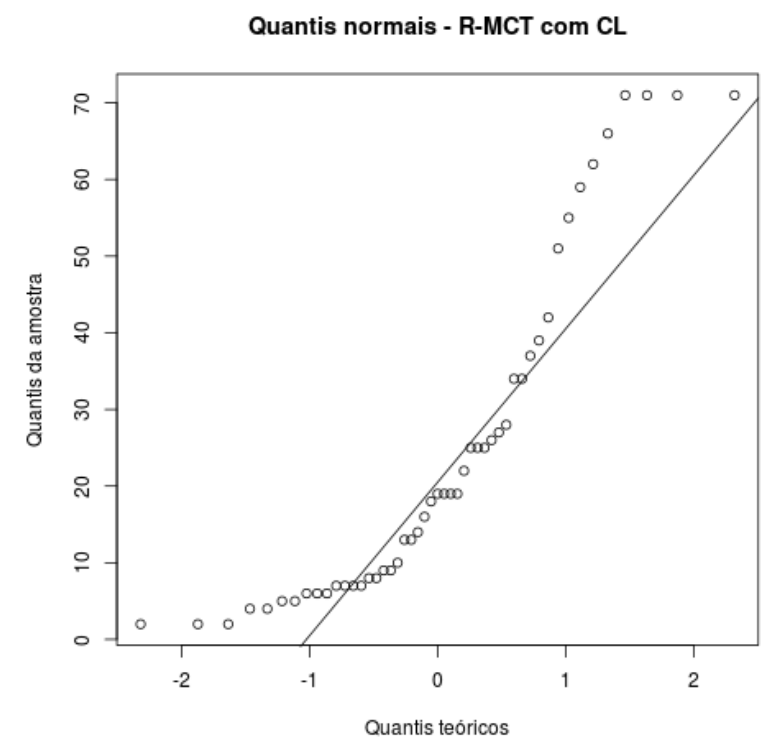

Figura 5.5 - Gráfico quantil-quantil para R-MCT usando $C L$. 


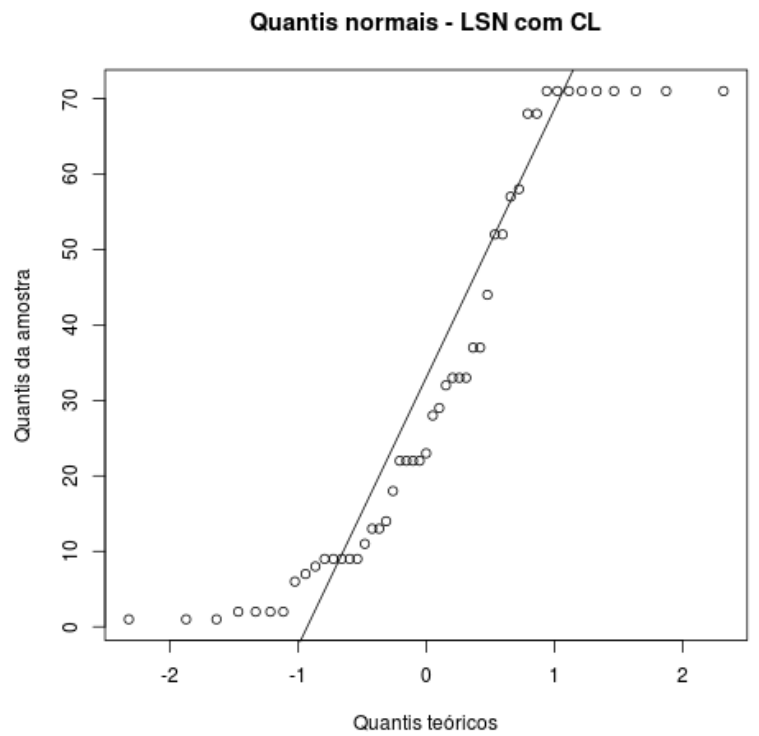

Figura 5.6 - Gráfico quantil-quantil para LSN usando CL.

Histograma - R-MCP com CHC

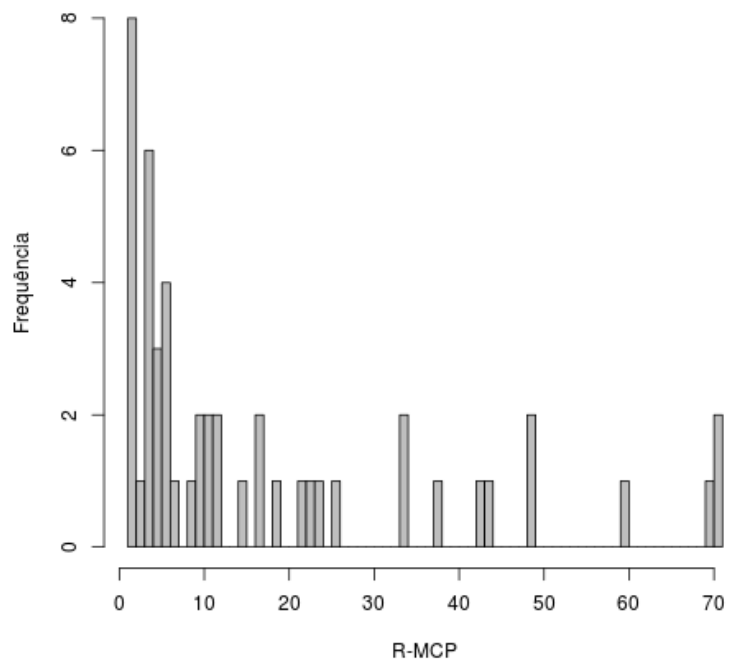

Figura 5.7 - Histograma para $R-M C P$ usando $C H C$. 


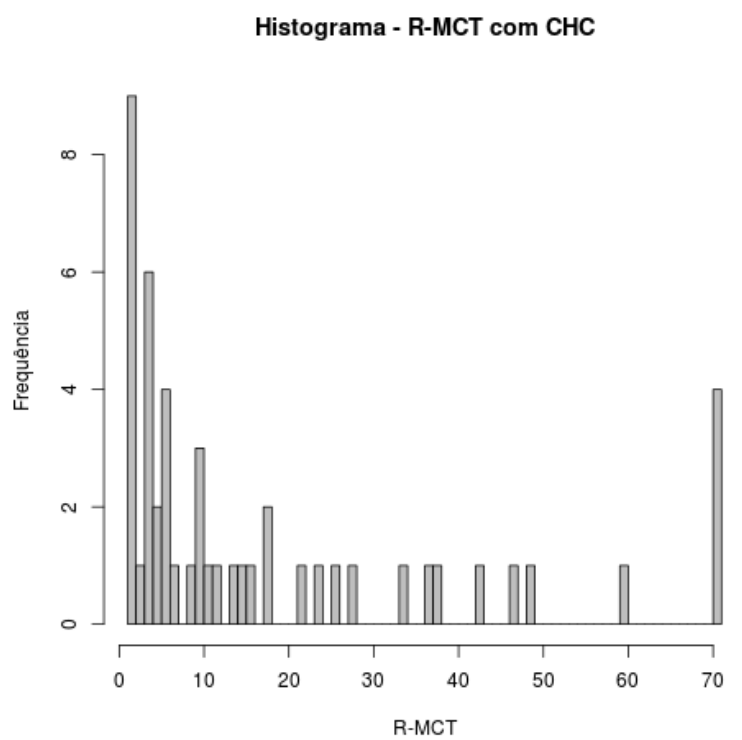

Figura 5.8 - Histograma para $R-M C T$ usando $C H C$.

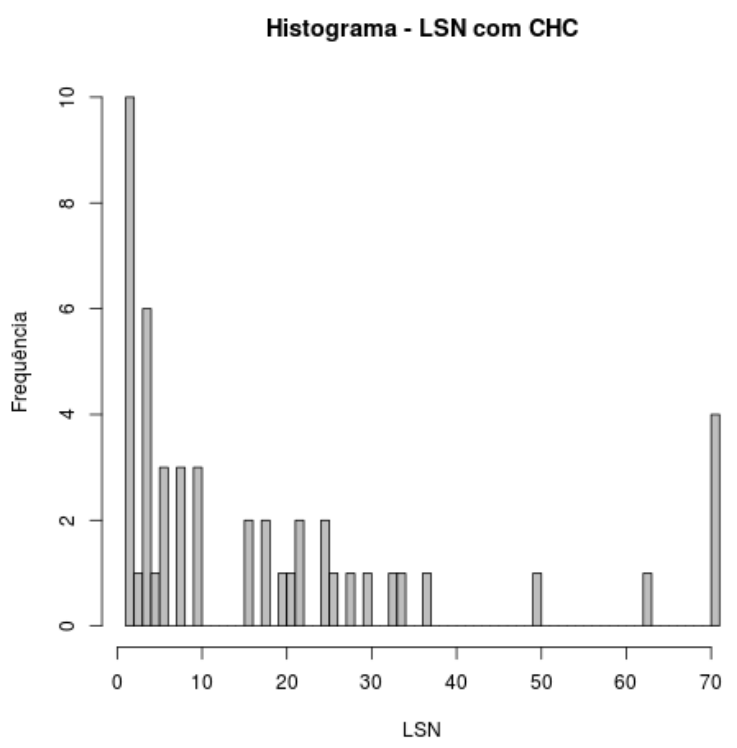

Figura 5.9 - Histograma para $L S N$ usando $C H C$. 
Portanto, para realizar o teste de hipótese, foi necessário selecionar um teste nãoparamétrico para realizar uma comparação entre dados das amostras, que são pareados e dependentes. Entre as opções estavam o Teste de Postos de Sinais de Wilcoxon e o Teste dos Sinais. O teste de postos de sinais de Wilcoxon serve para determinar se duas amostras dependentes possuem a mesma distribuição (LARSON; FARBER, 2010, p. 485-527).

No entanto, não foi possível utilizar esse teste porque ele parte da suposição de que os dados sejam contínuos. Foi escolhido o teste dos sinais de amostra emparelhada. O teste dos sinais faz menos suposições que o teste de Wilcoxon, sem exigir que os dados sejam contínuos, e é usado para testar a diferença entre duas amostras contra um valor hipotético para a mediana das amostras. O teste dos sinais é menos robusto que o teste de Wilcoxon porque considera somente os sinais das diferenças entre as amostras emparelhadas, enquanto o teste de Wilcoxon considera a magnitude das diferenças dessas amostras. Entretanto, o teste dos sinais pode ser usado para dados discretos (SÁ, 2007, p. 171-222).

A partir das diferenças entre as amostras comparadas, é feita a comparação para verificar se a mediana é igual zero. Nesse caso, a hipótese nula é confirmada e não há diferença significativa entre os valores comparados, considerando o nível de significância de $95 \%$. A hipótese alternativa é que o primeiro valor da comparação é maior que o segundo, o que significa que o segundo conjunto de amostras é mais eficaz que o primeiro, necessitando de menos cliques para localizar o defeito. A seguir, são descritos os testes realizados para avaliar as coberturas, métricas e estratégias propostas.

\subsubsection{Teste de hipótese I - R-MCP, R-MCT e LSN com a métrica CL}

Foi comparada a eficácia de localização entre R-MCP, R-MCT e LSN usando a métrica CL para atingir o defeito. Os resultados são apresentados na Tabela 5.25 e detalhados a seguir.

Tabela 5.25 - Valores p obtidos para o teste de hipótese I.

\begin{tabular}{|r|r|r|}
\hline R-MCP X LSN (\%) & R-MCT X LSN (\%) & R-MCP X R-MCT (\%) \\
\hline 0,39 & 2,72 & 50 \\
\hline
\end{tabular}

\section{Comparação entre R-MCP e LSN}

Hipótese nula: A eficácia de R-MCP é igual à eficácia de LSN usando CL.

Hipótese alternativa: R-MCP é mais eficaz que LSN usando CL. 
Para esta comparação, o valor $p$ obtido foi 0,003958 ou $0,39 \%$. A hipótese nula foi rejeitada com significância de 5\%, indicando que R-MCP é mais eficaz que LSN usando CL para localizar o defeito.

\section{Comparação entre R-MCT e LSN}

Hipótese nula: A eficácia de R-MCT é igual à eficácia de LSN usando CL.

Hipótese alternativa: R-MCT é mais eficaz que LSN usando CL.

O valor $p$ foi de 2,72\%, rejeitando a hipótese nula. Pode-se afirmar que R-MCT é mais eficaz que LSN para a localização de defeitos usando CL, com significância estatística de $5 \%$.

\section{Comparação entre R-MCP e R-MCT}

Hipótese nula: A eficácia de R-MCP é igual à eficácia de R-MCT usando CL.

Hipótese alternativa: R-MCP é mais eficaz que R-MCT usando CL.

O valor $p$ obtido para esta comparação foi de 50\%. Assim, a hipótese nula é confirmada, e não há diferença entre as eficácias de R-MCP e R-MCT para a localização de defeitos usando CL.

\subsubsection{Teste de Hipótese II - R-MCP, R-MCT e LSN com a métrica $\mathrm{CHC}$}

Para esse teste foi comparada a eficácia de localização entre R-MCP, R-MCT e LSN usando CHC. Os valores $p$ obtidos são mostrados na Tabela 5.26.

Tabela 5.26 - Valores p obtidos para o teste de hipótese II.

\begin{tabular}{|r|r|r|}
\hline R-MCP X LSN (\%) & R-MCT X LSN (\%) & R-MCP X R-MCT (\%) \\
\hline 74,43 & 84,47 & 80,62 \\
\hline
\end{tabular}

\section{Comparação entre R-MCP e LSN}

Hipótese nula: A eficácia de R-MCP é igual à eficácia de LSN usando CHC.

Hipótese alternativa: R-MCP é mais eficaz que LSN usando CHC. 
O valor $p$ obtido na comparação entre R-MCP e LSN foi de 74,43\%, o que indica não haver diferenças na eficácia de localização de R-MCP e LSN considerando o uso de CHC.

\section{Comparação entre R-MCT e LSN}

Hipótese nula: A eficácia de R-MCT é igual à eficácia de LSN usando CHC.

Hipótese alternativa: R-MCT é mais eficaz que LSN usando CHC.

Comparando R-MCT e LSN o valor $p$ foi de $84,47 \%$, de modo que não há diferença com significância estatística entre R-MCT e LSN usando CHC.

\section{Comparação entre R-MCP e R-MCT}

Hipótese nula: A eficácia de R-MCP é igual à eficácia de R-MCT usando CHC.

Hipótese alternativa: R-MCP é mais eficaz que R-MCT usando CHC.

O valor $p$ foi de 80,62\% para o teste dos sinais entre R-MCP e R-MCT. Portanto, não há diferença entre a eficácia de localização entre os dois roteiros usando CHC.

\subsubsection{Teste de Hipótese III - Uso de CHC e CL para R-MCP, R-MCT e LSN}

Para esse teste foi comparada a eficácia de localização usando as métricas CHC e CL para R-MCP, R-MCT e LSN. A Tabela 5.27 mostra os valores $p$ obtidos por R-MCP, R-MCT e LSN usando CL e CHC.

Tabela 5.27 - Valores p obtidos para o teste de hipótese III.

\begin{tabular}{|r|r|r|}
\hline \multicolumn{3}{|c|}{ CL X CHC } \\
\hline R-MCP (\%) & R-MCT (\%) & LSN (\%) \\
\hline $1.819 \mathrm{e}-10$ & $1.819 \mathrm{e}-10$ & $7.276 \mathrm{e}-10$ \\
\hline
\end{tabular}

\section{Comparação do uso de CHC e CL para R-MCP}

Hipótese nula: A eficácia de R-MCP é igual usando CHC ou CL.

Hipótese alternativa: O uso de CHC melhora a eficácia de localização para R-MCP. 
Comparando a quantidade de cliques usando CHC e CL para R-MCP, o valor $p$ foi de $1.819 \mathrm{e}-10 \%$, indicando que o uso de CHC foi mais eficaz na localização de defeitos com significância estatística de $5 \%$.

\section{Comparação do uso de CHC e CL para R-MCT}

Hipótese nula: A eficácia de R-MCT é igual usando CHC ou CL.

Hipótese alternativa: O uso de CHC melhora a eficácia de localização para R-MCT.

Para R-MCT, o valor $p$ foi o mesmo da comparação para R-MCP, 1.819e-10\%, indicando também que o uso de CHC foi mais eficaz para localizar os defeitos para R-MCT.

\section{Comparação do uso de CHC e CL para LSN}

Hipótese nula: A eficácia de LSN é igual usando CHC e CL.

Hipótese alternativa: O uso de CHC melhora a eficácia de localização para LSN.

O valor $p$ foi de $7.276 \mathrm{e}-10 \%$ para a comparação do uso de CHC para LSN. Assim, o uso de CHC foi significativamente mais eficaz para a localização de defeitos também para LSN.

\subsubsection{Teste de Hipótese IV - Posição dos métodos defeituosos em R-MCP e R-MCT}

O objetivo deste teste foi comparar a posição de classificação dos métodos defeituosos entre os roteiros de busca R-MCP e R-MCT para avaliar se algum dos roteiros classifica os métodos defeituosos de forma mais eficaz que o outro.

\section{Comparação da posição dos métodos defeituosos entre R-MCP e R-MCT}

Hipótese nula: A eficácia de classificação dos métodos defeituosos é igual entre R-MCP e R-MCT.

Hipótese alternativa: A classificação dos métodos defeituosos em R-MCP é mais eficaz do que em R-MCT.

O valor $p$ obtido para este teste foi de $72,56 \%$, o que significa que não há diferença entre as posições em que os métodos defeituosos são classificados por R-MCP e R-MCT. 


\subsection{Discussão}

\subsubsection{Considerações gerais}

Nesta seção é feita a discussão dos resultados obtidos pela técnica DCI. A técnica propõe o uso de cobertura de integração para auxiliar a localização de defeitos. Uma das formas de obter informações de integração é a geração das coberturas de integração MCP e MCT. Essas coberturas são usadas pela DCI para indicar os pares ou triplas de chamadas de métodos mais suspeitas de conter defeitos, por meio da geração de listas dos requisitos mais suspeitos de conter defeitos.

A partir dessas listas classificadas por ordem de suspeição são gerados os roteiros de busca, tanto para MCP quanto para MCT, contendo os métodos que estão presentes nas listas de suspeição. No roteiro de busca, os métodos são organizados pela ordem em que aparecem na lista de suspeição, com o maior valor de suspeição com o qual são classificados, sendo registrados uma única vez no roteiro. A ideia do roteiro de busca é criar um guia para que o programador procure o defeito a partir dos métodos mais suspeitos exercitados na integração ocorrida e capturada durante a execução dos testes. Para permitir que a busca seja feita dentro dos métodos, são acrescentadas informações de cobertura de unidade, como a cobertura de Nós utilizada nos experimentos.

A DCI gera também uma lista que ordena os requisitos de unidade (no caso Nós) dentro de sua hierarquia de código, atribuindo aos pacotes, classes e métodos o maior valor de suspeição atingido pelos seus requisitos internos, assim como a quantidade de requisitos que possui tal valor. O objetivo é indicar quais pacotes, classes e métodos contêm os requisitos mais suspeitos, servindo como uma heurística de busca para indicar quais desses pacotes, classes e métodos devem ser verificados primeiro na busca pelo defeito.

Para avaliar a DCI, foi proposta a métrica de quantidade de cliques para localizar o defeito supondo duas situações: a quantidade de cliques necessários para chegar usando a organização por hierarquia de código proposta $(\mathrm{CHC})$ e a quantidade máxima de cliques necessária sem uso da hierarquia de código (CL), que considera todos os nós retornados que contenham os mesmos valores que o nó defeituoso. Foi estabelecido um critério de parada para a quantidade de cliques e métodos a serem inspecionados com o objetivo de tornar a tarefa de depuração viável para um programador que esteja procurando pelo defeito. Os limites de 70 cliques e 20 métodos foram estabelecidos arbitrariamente, de forma que o programador tenha que verificar aproximadamente uma quantidade de 100 
linhas de código sem desistir de usar a técnica, considerando que um nó pode equivaler a mais de uma linha de código.

A ideia de estabelecer esses limites é evitar a avaliação do desempenho das técnicas com uso de valores relativos, como no caso da métrica EXAM score. Na métrica EXAM score, ao determinar uma porcentagem de código a ser inspecionado, o número de requisitos pode ser grande dependendo do tamanho do programa, o que pode dificultar a adoção da técnica de depuração automatizada na prática, como foi apontado por Parnin e Orso (2011). Portanto, o uso de um valor absoluto, como a quantidade de cliques, indica para o programador um determinado número de requisitos que ele vai precisar examinar para localizar o defeito independente do tamanho do programa.

A técnica DCI também propõe o uso de um valor de suspeição delta para os casos em que o defeito não foi localizado usando o valor de suspeição do método indicado pelo roteiro de busca. O valor adotado varia de $97 \%$ a 100\% do valor de suspeição do método, permitindo que nós que contenham um valor de suspeição até $3 \%$ menor que o valor de suspeição do método sejam considerados durante a busca pelo defeito. Dessa forma, é possível localizar uma quantidade maior de defeitos, e a quantidade de cliques para os defeitos que necessitaram do uso da suspeição delta continua dentro dos critérios de parada estabelecidos para este trabalho.

Analisando os defeitos existentes, foi observado que esse tipo de situação costuma ocorrer em defeitos presentes em comandos condicionais. Durante a execução, um defeito em um comando condicional pode ocasionar um erro que faz com que, sempre que o nó interno a esse comando defeituoso seja percorrido (dependência de controle, ver Apêndice B), ocorra uma falha. No entanto, esse comando condicional pode ser executado por casos de teste de sucesso sem que o nó interno ao comando condicional seja percorrido. Tal fato pode fazer com que as heurísticas de localização atribuam um valor maior para esse nó dependente do que para o nó que realmente contém o defeito. Para os experimentos realizados, o uso da suspeição delta auxiliou a localização de alguns defeitos que comportam-se da forma que foi explicada. Além disso, para os defeitos em que foi necessário o uso do valor delta, a quantidade de cliques não excedeu o limite estabelecido.

\subsubsection{Utilizando a DCI para a localização de defeitos}

Foram utilizados programas reais para os experimentos e a maioria dos defeitos foi localizada usando as estratégias propostas. Tal fato indica a possibilidade de uso da DCI em outros programas de médio e grande porte, embora mais experimentos sejam 
necessários para comprovar sua eficácia. Para o programa Commons-Math, contendo defeitos reais, com o uso dos roteiros de busca R-MCP e R-MCT foi possível identificar todos os defeitos. Já para o programa XML-security, dos 13 defeitos avaliados, R-MCP, R-MCT e LSN localizaram 4, 3 e 5 defeitos, respectivamente.

A maioria dos defeitos não localizados do XML-security possui um grande número de nós classificados com altos valores de suspeição, na ordem de algumas centenas de nós, o que fez com que os limites estabelecidos fossem ultrapassados. Portanto, para os casos em que há muitos requisitos classificados com altos valores de suspeição, o uso da DCI pode não colaborar para a localização dos defeitos. Para tais casos, o uso da lista de suspeição de Nós vai acarretar problema semelhante. Dessa forma, é necessário refinar os casos de teste para obter melhores resultados para esses programas.

Os experimentos mostraram que R-MCP e R-MCT têm uma eficácia de localização parecida para maioria dos defeitos avaliados, com algumas exceções. Considerando a eficácia de localização sem o uso da hierarquia de código, R-MCP e R-MCT superam LSN. Utilizando a hierarquia de código, os resultados obtidos por R-MCP, R-MCT e LSN são semelhantes, o que demonstra que a lista LSN, que é equivalente à lista de requisitos de Nós, apresentou uma melhoria em sua eficácia usando essa abordagem.

Pode-se dizer que a abordagem HC funciona como uma heurística de busca que utiliza informações estáticas de integração (pacotes, classes e métodos aos quais os nós pertencem) para a cobertura de unidade, indicando pacotes, classes e métodos do programa que podem ser verificados primeiro na procura por defeitos. Ao invés de fornecer apenas uma lista com os requisitos mais suspeitos, o uso de informações sobre a estrutura do código traz mais informações sobre o contexto do programa, o que é apontado por programadores que participaram de experimentos realizados por Parnin e Orso (2011) como uma forma de auxiliar a localização de defeitos.

De forma inversa, os roteiros de busca, baseados nas informações dinâmicas das coberturas de integração MCP e MCT, usam informações de cobertura de unidade para possibilitar a busca pelo defeito nos nós que estão contidos dentro dos métodos considerados suspeitos. Portanto, ao verificar um método suspeito, pode-se utilizar HC para investigar os requisitos de unidades relacionados àquele método, o que seria mais difícil de identificar tendo somente uma lista de requisitos de unidade ordenada por valores de suspeição sem as informações sobre o método ao qual pertencem.

Quanto à localização de defeitos de integração, a técnica DCI, por meio dos roteiros de busca R-MCP e R-MCT, não apresentou uma melhor eficácia de localização em relação 
à lista LSN. O desempenho para os defeitos de unidade também foi semelhante entre RMCP, R-MCT e LSN. Quanto à eficácia de localização em defeitos reais ou semeados, os resultados obtidos não indicam uma diferença de eficácia entre R-MCP, R-MCT e LSN. As diferenças obtidas parecem estar mais relacionadas à capacidade dos casos de teste

de exercitar de forma mais precisa o código que está sendo testado. Por exemplo, os programas Commons-Math e Ant possuem casos de teste que testam métodos específicos, o que pode colaborar para refinar os requisitos que são executados durante cada teste.

\subsubsection{Respondendo às questões de pesquisa}

Para responder objetivamente às questões de pesquisa, serão considerados os resultados obtidos pelos testes de hipótese realizados na Seção 5.8 .

1. DCI é mais eficaz para a localização de defeitos do que a cobertura de unidade?

O esforço de localização para os roteiros de busca R-MCP e R-MCT é menor em comparação com LSN considerando o uso de CL. Utilizando CHC, não há diferença na quantidade de cliques entre os roteiros baseados nas coberturas propostas pela técnica DCI e a lista de cobertura de Nós. Porém, ao considerar que as informações fornecidas pela hierarquia de código acrescentam informações estáticas de integração para a cobertura de Nós, a DCI possui um menor esforço de localização, pois consegue-se reduzir significativamente o esforço de localização da cobertura de Nós com o uso da hierarquia de código na comparação com a cobertura de Nós sem uso das informações de hierarquia de código.

2. DCI é mais eficaz para a localização de defeitos de integração do que a cobertura de unidade?

Não houve diferença significativa de eficácia de localização para os defeitos de integração e para os defeitos de unidade usando R-MCP, R-MCT e LSN, com ou sem uso da hierarquia de código.

3. O uso do roteiro de busca por métodos pode tornar a localização de defeitos mais eficaz?

Considerando o uso da métrica CL, os roteiros de busca R-MCP e R-MCT são significativamente mais eficazes para a localização de defeitos que LSN.

4. O acréscimo de informações estáticas de integração sobre os requisitos de unidade pode tornar a localização de defeitos mais eficaz? 
Sim. A abordagem de organização por hierarquia de código conseguiu melhorar a eficácia de localização de LSN. Usando a métrica CL, R-MCP e R-MCT conseguiram uma maior eficácia de localização que LSN com significância estatística de 5\%. Já com o uso de CHC, não houve diferenças significativas entre as três coberturas, o que mostra que HC melhorou a localização da cobertura de Nós.

5. A técnica DCI é eficaz para localizar defeitos em programas reais?

Sim. A DCI conseguiu localizar 78,18\% dos defeitos usando R-MCP e 74,55\% com RMCT. Já com LSN foram localizados 76,16\% dos defeitos. No entanto, a quantidade de defeitos que possuem requisitos com altos valores de suspeição influenciam a capacidade de localização da DCI.

6. O uso do valor de suspeição delta melhora a localização de defeitos?

Devido à quantidade de casos em que foi utilizado delta, não foi feito um teste estatístico para responder a essa questão. Na maioria dos casos em que foi usado o valor de suspeição delta, o defeito foi localizado. Para R-MCP, em 10 das 11 vezes em que delta foi usado o defeito foi localizado. Para R-MCT, em 9 das 13 vezes em que necessitou-se do valor de suspeição delta o defeito foi localizado e para LSN em 7 de 11 vezes o defeito foi localizado. Vale ressaltar que, tanto para R-MCP quanto para R-MCT e LSN, um dos casos em que a suspeição delta não colabora é o defeito do programa JTopas em que o nó defeituoso não é coberto pelo InSS.

\subsection{Ameaças à validade}

Os resultados obtidos pela técnica DCI limitam-se às versões dos programas que foram utilizados nos experimentos, não podendo ser generalizados para outros programas, versões ou defeitos diferentes dos avaliados neste trabalho. Podem ocorrer variações nos comportamentos dos defeitos que foram avaliados dependendo do computador e/ou sistema operacional em que forem executados. No entanto, tratam-se de programas reais, isto é, desenvolvidos para utilização efetiva, de médio e grande porte. Além disso, na prática, um único programador não irá depurar um programa com milhões de linhas de código, mas um módulo de médio porte; por isso, os programas selecionados são uma aproximação razoável da tarefa de depuração de um programador.

Ao supor a métrica de quantidade de cliques para localizar o defeito, está sendo considerada a situação de detecção perfeita, em que o defeito é localizado imediatamente 
ao ser examinado pelo programador. Esta situação pode não refletir um processo real de localização, visto que o programador pode examinar o comando defeituoso e não identificar o defeito. O orçamento de 70 cliques ou 20 métodos tem o objetivo de limitar essa suposição de detecção perfeita: se o defeito não for encontrado depois de 70 cliques ou 20 métodos visitados ele deve parar o processo e utilizar outra técnica de depuração.

Na CodeForest, os valores de suspeição obtidos no filtro trimmer possuem duas casas decimais, o que pode fazer com que sejam retornadas mais folhas e galhos do que o desejado, contendo diferenças da ordem de milésimos dos valores de suspeição. Assim, os experimentos realizados possuem essa limitação, que é igual para R-MCP, R-MCT e LSN. Outra limitação relativa à CodeForest é a possíbilidade de cliques repetidos ocorridos durante os experimentos. Em algumas ocasiões, realizar a busca por termos para métodos diferentes pode retornar os mesmos nós em diferentes pesquisas, o que pode fazer com que tenham sido contados cliques a mais para R-MCP e R-MCT, que usam esse filtro, fato que não ocorre com LSN.

Um fator que pode ter colaborado na localização dos defeitos para o Commons-Math é a precisão dos casos de teste deste programa. Para a maioria dos defeitos, existe apenas um caso de teste que falha e que testa especificamente o método que contém o defeito. A mesma situação ocorre para alguns defeitos do programa Ant. A consequência da existência desse tipo de conjunto de teste é que a eficácia de localização pode ser diferente em outros programas que não possuam casos de teste com essas características.

Porém, os programas JTopas e XML-security não possuem testes tão precisos como os testes dos programas Ant e Commons-Math, de forma que experimentos em programas com testes menos precisos também foram realizados. O defeito CNC_AK_1 do XMLsecurity, por exemplo, faz com que 23 dos 92 casos de teste existentes falhem. Esses casos de testes que falham estão distribuídos em 7 classes JUnit diferentes.

Durante os experimentos, alguns casos de teste foram retirados por causarem estouro de memória quando durante a coleta das informações de cobertura de MCP e/ou MCT. Esses casos de teste foram retirados dos experimentos para todas as coberturas. O uso desses casos de teste poderia alterar a posição de classificação dos requisitos de suas respectivas listas. 


\subsection{Considerações finais}

Este capítulo apresentou os procedimentos realizados para a execução dos experimentos, as questões de pesquisa, variáveis e métricas utilizadas. Os resultados obtidos foram sumarizados e analisados. Em seguida, foi feita uma análise estatística para possibilitar que as questões de pesquisa fossem respondidas, comparando a eficácia da técnica DCI para a localização de defeitos com a cobertura de Nós.

Os resultados obtidos foram discutidos e foram apresentadas as ameaças à validade identificadas. O próximo capítulo traz as conclusões, contribuições e trabalhos futuros relacionados a este projeto. 



\section{Conclusões}

Este trabalho apresentou a técnica Depuração de programas baseada em Cobertura de Integração (DCI) que propõe o uso da informações de cobertura de integração para a tarefa de localização de defeitos. A técnica é composta de duas coberturas propostas para este trabalho, MethodCallPair (MCP) e MethodCallTriple (MCT), baseadas em fluxo de controle, que representam as relações entre chamadas de método que ocorrem durante a execução dos testes. A DCI gera roteiros de busca por métodos para MCP (R-MCP) e MCT (R-MCT) contendo os métodos executados ordenados por valor de suspeição. Esses roteiros servem como um guia para a localização de defeitos, indicando uma sequência de métodos a serem examinados na busca pelo defeito. As informações de cobertura de unidade são usadas para procurar pelos nós defeituosos dentro dos métodos mais suspeitos. Os valores de suspeição foram obtidos usando a heurística Tarantula, que foi implementada para a técnica DCI. Os resultados mostram que os roteiros de busca R-MCP e R-MCT aumentam a eficácia da localização dos defeitos presentes nos programas reais usados nos experimentos.

A técnica DCI propõe também uma heurística de busca por defeitos que classifica os requisitos de unidade de acordo com sua organização hierárquica de código (HC), fornecendo informações estáticas de integração para os requisitos de unidade. Essa classificação atribui valores de suspeição aos pacotes, classes e métodos aos quais os requisitos pertencem, com base no maior valor de suspeição que seus requisitos atingem. Esses pacotes, classes e métodos recebem também um valor que representa a quantidade de requisitos internos que possuem o maior valor de suspeição. Assim, HC serve para indicar pacotes, classes e métodos que podem ser examinados primeiro na busca por defeitos. Usando HC na ferramenta de visualização de depuração CodeForest, foi possível melhorar a eficácia de localização de defeitos, em especial para a cobertura de unidade de Nós.

A métrica de quantidade de cliques é proposta para avaliar a eficácia na localização de defeitos da DCI e da cobertura de Nós. Foi adotado um critério de parada de 70 cliques para a localização do defeito, em cada clique implica um nó examinado, ou então 
a investigação de 20 métodos retornados nos roteiros de busca R-MCP e R-MCT. Entre $65 \%$ e $78 \%$ dos defeitos foram localizados atingindo esses limites, que foram estabelecidos arbitrariamente. O objetivo é mensurar uma quantidade absoluta de código a ser verificada, permitindo que o programador saiba qual é o esforço máximo que será empenhado para procurar por um defeito, independente do tamanho do programa.

A análise dos resultados mostra que o uso de R-MCP e R-MCT é mais eficaz que o uso da cobertura de Nós (LSN) sem uso de HC com significância estatística de $5 \%$ para o teste de hipótese dos sinais. Usando HC, há um aumento na eficácia de localização de LSN, e a partir de então não há diferenças significativas entre a eficácia de R-MCP, R-MCT e LSN.

Com o uso de HC, os roteiros R-MCP, R-MCT e a lista LSN foram mais eficazes para a localização de defeitos quando comparados com R-MCP, R-MCT e LSN sem uso de HC, com significância estatística de 5\%. Os testes de hipótese realizados mostram também que não diferença significativa no uso de R-MCP em relação a R-MCT.

Foi realizada uma análise dos defeitos usados nos experimentos, que foram classificados em defeitos de integração ou de unidade. No entanto, não foi verificada nenhuma diferença na eficácia de localização de R-MCP, R-MCT ou LSN para as duas categorias de defeitos. Quanto à comparação entre defeitos semeados e defeitos reais, R-MCP e R-MCT foram capazes de localizar todos os defeitos reais, enquanto que entre alguns defeitos semeados não foram localizados por R-MCP, R-MCT ou LSN. No entanto, a razão dessa diferença pode ser atribuída ao conjunto de testes mais precisos do programa que contém defeitos reais (Commons-Math). Como caso de teste mais preciso, considera-se aqueles que testam funcionalidades específicas em trechos de código como métodos, assemelhando-se a um caso de teste de unidade.

Conclui-se que o uso de informações estáticas e dinâmicas de cobertura de integração para a depuração automatizada é eficaz para a localização de defeitos para programas reais, acrescentando informações de contexto sobre o programa avaliado. O uso dessas informações de contexto dá-se por meio de roteiros de busca por métodos a serem verificados e pela indicação de uma ordenação dos pacotes, classes e métodos que podem ser verificados primeiro durante a busca pelo defeito. Além disso, o uso de informação de integração estática, que é a ordenação hierárquica dos pacotes, classes e métodos, alavancou o desempenho da cobertura de unidade (Nós) de forma a torná-la comparável ao uso dos roteiros R-MCP e R-MCT, baseados nas coberturas dinâmicas de integração (MCP e MCT). 


\subsection{Contribuições}

Este trabalho apresenta entre as suas principais contribuições:

1. Revisão sistemática sobre técnicas de depuração automatizada baseadas em cobertura de código.

2. Implementação de duas coberturas de integração, MCP e MCT, na ferramenta InSS.

3. Implementação da técnica DCI, que calcula a suspeição de requisitos de código e gera listas de classificação para diferentes coberturas e heurísticas.

4. Roteiros de busca de localização de defeitos que combinam cobertura de integração (R-MCP e R-MCT) com cobertura de unidade (nós).

5. Uma heurística de busca que ordena os requisitos de unidade de acordo com sua hierarquia de código (pacotes, classes e métodos), servindo como um guia para realizar a busca por defeitos a partir dos pacotes, classes e métodos que contenham mais requisitos suspeitos.

6. Um estudo experimental comparando a localização de defeitos usando a técnica DCI e a cobertura de unidade em programas reais.

7. Disponibilização de um novo programa contendo defeitos reais para experimentação de técnicas de teste e depuração de software .

\subsection{Trabalhos futuros}

Durante a realização deste trabalho, foram identificados vários aspectos que podem ser abordados para melhorar a localização de defeitos automatizada. Na fase de codificação, além da Tarantula, outras nove heurísticas foram implementadas: DRT, Jaccard, Kulczynski, McCon, Minus, Ochiai, $O^{p}$, Wong3, Zoltar. A avaliação do desempenho dessas heurísticas para a localização de defeitos com a DCI é um dos trabalhos futuros a ser realizado.

Outro trabalho que deve ser investigado é o desempenho da DCI para depurar programas contendo defeitos múltiplos. Essa avaliação é importante para permitir que a técnica possa ser usada para a localização de defeitos de forma prática, em programas em que não se conhece a quantidade de defeitos. 
O uso de informações de fluxo de dados para as coberturas de integração é uma outra linha de pesquisa a ser explorada futuramente, uma vez que as informações transmitidas entre variáveis globais e valores passados como parâmetros ou retornados entre métodos podem contribuir para a obtenção de mais informações de integração para a localização de defeitos.

A principal contribuição da técnica DCI é o uso de informações de integração para auxiliar a localização de defeitos. Outras informações sobre o código em execução podem colaborar ainda mais para melhorar a eficácia de localização. Uma ideia a ser estudada é a proposição de uma nova heurística de cálculo de suspeição que leve em consideração a quantidade de vezes que os requisitos são exercitados em uma mesma execução. Outra informação que pode ser avaliada é se a ordem de execução dos comandos pode influenciar a localização dos defeitos.

Uma alternativa para lidar com os defeitos em que foi necessário usar um valor delta para conseguir localizar os defeitos com as coberturas de integração é a geração de sublistas para cada método presente no roteiro de busca por métodos. Essas sublistas podem conter os valores de suspeição mais altos dos nós internos a cada um desses métodos. Dessa forma, utiliza-se mais informações das coberturas de unidade para as coberturas de integração. A realização de experimentos pode indicar se o uso dessa abordagem colabora para a localização de defeitos.

Os casos de teste utilizados parecem ter uma influência importante na localização de defeitos. Dessa forma, é possível realizar estudos para avaliar se casos de teste mais precisos colaboraram para melhorar a depuração automatizada.

Outra questão a ser avaliada é a granularidade dos casos de teste. Neste trabalho, as coberturas de cada método JUnit foram avaliadas separadamente. Os testes originais dos programas do repositório SIR geravam uma saída com os resultados de execução para cada classe JUnit. Quando apenas um método de uma classe JUnit falha e a classe inteira é considerada suspeita, a quantidade de requisitos classificados como suspeitos tende a aumentar. Um experimento para comparar o uso das informações divididas por método e por classe pode ser realizado para avaliar suas diferenças.

Para reduzir a quantidade de código a ser avaliado, pode-se estudar outras estratégias, como a possibilidade de filtrar trechos de código menos propensos a conter defeitos, como construtores de classes, e códigos de empacotamento, como getters e setters, muitas vezes gerados automaticamente por IDEs (Integrated Development Environment). Trechos de código executados na inicialização e finalização dos métodos JUnit, como nos métodos 
(setUp() / @Before) e (tearDown / @After) do JUnit também pode ser filtrados.

A realização de uma análise detalhada das características de cada defeito e a eficácia de localização da DCI e de diferentes heurísticas para tais defeitos também é um trabalho futuro que pode melhorar a eficácia das técnicas de depuração automatizada. Outro trabalho futuro é a realização de experimentos com indivíduos, importante para avaliar a usabilidade prática da técnica DCI em programas como a CodeForest. 



\section{Referências}

ABREU, R.; GONZÁLEZ, A.; ZOETEWEIJ, P.; GEMUND, A. J. C. van. Automatic software fault localization using generic program invariants. In: Proceedings of the 2008 ACM symposium on Applied computing. New York, NY, USA: ACM, 2008b. (SAC '08), p. 712 717. ISBN 978-1-59593-753-7. Disponível em: http://doi .acm.org/10.1145/1363686. 1363855.

ABREU, R.; ZOETEWEIJ, P.; GEMUND, A. J. C. van. On the accuracy of spectrumbased fault localization. In: Testing: Academic and Industrial Conference Practice and Research Techniques - MUTATION, 200\%. TAICPART-MUTATION 200\%. [s.n.], 2007. p. 89 -98. Disponível em: http://ieeexplore.ieee.org/xpl/freeabs_all.jsp? arnumber $=4344104$.

ABREU, R.; ZOETEWEIJ, P.; GEMUND, A. J. C. van. An observation-based model for fault localization. In: Proceedings of the 2008 international workshop on dynamic analysis: held in conjunction with the ACM SIGSOFT International Symposium on Software Testing and Analysis (ISSTA 2008). New York, NY, USA: ACM, 2008a. (WODA '08), p. 64-70. ISBN 978-1-60558-054-8. Disponível em: http://doi .acm.org/10.1145/ 1401827.1401841.

ABREU, R.; ZOETEWEIJ, P.; GEMUND, A. J. C. van. Simultaneous debugging of software faults. J. Syst. Softw., Elsevier Science Inc., New York, NY, USA, v. 84, p. 573586, April 2011. ISSN 0164-1212. Disponível em: http://dx.doi.org/10.1016/j.jss. 2010.11.915.

AGRAWAL, H.; ALBERI, J. L.; HORGAN, J. R.; LI, J. J.; LONDON, S.; WONG, W. E.; GOSH, S.; WILDE, N. Mining system tests to aid software maintenance. IEEE Computer, v. 31, n. 7, p. 64-73, July 1998.

AGRAWAL, H.; DEMILlO, R. A.; SPAFFORD, E. H. Dynamic slicing in the presence of unconstrained pointers. In: Proceedings of the Symposium on Software Testing, Analysis and Verification - TAV4. [S.l.: s.n.], 1991. p. 60-73.

ALI, S.; ANDREWS, J. H.; DHANDAPANI, T.; WANG, W. Evaluating the accuracy of fault localization techniques. In: 25 (Ed.). Proceedings of the 2009 IEEE/ACM International Conference on Automated Software Engineering. Washington, DC, USA: IEEE Computer Society, 2009. (ASE '09), p. 76-87. ISBN 978-0-7695-3891-4. Disponível em: http://dx.doi.org/10.1109/ASE. 2009.89.

ARAKI, K.; FURUKAWA, Z.; CHENG, J. A general framework for debbugging. IEEE Software, v. 8, n. 3, p. 14-20, 1991. 
ARAUJO, R. A.; ACCIOLY, A.; ALENCAR, F. A.; CHAIM, M. L. . Evaluating instrumentation strategies by program simulation. In: Proceedings of IADIS International Conference on Applied Computing (2011). Rio de Janeiro, Brazil: IADIS, 2011.

ARISTOTLE analysis system. Aristotle Research Group, 2007. Online. Disponível em: http://www.cc.gatech.edu/aristotle/. Acesso em: 06 jan. 2012.

BCEL (The Byte Code Engineering Library). The Apache Jakarta Project, Apache Software Foundation, 2003. Online. Disponível em: http://jakarta.apache.org/bcel. Acesso em: 05 jan. 2012.

BURGER, M.; ZELLER, A. Replaying and isolating failing multi-object interactions. In: Proceedings of the 2008 international workshop on dynamic analysis: held in conjunction with the ACM SIGSOFT International Symposium on Software Testing and Analysis (ISSTA 2008). New York, NY, USA: ACM, 2008. (WODA '08), p. 71-77. ISBN 978-160558-054-8. Disponível em: http://doi .acm.org/10.1145/1401827.1401842.

BURGER, M.; ZELLER, A. Minimizing reproduction of software failures. In: Proceedings of the 2011 International Symposium on Software Testing and Analysis. New York, NY, USA: ACM, 2011. (ISSTA '11), p. 221-231. ISBN 978-1-4503-0562-4. Disponível em: http://doi.acm.org/10.1145/2001420.2001447.

CHAIM, M. L.; ARAUJO, R. A. An Efficient Bit-wise Algorithm for Data-Flow Testing Coverage. 2012. Submetido para publicação.

CHAIM, M. L.; MALDONADO, J. C.; JINO, M. A debugging strategy based on requirements of testing. In: Proceedings of the Seventh European Conference on Software Maintenance and Reengineering. Washington, DC, USA: IEEE Computer Society, 2003. p. 160-. ISBN 0-7695-1902-4. Disponível em: http://dl.acm.org/citation.cfm?id= 872754.873600 .

CLEVE, H.; ZELLER, A. Locating causes of program failures. In: Proceedings of the ACM/IEEE 27th International Conference on Software Engineering. [S.l.: s.n.], 2005. (ICSE '05), p. 342-351.

CLOVER. Atlassian, 2012. Online. Disponível em: http://www.atlassian.com/ software/clover/. Acesso em: 05 jan. 2012.

COLLOFELLO, J. S.; COUSINS, L. Toward automatic software fault localization through decision-to-decision path analysis. In: Proceedings of the AFIP 1987 National Computer Conference. Chicago: [s.n.], 1987. p. 539-544.

COMMONS-MATH. The Apache Software Foundation, 2012. Online. Disponível em: http://commons . apache.org/math/.

DANIAL, A. Count Lines of Code, CLOC. 2012. Online. Disponível em: http://cloc. sourceforge.net/.

DEAN, B. C.; PRESSlY, W. B.; MALlOY, B. A.; WHITLEY, A. A. A linear programming approach for automated localization of multiple faults. In: Proceedings of the 2009 IEEE/ACM International Conference on Automated Software Engineering. Washington, DC, USA: IEEE Computer Society, 2009. (ASE '09), p. 640-644. ISBN 978-0-7695-3891-4. Disponível em: http://dx.doi.org/10.1109/ASE.2009.54. 
DEBROY, V.; WONG, W. Using mutation to automatically suggest fixes for faulty programs. In: Software Testing, Verification and Validation (ICST), 2010 Third International Conference on. [s.n.], 2010. p. 65 -74. Disponível em: http://ieeexplore.ieee. org $/ x p l / f r e e a b s \_a l l . j s p ? a r n u m b e r=5477098$.

DEBROY, V.; WONG, W. E. Insights on fault interference for programs with multiple bugs. In: Proceedings of the 20th IEEE international conference on software reliability engineering. Piscataway, NJ, USA: IEEE Press, 2009. (ISSRE'09), p. 165-174. ISBN 978-14244-5375-7. Disponível em: http://dl . acm.org/citation. cfm?id=1802408. 1802433.

DEBROY, V.; WONG, W. E. On the equivalence of certain fault localization techniques. In: Proceedings of the 2011 ACM Symposium on Applied Computing. New York, NY, USA: ACM, 2011. (SAC '11), p. 1457-1463. ISBN 978-1-4503-0113-8. Disponível em: http://doi.acm.org/10.1145/1982185.1982498.

DELAMARO, M. E.; CHAIM, M. L.; VINCENZI, A. M. R. Técnicas e ferramentas de teste de software. In: Atualizações em Informática 2010 (JAI 2010). Rio de Janeiro: Editora PUC-Rio, 2010. p. 55-110.

DELAmARO, M. E.; MALDONADO, J. C.; JINO, M. Introdução ao Teste de Software. Rio de Janeiro: Elsevier, 2007.

DELAmARO, M. E.; MALDONADO, J. C.; MATHUR, A. P. Interface mutation: An approach for integration testing. IEEE Transactions on Software Engineering, v. 27, n. 3, p. 228-247, 2001.

DIMITROV, M.; ZHOU, H. Anomaly-based bug prediction, isolation, and validation: an automated approach for software debugging. SIGPLAN Not., ACM, New York, NY, USA, v. 44, p. 61-72, March 2009. ISSN 0362-1340. Disponível em: http://doi.acm.org/10. $1145 / 1508284.1508252$.

DO, H.; ELBAUM, S.; ROTHERMEL, G. Supporting controlled experimentation with testing techniques: An infrastructure and its potential impact. Empirical Software Engineering, Springer Netherlands, v. 10, p. 405-435, 2005. ISSN 1382-3256. 10.1007/s10664005-3861-2. Disponível em: http://dx.doi .org/10.1007/s10664-005-3861-2.

ENGINEERING Statistics Handbook. NIST, National Institute of Standards \& Technology, 2012. Online. Disponível em: http://www.itl.nist.gov/div898/handbook/.

GAMMA, E.; BECK, K. JUnit: A Cook's Tour. 1999. Disponível em: http://junit. sourceforge.net/doc/cookstour/cookstour.htm.

GCOV. The GNU Compiler Collection (GCC). Free Software Foundation, 1999. Online. Disponível em: http://gcc.gnu.org/onlinedocs/gcc/Gcov.html. Acesso em: 15 dez. 2011.

GENTlEMAN, R.; IHAKA, R. The R Project for Statistical Computing. 2012. Online. Disponível em: http://www.r-project.org/.

GUO, L.; ROYCHOUDHURY, A.; WANG, T. Accurately choosing execution runs for software fault localization. In: MYCROFT, A.; ZELLER, A. (Ed.). Compiler Construction. Springer Berlin / Heidelberg, 2006, (Lecture Notes in Computer Science, 
v. 3923). p. 80-95. ISBN 978-3-540-33050-9. 10.1007/11688839_7. Disponível em: http: //dx.doi.org/10.1007/11688839_7.

HARROLD, M. J.; MCGREGOR, J. D.; FITZPATRICK, K. J. Incremental testing of object-oriented class structures. In: Proceedings of the 14th international conference on Software engineering. New York, NY, USA: ACM, 1992. (ICSE '92), p. 68-80. ISBN 0-89791-504-6. Disponível em: http://doi.acm.org/10.1145/143062.143093.

JANSSEN, T.; ABREU, R.; GEMUND, A. J. C. v. Zoltar: A toolset for automatic fault localization. In: Proceedings of the 2009 IEEE/ACM International Conference on Automated Software Engineering. Washington, DC, USA: IEEE Computer Society, 2009. (ASE '09), p. 662-664. ISBN 978-0-7695-3891-4. Disponível em: http://dx.doi.org/ 10.1109/ASE. 2009.27.

JONES, J. A.; BOWRING, J. F.; HARROLD, M. J. Debugging in parallel. In: Proceedings of the 2007 international symposium on Software testing and analysis. New York, NY, USA: ACM, 2007. (ISSTA '07), p. 16-26. ISBN 978-1-59593-734-6. Disponível em: http: //doi.acm.org/10.1145/1273463.1273468.

JONES, J. A.; HARROLD, M. J.; STASKO, J. Visualization of test information to assist fault localization. In: Proceedings of the 24th ACM/IEEE International Conference on Software Engineering. [S.l.: s.n.], 2002.

LARSON, R.; FARBER, B. Estatística aplicada. 4. ed. São Paulo: Prentice Hall, 2010. 638 p.

LEE, H. J.; NAISH, L.; RAMAMOHANARAO, K. Study of the relationship of bug consistency with respect to performance of spectra metrics. In: Computer Science and Information Technology, 2009. ICCSIT 2009. 2nd IEEE International Conference on. [s.n.], 2009. p. 501 -508. Disponível em: http://ieeexplore.ieee.org/xpl/freeabs_ all $\cdot$ jsp?arnumber $=5234512$.

LEE, H. J.; NAISH, L.; RAMAMOHANARAO, K. Effective software bug localization using spectral frequency weighting function. In: Computer Software and Applications Conference (COMPSAC), 2010 IEEE 34th Annual. [s.n.], 2010. p. 218 -227. ISSN 07303157. Disponível em: http://ieeexplore.ieee.org/xpl/freeabs_all.jsp?arnumber= 5676260 .

LEMOS, O. A. L.; FRANCHIN, I. G.; MASIERO, P. C. Integration testing of objectoriented and aspect-oriented programs: A structural pairwise approach for java. Science of Computer Programming, v. 74, n. 10, p. 861 - 878, 2009. ISSN 0167-6423. Disponível em: http://www.sciencedirect.com/science/article/B6V17-4W91PRR-1/2/ df516d55dae92c2cb67faa884d52296a.

LEMOS, O. A. L.; VINCENZI, A. M. R.; MALDONADO, J. C.; MASIERO, P. C. Control and data flow structural testing criteria for aspect-oriented programs. J. Syst. Softw., Elsevier Science Inc., New York, NY, USA, v. 80, p. 862-882, June 2007. ISSN 0164-1212. Disponível em: http://dx.doi.org/10.1016/j.jss.2006.08.022.

MARIANI, L.; PASTORE, F.; PEZZE, M. Dynamic analysis for diagnosing integration faults. Software Engineering, IEEE Transactions on, v. 37, n. 4, p. 486 -508, july-aug. 
2011. ISSN 0098-5589. Disponível em: http://ieeexplore.ieee.org/xpl/freeabs_ all $\cdot$ jsp?arnumber $=5611554$.

MASRI, W. Fault localization based on information flow coverage. Softw. Test. Verif. Reliab., John Wiley and Sons Ltd., Chichester, UK, v. 20, p. 121-147, June 2010. ISSN 0960-0833. Disponível em: http://dx.doi.org/10.1002/stvr.v20:2.

MASRI, W.; ABOU-ASSI, R.; EL-GHALI, M.; AL-FATAIRI, N. An empirical study of the factors that reduce the effectiveness of coverage-based fault localization. In: Proceedings of the 2nd International Workshop on Defects in Large Software Systems: Held in conjunction with the ACM SIGSOFT International Symposium on Software Testing and Analysis (ISSTA 2009). New York, NY, USA: ACM, 2009. (DEFECTS '09), p. 1-5. ISBN 978-1-60558-654-0. Disponível em: http://doi .acm.org/10.1145/1555860.1555862.

MASRI, W.; ASSI, R. Cleansing test suites from coincidental correctness to enhance faultlocalization. In: Software Testing, Verification and Validation (ICST), 2010 Third International Conference on. [s.n.], 2010. p. 165 -174. Disponível em: http://ieeexplore. ieee.org/xpl/freeabs_all.jsp?arnumber $=5477086$.

MURTAZA, S.; GITTENS, M.; MADHAVJI, N. Discovering the fault origin from field traces. In: Software Reliability Engineering, 2008. ISSRE 2008. 19th International Symposium on. [s.n.], 2008. p. 295 -296. ISSN 1071-9458. Disponível em: http: //ieeexplore. ieee.org/xpl/freeabs_all.jsp?arnumber $=4700343$.

MutTi, D.; SOUZA, H. A. de; ARAujo, R. A. de; CEREJO, E.; CHAim, M. L. Codeforest - in search of bugs in the forest of code. Em preparação. 2012.

NAISH, L.; LEE, H. J.; RAMAMOHANARAO, K. Spectral debugging with weights and incremental ranking. In: Software Engineering Conference, 2009. APSEC '09. AsiaPacific. [s.n.], 2009. p. 168 -175. ISSN 1530-1362. Disponível em: http://ieeexplore. ieee.org/xpl/freeabs_all.j.sp?arnumber $=5358598$.

NAISH, L.; LEE, H. J.; RAMAMOHANARAO, K. Statements versus predicates in spectral bug localization. In: Software Engineering Conference (APSEC), 2010 17th Asia Pacific. [s.n.], 2010. p. 375 -384. ISSN 1530-1362. Disponível em: http://ieeexplore. ieee.org/xpl/freeabs_all.jsp?arnumber $=5693214$.

NAISH, L.; LEE, H. J.; RAMAMOHANARAO, K. A model for spectra-based software diagnosis. ACM Trans. Softw. Eng. Methodol., ACM, New York, NY, USA, v. 20, p. 11:1-11:32, August 2011. ISSN 1049-331X. Disponível em: http://doi.acm.org/10. 1145/2000791.2000795.

NAPSOL. Núcleo de Apoio à Pesquisa em Software Livre (NAPSoL), 2012. Disponível em: http://www . usp.br/prp/subpagina . php?menu=6\&pagina=23\&subpagina=67.

NEVES, V. d. O. Teste de Integração Contextual de Programas Orientados a Objetos e a Aspectos: critérios e automação. Dissertação (Mestrado) - Instituto de Ciências Matemáticas e de Computação, Universidade de São Paulo, 2010. Disponível em: http: //www.teses.usp.br/teses/disponiveis/55/55134/tde-08042010-163127. 
PARNIN, C.; ORSO, A. Are automated debugging techniques actually helping programmers? In: Proceedings of the 2011 International Symposium on Software Testing and Analysis. New York, NY, USA: ACM, 2011. (ISSTA '11), p. 199-209. ISBN 978-1-45030562-4. Disponível em: http://doi .acm.org/10.1145/2001420.2001445.

RENIERIS, M.; REISS, S. P. Fault localization with nearest neighbor queries. 18th IEEE International Conference on Automated Software Engineering 2003 Proceedings, IEEE Comput. Soc, v. 0, p. 30-39, 2003. Disponível em: http://ieeexplore.ieee.org/ lpdocs/epic03/wrapper.htm?arnumber=1240292.

SÁ, J. P. M. de. Applied Statistics Using SPSS, STATISTICA, MATLAB and R. 2. ed. Berlin, Heidelberg: Springer Berlin Heidelberg, 2007. 506 p.

SAFF, D.; ERNST, M. D. Mock object creation for test factoring. In: Proceedings of the 5th ACM SIGPLAN-SIGSOFT workshop on Program analysis for software tools and engineering. New York, NY, USA: ACM, 2004. (PASTE '04), p. 49-51. ISBN 1-58113910-1. Disponível em: http://doi.acm.org/10.1145/996821.996838.

SÁNCHEZ, A. G. Automatic Error Detection Techniques based on Dynamic Invariants. Dissertação (Mestrado) — Delft University of Technology, 2007. Disponível em: www . st. ewi.tudelft.nl/ albgonz/pub/mscthesis.pdf.

SANTELICES, R.; HARROLD, M. J. Efficiently monitoring data-flow test coverage. In: Proceedings of the twenty-second IEEE/ACM international conference on Automated software engineering. New York, NY, USA: ACM, 2007. (ASE '07), p. 343-352. ISBN 978-159593-882-4. Disponível em: http://doi .acm.org/10.1145/1321631.1321682.

SANTELICES, R.; JONES, J. A.; YU, Y.; HARROLD, M. J. Lightweight faultlocalization using multiple coverage types. In: IEEE 31st International Conference on Software Engineering. [S.1.]: IEEE, 2009. (ICSE '09), p. 56-66. ISBN 978-1-4244-3453-4.

SLOCCOUNT. Wheeler, David A., 2011. Online. Disponível em: http://www .dwheeler . com/sloccount/. Acesso em: 11 nov. 2011.

VALLEE-RAI, R.; HENDREN, L. J. Jimple: Simplifying Java Bytecode for Analyses and Transformations. Montreal, Quebec, Canada, 1998.

VAYANI, R. Improving Automatic Software Fault Localization. Dissertação (Mestrado) - Delft University of Technology, 2007. Disponível em: swerl.tudelft.nl/twiki/pub/ Main/RafiVayani/thesisvayani.pdf.

VInCEnZI, A. M.; MALDOnADO, J. C.; WONG, W.; DELAMARO, M. E. Coverage testing of java programs and components. Science of Computer Programming, v. 56, n. 1-2, p. 211-230, 2005. ISSN 0167-6423. New Software Composition Concepts. Disponível em: http://www.sciencedirect.com/science/article/B6V17-4F15003-5/2/ e45168e915c6ede8de1d4a04c29975ba.

WANG, X.; CHEUNG, S. C.; CHAN, W. K.; ZHANG, Z. Taming coincidental correctness: Coverage refinement with context patterns to improve fault localization. In: Proceedings of the 31st International Conference on Software Engineering. Washington, DC, USA: IEEE Computer Society, 2009b. (ICSE '09), p. 45-55. ISBN 978-1-4244-3453-4. Disponível em: http://dx.doi.org/10.1109/ICSE.2009.5070507. 
WANG, X.; GU, Q.; ZHANG, X.; CHEN, X.; CHEN, D. Fault localization based on multi-level similarity of execution traces. In: Software Engineering Conference, 2009. APSEC '09. Asia-Pacific. [s.n.], 2009a. p. 399 -405. ISSN 1530-1362. Disponível em: http://ieeexplore. ieee.org/xpl/freeabs_all.jsp?arnumber=5358777.

WONG, W.; QI, Y.; ZHAO, L.; CAI, K.-Y. Effective fault localization using code coverage. In: Computer Software and Applications Conference, 200\%. COMPSAC 200\%. 31st Annual International. [s.n.], 2007. v. 1, p. 449 -456. ISSN 0730-3157. Disponível em: http: //ieeexplore. ieee.org/xpl/freeabs_all.jsp?arnumber $=4291037$.

WONG, W.; SHI, Y.; QI, Y.; GOLDEN, R. Using an rbf neural network to locate program bugs. In: Software Reliability Engineering, 2008. ISSRE 2008. 19th International Symposium on. [s.n.], 2008b. p. 27 -36. ISSN 1071-9458. Disponível em: http: //ieeexplore. ieee.org/xpl/freeabs_all. jsp?arnumber $=4700307$.

WONG, W.; WEI, T.; QI, Y.; ZHAO, L. A crosstab-based statistical method for effective fault localization. In: Software Testing, Verification, and Validation, 2008 1st International Conference on. [s.n.], 2008a. p. 42 -51. Disponível em: http://ieeexplore.ieee. org $/ \mathrm{xpl} /$ freeabs_all.j.sp?arnumber $=4539531$.

WONG, W. E.; DEBROY, V.; CHOI, B. A family of code coverage-based heuristics for effective fault localization. Journal of Systems and Software, v. 83, n. 2, p. 188-208, 2010. Cited By (since 1996) 7. Disponível em: http://www.scopus.com/inward/record.url? eid=2-s2 . 0-73149083478\&partner ID=40\&md5=c4f8dc1 fa34426f e52da1 c03163cdeae.

XIE, X.; CHEN, T. Y.; XU, B. Isolating suspiciousness from spectrum-based fault localization techniques. In: Quality Software (QSIC), 2010 10th International Conference on. [s.n.], 2010. p. 385 -392. ISSN 1550-6002. Disponível em: http://ieeexplore.ieee. org $/$ xpl/freeabs_all.jsp?arnumber $=5562991$.

XIE, X.; WONG, W. E.; CHEN, T. Y.; XU, B. Spectrum-based fault localization: Testing oracles are no longer mandatory. In: Quality Software (QSIC), 2011 11th International Conference on. [s.n.], 2011. p. 1 -10. ISSN 1550-6002. Disponível em: http: //ieeexplore.ieee.org/xpl/freeabs_all.jsp?arnumber $=6004306$.

XSUDS User's manual. Telcordia Technologies, 1998. Online. Disponível em: http:// xsuds.argreenhouse.com/. Acesso em: 05 jan. 2012.

XU, J.; CHAN, W.; ZHANG, Z.; TSE, T.; LI, S. A dynamic fault localization technique with noise reduction for java programs. In: Quality Software (QSIC), 2011 11th International Conference on. [s.n.], 2011. p. 11 -20. ISSN 1550-6002. Disponível em: http://ieeexplore. ieee.org/xpl/freeabs_all.jsp?arnumber=6004307.

YU, K.; LIN, M.; GAO, Q.; ZHANG, H.; ZHANG, X. Locating faults using multiple spectra-specific models. In: Proceedings of the 2011 ACM Symposium on Applied Computing. New York, NY, USA: ACM, 2011. (SAC '11), p. 1404-1410. ISBN 978-1-4503-0113-8. Disponível em: http://doi.acm.org/10.1145/1982185.1982490.

ZELLER, A. Isolating cause-effect chains from computer programs. In: Proceedings of the Tenth ACM SIGSOFT Symposium on Foundations of Software Engineering (FSE). [S.l.: s.n.], 2002. p. 1-10. 
ZELLER, A. Why programs fail: a guide to systematic debugging. 2. ed. Burlington, MA: Morgan Kaufmann Publishers, 2009. 424 p. ISBN 978-0-12-374515-6.

ZHANG, W.; LIM, J.; OLICHANDRAN, R.; SCHERPELZ, J.; JIN, G.; LU, S.; REPS, T. Conseq: detecting concurrency bugs through sequential errors. SIGPLAN Not., ACM, New York, NY, USA, v. 46, p. 251-264, March 2011. ISSN 0362-1340. Disponível em: http://doi.acm.org/10.1145/1961296.1950395.

ZHANG, X.; GU, Q.; CHEN, X.; QI, J.; CHEN, D. A study of relative redundancy in test-suite reduction while retaining or improving fault-localization effectiveness. In: Proceedings of the 2010 ACM Symposium on Applied Computing. New York, NY, USA: ACM, 2010. (SAC '10), p. 2229-2236. ISBN 978-1-60558-639-7. Disponível em: http: //doi.acm.org/10.1145/1774088.1774556.

ZHANG, Z.; CHAN, W.; TSE, T.; HU, P.; WANG, X. Is non-parametric hypothesis testing model robust for statistical fault localization? Information and Software Technology, v. 51, n. 11, p. 1573-1585, 2009b. Cited By (since 1996) 2. Disponível em: http://www.scopus.com/inward/record.url?eid=2-s2 . 0-69749099373\&partner ID $=40 \& \mathrm{md} 5=\mathrm{d} 9 \mathrm{c} 4 \mathrm{ab} 57 \mathrm{~d} 7 \mathrm{~d} 22 \mathrm{~d} 8 \mathrm{~b} 77 \mathrm{e} 50 \mathrm{f} 6413 \mathrm{fbb} 47 \mathrm{c}$.

ZHANG, Z.; CHAN, W.; TSE, T.; YU, Y.; HU, P. Non-parametric statistical fault localization. Journal of Systems and Software, v. 84, n. 6, p. 885-905, 2011. Cited By (since 1996) 0. Disponível em: http://www.scopus.com/inward/record.url?eid= $2-$ s2.0-79953688693\&partnerID $=40 \& \mathrm{md} 5=3 a e 90 b f 5 e 239 c 05034 f 76100$ eaeaa20c.

ZHANG, Z.; CHAN, W. K.; TSE, T. H.; JIANG, B.; WANG, X. Capturing propagation of infected program states. In: Proceedings of the the 7th joint meeting of the European software engineering conference and the ACM SIGSOFT symposium on The foundations of software engineering. New York, NY, USA: ACM, 2009a. (ESEC/FSE '09), p. 4352. ISBN 978-1-60558-001-2. Disponível em: http://doi.acm.org/10.1145/1595696. 1595705.

ZHAO, L.; WANG, L.; XIONG, Z.; GAO, D. Execution-aware fault localization based on the control flow analysis. In: ZHU, R.; ZHANG, Y.; LIU, B.; LIU, C. (Ed.). Information Computing and Applications. Springer Berlin / Heidelberg, 2010, (Lecture Notes in Computer Science, v. 6377). p. 158-165. ISBN 978-3-642-16166-7. 10.1007/978-3-64216167-4_21. Disponível em: http://dx.doi.org/10.1007/978-3-642-16167-4_21. 


\section{APÊENDICE A - Algoritmos de geração das coberturas $M C P$ e $M C T$}

Os Algoritmos 6 e 7 representam como são formados, respectivamente, os pares e triplas de chamadas de métodos durante a execução dos programas instrumentados usando a ferramenta InSS. A instrumentação é feita em cada bloco de código. Quando o bloco executado é de entrada, ele é armazenado em um pilha e quando o bloco é de saída ele é desempilhado e então pega-se a informação do bloco anterior para formar o par, ou dos dois blocos anteriores para formar a tripla. Em seguida, o par ou a tripla é armazenado em uma lista e o arquivo de cobertura é gerado.

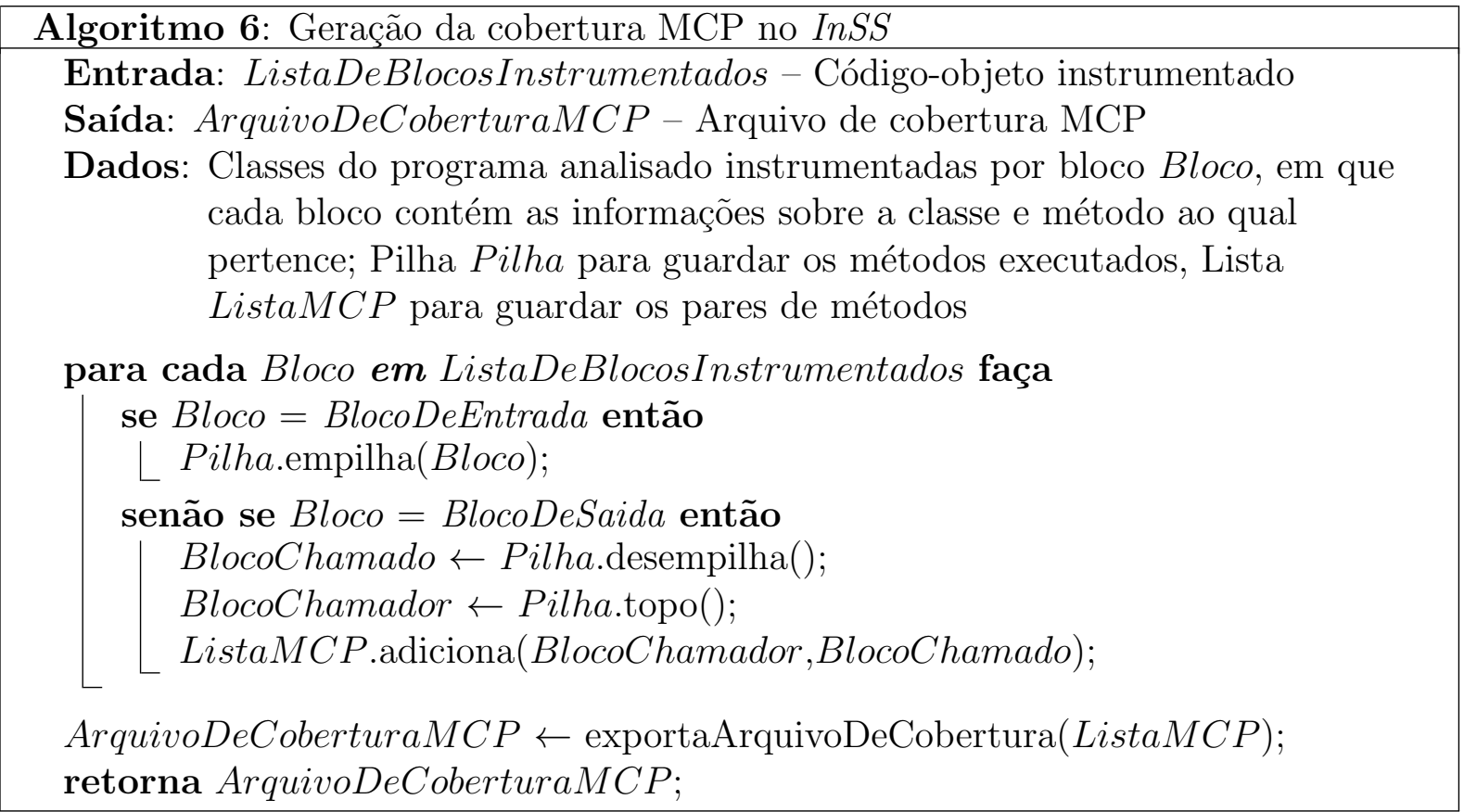


Algoritmo 7: Geração da cobertura MCT no InSS

Entrada: ListaDeBlocosInstrumentados - Código-objeto instrumentado

Saída: ArquivoDeCoberturaMCT - Arquivo de cobertura MCT

Dados: Classes do programa analisado instrumentadas por bloco Bloco, em que cada bloco contém as informações sobre a classe e método ao qual pertence; Pilha Pilha para guardar os métodos executados, Lista ListaMCT para guardar as triplas de métodos

para cada Bloco em ListaDeBlocosInstrumentados faça

se Bloco $=$ BlocoDeEntrada então

L Pilha.empilha(Bloco);

senão se $B l o c o=$ BlocoDeSaida então

BlocoChamado $\leftarrow$ Pilha.desempilha();

BlocoIntermediario $\leftarrow$ Pilha.topo () ;

BlocoChamador $\leftarrow$ Pilha.pega(Pilha.tamanho - 2) ; // Penúltimo item da pilha

ListaMCT.adiciona(BlocoChamador,BlocoIntermediario,BlocoChamado);

ArquivoDeCobertura $M C T \leftarrow$ exportaArquivoDeCobertura $($ ListaMCT $)$;

retorna ArquivoDeCoberturaMCT; 


\section{APÊNDICE B - Técnicas de depuração automatizada}

\section{B.1 Técnicas de depuração}

Existem diferentes formas de realizar a depuração de programas, de forma manual ou automática. O objetivo das técnicas de depuração é facilitar a localização de defeitos reduzindo a quantidade de código a ser verificada pelos desenvolvedores. A seguir são apresentadas outras técnicas de depuração utilizadas para a localização de defeitos.

\section{B.1.1 Slicing}

O slicing ou fatiamento de programas é uma técnica que reduz a quantidade de código a ser verificada de forma que apenas os comandos que afetam um determinado critério de slicing são selecionados. Esse conjunto de comandos é chamado de slice ou fatia. O critério de slicing é determinado por um conjunto de variáveis e um ponto do programa (DELAMARO et al., 2007). O slicing retorna o subconjunto de comandos que possuem uma relação de dependência com aquele critério, de acordo com a direção na qual o slicing está sendo executado. O forward slicing (fatiamento para frente) vai trazer o subconjunto de comandos dependentes e o backward slicing (fatiamento para trás) retorna os comandos dos quais o comando e as variáveis de interesse dependem (ZELLER, 2009).

Os slices podem ser obtidos de forma estática ou dinâmica. O slicing estático traz todos os comandos que podem afetar ou serem afetados pelo comando de interesse, resultando em um slice maior em relação ao slicing dinâmico, que retorna o slice que de fato afeta ou é afetado a partir dos valores de entrada. Além disso, o slice pode ser executável ou não, sendo que o slice executável costuma ser maior em relação ao não executável por conter comandos que são necessários à execução, mesmo que não afetem o critério de slicing (DELAMARO et al., 2007). 
No entanto, mesmo que a técnica sirva para reduzir a quantidade de comandos obtidos, o tamanho slices pode ainda ser grande. O custo de execução da técnica para identificar os comandos e valores relacionados ao critério de slicing é alto (DELAMARO et al., 2007; BURGER; ZELLER, 2011), o que pode dificultar a adoção da técnica em programas com longas execuções.

\section{B.1.2 Depuração delta}

O algoritmo de depuração delta, proposto por Zeller (2002), foi inspirado na busca binária e pode ser utilizado para a identificação de trechos de um programa que causam a ocorrência de falhas (DELAMARO et al., 2007). A partir da execução de uma versão do programa que manifesta uma falha, o algoritmo de depuração delta divide o código dessa versão pela metade. Se em uma das metades da versão a falha continuar ocorrendo, essa metade provavelmente contém o trecho responsável pela falha. Esse código é novamente dividido pela metade, e assim sucessivamente, até que seja possível isolar o trecho que causa a ocorrência da falha.

Embora a precisão de localização da depuração delta possa ser bastante eficaz para indicar comandos defeituosos, a técnica possui um alto custo de execução, já que necessita ser reexecutada diversas vezes para atingir seu objetivo (BURGER; ZELLER, 2008; WONG et al., 2010). Além disso, é necessário determinar se a saída obtida em cada execução é correta ou se ocorre uma falha igual ou diferente da falha investigada.

\section{B.2 Dependência de comandos}

Em geral, os comandos de um programa afetam ou são afetados pelo fluxo de informação de controle ou de dados de um programa. Os comandos afetam a execução alterando o valor de uma variável ou a ordem de execução dos comandos. Os comandos afetados farão uso dos valores atribuídos ou serão executados após um desvio de fluxo. A relação existente entre dois comandos é conhecida como dependência, na qual o comando dependente somente será executado se um outro comando do qual o primeiro depende também for executado ou então um comando usará um valor que foi atribuído a uma variável por outro comando (ZELLER, 2009). Os comandos dependentes estão presentes na sequência do fluxo de execução de comandos condicionais ou são comandos que usam variáveis definidas por outros comandos. Essa dependência pode estender-se em diferentes níveis, a partir de uma dependência direta ou indireta. Por exemplo, um comando $c$ que 
usa uma variável $x$ depende de forma direta do comando $b$ que atribui um valor a $x$ e de forma indireta de um comando $a$ se o comando $b$ usa o valor de uma variável $y$ definida em $a$ para atribuir o valor de $x$.

A dependência pode ser estática ou dinâmica. Na dependência estática, todas as possíveis relações entre os comandos devem ser consideradas, resultando em um número maior de dependências. Já na dependência dinâmica ou de execução são consideradas as dependências existentes de acordo com o fluxo executado a partir de um caso de teste executado, o que reduz a quantidade total de relações de dependência, criando uma instância da dependência estática. Além disso, a dependência pode ser vista em outros níveis, como a dependência entre métodos ou classes, que podem ser usadas para realizar o teste de integração. A dependência de comandos pode ser de controle ou de dados.

\section{B.2.1 Dependência de controle}

Na dependência de controle, a relação de dependência entre os comandos está associada aos fluxos existentes na estrutura do programa, presente em comandos de desvio de fluxo. A execução de um comando depende do resultado de outros comandos (ZELLER, 2009). Por exemplo, no método max (Figura 2.1, Página 8) o comando da linha 5 será executado somente caso o valor da variável array[i] seja maior que o valor da variável max no comando condicional da linha 4.

\section{B.2.2 Dependência de dados}

A dependência de dados ocorre nas relações entre atribuição e uso das variáveis. Um comando que contém uma variável usada é dependente do comando no qual essa variável foi definida. Ou seja, o valor lido em um comando é influenciado pelo valor definido em outro comando (ZELLER, 2009). No método somaMax (Figura 2.2, Página 2.2), o comando da linha 8 é dependente do comando da linha 6 com relação à variável max1.

\section{B.3 Análise de fluxo de informações dinâmica}

A análise de fluxo de informação, conhecida como DIFA (Dynamic Information Flow Analysis), foi desenvolvida para identificar fluxos de informações entre objetos (incluindo variáveis e comandos) e pode representar interações complexas de execução (MASRI, 2010). A cobertura DIFA pode ser usada para obter informações de integração. 
Masri (2010) adaptou a cobertura DIFA para a tarefa de localização de defeitos. As interações em DIFA são representadas pelas dependências existentes entre fluxos de controle e de dados entre variáveis e comandos do programa analisado. A cobertura DIFA trabalha com o conceito de ação. Ação é um comando $c^{k}$, em que $c$ é o comando e $k$ é a ordem na qual esse comando foi executado. Por exemplo, no método max (Figura 2.1), pode-se ter a sequência de execução $\left(1^{1}, 2^{2}, 3^{3}, 7^{4}\right)$ se a condição do comando (ação) 3 não for atendida.

DIFA utiliza dependência dinâmica de controle direta (directly dynamic control dependence - DDynCD) para verificar ações que influenciam diretamente o fluxo de execução de uma ação dependente. De forma semelhante, DIFA utiliza dependência dinâmica de dados direta (dynamic direct data dependence - DDynDD) para verificar variáveis ou objetos definidos que influenciam diretamente uma ação que usa tal variável ou objeto. Além das duas dependências citadas, outros três tipos de dependências dinâmicas de integração (ou interprocedimentais) são utilizadas: o uso de um valor retornado; o uso de um valor passado por parâmetro; e a dependência de controle de uma instrução de chamada de método.

A combinação dessas cinco dependências é chamada de influência direta ou DInfluence (MASRI, 2010). A influência direta inclui os objetos usados na ação dependente e aqueles que influenciam diretamente essa ação. Por exemplo, no método somaMax (Figura 2.2), o comando da linha 6 é diretamente influenciado pelo valor retornado pelo comando da linha 7 do método max (Figura 2.1), e pelos comandos das linhas 4 e 5 de somaMax, responsáveis pelo fluxo de controle que determina se a linha 6 será ou não executada. Assim, para uma dada execução, pode-se ter DInfluence $\left(6^{6}\right)=\left\{4^{4}, 5^{5}, 7^{13}\right\}$.

O perfil de fluxo de informação indica a frequência de fluxos que ocorrem durante uma execução. Tais perfis são formados por pares de fluxo de informação (information flow pairs - IFP), que podem representar as dependências que formam a DInfluence. A representação do perfil de fluxo de informação é $(s, x, t, y, l)$, em que a informação pode fluir entre os pares $(s, x)$ (fonte) para $(t, y)$ (alvo) seguindo diferentes caminhos, $s$ representa a ação que causa a dependência na ação $t, x$ representa o objeto definido em $s$ e $y$ o objeto usado em $t$, indicando o fluxo entre os objetos. Os objetos podem ser também variáveis locais ou globais. O valor $l$ representa o tamanho do caminho de $s$ para $t$, que é o tamanho da cadeia de dependência dinâmica de dados e de controle entre $s$ e $t$. Por exemplo, para uma dada execução, a ação $6^{6}$ de somaMax tem $\left(7^{13}\right.$, max, $6^{6}$, max1, 1) e $\left(4^{4}, \operatorname{array} 1,6^{6}, \operatorname{array} 1,1\right)$. 